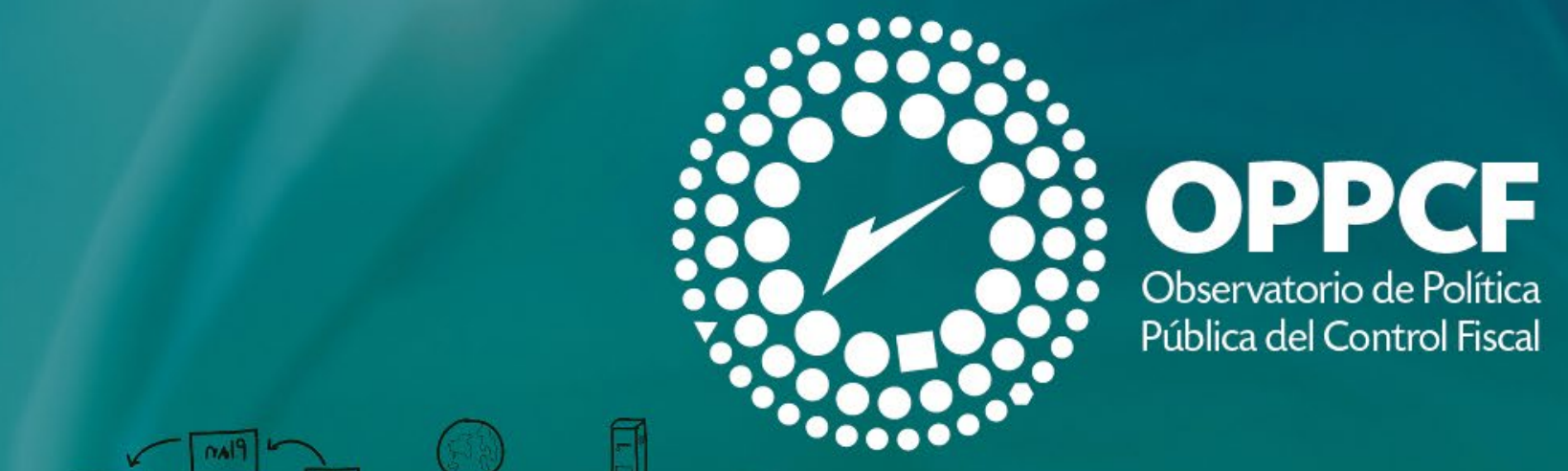

\title{
TRANSFORMACIONES Y CONTINUIDADES EN LAS INSTITUCIONES DE CONTROL FISCAL
}

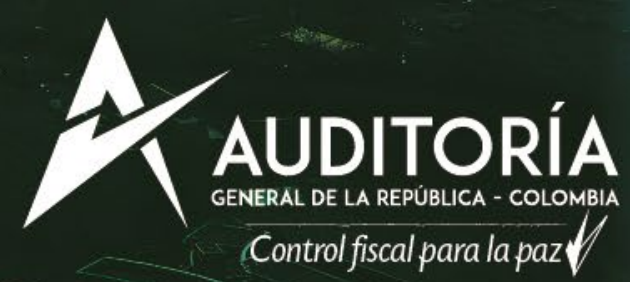




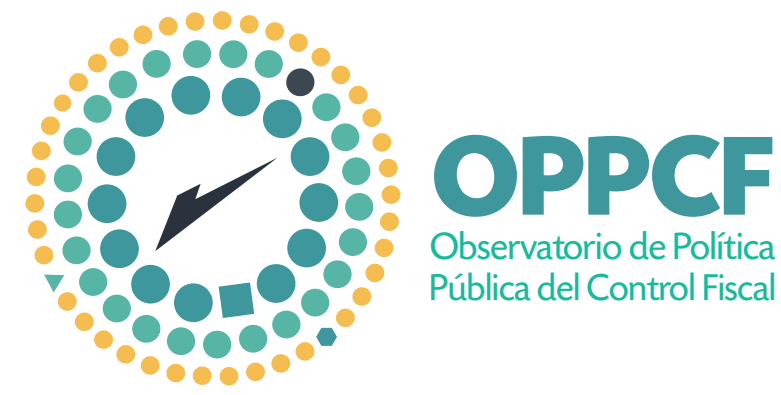

Transformaciones y Continuidades en las Instituciones de Control Fiscal.

Auditoría General de la República, 2019. @

Edición: Auditoría General de la República Carlos Hernán Rodríguez Becerra Auditor General de la República

Coordinación académica: Manuel Fernando Moya Vargas

Coordinación editorial: Liliana Patricia Ortiz Ospino

Autores: Manuel Fernando Moya Vargas

Alexandra González Zapata

Diana Maite Bayona Aristizabal

Dalia Carreño Dueñas

Fabio Iván Rey Navas

Diseño y diagramación : Juan Pablo Dueñas Báez

Impresión: Imprenta Nacional de Colombia

Impreso en Colombia

Bogotá, D.C., agosto de 2019

Primera edición: 500 ejemplares

ISBN: 978-958-57947-7-1 


\section{ÍNDICE}

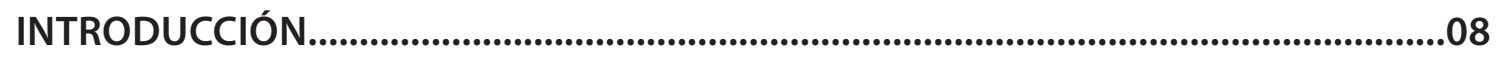

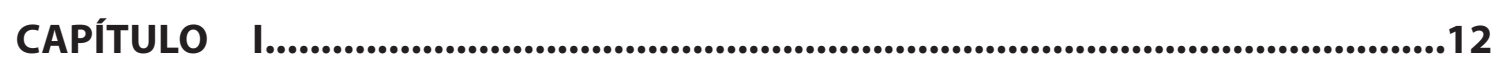

LA CUESTIÓN EPISTEMOLÓGICA EN TORNO AL OBSERVATORIO DE POLÍTICA PÚBLICA DEL

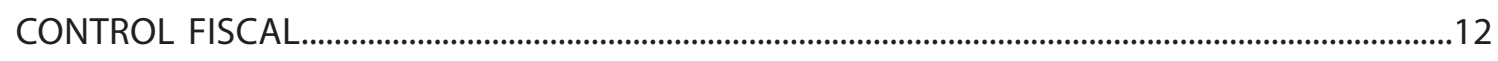

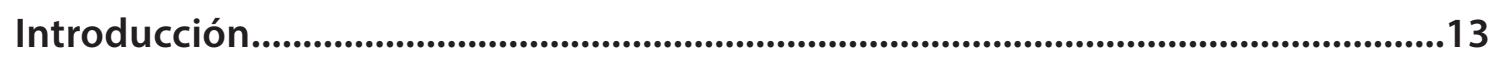

I. La cuestión epistemológica como opción de la teoría del conocimiento....................16

II. La cuestión epistemológica en su proyección al Siglo XXI..............................22

III. La nueva fenomenología del conocimiento....................................................27

IV. La cuestión epistemológica en consideración a los métodos..........................36

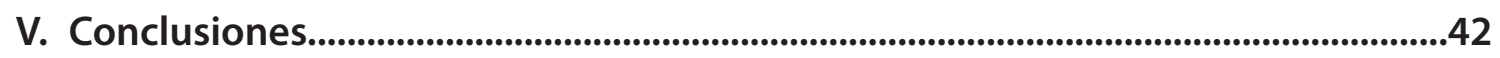

VI. Referencias bibliográficas.....................................................................................44

CAPÍTULO II.........................................................................................................48

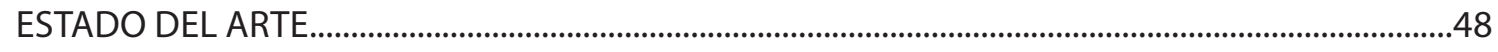

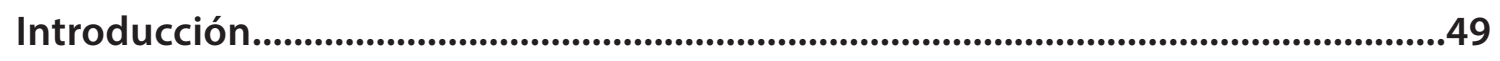

I. Presupuestos para una política pública del control fiscal.............................................51

II. Naturaleza y orientación del control fiscal....................................................................52

III. La perspectiva de los Derechos Humanos: hacia la justicia fiscal..........................62

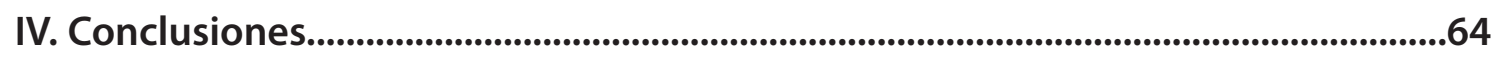

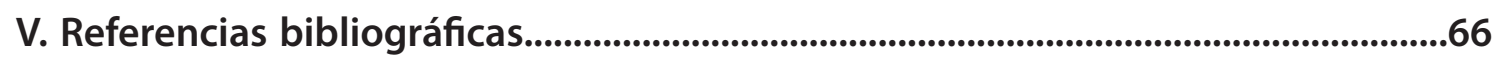

CAPÍTULO III.................................................................................................76

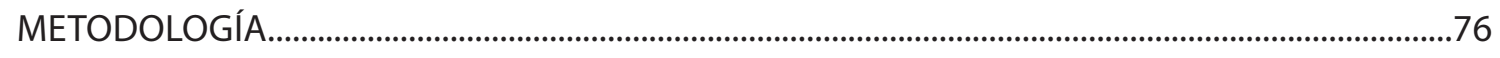

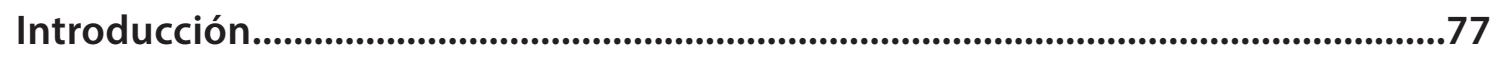

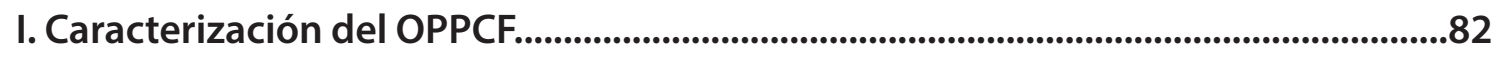

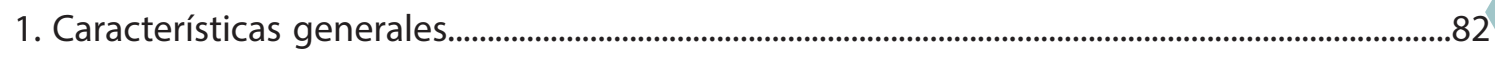




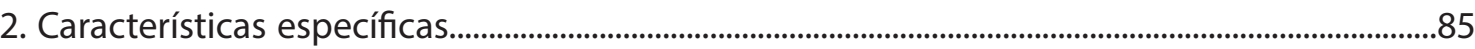

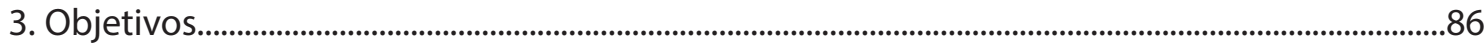

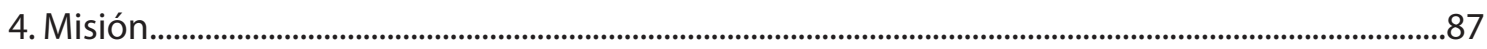

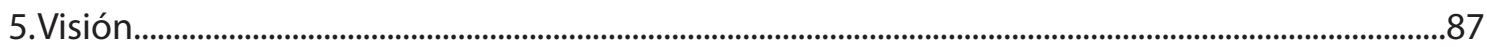

6. Justificación .....................................................................................................................................................

7. Resultados esperados....................................................................................................................94

8. Productos esperados...............................................................................................................................95

II. Identificación del método de producción de conocimiento......................................96

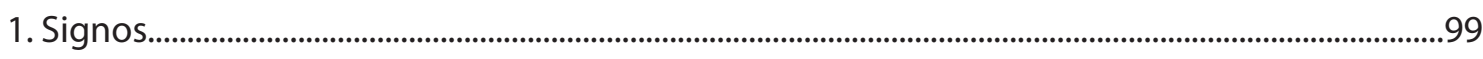

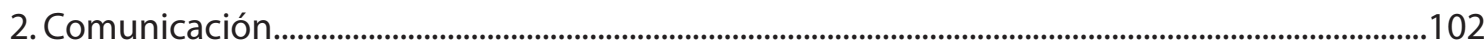

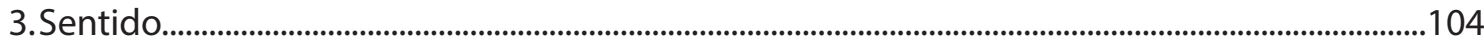

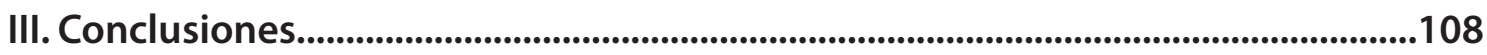

IV. Referencias bibliográficas................................................................................109

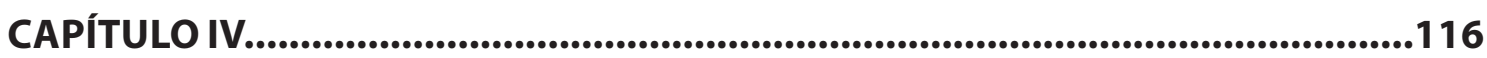

EL ESPÍRITU CONSTITUYENTE DEL CONTROL FISCAL.................................................116

Transformaciones y continuidades en las instituciones de control fiscal en Colombia.........116

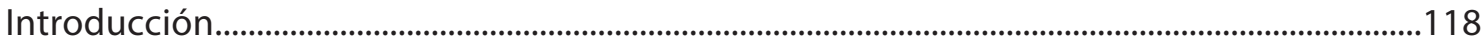

I. Estructura del Estado y equilibrio de poderes públicos...........................................119

II. Democracia y elección de la rama fiscal...............................................................124

III. Estructura y mandato del Control Fiscal....................................................................133

IV. El control fiscal de las entidades territoriales.............................................................143

V. El control del control: el espíritu de la Auditoría General de la República...........144

VI. Referencias bibliográficas.............................................................................145 


\section{CAPÍTULO V.}

LEGISLACIÓN INTERNACIONAL EN MATERIA DE CONTROL INTERNOY FISCAL - INTOSAI........150

Introducción.

I. Normas de control interno. .153

1. Generales 153

1.1 Garantía razonable. 153

1.2 Respaldo 154

1.3 Integridad y competencia 154

1.4 Objetivos del control. 156

1.5 Vigilancia de los controles.. 156

2. Específicas. .156

2.1 Documentación. 157

2.2 Registro oportuno y adecuado de transacciones y hechos 157

2.3 Autorización y ejecución de transacciones y hechos 157

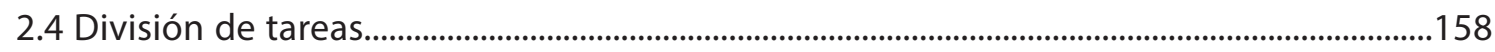

2.5 Supervisión.....................................................................................................................................158

2.6 Acceso a los recursos y responsabilidades ante los mismos.................................................158

II. Control interno..................................................................................................159

1. Componentes del control interno..................................................................................................161

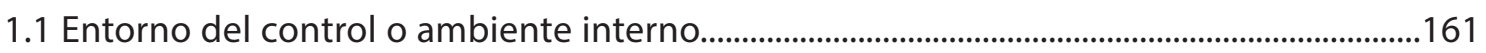

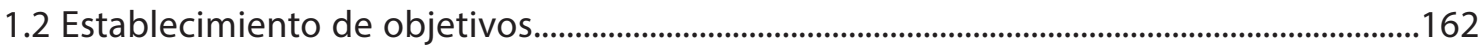

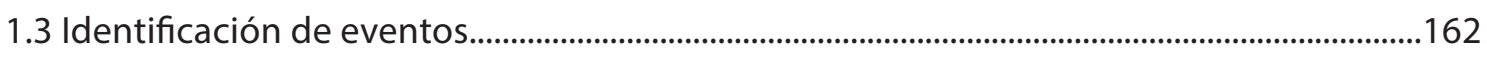

1.4 Evaluación del riesgo.........................................................................................................................163

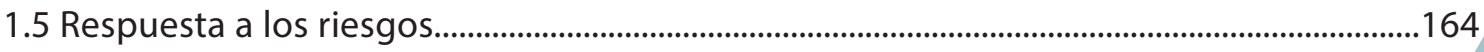




\section{OPPCF}

2. Actividades de control.

2.1. Información y comunicación.......................................................................................................166

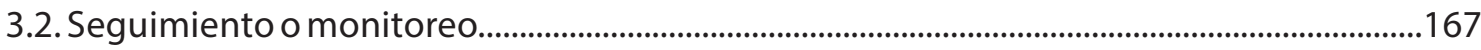

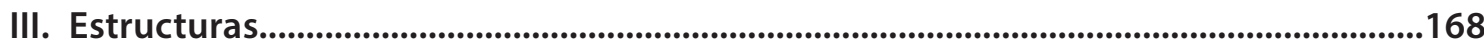

IV. Auditoría en el sector...........................................................................................................168

1. Principios de la Auditoría en el sector público................................................................................170

1.1. Principios generales de auditoría en el sector público...............................................................170

1.2. Principios relacionados con el proceso de auditoría...............................................................173

2. Clases de auditoría en el sector público.....................................................................................174

3. Elementos de auditoría en el sector público..............................................................................174

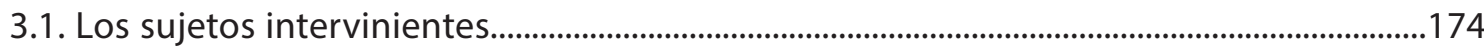

3.2. El objeto de auditoría...................................................................................................................175

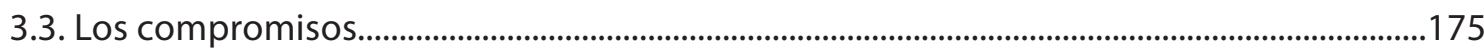

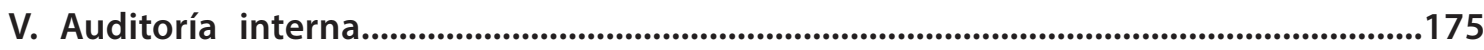

VI. Auditoría financiera del sector público.......................................................................178

VII. Conclusiones....................................................................................................................................180

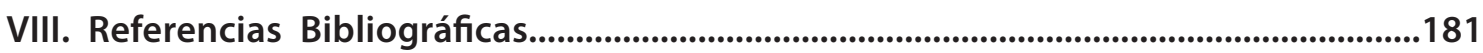

CAPÍTULO VI........................................................................................................................184

LÍNEA JURISPRUDENCIAL CONTROL FISCAL EN COLOMBIA ..........................................................184

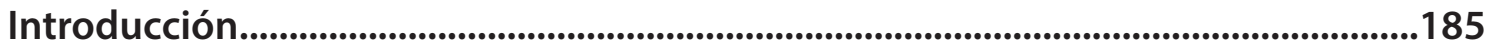

I. La metodología de trabajo............................................................................................................187

II. El telón epistemológico de la política pública del Control Fiscal...........................189

III. Contribución al Observatorio de la Ventana de línea jurisprudencial.................189

IV. La prospectiva...........................................................................................................................190 


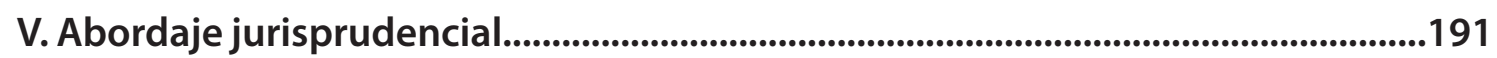

1. Abordaje desde la jurisprudencia de la Corte Constitucional...................................................191

2. Jurisprudencia del Consejo Superior de la Judicatura....................................................................197

3. Jurisprudencia del Consejo de Estado.......................................................................................199

4. Jurisprudencia de la Corte Suprema de Justicia, Sala Penal.......................................................203

VI. Conclusiones........................................................................................................209

VII. Referencias bibliográficas...........................................................................210

CAPÍTULO VII.......................................................................................................218

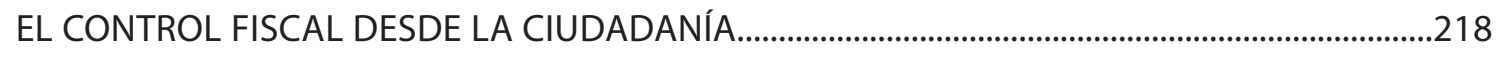

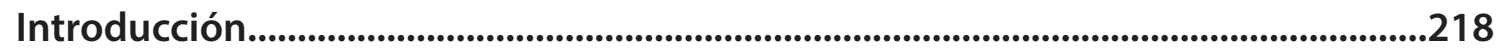

II. ¿Qué es el control ciudadano?.............................................................................219

III. ¿Cómo hacer el control ciudadano? .......................................................................220

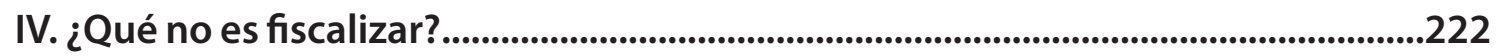

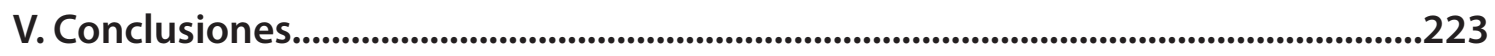

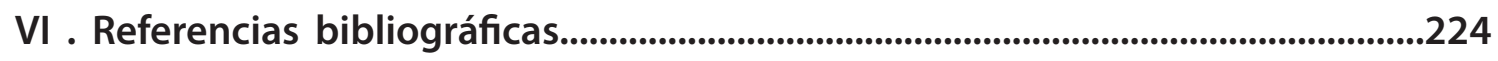




\section{INTRODUCCIÓN}

La creación del Observatorio de Política Pública del Control Fiscal (OPPCF), como se explica ampliamente en el capítulo tercero sobre la metodología, obedece a unas circunstancias específicas. Entre ellas tenemos la necesidad de proporcionar una herramienta de naturaleza científica, que sirva para producir conocimiento en la materia. Pero también, y de forma muy especial, a la divulgación del conocimiento del cual precisa la comunidad, para ejercer su función de control.

En efecto, el OPPCF fue implementado en consideración al efecto que tiene sobre la eficacia de los Derechos Humanos, por lo que en su hipótesis descansa a idea de ser en sí mismo un derecho tan fundamental como aquellos a los cuales presta su servicio de garantía.

De la misma forma, se considera que ningún sistema de control y vigilancia fiscal es suficienteporsímismo, sinoquecomplementa el control ciudadano que, en desarrollo del Estado democrático, social y de derecho, le corresponde constitucionalmente. Para ello es preciso que la comunidad lo entienda, lo cuestione, lo asimile $y$, particularmente, lo ejerza de forma responsable.

Con la finalidad de crear esta herramienta se constituyó un grupo de investigación, del cual hacen parte tanto funcionarios de la Auditoría General de la República, como investigadores externos, y se procedió al registro ante Colciencias.

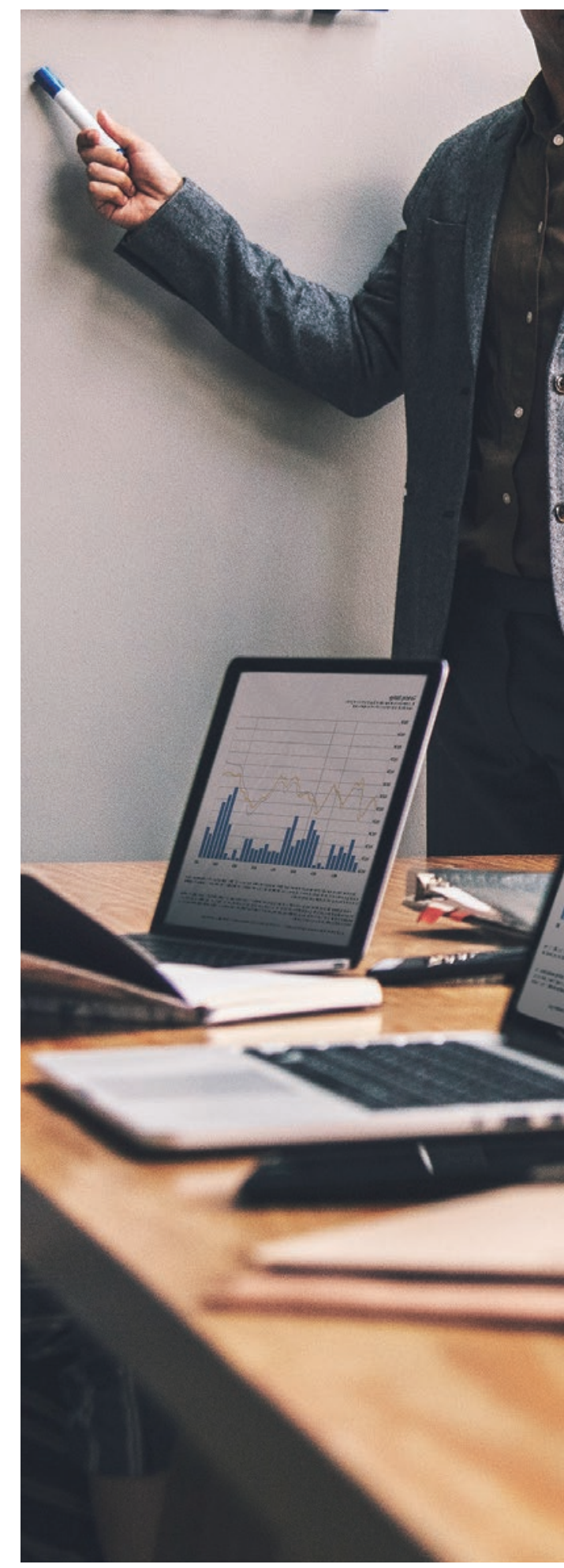




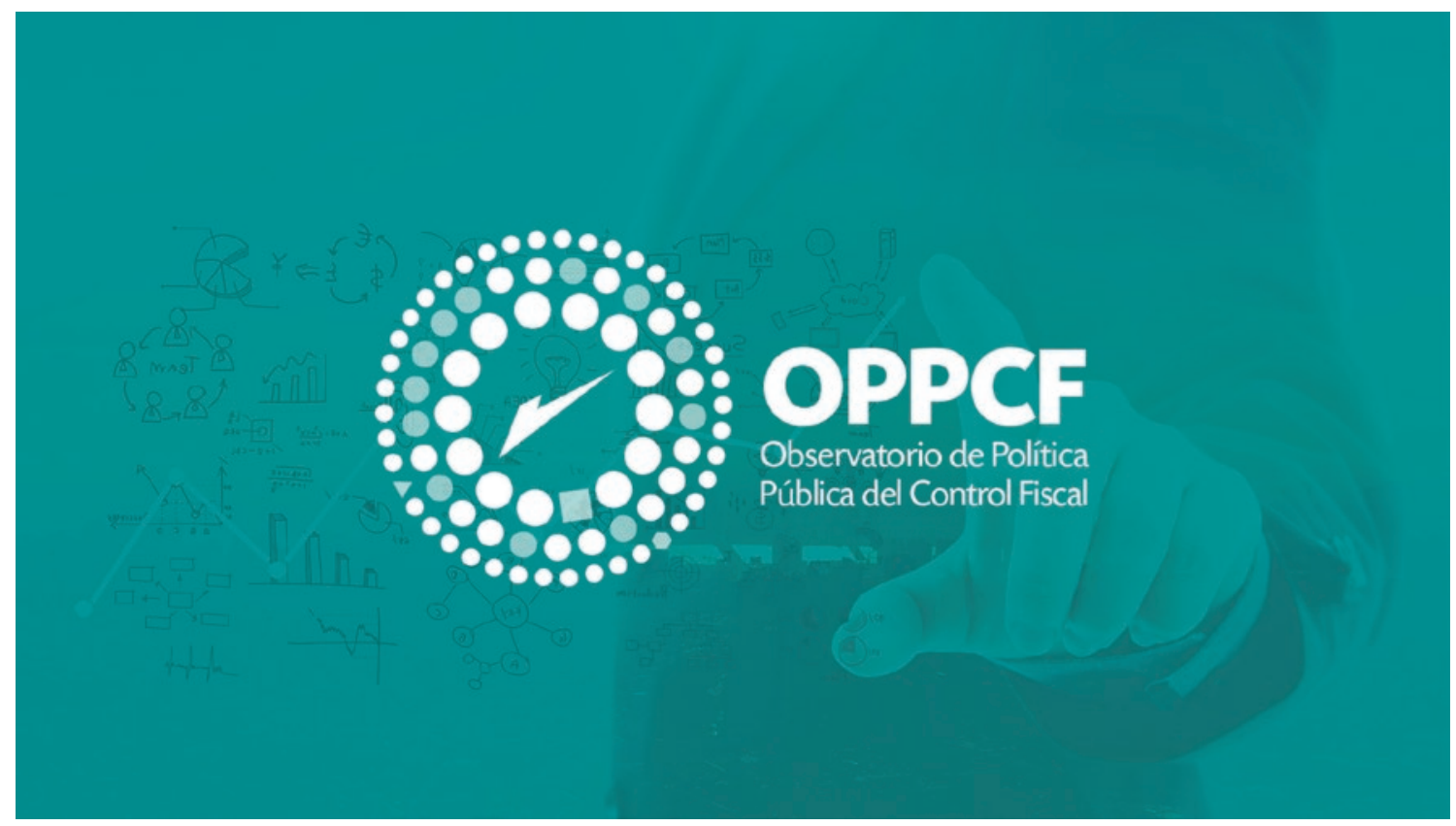

El OPPCF es fruto en sí mismo de un proceso investigativo, cuyo resultado es la constitución de la herramienta.

Se trata de un mecanismo del tipo observatorio, con características tanto cualitativas como cuantitativas, bien que predominan las primeras.

El diseño corresponde a cinco ventanas de observación:

1. Orígenes constitucionales y legales. Al respecto, se reconstruyó históricamente el desarrollo del control fiscal en la Asamblea Nacional Constituyente, lo cual arrojó el desarrollo de los respectivos instrumentos de procesamiento de la información. Estado actual: la información se encuentra disponible para ser incorporada dentro de la ventana

2. Doctrina. Se construyó el estado del arte, con una cobertura básica que asocia la interpretación nacional del control fiscal, la doctrina internacional y, su relación básica con los DDHH. El resultado es un documento Word para ser incorporado a la respectiva ventana.

3. Legislación internacional. Se recopiló la legislación internacional. Se tiene el inventario de normas, así como un documento Word de análisis.

4. Jurisprudencia. Se impactó la jurisprudencia de la Corte Constitucional, Sala Penal de Casación de la Corte Suprema de Justicia, Consejo de Estado y Consejo Superior 


\section{OPPCF}

de la Judicatura. Al respecto, se encuentran procesados los instrumentos de captura, hasta el mes de mayo de 2018. Así mismo, se cuenta con un documento Word de líneas jurisprudenciales.

5. Intervención ciudadana. Esta ventana supone la vinculación de los sistemas de información internos de la Auditoría General de la República, así como la incorporación de los textos publicados y la Revista.

Como documento fundamental se presenta este libro, producto de investigación, en donde se da cuenta de las anteriores ventanas, pero también de los fundamentos basales del OPPCF.

De tal suerte, en el capítulo primero se hallará una explicación de carácter epistemológico. Es así por cuanto, como se indica en el mismo, la epistemología constituye el fundamento de legitimación científica del saber, de tal suerte, se explica su desarrollo histórico y los presupuestos sobre los cuales descansa el OPPCF.

A continuación, en el capítulo segundo, se hallará el estado del arte, en el cual se muestran las tendencias del conocimiento en materia de control fiscal, y se evidencia cómo se puede orientar ese conocimiento hacia el desarrollo de su relación con los Derechos Humanos. Relación que e OPPCF se dispone a llevar a su máximo desarrollo.

Como es característico de todo proceso de producción de conocimiento científico, la herramienta dispone de una metodología de base, la misma que sirvió a su concepción y consolidación como mecanismo de producción de conocimiento. Se trata del método semiótico, no sólo por los objetivos característicos, que allí mismo son descritos, sino por algo muy importante, y es que se pretende desarrollar la producción de conocimiento sobre control y vigilancia fiscal, en consideración a la justicia fiscal, entendida como el sentido socialmente construido, que sirve de trasfondo en donde se proyectan los ideales sociales en materia de control fiscal y, que de una u otra forma, permite a las administración pública dialogar y ejercer dicho control.

En el capítulo cuarto se abordan os orígenes constitucionales, sobre los cuales descansa toda la producción legislativa en materia de control y vigilancia fiscal. De hecho, fue reconstruido desde las entrañas de la Asamblea Nacional Constituyente, con el objeto de poder entender qué fue lo que se hizo y se consolidó en la Constitución de 1991, en materia de control y vigilancia fiscal, por qué quedó como quedó, cuáles fueron las tendencias políticas e ideológicas involucradas, qué fue lo que se quiso cambiar. Precisamente, se consolida este segmento histórico-político para saber cuál es el punto de partida, qué tanto se alcanzó y qué tanto se ha fracasado, por consiguiente, qué hay que hacer de ahora en adelante.

El capítulo quinto analiza la normativa internacional, teniendo en cuenta que el control fiscal es asunto no sólo de los países individualmente considerados, sino de la 
comunidad internacional. De tal suerte, existe todo un entramado legislativo que cada país debe considerar, no para agotarse en él, sino para integrarse cada vez más estrechamente a la comunidad internacional. Luego la normativa de ese origen es necesariamente considerada como referente de construcción de la política pública respectiva.

En el capítulo sexto se establecen las líneas jurisprudenciales en materia de control fiscal. Se estiman las posturas de las altas cortes, porque como se dijo, el OPPCF busca el desarrollo de la justicia fiscal, entendida como construcción colectiva, en donde se reconoce el papel protagónico de la comunidad, y lo que hacen los jueces con ese sentido de justicia que procede de las entrañas sociales.

Finalmente, el capítulo séptimo fundamenta la quinta ventana del OPPCF, es decir la de control ciudadano, para asumir el desarrollo de los sistemas de información que se vincularán a dicha ventana. 


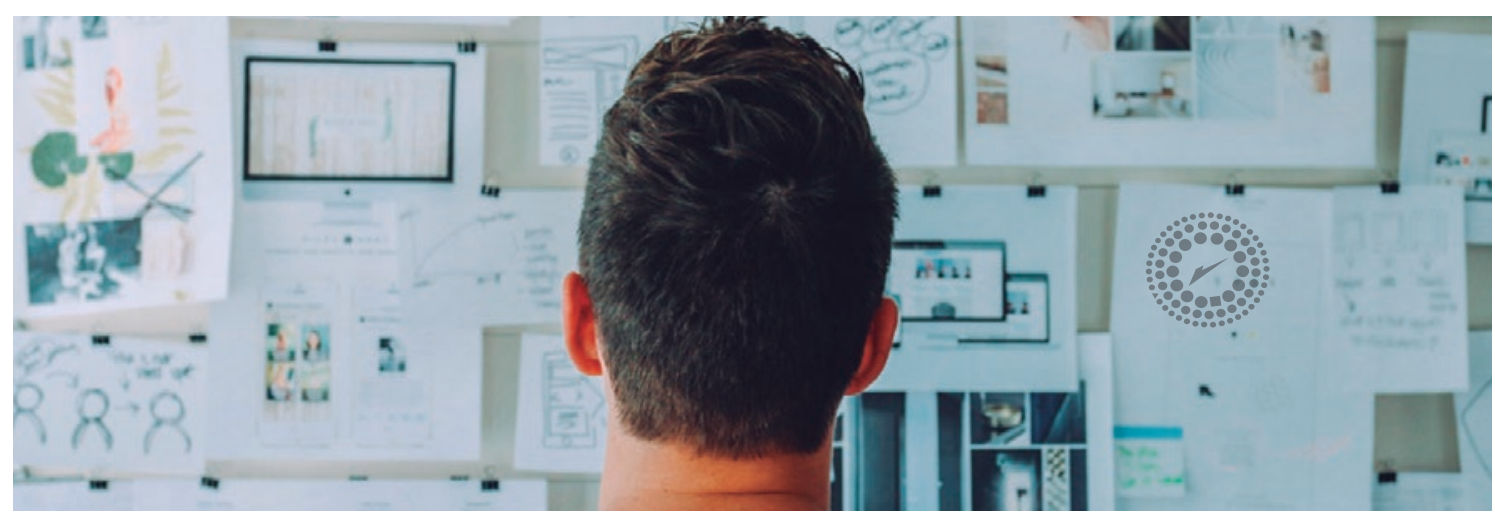

\section{CAPÍTULO I}

\section{LA CUESTIÓN EPISTEMOLÓGICA EN TORNO AL OBSERVATORIO DE POLÍTICA PÚBLICA DEL CONTROL FISCAL}

\section{The Epistemological Issue Concerning the Observatory of Public Political of Fiscal Control}

\section{Manuel Fernando Moya Vargas ${ }^{1}$}

Temario: Introducción. I. La cuestión epistemológica como opción de la teoría del conocimiento. II. La cuestión epistemológica en su proyección al Siglo XXI. III. La nueva fenomenología del conocimiento. IV. La cuestión epistemológica en consideración a los métodos. V. Conclusiones. REFERENCIAS BIBLIOGRÁFICAS

\section{Resumen}

La epistemología proporciona sentido al conocimiento, por ello es considerada la base de legitimidad del saber. A través de la historia ha tenido oscilaciones, pues inicialmente se debatió entre la necesidad de alcanzar un estado inamovible, de total confianza, y la que implicaba la contingencia permanente del conocimiento. Fenómenos posteriores, como el reconocimiento del saber abductivo y el Estado democrático, social y de derecho, orientaron el conocimiento hacia la dignificación del ser humano.

\begin{abstract}
Epistemology provides meaning to knowledge, therefore it is considered the basis of legitimacy of knowledge. Throughout history it has had oscillations, because initially it was debated between the need to reach an immovable state, of total confidence, and the one that implied the permanent contingency of knowledge. Subsequent phenomena, such as 1 Investigador Senior de la Universidad Santo Tomás y de la Auditoría General de la República.
\end{abstract}


the recognition of abductive knowledge and the democratic, social and legal State, oriented knowledge toward the dignification of the human being.

\section{Palabras clave}

Conocimiento científico, Epistemología, Saber

\section{Keywords}

Epistemology, Knowledge, Scientific knowledge.

\section{Introducción}

En la práctica investigativa avalada por la comunidad científica el asunto epistemológico cumple una función esencial, consistente en proporcionar un fundamento y con ello una cierta orientación al proceso de producción de conocimiento.

Podríamos decir que llamamos a la cuestión epistemológica, al trasfondo en el cual se proyecta el conocimiento que se genera, pues es en él en donde adquiere sentido.

No obstante, de alguna forma podría parecer pleonástico que, en todo vestigio investigativo -científicamente sólido desde luego, se siga demandando la precisión epistemológica y, más que ello dar cuenta de su origen. Lo cual implica persistir en hacer una descripción teórica más o menos densa, en que se revele el horizonte al cual pertenece el conocimiento, pero que de una u otra forma implica repetir lo que se encuentra muchas veces dicho.

Es decir, si a todo proceso investigativo le es exigido un presupuesto de este orden, ¿por qué abrir explicaciones específicas al respecto? Precisamente, ¿no es de esperarse que un proceso investigativo fluido y diáfano en cada una de sus expresiones permita revelarlo sin que se requiera de un capítulo aparte cumpliendo esa función?

La explicación a esta -que puede ser una inquietud menor respecto de otras construcciones de conocimiento, adquiere cierta importancia ahora mismo dado el decidido propósito de claridad que caracteriza esta nueva experiencia investigativa. Específicamente refiriéndonos no sólo al proceso que desató el Observatorio de Política Pública del Control Fiscal (OPPCF), sino aún más respecto de los que surgirán con fundamento en él, podemos declarar el compromiso de revelar claramente el asunto epistemológico de sustento, con base en las siguientes razones fundamentales.

Por un lado, reconoce que el conocimiento no es en sí mismo democrático, tanto menos en cuanto ha sido el control fiscal un asunto acentuadamente técnico. Para ser real su acceso indiferenciado, es decir, implicando al lego, se precisa de ser ofrecido de tal manera que ello sea posible. En otros términos, que tanto profanos como expertos puedan apropiarse de 
su expresión, lo cual no conlleva liberarlos del más mínimo esfuerzo, pues ello haría del saber algo elemental y hasta vulgar. Más bien se trata de exigencias que se puedan cumplir sin contar preliminarmente con las condiciones del experto.

Así como hay un gran trabajo por parte de los investigadores, quien quiera beneficiarse de los resultados del proceso, deberá también acometer algún esfuerzo en ofrenda al denuedo que precede al resultado ofrecido.

De esta suerte, si bien el experto puede disponer de la idoneidad que permite derivar los presupuestos epistemológicos a partir nada más que de su propio análisis, al lego en cambio no le es tan sencillo. $Y$ por ello se prefiere aclarar el fundamento que sirvió de base a la generación del conocimiento allanado y expuesto al escrutinio del crítico y al deseo de quien opta por saber más del tema.

Otra razón considerada es que la exposición epistemológica sirve no sólo para la difusión temática, sino también para precisar los presupuestos, atenuando la impertinencia de algunas disputas o, al menos, su tono. Sobre todo, es una forma de evitar la exposición como consecuencia de la incompletitud o la penumbra que precede a la complejidad. Como también para mantener en línea de coherencia al investigador.

En efecto, la generación de conocimiento no sólo es una labor ardua, consecuencia de estar sujeta a las muy difíciles condiciones previstas por la comunidad científica, particularmente a causa de la inconmensurable responsabilidad social que implica, sino que suele ser objeto de cuestionamientos más o menos severos, en ocasiones injustos.

Si bien generar conocimiento es por definición el objeto de todo proceso investigativo, su efecto sobre la conciencia individual y colectiva apareja propiciar condiciones de realidad social. A partir de él, se corre el riesgo de generar cambios o cuando menos, algún tipo de impacto sobre fenómenos frecuentemente caros al patrimonio moral de la comunidad humana, sin importar contraer sus dimensiones a una región, a un país, o a una localidad. De ahí su trascendencia.

Ahora bien, siendo -como es, contingente el proceso de producción del conocimiento, se sujeta al albur que implica seguir un camino del cual no se sabe anticipadamente y con exactitud a dónde confluirá.

No existen caminos unívocos, unidimensionales, excluyentes o exclusivos, es decir, que asegurados por su simplicidad conduzcan fatalmente al destino del saber, entendiendo que se trata de un proceso de creación. Como tampoco existen saberes asegurados como consecuencia de la selección de una cierta ruta.

En cambio, los caminos que tienen por cometido constituir conocimiento suelen ser múltiples, polivalentes, complejos y acentuadamente intranquilizantes. Paradójicamente el acecho de las 
inexactitudes, de los desaciertos y de los errores parece ser parte de su propia esencia. Y si bien nada inmuniza completamente a los procesos de las vicisitudes en que se manifiestan, son menos probables cuando se dispone de la suficiente claridad epistemológica de partida.

Entonces, desnudar la selección del trasfondo epistemológico elegido, hace parte de la humildad con que los investigadores asumen el proceso. Y como efecto, proporciona un panorama menos incierto a la producción de conocimiento, y esto es tan válido para el destinatario experto como para el lego. Y acaso, muchísimo más al propio productor del conocimiento, quien se beneficia al disponer de una especie de brújula que le indica cuándo reconducirse al amparo de los riesgos de incongruencia o levedad argumentativa que le asedian.

Aunque -todo sea dicho, es así mismo eidético al conocimiento y con él a las rutas de constitución elegidas, el estar nunca libre de cuestión. Y así como también hay conocimiento carente de valor intrínseco, no faltan los cuestionamientos predicados del conocimiento valioso pero despojados de esa misma condición.

Así que precisar la cuestión epistemológica apresta condiciones correspondientes a mejores juicios, pues exige mayor cuidado y atención tanto al investigador como al crítico de su labor. Con ello, sirve la declaración epistemológica a dispensarse de tener que dar explicaciones respecto del asedio de los diletantes asiduos a las críticas ligeras, quienes se verán enfrentados a dar cuenta de asuntos mayores infranqueables a su acostumbrada insensatez.

A estas razones debemos sumar la tercera y cuarta, profundamente asociadas a la naturaleza del OPPCF, y de los procesos investigativos que se formularán y ejecutarán con fundamento en él, conforme se desprende de su misión.

Por un lado, el Observatorio es en sí mismo una herramienta científica, fruto de un proceso investigativo, para el desarrollo -a su turno, de ulteriores investigaciones aún más exigentes, en materia de control fiscal.

Desde este punto de vista se dirige a la comunidad científica, concitándola para acometer un mayor y más satisfactorio desarrollo del conocimiento acerca del tema, y de los problemas que lo caracterizan, en un país autorreferente y difícil de aprehender en sus distintas y especiales manifestaciones.

Por otro lado, se tiene por orientación primordial la divulgación, no sólo del conocimiento científico, sino de dicho conocimiento en favor del propósito constitucional de realizar el control social. En este caso específicamente se refiere al control fiscal que compete a la sociedad, como medida de anticipo o prevención a la corrupción, cuando no de reacción 
democrática, social y en derecho a sus manifestaciones lamentablemente realizadas.

Por consecuencia el OPPCF propicia el encuentro de la ciencia con la comunidad, para que ésta se valga de aquélla y la ejerza en una de sus funciones sociales primordiales.

A esta finalidad encuentra que evidenciar con máxima claridad la condición epistemológica, contribuye determinantemente a posibilitar este propósito. Así es que procedemos con un ritmo deductivo y, más que ello, denotativo, con el fin de perfilar de la forma más sencilla pero más completa posible, el asunto epistemológico que rodea el OPPCF y, como se dijo, también a los procesos investigativos a los cuales tributa.

\section{La cuestión epistemológica como opción de la teoría del conocimiento}

La historiografía epistemológica revela claramente que desde sus propios inicios el debate por el saber se ha manifestado en la tensión entre dos tendencias (SOSA E., 2018). Por un lado, la que formula el descubrimiento de la verdad como objetivo único, cuya característica es precisamente la existencia de una versión absoluta y concluida de dicha verdad, en su asociación con el fenómeno estudiado u observado.

Por otro lado, se tiene la tendencia constructivista. Conforme a ella la realidad -término preferido al menos en la versión de la filosofía del lenguaje, se construye socialmente. Es decir, la verdad de los fenómenos -quizás acertemos más en decir el conocimiento de ellos, no es algo que se encuentre en el horizonte de la conciencia a la espera de ser arrebatada a la oscuridad de la ignorancia sino que, por el contrario, no hay una busca como tal, en cambio más bien un proceso de coautoría, del cual participa el fenómeno como hecho bruto, el investigador o científico, pero también la sociedad o comunidades involucradas en las manifestaciones noéticas del objeto.

Sin duda el investigador o científico pueda siquiera ser considerado el autor principal de la creación del conocimiento, pese a lo que indiquen las apariencias. Más que una aproximación al fenómeno, lo que promueve es la expresión del fenómeno, y frecuentemente es su propia voz. Ónticamente participa de él, ya que en tanto portador de un cierto sentido -que normalmente no depende de él, es originado en las comunidades de hablantes, para propiciar el encuentro con las posibilidades de sentido que a su vez emergerían a propósito del fenómeno.

Podríamos decir que se trata de un eterno debate, expresado históricamente mediante fórmulas transfiguradas en distintas manifestaciones. Entre ellas, quizás las que alcanzaron mayor claridad habrían sido la fórmula aristotélica y la platónica.

Es evidente que en la filosofía de Aristóteles (Metafísica, 2008) el servicio que presta la 
ciencia es permitir el acceso a la verdad, esto es, en su única versión posible. Las cosas de tal o cual manera, sin que admitan mayormente espacios secantes o expresiones ambivalentes. Verdad, conocimiento y certeza no son apenas términos afines sino cualidades de una misma condición. El único conocimiento válido es el verdadero, y ello es sinónimo de certeza.

Mientras que Platón (Obras Completas, 1871) había revelado en sus diálogos la negación de la alteridad, y el riesgo de contingencia implicados en la admisión de una sola versión de la verdad. Lo cual termino por comprometer hasta los cimientos de la república, no sólo para dar a paso a la inevitable intervención del observador en dicho curso, sino sobre todo porque la verdad no podría ser otra cosa que el fruto de un proceso creativo, en el que la democracia se cuela en mayor o menor medida, porque el investigador no es un individuo que haya surgido en paralelo a su comunidad, sino que la lleva dentro y, como un todo ser resuelve sobre el fenómeno que interviene para crear conocimiento respecto de él.

En tanto la filosofía platónica fue la base epistemológica fundamental a la física (MOORE, 2017, págs. 4-8), la tradición aristotélica se fue adueñando principalmente de las áreas del saber estrechamente vinculados al espíritu. Esto es lo que conoceríamos posteriormente como ciencias sociales y humanas, alcanzando su principal expresión en el medioevo.

Quizás esto se deba a la condición sociopolítica que distinguió al gran filósofo y de la cual en cambio careció su maestro. No en vano Aristóteles debió verse más exigido en la práctica por la necesidad de orientar con suficiencia a su famoso y exclusivo pupilo. Al fin y al cabo, nadie niega la grandeza de Alejandro, y su condición simbólica para la posteridad en cuanto tiene que ver con la virtud, con la política, con la ética, con el arte de gobernar y, en fin, con la destreza de traficar sabiamente el poder. Toda una metafísica, sin duda.

Lo cual no deja de ser en cierto modo paradójico, pues mientras que Platón admitía la participación del ser humano en la constitución de su propia fenomenología, Aristóteles asumió la existencia de una irreductible realidad superpuesta a su voluntad -sin opción alguna de co-creación humana, frecuentemente según algunas manifestaciones teológicas, impuesta con una fuerza de tal contundencia que la aventajaba hasta anularla. Por ello mismo la virtud del hombre no podría ser otra que empeñarse con tesón en acceder a dicha verdad que, en todo caso, nunca se le revelaría sencilla y evidente, sino difícil y resistente (RABADE ROMEO, 2017).

El medioevo sea quizás la mejor expresión de esa filosofía del conocimiento humanístico -que es también una moral, y el presupuesto de una eticidad basada en el autosacrificio del investigador.

El punto de discrepancia está en qué tanto se quiere reconocer la participación del hombre 


\section{OPPCF}

en la constitución de su propio ser y la realidad de la que participa. Lo cual compromete una consideración tanto estética cuanto filosófica, tanto teológica cuanto científica. En fin, una semiosis de su propia manifestación (NIETZSCHE, 2012).

Así, podríamos formular que no existe una única teoría del conocimiento, sino un abanico de posibilidades (O'BRIEN, 2016), capaces de facilitar-cuando no desafiar, las condiciones de producción del saber y su utilidad social. Lo cual, dicho sea de paso, no ha de confundirse con la historiografía del conocimiento, en caso de considerar un curso de producción informativo que se bifurca con ocasión de las distintas historias a las que puede ser traducida.

Precisamente, una línea iniciada por Sócrates y Platón habría sido continuada -no sin algún tipo de redirección, por la dialéctica hegeliana (HEGEL, 2017), que en su encuentro con la fenomenología de Husserl (Investigaciones Lógicas, 1999), terminaron por abrirle el paso a trabajos que desde Merleau Ponty (Sense and Nonsense, 1964), se dirigieron a restañar al investigador dentro del fenómeno observado, hasta erigirlo en constituyente de su propia realidad (SEARLE, 1995).

Es fácilmente atendible que la epistemología ha procedido mediante una puesta en cuestión del conocimiento (ADORNO, 2015). Es decir, su valor ha sido también proporcionar las condiciones que permiten a quien se enfrenta al saber, el apropiarse de él a través de un paso previo consistente en interpelarlo. Sea en su propio contenido, sea en su método, sea en su representación y, no menos en las funciones que cumple, el valor del conocimiento ha sido frecuentemente derivado de la capacidad que tienen los modelos teóricos de dar respuesta a un máximo de inquietudes. Tantas más respuestas porte, tanto mejor hecho se encuentra, tal y como lo registró Moore en su obra Seis Ideas Fundamentales (2017).

Como se sabe, el conocimiento no es un en sí, sino que es susceptible de explicaciones que no necesariamente provienen de la ciencia, acaso más acentuadamente de otras áreas cuyas epistemes han venido ocupando lugares importantes en el núcleo de otros saberes, como son la política y la economía. De forma similar a lo ocurrido con la sicología durante el Siglo XIX, lo cual afectó hasta la indignación a Husserl, cuyas investigaciones lógicas son una tentativa bastante aventajada por recuperarle el terreno a la fenomenología.

Desde luego, lo que vivenciamos ha generado el debate en torno a la relación del conocimiento con las circunstancias de su producción y, acaso más que ello, de su uso.

Sin embargo, haber pretendido pensar el conocimiento en función política en el medioevo, la época de máxima iluminación en términos de ciencia habría sido una apostasía que los escolásticos habrían seguramente conjurado con su armadura aristotélica. La paradoja es sin embargo algunas de sus más brillantes manifestaciones pueden explicarse desde este 
punto de inflexión -o invasión, pues no sin ella la distinción ulterior entre el poder humano y el poder atribuido a los representantes de Dios en la tierra, habría sido mayormente posible.

Si bien existe el conocimiento producido específicamente en relación con el poder y su ejercicio, cuya interdependencia pone de manifiesto un vínculo con un objeto específico, el conocimiento que no tiene directamente por objeto el poder, sin embargo, mantiene con él un cierto tipo de relación.

No se sabe con exactitud en qué medida el poder se sirva del conocimiento y en qué otra el conocimiento se sirva del poder (HENRY, 2017). Más precisamente, qué tanto lo uno dependa de lo otro, y si hay una especie de superposición, por suerte que algo pese más de forma definitiva o de forma eventual, caso en el cuál, la interpelación acerca de qué dependería, se torna más que suficientemente válida.

Lo cierto es que la existencia de esa correlación ya no se pone en duda, resultando actualmente más inquietante identificar en casos específicos la intensidad en que se desenvuelve la asociación dialéctica. Como se sabe, se habló de la sociedad de la información y, se llegó a profetizar que la posesión del conocimiento implicaba la magnitud del poder (ANDERSON, 2008, págs. 5-22).

Por otra parte, la economía tiene implicancias determinantes sobre la generación del conocimiento. No sólo en el entendido de ser el conocimiento una mercancía que se trafica en un universo en donde resulta cada vez más enajenable, y el valor de uso y el valor de cambio juegan con tanto o mayor dinamismo que el valor de producción. De hecho, producir conocimiento es en sí mismo costoso.

Pero al tiempo, el conocimiento y la información que con base en él se construye suele ser objeto de inquietud, tanto más en cuanto la sociedad se complejiza.

Adicionalmente, se produce conocimiento para hacer posibles ciertos cursos económicos y políticos, inicialmente considerados en paralelo a él, pero ha venido aceptándose la idea de una unidad -o tal vez complejidad, para descubrir un constructo polifacético de la cual el conocimiento es apenas una variable (EVANS, 2013).

La pretensión positivista de un conocimiento universal capaz de dar respuesta a todas las inquietudes que teórica o prácticamente se le formularan, identificó a la epistemología decimonónica.

Sin duda se trata de un legado o el efecto de una concepción universalista que hunde sus raíces -así mismo, en la filosofía aristotélica. Al fin y al cabo, la pretensión del filósofo y de las escuelas que se derivaron de su fórmula, fue alcanzar un estatus quo de saber planetizado, 
entendiendo que su validez dependía de ser incuestionable por razones historiográficas o geográficas. Se trataba al fin y al cabo del alcanzar un punto de conquista que implicara la imposibilidad de su caducidad.

Se buscó entonces un conocimiento independiente y autónomo, imprescriptible y ajeno a los azares implicados en las contingencias históricas. La ciencia, o lo auténticamente científico, debía sujetarse a este tipo de escrutinio y de sus resultados dependería la validez del saber. Se trataba de alcanzar un estado en que no había nada más que saber, puesto que había sido aprehendida la esencia -el Eidos de Aristóteles, y, con ello, la tranquilidad derivada de la más absoluta certeza. De tal suerte ese tipo de conocimiento podía ser sujeto a la verificación independiente del lugar y el momento.

De esta forma, la ciencia se convirtió en la supuesta fuente de la estabilidad social, y desde luego, todas las áreas del saber social y no social se empeñaron en alcanzar este punto cimero de permanencia.

Sin duda implicó una caracterización deseable en términos de confianza en la ciencia. Pero ulteriores desarrollos, como el conocido principio de incertidumbre, cuestionaron seria y definitivamente esa pretensión que, pese a ello, no ha sido completamente abandonada, dando auge a una orientación de la teoría del conocimiento que pasó a considerarlo como algo apenas probable (ROWBOTTOM, 2015).
No hubo otra alternativa que admitir la existencia de epistemes, lo cual se enderezó a precaver de conocimientos cuya validez resultaba tributaria de una especie de "estabilidad inestable". Es decir, en un momento dado y en un lugar dado, podía producirse conocimiento válido, característica que en sí misma no cuestionaba a la ciencia, aun cuando forzaba cierto tipo de prevención y de custodia acerca de los procedimientos con base en los cuales se generaba.

Las epistemes constituyen el decreto que legitima de la prescriptibilidad del conocimiento, de la ciencia y del saber en general. Fue la apertura del conocimiento a la admisibilidad de su contingencia innata, lo que no le restaría importancia, sino que -por el contrario, la seguridad de esta su característica, lo realzaría en su resistencia a ser desechable, más no por ello efímero.

Se fue gestando así la determinante intervención de las comunidades científicas, que servirían de ahora en adelante para patentizar la vigencia y validez del conocimiento.

Admitida la contingencia del conocimiento como un en sí mutable, la vigilancia se posó más que en la posibilidad universalista del saber,enlosprocedimientosinquebrantables, aunque sujetos a la revisión insidiosa de la comunidad científica. Una especie de cadena de custodia que se hartaría de la estrategia valedera con sello de legalidad para la teoría del conocimiento, consistente en orientarse hacia la metodología. De tal suerte hizo de 
ella su nuevo baluarte y cinturón de castidad. Por manera que los resultados verificables conforme a ciertos patrones metodológicos garantizarían la cientificidad del conocimiento.

Y esa metodología, al fin y al cabo, heredera de alguna vertiente escolástica y muy acentuadamente de los presupuestos del Siglo XIX, se identificó con un empirismo basado en la verificación de los datos, como se dijo.

Toda una nueva ideología de la verdad sustituyó aquella que la erigía como objeto último del conocimiento, al cual se accedía mediante un mecanismo de descubrimiento. Es decir, el investigador y su proceso aplicado dejaron de ser para siempre jamás una mediación sustituible entre la consciencia y la naturaleza. Pero este empirismo sucedáneo es en sí mismo una teoría del conocimiento que informa de cierta praxiología a la ciencia.

No se piensa el valor del saber científico apenas en sus expresiones teoréticas, en todo caso muy importantes, sino en evidencia manifiesta en la aproximación del investigador al fenómeno, y en una orientación pragmatista. Si hay conocimiento, ha de servir de algo justamente porque surgió de algo práctico (HAACK, 1995).

No se niega que el científico o investigador en alguna medida intervenga el fenómeno. Pero su noema se mantiene, con independencia de él, a condición de que, como dijera Hegel, haya atendido la racionalidad intrínseca del fenómeno. Se trata de cauterizarlo de la imposición hegemónica o fruto de la ignorancia, de una racionalidad que le es ajena.

Consecuencia ineludible es que la ciencia se encuentre compuesta por su propia entidad semántica, como quiera que expresa sus propios métodos, para apropiarse de los fundamentos sintagmáticos de los fenómenos u objetos de aproximación empírica.

No se trató de negar cualquier valor a las investigaciones meramente teóricas. Pero en todo caso quedarían sujetas a la demostración de sus postulados, así prevengan aproximaciones ausentes de demostraciones sustanciales. Al fin al cabo, buena parte de la teoría de Einstein fue demostrada mucho tiempo después de la muerte de su creador -no del descubridor de tal o cual verdad, mientras que otras están bien lejos de la demostrabilidad deseada, no sin que se perpetúe el empeño por lograrlo y de ello dependa más su valía que en su posibilidad praxiológica, tal como sucede con la teoría de la evolución, por citar un ejemplo.

Podríamos formular que la cuestión epistemológica ha venido siendo la respuesta a la principal tensión registrada por la teoría del conocimiento. Porque su valía científica, dada la inquebrantable relación entre el investigador y el fenómeno, y con aquél de la sociedad con éste, depende de la administración de esa relación y en manera alguna de su negación.

En efecto, esa relación se tradujo en la oposición objetividad-subjetividad. Y podríamos 
formular que la cualidad ecuménica cedió en favor de la objetividad, sin que ella fuera sinónimo de hegemonía absoluta e irreversible en cuanto a la vigencia del conocimiento.

La ciencia terminó optando por la objetividad epistemológica, por oposición a la ontológica, en cuanto permite la verificabilidad de los resultados con independencia de los investigadores u observadores.

Resulta muy importante distinguir que la ciencia abrigó la objetividad de tipo epistemológico. Y de ahí mantenemos que la cuestión epistemológica ha venido siendo la respuesta a la tensión indicada, porque reconoce lo que se había negado con necedad positivista: el investigador participa de la condición eidética del fenómeno. La fórmula de la epistemología consistió en admitir los postulados manifiestos en hipótesis, inferencias, deducciones, etc., cuya particularidad consista en que su valor de verdad no puede depender de las particularidades de los enunciantes, llámense científicos, investigadores, observadores o, -por qué no, filósofos.

Esto por oposición a la subjetividad epistemológica, según la cual el valor de verdad de sus proposiciones depende, por el contrario, de las especiales convicciones de los enunciantes.

Esta subjetividad se erigió en el límite cuyo umbral anuncia el fin del conocimiento científico. Luego la cuestión epistemológica no ha sido nada más que señalar la ruta de la ciencia, o delimitar la frontera a partir de la cual se encuentra el saber paralelo. Más bien, parafraseando a Merleau Ponty, es el trasfondo donde se proyecta la silueta de la sociedad jugando a saber algo más.

Por su parte, la ontología ocupó el lugar de la precisión fenomenológica. Así que mientras la epistemología dio cuenta de la ciencia estimada en el en sí conocimiento, la ontología se precia de precisar el para sí de la misma ciencia.

De donde los enunciados ontológicamente objetivos, en cuanto predicados de cosas, no aseguran la ecuanimidad que en cambio sí cuida la objetividad epistemológica. Como tampoco los enunciados ontológicamente subjetivos, porque el estar predicados de personas no implican necesariamente su objetividad, epistemológicamente hablando (AXTELL, 2016).

\section{La cuestión epistemológica en su proyección al Siglo XXI}

La cuestión epistemológica fue la mejor respuesta a toda la resignificación implicada con transfiguración de la teoría del conocimiento adquirida entre el decimonónico y la segunda mitad de Siglo XX.

Lo cual no significa haber adquirido la condición de oráculo infalible capaz de dar cuenta 
de cuanta respuesta se demande, pero sí de una ampliación o, lo que es más preciso, una des-simplificación, en cuanto a la epistemología le fue permitido manifestarse respecto de asuntos antes omitidos. Lo más objetivo es que se proveyó una condición de sensatez a la producción de conocimiento.

Pero esto no ha estado exento de "disturbios cognoscitivos", -quizás debamos admitir que aún no alcanzado suficiente completitud. Lo cierto es que se trata de un proceso que sigue su curso, y resulte conveniente seguirle los pasos en favor de fijar un presupuesto epistemológico más claro.

Decíamos que hubo toda una resignificación, pero sería más acertado hacer referencia a una re-cognición.

Esto no quiere decir que haya habido errores o desaciertos que se estén superando mediante una epistemología sobreviniente. Como tampoco que exista un camino de discreción evolutiva, en el cual se identifique "lo anterior" como algo más o menos vulgar, sucedido por algo más consubstancial a un nivel de adaptación inflexible y vehemente. Simplemente damos cuenta de una mutación.

En rigor, la epistemología que se tuvo respondió conforme a las condiciones que le fueron impuestas, abonadas por una teoría del conocimiento empeñada en el pretendido descubrimiento de "la verdad verdadera".

Sin embargo, las condiciones se fueron alterando, permitiendo abrirse a una concepción menos conservadora, más dinámica y, si se quiere, más humana.

Para comenzar, la ciencia misma es reconsiderada, para ser apreciada de ahora en adelante como un hecho institucional, empleando las palabras de Searle, que hunde sus orígenes en Platón, en Hegel y en Husserl, principalmente.

Su (...) eidos se sustenta en la creencia socialmente compartida de ser lo que representa. A toda institución subyace el nivel de las intenciones, entendiendo que la creación tiene un cometido; precisamente, no descansa en el azar como secuencia de creación accidental sino que despliega un propósito sistémico: le ha sido asignada una función, con ello se genera una expectativa entre los operadores que juegan el rol atribuido dentro del juego que la institución propone.

Según Searle los hechos que satisfacen la regla que él describió como, " $X$ vale $Y$ en $C$ ", son institucionales, amén de otras cualidades, 


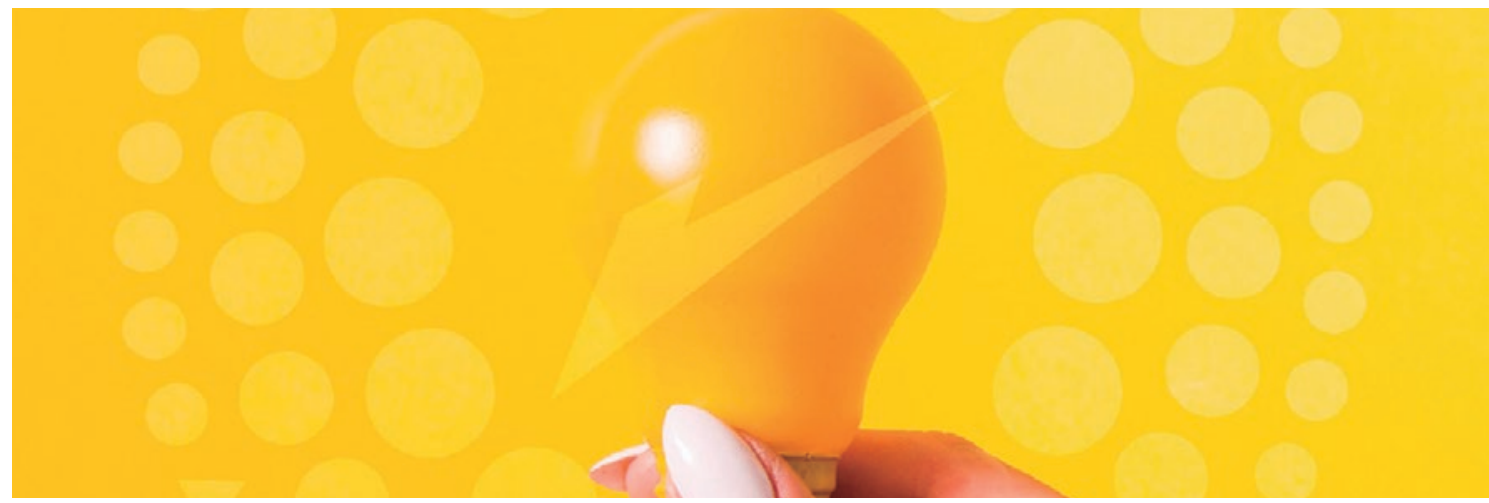

esta es según el filósofo del lenguaje la principal insinuación de hallarse frente a un hecho no bruto. (...) (MOYA VARGAS, 2012, págs. 24-25).

Con lo cual se describe una cierta condición, conforme con la cual el conocimiento es un producto creado por el hombre, y su vigencia se condiciona, como cualquier otra institución, a la creencia social depositada en él.

El saber en el cual la sociedad deposita su confianza hace parte de su propia realidad, constituida por ella misma. No se trata entonces de alcanzar certezas en términos de verdad inquebrantable, sino de unas reglas de juego, específicamente, del juego científico, con lo cual se realza definitivamente la metodología.

Por suerte que podríamos predicar que la ciencia participa de la misma condición contingente de otros hechos igualmente institucionales, como el dinero -para emplear el ejemplo de Searle. Es en sí un producto susceptible de ser enajenado, y sus múltiples expresiones responden a órdenes que no se explican nada más que por el conocimiento y su vínculo con una pretendida verdad ajena a la voluntad humana. Y acaso, las circunstancias políticas y económicas sirvan mejor que los "hallazgos", a las explicaciones del por qué la ciencia tiene ciertos cursos, dinámicas, especificidades, etc.

Es decir, la epistemología vertida particularmente en el curso concluyente del Siglo XX y que sirvió de fundamento a los inicios de la siguiente centuria, se caracterizó por admitir una serie de condiciones del saber que no se explican por él mismo, sino por influencias que aun cuando provienen de sus exterioridades, terminan haciendo parte de su propia expresión.

Se abandonó la pretensión derivada de una fe dogmática en el conocimiento y en la verdad, en favor del reconocimiento de unas ciertas condiciones de producción del conocimiento y de configuración de la verdad. Aquél es susceptible de condicionamientos, mientras que la 
verdad es creada y finita. Esto es algo que inevitablemente ha implicado el re-conocimiento del significado de la verdad, al menos en la fórmula medieval (COADY, 2012).

Desde luego, la epistemología cambió junto con su objeto de conocimiento. Si la verdad procede del conocimiento o el conocimiento de la verdad, son cuestiones vigentes, que quizás en la época de la más absoluta hegemonía aristotélica ni siquiera resultaba sensato plantear.

Ahora se descubre una relación poco tranquila, susceptible de lecturas que no necesariamente convergen en sus lineamientos, pero que en todo caso admiten el peligro de unas opciones proyectadas hacia destinos nada amables con la existencia del ser vivo en general (WRENN, 2014).

De la misma forma, las comunidades científicas, hablantes autorizadas por razones más políticas y económicas que absolutamente científicas, adquirieron un reconocimiento que no las agota en el lugar de portavoces autorizados, sino de gestores de intereses compuestos por múltiples vertientes, no siempre declarados ni necesariamente identificables a partir de los presupuestos rígidos de una teoría del conocimiento agotada.

Pensar la sociedad en abstracto como comunidad vinculada por un contrato social, sigue siendo una ilustrada construcción teórica, sin verificación ostensible en las prácticas que supuestamente la sustenta. Hay estrategias, evasiones, direccionamientos, objetivos claros y no tan claros, enfoques y diferencias, todo un teatro de sombras, que autorizan a señalar preferiblemente como responsables de los constructos de conocimiento, a grupos que pujan conforme a los idearios de su integración, pero que lejos de desmentir, acentúan su carácter supra-científico (PERRON TOLLEFSEN, 2015).

La epistemología sigue ocupando el lugar filosófico que entrañó. Pero la pretensión de explicación absoluta del conocimiento, como todo elaborado y acabado, chocó irremediablemente con las prácticas irreductibles que hoy nada mejor puede describirlo como lo ha logrado la complejidad.

Para comenzar, la epistemología ha podido menos que admitir los límites a los que se encontraba reducida. No porque el estado de cosas asociadas al saber y a la verdad, simplemente fuese así y no hubiese más que hacer. Para esa vertiente, al fin y al cabo, no todo lo que integra el conocimiento puede ser epistemológicamente explicado. Lo cual en absoluto controvierte que la cuestión epistemológica determine la condición necesaria de coherencia $y$, muy acentuadamente, de objetividad que caracteriza al conocimiento científico.

Pero la epistemología le formula exigencias a la producción del conocimiento, derivadas 
de una cierta identidad institucional correspondiente.

Los procesos de producción del conocimiento registran límites de saturación o clausura epistemológica (TURRI, 2013). De ello depende conservar una cierta identidad, pues hace parte de los hechos institucionales el ser de alguna forma coherente. Para emplear un símil, hay unas reglas del ajedrez cuya aplicación hace que surja el juego del ajedrez $y$, en consecuencia, no sea otra cosa como por ejemplo croquet o damas chinas. Allí donde ya el conocimiento pierde identidad, es donde se halla la clausura epistémica.

Surge entonces una especie de sinapsis entre esos límites epistemológicos en una relación de continuidad en red, que no es necesariamente convergente a un punto de partida. Es precisamente eso, continuidad más no linealidad, hay entropía y no uniformidad estática, sincrética y obediente. Lo que surge, por ejemplo, en un origen dogmático, bien puede proyectarse en favor de finalidades democráticas, según se comprometa el conocimiento en usos favorables a dichas manifestaciones.

Precisamente, la incursión de la ciencia en el modo de ser y vivir social e individual, ya se había admitido con una serie de condicionantes que escapan a la reducción epistemológica de base aristotélica. Esto ha llevado a una nueva moral del saber, es decir, a una nueva relación del hombre con el conocimiento. Bien que una cosa es accederlo, otra muy distinta lo que se puede hacer con él. Decididamente el conocimiento faculta un cierto tipo de poder hacer, más ello no implica que cualquiera pueda hacer cualquier cosa con él (KLIMOVSKY, 1995).

En definitiva, la epistemología actual no integra, sino que reconoce la integración institucional del conocimiento. De donde resulte preciso leerlo en consideración a la red institucional a la cual pertenece.

De esta forma, en un modelo político basado en la democracia, en el predominio de lo social y el derecho como condición de legitimidad compartida, el conocimiento entraña una función social. Luego, la legitimidad constitucional del conocimiento, es decir, su epistemología, orienta tanto en cuanto a su producción como a su utilización. Por científicamente valioso que pueda resultar, crear conocimiento para la destrucción social no tiene soporte dentro de los límites de saturación epistemológica que se describe.

De la misma forma, los usos del conocimiento pueden ser propicios a las injusticias sociales o a cualquier otra forma de negación del ser. Los límites de saturación epistemológica encauzan las posibilidades en previsión de servir a vehicular propósitos de negación. La epistemología actual no daría sustento, por ejemplo, a prácticas como las que se aplicaron durante la segunda guerra mundial por el nacional socialismo, para generar un cierto tipo de conocimiento.

En esta tendencia adquirida por la epistemología, lo que se busca es emancipar 
la sociedad de los límites impuestos por los órdenes feudales que, en materia de conocimiento, ha sido una de las fórmulas para cerrar las cribas de las servidumbres (De SOUSA SANTOS, 2009).

En esta visión epistemológica, pensar la sociedad como destinataria del conocimiento, no puede ser más que una paradoja. Es en las entrañas sociales desde donde se forja el conocimiento, bien que de ello haya de encargarse las comunidades científicas, luego parte de la sociedad para ella misma. Es de alguna forma lo que Merleau Ponty expresaba como el ser del mundo, es decir, una de las formas que tiene para apropiarse del mundo en que apareció.

Decantada, la del Siglo XXI es una epistemología de la complejidad (MORíN, 2004). Precedida por la pretensión de un conocimiento científico de estirpe aristotélico, empeñado en el denuedo de establecer las inquebrantables leyes regulativas de los fenómenos, cuyo dominio se traduciría de hecho en la simplificación del fenómeno. Lo que al cabo se revela en una ideología del dominio.

De tal suerte el fenómeno estudiado científicamente era el que había desaparecido en el espectro de lo misterioso, para convertirse en virtud de la ciencia en predecible y, con ello, susceptible de ser dominado; más precisamente, utilizable conforme a fines estratégicamente diseñados.

Mientras que la epistemología de la complejidad conserva la mística del fenómeno, pues no es su interés domesticarlo, sino atender a sus sinuosidades y a sus peligros: se trata -más bien, de considerar su carácter, y con él la contingencia de su personalidad. Por suerte que el fenómeno conserva su misterio, en cuanto deja de ser objeto de dominio, sino medio de expresión en favor del ser, de la sociedad, de la humanidad.

De ahí que se hable de aparentes antinomias provenientes de la epistemología como la temporalidad atemporal del fenómeno, o su especificidad abstracta.

Hace parte del fenómeno y con él, de la institucionalidad del conocimiento, su contingencia, su incertidumbre, su entropía, todos en favor de la sociedad de la cual surge.

\section{La nueva fenomenología del conocimiento}

Conforme lo evidencia el recorrido histórico, la relación del hombre con el conocimiento nunca ha sido estable. Unas veces con ocasión de las profundas diferencias entre las fórmulas filosóficas que la han sustentado; otras por las contingencias sociales, particularmente en cuanto a su intervención política y economicista. 
Unas y otras con pocas o ninguna convergencia, ni propósitos compartidos. Lo cual sugiere que no ha habido propiamente una empresa dispuesta a propiciar una teoría unificada y sólida del conocimiento, capaz de servir a una epistemología trascendental. En cambio, lo que se manifiesta es el fruto del albur implicado por la coexistencia de múltiples pretensiones.

Por ello mismo durante la segunda mitad del Siglo XX se desató una especie de revisión crítica. Qué tan detallada o profunda haya sido no es algo que competa ahora mismo, pues interesa más el alcance de las condiciones transversales halladas. Entendiendo como tales condiciones, aquellas que informan de un cierto sentido común y, por ello mismo, capaz de explicar el estado actual de la cuestión epistemológica.

En esta perspectiva el conocimiento científico se entiende como algo connatural al hombre. Por consiguiente, dejó de ser asumido entre todo aquello a lo que puede o no accederse conforme se ocupe los lugares que socialmente puedan permitir ese privilegio, o mediante ciertas relaciones de poder o, condiciones económicas afines.

Luego, el conocimiento se relaciona con aspectos esenciales y no experimentales de la vida de los individuos y de las comunidades, por suerte que sobre la base de ese vínculo considerado ahora como ineludible, es que se redescubre la vocación de su constitución.

En este contexto, la epistemología con su particulary entrañable relación con el conocimiento forzó a su vez algunas revisiones.

Ante todo, el Siglo XXI políticamente se enseñorea en los presupuestos del Estado democrático, social y de derecho como un presupuesto de legitimidad básica, a partir del cual no es posible seguir dándole soporte a la tendencia que ubicaba el conocimiento científico como capital simbólico de algunas élites. Lo que no implica la pretensión -sería necia- de negar la relación del conocimiento con el poder. Aun cuando sí hay una inevitable modulación de dicha relación, puesto que dejó de ser un mecanismo orientado a capitalizarlo conforme a estrategias que desafían su actual virtud, pese a los desafíos implicados en la actual crisis que padecen algunas de las ciencias humanas.

Se trata de una construcción, pero cabe controvertir el tipo de constructo que puede elaborarse para que adquiera identidad de conocimiento científico.

A una remozada identidad democrática sobrevino la asociación pertinente con el conocimiento. Es decir, es tributario de dicha identidad. La condición del ciudadano apareja un complejo de derechos inquebrantables -la verdad sea dicha unos menos y otros más, que no sólo son propicios a la vida de los individuos y sus comunidades, sino a una cierta forma de ser, distinguida por reivindicar como valor supremo la dignidad de todos y cada uno. 
El empeño de la teoría de los derechos fundamentales se inclina recientemente por desentrañar lo más fundamental que involucra esta ideología, sea ella la dignidad propiamente dicha o la autonomía de los pueblos, es lo cierto que el carácter esencialista se profundiza cada vez más insustituible (FERRAJOLI, 2017).

Si el conocimiento puede tener un cierto tipo de relación con el poder y es un bien que incorpora a su turno, cierto tipo de valoración económicamente expresable, tanto como si es susceptible de direccionamientos estratégicos conforme a intereses políticos concretos, es algo que ya no inquieta porque hace parte de su propia óntica. Lo que en cambio fuerza las consideraciones entorno a él, es su importancia -inevitabilidad si se quiere, y muy particularmente, el derecho o los derechos que se tienen sobre o respecto de él. Sin disminuir -en manera alguna- que su cometido axiológico se condiciona a la realización constante de la dignidad humana, como valor transversal del modelo Estado democrático, social y de derecho.

En consecuencia, de la concepción política homo-centrista que identifica el ingreso en el nuevo Siglo, se implica el derecho fundamental de acceder al conocimiento científico, no solo como efecto del saber intelectual, sino en cuanto a sus beneficios. Bien entendido, no se trata de la posibilidad de un ejercicio de intelectualidad banal indiferenciado, sino de la dignificación del ser a partir, también y entre otros, del saber, a fin de servirse de él como un recurso permanente. Por suerte que podemos tranquilamente declarar que el saber tiene actualmente las características propias de cualquier otro derecho fundamental (HACKER, 2013).

La forma como se llegó a este estado de cosas atiende a que el conocimiento se sujetó a un proceso de redescubrimiento, el cual evidenció sus implicancias sociales, tanto en su origen como en su destino.

La nueva legitimidad del conocimiento compromete no sólo su origen sino también su razón de ser, entendiendo que se trata de toda una acción social que involucra a la comunidad, su sentido, su cultura, sus impuestos, etc. Se desasoció de su condición de objeto suntuoso, para vincularse a la de patrimonio público, bien que el acceso y hasta su uso pueda de alguna forma ser facilitado o dificultado por razones de clase.

Lo cierto es que las tendencias de las políticas públicas referidas directa o indirectamente al conocimiento tienen una dirección muy distinta a la aristocrática y excluyente.

Con ello surgió una nueva fenomenología del conocimiento que revela un aspecto noemático predominantemente social y de vocación democrática, que adicionalmente fuerza considerar el pensamiento como acceso primario al conocimiento (MORAN, 2013). 
Ahora bien, las condiciones fundamentales de acceso al conocimiento aparejan otra particularidad. Podríamos convenir en que el principal acceso al conocimiento es el pensamiento. Sin duda el principio de igualdad revertida en el modelo democrático, social y de derecho implica que bien puede haber diferencias derivadas de factores múltiples entre los miembros de una comunidad, pero sin poder más que admitir como connatural al ser humano el pensar, su dirección al conocimiento es así mismo inevitable, con todas las diferencias que puedan evidenciarse en las distintas sociedades. Diferencias originadas en razones menos que la imposición forzada o la hegemonía de doctrinas, ideologías o religiones.

Con toda su importancia y trascendencia, el pensamiento es susceptible de ser conductistamente direccionado. Empero, su fenomenología desnuda que esto es mucho más probable en tanto y cuanto se pretenda agotarlo en apenas alguna de sus manifestaciones.

Precisamente, lo que se halla es que todo pensamiento es inferencial, es decir, se trata de una función innata al ser humano que le permite hacer asociaciones entre lo que se tiene por sabido o conocido, con lo que carece de esa entidad consciente.

Pensar sirve para conocer y conocer consiste en hacer presente algo, cualquier cosa, a la conciencia. Puede haber equivocaciones, pero ello no le resta valor inferencial.

Desde luego, la misma fenomenología revela el predominio del pensamiento racional, más precisamente, del lógico-formal que, por cierto, también arraiga en la tradición aristotélicotomista (BROOME, 2013).

Las principales expresiones del pensamiento racional siguen siendo la deducción y la inducción que, como se dijo, predominaron hegemónicamente desde sus orígenes demostrados en la filosofía helénica.

Sin embargo, la razón no es la herramienta exclusiva -ni la preferida, de adaptación y desarrollo humano. Su otra capacidad, la no racional, que desarrollamos y practicamos como intuición, coexiste a la racional, con mayor o menor impacto, según el individuo (VILA CORTS, 2005). Y puede resultar tanto o más importante que la razón para el desarrollo del pensamiento, particularmente cuando procede de una base experiencial, que le proporciona material fundamental a la razón.

Pero del pensamiento racional se ha hecho algo completamente impermeable a lo que no sea razón estrictamente. Fruto del largo pasado de tradición aristotélica, hubo una tendencia reduccionista consistente en no considerar más que la razón como herramienta del pensamiento. 
Lo cual resultó propicio al agotamiento de las opciones entre la inductiva y la deductiva, y sin que pretendamos señalar de errático, sí es cuando menos reduccionista, con un evidente déficit de esa otra condición que, sin embargo, trasciende en el pensamiento tanto o más que la razón.

Así aún, dispuesta como se halla en dirección inductiva o deductiva, no es apenas sino una posibilidad cuyo predominio no implica la imposibilidad de una alteridad distinta al error.

En cuanto pensamiento esa otra opción ha sido comúnmente designada como abducción. Y de ella proviene el pensamiento abductivo.

Para comprenderlo es preciso volver sobre las características generales de la inferencia. Simplemente para reconocer que la deducción revela una dinámica conforme con la cual, dada una premisa general, respecto de un caso particular conocido, se puede obtener una conclusión originalmente desconocida, -su equivalente semiótico sería la connotación, que relaciona dentro de una generalidad sintagmática, las posibilidades semánticas de un signo intensionalmente considerado.

Mientras que la inducción procede a la inversa, esto es, dado un caso conocido frente a una premisa específica, puede derivarse una premisa general desconocida, -su equivalente semiótico corresponde a la denotación, que asocia un signo con un significado intencionalmente previsto.

En ambos, la experiencia empírica se basa en el conocimiento del caso, el cual se confronta a una premisa general o a una premisa especial, dependiendo de la situación, para derivar una conclusión, que en el primer evento es la premisa especial y, en el segundo la general.

En cambio, para una mejor comprensión del pensamiento abductivo -muy afín al método semiótico, es preciso considerar que relaciona la que puede ser una premisa general con otra especial, para intuir el caso -en semiótica un signo suscita una experiencia "no experimentada" mediante un juego de sustitución. Es decir, lo que se "infiere" es la realidad, o experiencia cognoscible, lo cual resulta aparentemente inexpugnable desde el punto de vista del pensamiento lógico formal. Pues pareciera que su premisa fundamental consiste en la porción de verdad o realidad dada, que requiere ser escrutada mediante la razón.

Hasta cierto punto el pensamiento abductivo pareciera un juego de abalorios, en que el pensador asume que esto o aquello fue o será de cierto modo, nada más que a partir del conocimiento con que cuenta. Formalmente, se describe como a partir de la consideración de una premisa general, a la que es contrapuesta otra especial, para intuir un caso desconocido.

Por ejemplo, si tenemos por premisa general,"el consumo excesivo de dulce durante la infancia 
crea riesgo de obesidad". Y otra específica, "los niños no deben consumir dulce hasta después de los cinco años para evitar riesgo de obesidad". Podríamos abductivamente derivar el caso, "mi hija de tres años puede comer dulce moderadamente".

Sometiéndolo al escrutinio ortodoxo de la lógica, el resultado puede resultar no sólo inexacto sino hasta caprichoso o, cuando menos, carente de la pretendida exactitud que caracteriza a la inducción y a la deducción.

Más aún, puede haber quien lo señale de absurdo y hasta de encubrir falacias argumentativas, porque desafía el presupuesto empírico, y al conocimiento exacto o inexacto, le sucede un complemento de irracionalidad, entendiendo por ello lo que no procede de la razón sino de la intuición.

No obstante, la recurrencia con que nos relacionamos en la vida mediante abducción conlleva considerar que puede ser una forma de pensar más importante en la cotidianidad de las comunidades. De ello da sobrada cuenta la semiótica. Es decir, hay más realidad construida mediante abducción que mediante deducción o inducción. Al cabo, más que certeza en términos de exactitud de tipo matemático, se trata de una forma de ser, y a diferencia de la lógica formal, tienen cabida una serie de elementos como los sentimientos, las sensaciones, los gustos, los disgustos, las intuiciones, las indiferencias, etc., todo aquello que quiérase o no, hace parte de los seres humanos.
Por supuesto, esto es algo que desafía la lógica de origen aristotélico, normalmente hegemónica, aun así, fuertemente golpeada en su monarquía a propósito de las investigaciones de Charles Sanders Peirce.

No es que haya descubierto ese alter, más bien le confirió la importancia que hasta ahora le había sido ocultada. Al fin y al cabo, hasta el mismo Aristóteles tuvo ocasión de advertir de su existencia, pero pareciera el límite de la racionalidad, su negación o el punto que no debía franquearse.

La propuesta de Peirce es simplemente reconocerlo como algo que quiérase o no, ocurre y que considerarlo como la némesis de la razón, es simplemente negar el noema del fenómeno del conocimiento. Incluso, podrían el pensamiento lógico formal y el abductivo llegar a prestarse algún tipo de servicio orientado a la consolidación de los dos.

Peirce llamó la atención respecto de la particular importancia social del pensamiento abductivo, pues es más recurrido en la vida cotidiana, así como en la intimidad del ser, y por ello mismo tiene una relación mucho más estrecha con la realidad social, que la registrada por el pensamiento racional en su proporción lógico formal.

Es así precisamente porque su práctica entraña en las creencias sociales, de hecho, son su fundamento, pues si bien es pensamiento inferencial, invierte la estructura lógica que caracteriza a la inducción y a la deducción. 
Para asumir sus cualidades es preciso advertir que la vinculación del pensamiento con la creación social de la realidad no demanda mayores inferencias de estirpe sicológica. Sino que a partir de la fenomenología misma del pensamiento se enciende la conciencia de su dinámica.

Así, se aprecia que mediante el pensamiento se activan las creencias. Las creencias son propicias a que su portador experimente el ímpetu comprometido en sus sentimientos y sensaciones. $Y$ con ello vienen las acciones sociales.

Precisamente, la teoría de la acción social permite derivar las implicancias constitutivas de la realidad socialmente constituida (WEBER, 1978). Se trata, empleando palabras de Searle nuevamente, de creencias compartidas, tal y como escenifica los hechos institucionales, por su elemento.

Las sociedades se proyectan a sí mismas mediante sus creencias compartidas, y sobre esa base emerge su realidad, igualmente compartida.

Si consideramos el origen de las creencias, se comprende mejor la asociación del pensamiento abductivo con la creación social de la realidad.

Al respecto es importante considerar lo que antropológicamente se ha diseñado en relación con la cultura. Ha tendido a precisarse el significado de las culturas que, superando la ideografía de las prácticas repetidas de forma inveterada, redireccionando hacia los procesos de decodificación, sobre la base de busca de sentido. Allí donde ese sentido se comparte, hay convergencia cultural. Se trata al cabo de una condición de semiosis, porque en rigor lo que se decodifica son los signos. Y el sentido en su versión sintáctica se manifiesta en creencias (GEERTZ, 1993).

Lo que la antropología revela como explicación demostrada, ha sido sin embargo objeto de explicaciones originalmente propias de una cierta metafísica de origen socrático, como la consideración filosófica de los diálogos en Platón. Sirviendo a propuestas recientes que indican cómo las creencias surgen ciertamente de diálogos, y aquellas que tienen este origen son estimadas como más nobles (FERREIRO, 2006).

Lo cual evidentemente consulta la división habermasiana en favor de la acción comunicativa, consideradas las acciones instrumentales y estratégicas (HABERMAS, 1984).

El propio Peirce para explicar el pensamiento abductivo, se sirvió primero de precisar las características generales del lógico-formal,

(...) El objeto de razonar es averiguar algo que no conocemos a

partir de lo que ya conocemos. Consecuentemente, razonar es 
bueno si es tal que da lugar a una conclusión verdadera a partir de premisas verdaderas, y no a otra cosa. La cuestión de la validez es así algo puramente de hecho y no de pensamiento. Si A son los hechos enunciados en las premisas y $B$ lo concluido, la cuestión es si estos hechos están relacionados de tal manera que si A entonces generalmente B. Si es así, la inferencia es válida; si no, no. La cuestión no es en lo más mínimo la de si al aceptar la mente las premisas sentimos o no también un impulso a aceptar la conclusión. Es verdad que en general por naturaleza razonamos correctamente. Pero esto es accidental; la conclusión verdadera seguiría siendo verdadera aun cuando careciéramos de todo impulso a aceptarla; y la falsa seguiría siendo falsa, aun cuando no pudiésemos resistir la tendencia a creer en ella. (...) (PEIRCE, 1988, pág. 175)

Con una particular lucidez no sólo expresó a su vez, las características generales del pensamiento abductivo, sino que adicionalmente reveló de sus propios cimientos cómo incluso los orígenes del pensamiento racional, revelan inclinaciones abductivas considerables

(...) Hay que adoptar un método nuevo y diferente de establecer opiniones, que no sólo produzca un impulso a creer, sino que decida también cuál es la proposición a creer. Liberemos pues de impedimentos la acción de las preferencias naturales, y que los hombres, bajo la influencia de éstas, conversando unos con otros y considerando las cuestiones bajo perspectivas diferentes, desarrollen gradualmente creencias en armonía con las causas naturales. Este método se parece a aquél mediante el cual han madurado las concepciones artísticas. El ejemplo más perfecto del mismo se encuentra en la historia de la filosofía metafísica. Usualmente los sistemas de este tipo no se han basado en hechos observados, al menos no a un cierto nivel relevante. Básicamente se han adoptado porque sus proposiciones fundamentales parecían "agradables a la razón". Es esta una expresión adecuada; no significa aquello que concuerda con la experiencia, sino aquello que nos encontramos inclinados a creer. Platón, por ejemplo, encuentra agradable a la razón que las distancias unas de otras de las esferas celestes sean proporcionales a las diferentes longitudes de las cuerdas que producen acordes armoniosos. Muchos filósofos han llegado a sus conclusiones fundamentales mediante consideraciones de este tipo; pero esta es la forma más elemental y menos desarrollada 
que adopta el método, pues está claro que otro puede encontrar como más agradable a su razón la teoría de Kepler de que las esferas celestes son proporcionales a las esferas inscritas y circunscritas de los diferentes sólidos regulares. Pero la contrastación de las opiniones llevará pronto a los hombres a apoyarse en preferencias de naturaleza mucho más universal. Tomemos, por ejemplo, la doctrina de que el hombre sólo actúa egoístamente, es decir, a partir de la consideración de que actuar en un sentido le reportará mayor placer que actuar en otro. Esto no se apoya en hecho alguno, $y$, sin embargo, ha tenido una amplia aceptación hasta ser la única teoría razonable. (...) (PEIRCE, 1988, pág. 179).

Pese a la claridad con que Peirce describió el pensamiento abductivo, la condición inferencial que los caracteriza ha sido ocasión de pretender homogenizarlo a la inducción y a la deducción, como si se tratase de una variable irregular, cuando no imperfecta de pensamiento lógico-formal.

Lo cual sin equívoco conduce a su propio equívoco. Pues así como epistemológicamente no es considerado por extraviado, escrutar lo que procede de la dogmática con mente hermenéutica, tampoco es justo con la hermenéutica ser sujeta a cuestión con patrones dogmáticos; como tampoco se hace justicia a la sociología cuestioonarla con base en los presupuestos de la semiótica, o a ésta con función hermenéutica o dogmática.

El extravío proviene de la intención de hacer encajar a las malas la intuición -si se prefiere la capacidad de creer, en la lógica formal, cuando el pensamiento abductivo formula que es una condición que hace posible la producción de conocimiento que puede llegar a ser susceptibles de verificación deductiva o inductiva, pero no necesariamente.

Posiblemente el conocimiento adquirido mediante abducción no cuente con el sello de garantía que aplican las comunidades científicas al otro pensamiento proveniente de las investigaciones pasadas por su filtro, más no por ello carente de la calidad de saber que trae aparejada a producción social de la realidad.

Esa homogenización artificial y forzada es realmente una reducción del pensamiento abductivo a un modelo de inferencia lógica de un pretendido -y frecuentemente fallido, paralelismo a la deducción-inducción, ha sido inevitablemente atemperado por la inevitable naturalidad de una especie de instinto de saber, sin mayor identidad con el pensamiento lógico-formal, aun cuando relacional al método científico.

Precisamente Aguayo citando a Peirce, da cuenta de las razones anticipadas del pensador en 


\section{OPPCF}

cuanto al riesgo de dicha reducción,

(...) However man may have acquired his faculty of divining the ways of Nature, it has certainly not been by a self-controlled and critical logic. Even now he cannot give any exact reason for his best guesses. It appears to me that the clearest statement we can make of the logical situation -the freest from all questionable admixture- is to say that man has a certain Insight, not strong enough to be oftener right than wrong, but strong enough not to be overwhelmingly more often wrong than right, into the Thirdnesses, the general elements, of Nature. An Insight, I call it, because it is to be referred to the same general class of operations to which Perceptive Judgments belong. This Faculty is at the same time of the general nature of Instinct, resembling the instincts of the animals in its so far surpassing the general powers of our reason and for its directing us as if we were in possession of facts that are entirely beyond the reach of our senses. It resembles instinct too in its small liability to error; for though it goes wrong oftener than right, yet the relative frequency with which it is right is on the whole the most wonderful thing in our constitution. (...) (AGUAYO, 2011).

De donde, podamos concluir que el pensamiento abductivo no riñe con el pensamiento que tradicionalmente procede de lógica inductiva o deductiva. Mas su entrañable práctica instintiva hace de él una condición de generación de la realidad, en la cual converge con el otro.

Al cabo se trata de un conjunto de capacidades antepredicativas que hace posibles los estados intencionales de pensamiento, capaz de producir conocimiento que incorpora lo que en cambio desdeñan del ser humano la inducción y la deducción.

Por suerte que el pensamiento abductivo implica que no se requiere de mayores conocimientos de lógica para pensar lógicamente, ni ser científico para generar conocimiento científicamente sostenible. Aguayo lo llama en el texto en cita, lógica utens, complementada por la lógica tradicionalmente entendida o lógica docens.

\section{La cuestión epistemológica en consideración a los métodos}

Posiblemente urja la respuesta a una inquietud que ni siquiera al experto resulta del todo sencillo de formular. Esa inquietud es, ¿Para qué sirve la epistemología?

Y la respuesta no la haremos esperar más, esto es, la importancia de la cuestión epistemológica 
consiste en que aporta claramente el sentido que corresponde a la construcción de conocimiento.

La ausencia de sentido tiene repercusiones múltiples, que van desde la indiferenciación hasta la ausencia de valor.

Por ejemplo, en el Libro de Pandectas del Corpus luris Civilis, se refieren situaciones específicas que los juristas analizaron como por ejemplo la famosa escena del barbero que aceptó rasurar a un cliente en plena vía pública, a quien terminó degollando como consecuencia del impacto que accidentalmente produjo un niño con un objeto de juego sobre la mano con que hacía su labor.

Los juristas debatieron en torno a quién debía atribuirse la muerte del cliente. Y conjeturaron acerca de quién resultaba más susceptible de serle imputada la responsabilidad, como consecuencia de haber sido menos adecuado a la conducta de un hombre medianamente diligente.

Consideraron al barbero por haber aceptado rasurar al cliente por fuera del local donde podía ejercer su profesión. Pero también al cliente por haber hecho la propuesta que resultó aceptada. $\mathrm{O}$ al Pater Familias del menor. Y no menos a la gendarmería romana encargada de hacer cumplir las normas urbanas. Quizás el niño que golpeó la mano del barbero, ¿por qué no?

En tiempos de los juristas clásicos esto se comprendió como algo asociado a la responsabilidad por diligencia y, en consecuencia, quién era el más culpable, para ser declarado responsable.

La culpabilidad es el fundamento del juicio de reproche a quien debe responder, como consecuencia de su dolo o de su culpa. Este fue el sentido que adquirió el conocimiento creado por los juristas. Es decir, el de una justicia basada en la culpa que, si se coloca en términos menos técnicos -como lo dijera Kant, sería poco más o menos: lo justo es que responda el que obró con más maldad.

En cambio, si nos trasladamos a la actualidad, el mismo conocimiento adquiriría un sentido absolutamente distinto, formulando un presupuesto de responsabilidad profundamente diferente al primero.

En efecto, buscaríamos un responsable por imputación objetiva, es decir, a quien creó un riesgo antijurídico como consecuencia de haber disfuncionado socialmente, hasta lograr la producción de un resultado que pudiendo haber evitado, sencillamente no lo hizo.

Aquí el sentido informa algo así como, lo justo es que cada quien haga lo que le corresponde, sin importar qué tan bueno o malo sea, es decir, qué tan culpable resulte, por disfuncional 


\section{OPPCF}

deberá responder.

Probablemente en ambos casos se concluya que el responsable es la misma persona, no obstante, el sentido de justicia se informa de contenidos no sólo distintos, sino opuestos.

Reiteramos que el conocimiento es el mismo, es decir, los presupuestos que conducen a la responsabilidad. Pero la variación fue de sentido. En el primero, un sentido que parte de razones más subjetivas que objetivas; mientras que el segundo fue exactamente al contrario, es decir, por razones más objetivas que subjetivas.

Si se hubiese invertido, es decir, pretendido que la imputación objetiva hubiese sido el sentido otorgado por los juristas, posiblemente se habría considerado un conocimiento enrarecido, quizás errático, en fin, no se habría podido entender y si existió ese sentido, no habría sido considerado por falta de valor jurídico en el contexto existente.

O el rechazo a ese conocimiento estaría explicado más por la indiferencia, ante la imposibilidad de ubicarlo en el horizonte de sentido acostumbrado por las escuelas sabiniana y proculeyana de la época.

La epistemología sirve precisamente para eso, esto es la definición de sentido que caracteriza a la construcción propiciada que llamamos conocimiento, en curso a su valía intrínseca y hacerlo presente a la consciencia.

Ahora bien, señalamos que la cuestión epistemológica fue la respuesta de la teoría del conocimiento, cuando buscó la cientificidad basada en los métodos, al abandonar la pretensión fallida de un saber asociado a una verdad inquebrantable, absoluta y universal.

La específica relación entre la cuestión epistemológica y el método es entrañable. Puesto que aquélla proporciona un cierto sentido el método es al cabo un mecanismo de establecimiento de las posibilidades de sentido. De donde un método aplicado conduzca invariablemente a una cierta epistemología.

Más claramente diremos que un método no es apenas una guía dispuesta a conducir a un cierto resultado que al conseguirse, adquiere condición de conocimiento constituido. En realidad, el método mismo se proyecta en el trasfondo epistemológico que le corresponde. Por suerte que un método aplicado arroja necesariamente la epistemología de base, porque nada como el resultado del método puede y debe descubrir lo más auténtico de una epistemología. De ella parte y a ella retorna para hacerla más clara.

Consecuencia de lo cual es que las opciones de sentido derivadas de la cuestión epistemológica resulten más aprehensibles a través de los métodos. En este caso, nos interesan particularmente los que respaldan a las ciencias sociales y humanas. 
Así, por ejemplo, de la aplicación del método dogmático emerge una epistemología cuyo presupuesto se origina en la vinculación de los principios que, a su vez, informan de sentido a los elementos de la estructura del fenómeno.

Mientras que la hermenéutica se caracteriza por establecer el sentido en los elementos de la estructura del fenómeno (WARNKE, 2013).

En otros términos, la dogmática es propicia a derivar el sentido de las exterioridades de esos elementos, pero siempre en las interioridades de la estructura. Por ello le resulta muy probable asaltar esos elementos y casi que hasta violentarlos, para conservarlos dentro del cauce de sentido que identifica a la estructura.

A diferencia de la dogmática, la hermenéutica -incluso la hermenéutica contextual, se empeña en el sentido dentro de los elementos o manifestaciones específicas del fenómeno, aun cuando para ubicar su significado y por esta ruta aprehender el sentido, considere la coincidencia de una multiplicidad de circunstancias, que van desde lo histórico, geográfico, hasta lo ideológico y político (GADAMER, 2005), de donde pueda surgir una cierta semejanza con la dogmática.

La dogmática no dispone de manuales, ni siquiera por parte de la teología, respecto de la cual primeramente se habría desarrollado, por lo que no son para nada extraños los ejercicios de estudios teológicos que tienden a identificarlos (SOLANO, 1858).

En cambio, identifica a la hermenéutica disponer de varias guías, lo cual facilita la posibilidad de adquirir una mayor familiaridad con tal método. Al respecto podemos señalar que el título preliminar del Código Civil colombiano contiene toda una guía hermenéutica de interpretación (COLOMBIA, 1873, arts., 25-32).

No obstante, debemos observar que algunas guías incorporan la palabra "manual" para referirse a la teología dogmatista, sin que por ello constituyan textos de enseñanza del método dogmático. (OTT, 2009).

Con posterioridad a la teología, la dogmática fue puesta al servicio del derecho. Ciertamente, en materia jurídica surgió aplicada a través de los trabajos de Kant (KANT, 2012) y de Hegel (HEGEL F. , 1999), quienes se dieron a la tarea de darle una explicación estructural y sistémica al derecho respectivamente, partiendo de un modelo teórico de responsabilidad que informa de un cierto sentido de justicia.

Y siguiendo con el caso del derecho, se aprecia que existe toda una producción asociada a la dogmática igualmente aplicada bien a derecho penal, bien al derecho constitucional, y difícilmente es referida a otras áreas del derecho. 
Lo cierto es que no se halla una obra dispuesta a la enseñanza del método dogmático. Incluso hay quien piensa que la dogmática es el método científico del derecho, desconociendo que no lo es menos la hermenéutica y desde mucho tiempo atrás; así como que la dogmática hunde sus raíces más profundas en la teología.

Por otra parte, el método sociológico (GIDDENS, 2012), se sale de las interioridades de las estructuras de los fenómenos para establecer el sentido a partir de las interacciones sociales. Es decir, el sentido procede de esa relación con las sociedades que, conforme a un enfoque eminentemente conflictualista (COSER, 1961), deriva predominantemente del tipo de relación en que se manifiestan las antinomias, oposiciones o tensiones, normalmente procedentes del origen; es decir, cuando las sociedades experimentan las estructuras institucionales normalmente, como procesos de agresión, imposición, o cuando en sí misma no es considerada a efecto de ingresar en la estructura social, la estructura del fenómeno en cuestión.

Mientras que conforme al enfoque estructural-funcionalista (LUHMANN, 2007), el tipo de relación que informa el sentido estaría dada por la integración sistémica del fenómeno a la gran estructura social, consideradas las funciones y disfunciones susceptibles de impactar el estatus quo social.

$Y$, un cuarto método es el semiótico que, si bien ocupa un lugar distinguido en la metodología del OPPCF, por ser la opción epistémico-metodológica precisamente, se ha preferido justificarlo desde su propia descripción.

Como sucede con los demás, algunas de sus características parecen coincidir con los anteriores. Sin embargo, le es característico integrar tres aspectos de los fenómenos. Por una parte, los sistemas sígnicos vinculados a él. Por otro, los procesos comunicativos que se ejecutan en uso de los sistemas sígnicos. Y, también, el sentido que se crea y circula a través de los procesos comunicativos (MOYA VARGAS, cerca del principio de congruencia: estudio para un análisis semiótico en el proyecto de reforma a la ley 906 de 2004, 2016).

Claramente es de la esencia misma del método semiótico el establecimiento del sentido. No obstante, lo que rastrea es su proceso de producción y circulación, para lo cual se vale de las acciones comunicativas mediante las cuales es actuado.

Se dirá que lo más acentuado del método semiótico son los signos. Y respecto de ello no se plantea una disputa, sino más bien una ampliación, puesto que signos, comunicación y sentido son aspectos del mismo fenómeno, esto es, de la semiosis sígnica.

La semiosis consiste en la realización de la función sígnica (GREIMAS A. y., 1991) -conforme

a la concepción de Saussure y no la de Hjelmslev formulada en el texto. Es decir, la semiosis 
acontece cuando mediante el signo se logra la plenitud representativa para la cual fue creado. Lo cual implica la operación de nuclear en el representamen su referente, su significado y el sentido.

Desde luego, se trata de algo que debe acontecer en la conciencia, porque lo que al respecto se diga o haga, tiene que ver ya con los procesos comunicacionales.

Por ejemplo, tomemos el tradicional signo CP -en inglés PC. Es símbolo es la expresión sensible - representamen, es decir aquello que lo hace manifiesto, de las constituciones políticas -referente. Significa la estructura política que integra con elementos de diverso tipo a una organización reconocida como tal-significado. Conforme todo lo anterior a un cierto sentido, por ejemplo, los elementos de un Estado, o a la democracia, o al reconocimiento de la comunidad internacional, o a la trascendencia política de una organización, o incluso a su identidad.

Hay semiosis de ese signo cuando, dado $\mathrm{CP}$, es asociado en la consciencia de una persona capaz de decodificarlo, provocando la asociación con la organización política de un cierto Estado o, con el fenómeno del cual se ocupa el derecho constitucional, dentro de un marco experiencial -racional y/o sensible, de sentido correspondiente.

Si se practica un cierto sentido de dicho signo puede ser propicio a la experiencia de la solidez y tradición democrática de un Estado, como suele suceder al aludirse a la Constitución de Filadelfia. Tanto como a todo lo contrario, por ejemplo, la constitución republicana del incipiente imperio romano, con ocasión del primer triunvirato.

La semiosis implica que la asociación es excluyente, es decir, que CP -siguiendo el ejemplo, no vincula con código penal, por ejemplo, ni con cualquier otra cosa que se le parezca icónicamente o no.

Al suceder la función sígnica para la cual se creó el signo, ocurre su semiosis, es decir, se trata de una actualización del signo en el ejercicio de su función que acontece a nivel de la conciencia.

De tal suerte la semiosis asocia tres aspectos propios del estatuto científico de la semiótica. Los tres considerados y no aislados, seguramente evitaría la que alguna vez fue la disputa que engolosinó entre otros a Ricoeur (Between Hermeneutics and Semiotics, 1990).

Los tres constituyen la unidad de la cual se ocupa el método semiótico, tal y como se empeñan los manuales más precisos en advertir (ECO, 1991). Al fin y al cabo, los signos sirven para comunicarse y, la comunicación a su vez para circular el sentido, y hasta para suscitarlo.

De cualquier forma, la historiografía de la semiótica revela el acento que ha caracterizado 
algún aspecto de su estatuto científico, y no podemos desconocer que los signos han tenido el privilegio, sin prescindir totalmente de los restantes, pero algunas veces desconocido en su trascendencia (CASTAÑARES, 2014). Otras veces, se hallan ejercicios semióticos que privilegian aspectos como la comunicación o el sentido, tal como sucede con trabajos de Greimas y Fontanille (Semiótica de las Pasiones. De los estados de cosas a los estados de ánimo, 1994, págs. 21-95).

\section{Conclusiones}

La teoría del conocimiento describe las circunstancias de validez en que se produce el saber, al menos en su versión científica.

Esa misma teoría nos ha conducido a señalar que el fenómeno de la ciencia sucede cuando se dispone, al menos, de tres elementos. Un discurso o modelo teórico de respaldo, un método y un estatuto científico u objeto de conocimiento.

Pese a que la epistemología aparece en todos y cada uno de forma dinámica, su función consiste en servir de proveedor de sentido al conocimiento, entendido como construcción de saber que sirve para establecer un cierto tipo de relación entre el hombre y su mundo. Más precisamente, la epistemología es ese trasfondo en el que se proyecta el sentido del conocimiento.

Históricamente ha tenido oscilaciones, pues nunca ha sido completamente estática, si bien ha habido la pretensión de una inamovilidad que garantice la confianza en la absolutidad del conocimiento. Pretensión que, si bien es en sí misma una epistemología, hunde sus raíces en los más característico de la filosofía aristotélica, y ha sido adecuada a momentos históricos precisos, tales como escolástica en el medioevo, y positivismo en el decimonónico.

Pero otra posibilidad admite la contingencia, la inestabilidad, la entropía y la sinergia del saber. Por suerte que concibe el conocimiento no como algo que se descubre en la naturaleza o en una dimensión sub o supra humana, sino que lo concibe como una construcción que va adquiriendo formas y estructuras diversas.

Es una visión más afín a la filosofía de Platón, que adquirió en la de Hegel una versión ampliada, y que en el siglo XX tiende a recuperar el escenario que hegemónicamente conservó la otra opción.

Algo muy importante es que la teoría de la complejidad sirvió para involucrar no sólo distintos saberes, sino a ese complejo con la sociedad. El modelo del Estado democrático, social y de derecho trajo consigo unas condiciones en que el conocimiento debía servir a la dignificación del ser, lo que hizo más que evidente la entrañable relación que identifica la 
ciencia con la economía, la política y muchas otras expresiones del conocimiento.

Siendo el saber la relación entre el hombre con la ciencia, los modelos de pensamiento dejaron de ser exclusivamente los eminentemente racionales, para dar paso a otros, tan caros a las comunidades como es el que proviene de un modelo inferencial paralelo a la inducción y a la deducción, como es el conocimiento que en términos de Peirce es llamado abductivo.

Dicho pensamiento indica que, sobre una base situacional, incluso un lego puede llegar a derivar saber con condiciones de cientificidad sostenibles.

Es entonces donde los métodos marcan la gran diferencia. El conocimiento científico deja de ser el patrimonio exclusivo de los expertos, es decir de los científicos, para ser social. Pero el científico es acentuadamente el experto en la derivación del saber basada en los métodos.

Así, en materia de ciencias sociales y humanas, la hermenéutica, la dogmática, la sociología y la semiótica, han abanderado la producción del saber científico.

Pese a las bondades que cada uno evidencia, e último es la opción epistemológica elegida para el OPPCF, precisamente por la completitud que, en cambio se echa de menos en los otros métodos.

Completitud manifiesta particularmente en que, al rastrear el sentido, la semiótica considera la participación de la sociedad, con máxima autoridad. En otros términos, a diferencia de los que ocurre con la hermenéutica y la dogmática, la semiótica no contrae la participación en el proceso genitivo del sentido, en los órdenes de los especialistas, sino que descubre que la sociedad tiene voz y voto en dichos procesos, y que muchas veces los expertos apenas hacen especies de traducciones o versiones técnicas de lo que hallan en las exterioridades de sus campos.

La sociología tiende hacia algo similar, pues sobre la base de las relaciones de poder y las disputas de clase, por un lado, consideran que el sentido es impuesto o, cuando menos, definido por grupos concretos, en medio de relaciones de tensión. Con lo cual, si bien la semiótica no disputa, tampoco halla que invariablemente sea así y, que en todo caso, a través de los procesos de individuación, desconoce, la sociedad termina siendo autora o no nuda destinataria del sentido.

Por otro lado, la sociedad entendida como una estructura tampoco es una idea que la semiótica dispute. Pero a diferencia de la tradicional teoría de sistemas, no le niega la identidad o el alma a las sociedades, y por el contrario, halla que esa identidad suele ser el sentido, posiblemente aquello que con tanto desprecio es señalado como sentido social. 


\section{OPPCF}

Por suerte que resulta ser el método más afín al OPPCF, epistemológicamente considerado, dado que aquí se permite a la sociedad lega participar, no como un destinatario inválido de un cierto tipo de institución y de conocimiento, sino por el contrario, como un agente que participa y crea, que cuestiona, indaga y propone en materia de control fiscal.

\section{Referencias Bibliográficas}

ADORNO, T. (2015). Against Epistemology: A Metacritique. (W. Domingo, Trad.) New Jersey: Wiley.

AGUAYO, P. (2011). La Teoría de la Abducción de Peirce: lógica, metodología e instinto . Ideas y Valores, 60(145), 33-53. Recuperado el 01 de Agosto de 2018

ANDERSON, R. (2008). Implications of the Information and Knowledge Society for Education, In: Voogt J., Knezek G. (eds) International Handbook of Information Technology in Primary and Secondary Education. (Vol. 20). Bodton: Springer.

ARISTÓTELES. (2008). Metafísica. (M. L. Alberca, Trad.) Madrid: Alianza.

AXTELL, G. (2016). Objectivity. New Jersey: Wiley.

BROOME, J. (2013). Rationality Through Reasoning. New Jersey: Wiley.

CASTAÑARES, W. (2014). Historia del Pensamiento Semiótico (Vols. 1, 2 y 3). Madrid: Trotta.

COADY, D. (2012). What to Believe Now: Applying Epistemology to Contemporary Issues. New Jersey: Waily.

COLOMBIA. (1873). Ley 84 de 1873. Código Civil. Bogotá, Colombia: Diario Oficial 2867 del 31 de mayo de 19873.

COSER, L. (1961). Las Funciones del Conflicto Social. (R. B. Berta Bass, Trad.) México D.F.: Fondo de Cultura Económica.

De SOUSA SANTOS, B. (2009). Una epistemología del sur: la reinvención del conocimiento y la emancipación social. México D.F.: Siglo XXI.

ECO, H. (1991). Tratado de Semiótica General (5 ed.). (C. Manzano, Trad.) Barcelona: Lumen.

EVANS, I. a. (2013). Knowledge. New Jersey: Waily.

FERRAJOLI, L. (2017). La Democrazia Constitutizionale. Bologna: Societá Editrice II Mulino .

FERREIRO, A. (2006). Procesos educativos y procesos de construcción de hábitos: de la fijación de la creencia al pensamiento abductivo. Semiótica, lógica y conocimiento: Homenaje a Charles 
Sanders Peirce. México D.F.: Universidad Autónoma de México.

GADAMER, H. (2005). Verdad y Método. (A. A. Aparaicio, Trad.) Salamanca: Ediciones Sígueme. GEERTZ, C. (1993). The Interpretation of Cultures. London: William Collins.

GIDDENS, A. (2012). Las Nuevas Reglas del Método Sociológico (3 ed.). (S. Merener, Trad.) Buenos Aires: Amorrortu.

GREIMAS, A. y. (1991). Semiótica. Diccionario Razonado de la Teoría del Lenguaje. (E. B. Carrión, Trad.) Madrid: Gredos.

GREIMAS, A. y. (1994). Semiótica de las Pasiones. De los estados de cosas a los estados de ánimo (2 ed.). (G. H. Flórez, Trad.) México D.F.: Siglo XXI Editores.

HAACK, S. (1995). Evidence and Inquiry: Towards Reconstruction in Epistemology. Nw Jersey: Wiley.

HABERMAS, J. (1984). The Theory of Communicative Action. Reason and the rationalization of society (Vol. 1). (T. McCarthy, Trad.) Boston: Beacon Press.

HACKER, P. (2013). The Intellectual Powers: A Study of Human Nature. New Jersey: Wiley.

HEGEL, F. (1999). Principios d ela Filosofía del Derecho (2 ed.). (J. L. Vermal, Trad.) Barcelona: Edhasa.

HEGEL, G. (2017). Fenomenología del Espíritu. (G. Leyva, Trad.) México D.F.: Fondo de Cultura Económica.

HENRY, J. (2017). Knowledge is Power. How magic, the government and apocalyptic vision helped Francis Bacon to create modern science. London: Iconscience.

HUSSERL, E. (1999). Investigaciones Lógicas (Vol. 1 y 2). (J. G. Morente, Trad.) Madrid: Alianza. KANT, I. (2012). Fundamentación Para una Metafísica de las Costumbre (2 ed.). (R. R. Aramayo, Trad.) Madrid: Alianza.

KLIMOVSKY, G. (1995). Las desventuras del conocimiento científico. Una introducción a la epistemología. Buenos Aires: AZ editores.

LUHMANN, N. (2007). La Sociedad de la Sociedad. (J. T. Nafarrate, Trad.) Méxic D.F.: Herder.

MERLEAU PONTY, M. (1964). Sense and Nonsense. Northwestern: Northwestern University Press. 
MOORE, T. (2017). Six Ideas That Haped Physics: Unit C, N and T (3 ed., Vol. I). New York: McGrawHill Companies.

MORAN, D. (2013). Edmund Husserl: Founder of Phenomenology. New Jersey: Waily.

MORÍN, E. (2004). La Epistemología de la Complejidad. Granada: Universidad de Granada.

MOYA VARGAS, M. (2012). La Verdad y el Espacio Procesal Penal (Vol. I). Bogotá: Universidad Católica de Colombia.

MOYA VARGAS, M. (2016). cerca del principio de congruencia: estudio para un análisis semiótico en el proyecto de reforma a la ley 906 de 2004. Pensamiento Jurídico(44), 259-290.

NIETZSCHE, F. (2012). Sobre Verdad y Mentira en Sentido Extramoral y Otros Fragmentos de Filosofía del Conocimiento. (M. Garrido, Trad.) Madrid: Tecnos.

O'BRIEN, D. (2016). An Introduction to the Theory of Knowledge, 2nd Edition. New Jersey: Wiley.

OTT, L. (2009). Manual de Teología Dogmática. (C. R.-G. Cortés, Trad.) Madrid: Herder.

PEIRCE, C. S. (1988). El hombre, un signo (El pragmatismo de Peirce). (J. Vericat, Trad.) Barcelona: Crítica.

PERRON TOLLEFSEN, D. (2015). Groups as Agents. New Jersey: Wiley.

PLATÓN. (1871). Obras Completas. (P. d. Azcárate, Trad.) Madrid: Medina y Navarro. Obtenido de www.filosofia.org./cla/pla//azcarate.htm

RABADE ROMEO, S. (2017). Raíces Históricas de la Teoría del Conocimiento. Madrid: Escolar y mayo.

ROCOEUR, P. (1990). Between Hermeneutics and Semiotics. . International Journal for the Semiotics of Law., 3(2), 115-132. Obtenido de https://link.springer.com/journal/ volumesAndlssues/11196.

ROWBOTTOM, D. (2015). Probability. New Jersey: Wiley.

SEARLE, J. (1995). The Construction of Social Reality. New York: Simon and Schuster.

SOLANO, V. (1858). Compendio de Teología Dogmática, o Breve Exposición de las Pruebas y de los Dogmas de la Religición Católica, con Solución de las Principales Dificultades. Lérida: Imprenta y Librería de D. José Sol.

SOSA E., K. J. (2018). Contemporary Epistemology: An Anthology. New Jersey: Wiley. 
TURRI, J. (2013). Epistemology: A guide. New Jersey: Wiley.

VILA CORTS, A. y. (2005). Matemáticas Para Aprnder a Pensar. El papela d elas creencias en la resolución de problemas. Madrid: Narcea S.A. de Ediciones.

WARNKE, G. (2013). Gadamer: Hermeneutics, Tradition and Reason. New Jersey: Wiley.

WEBER, M. (1978). Enomy and Society. (G. R. Wittich, Ed.) Los Ángeles: University of California Press.

WRENN, C. (2014). Truth. New Jersey: Wiley. 


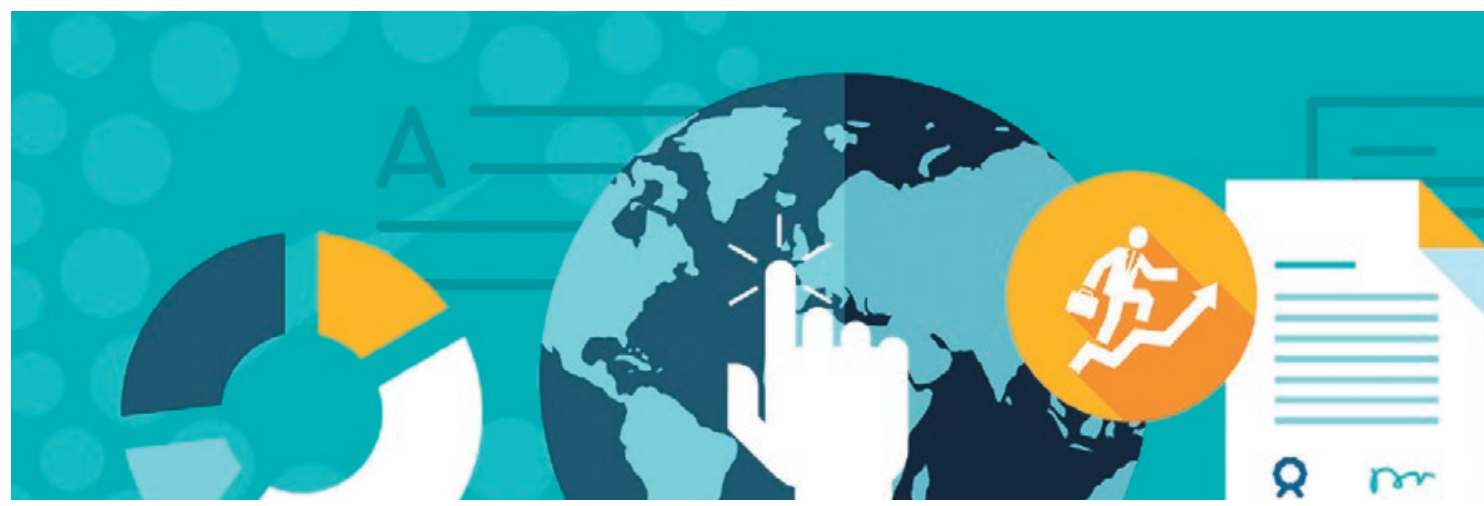

\title{
CAPÍTULO II
}

\section{ESTADO DEL ARTE}

\section{Situation of Art}

\section{Manuel Fernando Moya Vargas ${ }^{2}$}

Temario: Introducción. I. Presupuestos para una política pública del control fiscal.II. Naturaleza y orientación del control fiscal. III. La perspectiva de los Derechos Humanos: hacia la justicia fiscal. IV. Conclusiones. REFERENCIAS BIBLIOGRÁFICAS

\section{Resumen}

En consideración a los presupuestos para un apolítica pública del control fiscal, desde su perspectiva y valide internacional, se ha hallado que la producción de conocimiento en relación con el control fiscal ha tenido una dinámica que observa diversas tendencias. Mientras que en algunos momentos ha predominado el aspecto técnico, en otros ha tenido más relieve la eficiencia, el aspecto político, y más recientemente se empieza a construir un saber orientado esencialmente hacia su conexión con los derechos humanos.

\begin{abstract}
In consideration of the budgets for a public apolitics of fiscal control, from its perspective and international validation, it has been found that the production of knowledge in relation to fiscal control has had a dynamic that observes various trends. While at times the technical aspect has predominated, in others the efficiency, the political aspect has had more prominence, and more recently a knowledge oriented essentially towards its connection with human rights begins to be built.
\end{abstract}

$\overline{2}$ Investigador Senior de la Universidad Santo Tomás y de la Auditoría General de la República. 


\section{Palabras clave}

Control fiscal, Derechos Humanos, Estado del arte, Política pública.

\section{Keywords}

Art of fiscal control, Fiscal control, Human Rights, Public politics.

\section{Introducción}

Es característico de las políticas públicas expresar la concepción administrativa o gerencial con que se aborda una específica función del Estado o, un aspecto relacionado con ella, y su articulación con las expectativas sociales, así como con el sistema constitucional en que se fundamenta.

En el caso de la vigilancia y el control fiscal, una política pública se empeña en establecer programáticamente unos objetivos, a cuyo alcance se encuentran los actores involucrados, lo cual implica considerar y organizar los recursos materiales y humanos con que se cuenta, así como el o los modelos de ejecución, los productos esperados, los resultados alcanzados y, su impacto socioeconómico.

Todo esto manifiesto en relaciones interinstitucionales programadas conforme a los presupuestos constitucionales en que se soportan y que, conforme al modelo del Estado democrático, social y de derecho, implica la realización de los principios y valores que identifican a la sociedad que, como un actor fundamental, está asistida del derecho a exigir efectos precisos de la vigilancia y control fiscal.

Consecuencia de lo cual, las fuentes asociadas a la construcción de una política pública de la vigilancia y el control debe consultar fuentes diversas como la proveniente de la comunidad internacional, el presupuesto constitucional y legal, y no menos la doctrina y, desde luego, la realidad específica que se pretende impactar. Lo cual reclama una acción basada en el conocimiento verificable, que sirva de base a la concepción y construcción de una política basada en razones, a cuya construcción han contribuido diferentes actores, a través de las vías que les corresponde.

Si como ha sido costumbre, prefiriera el Estado contraerse a la fuente legislativa, se caería repetidamente en lo restrictivo y hasta cuestionable, pues la relación entre política pública y ley no ha sido clara en Colombia.

Si la ley debiera provenir de una política pública o lo contrario, no parece un tema sencillo, aun cuando tenemos que a partir de la Ley 1147 de 2007, las modificaciones legislativas en Colombia y, con ello, las políticas públicas necesariamente, deben provenir de estudios 
que con suficiencia investigativa -si se quiere científica, orienten los diseños de lo uno y lo otro. De tal suerte que tanto las normas como las políticas públicas deben provenir de razones objetivas, en consideración a una realidad que ha de ser ser explorada, analizada y diagnosticada, para favorecer al máximo los fines sociales y constitucionales que las justifican.

Como consecuencia, los programas que integran las políticas públicas son tanto más frágiles cuanto provengan de fuentes aisladas o inconsultas de las demás, pues sugieren improvisación, y el capricho de las intuiciones que, por bien intencionadas, no sustituyen válidamente el conocimiento científico como base de formulación.

Para formular esa política pública, como se dijo, es preciso disponer de una plataforma investigativa idónea para producir conocimiento especializado. A tal fin se ha implementado el Observatorio de Política Pública del Control Fiscal. No obstante, se trata de una plataforma, precisamente, es decir, una base sobre la cual deben diseñarse procesos de investigación que satisfagan esa generación de conocimiento, apto para concretarse en el resultado de la política púbica del control fiscal.

Considerado este objetivo, el OPPCF dispone de un presupuesto teórico, dispuesto de conformidad con tres características fundamentales:

a. Se busca producir una modelo de política pública en materia de control fiscal, que consulte los estándares internacionales bajo los cuales la comunidad internacional legitima esos diseños. De tal suerte, se busca no sólo el diseño en sí de la política, sino que, mediante ella, Colombia cumpla sus obligaciones internacionales, lo cual conviene a la reafirmación de su soberanía, de acuerdo con la línea jurisprudencial de la Corte Internacional de Justicia.

b. Por estado del arte no se entiende nada más que un acopio nutrido de teorías, autores y obras, de las cuales se resalta su diferencia, sino por el contrario, se refiere considerar un proceso complejo de construcción de conocimiento, del cual participa la comunidad científica, en busca de impactar la realidad social, conforme a un cierto sentido. Desde este punto de vista, el marco teórico debe surgir en torno a la realidad social específica que se considera, en este caso, la colombiana.

c. La relación aprestada mediante el estado del arte se vincula con una realidad social enmarcada por el encuentro entre el control fiscal y los Derechos Humanos. No se trata, en consecuencia de una asociación de estirpe intelectual, si se quiere abstracta, sino praxiológica y evidenciable, lo cual termina siendo el sentido mismo del estado del arte, es decir, un modelo teórico de respaldo para el hallazgo de la racionalidad que caracteriza un aspecto de la realidad social del cual participan el control fiscal y los Derechos Humanos. 


\section{Presupuestos para una política pública del control fiscal}

La Organización Internacional de Entidades Fiscalizadoras Superiores (INTOSAI), produjo la INTOSAI GOV 9400, mediante la cual fijó las directrices para la evaluación de las políticas públicas (INTOSAI, 2016).

En ella, se distinguen los elementos estructurantes de la política pública en materia de control fiscal y, sobre todo, la necesidad de sujetarlo a evaluación permanente, en curso a establecer su utilidad.

Es decir, a la necesidad de fijar la respectiva política pública, sobreviene necesariamente su evaluación, cuyo modelo hace parte esencial de la política misma.

Lo que debe evaluarse, señala la norma, son "los objetivos, la ejecución, los productos, los resultados y el impacto socioeconómico de una política y mide su rendimiento con el fin de evaluar finalmente su pertinencia o adecuación."

Sin embargo, una evaluación ex ante puede también ser útil para evaluar la pertinencia y condiciones para la puesta en marcha de la política antes de que se produzcan los primeros gastos.

Ahora bien, el que deba fijarse la política pública y sujetarla a un proceso sistémico de evaluación, implica la absoluta independencia de la evaluación, pero las recomendaciones no deben ser vinculantes para el poder ejecutivo ni para el legislativo.

De tal suerte que una política pública satisfactoria, conforme al estándar internacional, debe ser capaz de dar cuenta acerca de:

a. Su planificación y su eficiencia.

b. Su redición de cuentas.

c. Su ejecución.

d. Su producción de conocimiento.

e. El fortalecimiento institucional que surge de la política en concreto.

De tal suerte una política pública debe diseñarse sobre presupuestos que proyecten su pertinencia y su utilidad. Lo cual evidencia la importancia de los estudios en que se fundamenta.

Adicionalmente, se recomienda que la evaluación de la política pública y con ello su diseño, no resulte excluyente, sino que considere la intervención de sectores como el académico, lo 


\section{OPPCF}

cual ha sido estimado al pensar el Observatorio de Política Pública del Control Fiscal.

En suma, no se trata apenas de diseñar la política pública, sino de anticipar un modelo incluyente de evaluación, cuyos resultados sirvan tanto a las entidades encargadas del control fiscal, como al legislador en su trabajo regulador, y a la adecuación o ajuste de dicha política.

Ahora bien. Una política pública auténtica, sólida y prospectiva, parte de la realidad, pues debe pensarse en consideración de la situación verificada y actual de una función del Estado, en un tiempo y espacio concretos.

\section{Naturaleza y orientación del control fiscal}

El artículo 267 de la Constitución Política de 1991 estableció la naturaleza del control fiscal, erigiéndola en función pública.

Significa lo anterior que el control fiscal es uno de los cometidos del Estado, integrado a todo el circuito funcional conforme a los principios y valores en que se sustenta el estado comprendido como un todo compacto, así como a su identidad democrática, social y de derecho, por lo que debe ser siempre leído conforme a esa integración.

Como función pública, se encuentra asignada a la Contraloría General de la República, y consiste en vigilar la gestión fiscal de la administración pública y de los particulares o entidades privadas que manejen recursos públicos.

Pero es importante señalar que la doctrina no entiende que no se trate de una cuestión de dimensiones matemáticas. Es decir, que se deba ver la misma condición necesaria de control que se verifica a nivel microeconómico, trasladada a un nivel macro. Más bien hay una distancia de tipo geométrico, en donde el control fiscal no resulta ser apenas un asunto económico, sino una condición axiológica que hace posibles los fines del Estado (Gómez Lee, 2006).

La primera característica que se distingue en la norma constitucional es que dicho control se debe practicar ex post, lo cual coincide con la corriente conforme con la cual la libertad de ejecución del gasto público no puede frenarse con ocasión del control fiscal, porque elonga los tiempos hasta hacer prácticamente improbable un importante sector de la economía y, además porque terminaría invirtiendo importantes principios constitucionales como la presunción de buena fé (Blöchliger y King, 2006).

En la misma línea deriva como otra característica el no generalizarse. Es decir, si bien ha de existir un mecanismo racional de selección de los objetos de control, no puede abrigarse todo objeto susceptible de control (Eichengreen y Bayoumi, 1994). Hay selectividad 
atendiendo a criterios que mejor racionalicen el control y la dinámica económica que impacta, en consecuencia es selectivo y favorable a la realidad de las dinámicas económicas que imponen, incluso relaciones de temporalidad que no necesariamente convergen con los planes anualizados (Auerbach, 2006).

Así mismo, atiende a un criterio de legalidad estricta, en cuanto a los procedimientos, los sistemas y los principios en que se fundamenta. Esto implica que los administradores o gobiernos de las entidades dedicadas al control fiscal, no pueden improvisar ni asaltar a los sujetos de control a través de sistemas o procedimientos que no hayan podido conocer previamente.

Al respecto, generalmente se ha entendido que las referencias a la ley abrigan exclusivamente el sistema normativo interno, lo cual suele reducirse a la ley de carácter nacional, importa los instrumentos internacionales ratificados por Colombia hacen parte del mismo sistema.

Pero y en consideración a que uno de los objetivos del Observatorio consiste precisamente en acreditar el vínculo estrecho que existe entre el control fiscal y los derechos fundamentales. Lo cual conlleva a erigirlo en uno de esos derechos, pues la ausencia del control haría improbable su eficacia. De donde cabe como hipótesis derivada, que es posible el ingreso de las normas fiscales internacionales a través del bloque de constitucionalidad no obstante no haber sido ratificadas, siempre que de su aplicación dependa la eficacia de otro derecho catalogado como fundamental (Cukierman, Edwards y Tabellini, 1989).

Indica la disposición constitucional que la misma normatividad puede autorizar a entidades privadas el ejercicio de dicha función, siempre y cuando se trate de casos especiales, las entidades sean contratadas previo concurso de méritos, y la posibilidad tenga aval previo del Consejo de Estado, lo cual converge con la concepción de la OCDE (Lane, 2003).

Entonces, el control fiscal es una función pública que ejercerá la Contraloría General de la República, la cual vigila la gestión fiscal de la administración y de los particulares o entidades que manejen fondos o bienes de la Nación (Alesina, Hausmann, Hommes y Stein, 1999).

Dicho control se ejercerá en forma posterior y selectiva conforme a los procedimientos, sistemas y principios que establezca la ley. Esta podrá, sin embargo, autorizar que, en casos especiales, la vigilancia se realice por empresas privadas colombianas escogidas por concurso público de méritos, y contratadas previo concepto del Consejo de Estado.

Por otro la vigilancia de la gestión fiscal implica tres tipos de control:
a. Control financiero
b. Control de gestión 
c. Control de resultados

Los criterios de principalidad con que se ejerce dicho control son la eficiencia, la economía, la equidad y la evaluación de los costos ambientales.

De la misma forma, por excepción la ley puede autorizar a la Contraloría para que intervenga las cuentas de cualquier entidad territorial.

Tras definir el control y la vigilancia fiscal, así como atribuirla a la Contraloría general de la República, en la norma se especifica que se trata de una entidad técnica, con autonomía administrativa y presupuestal, luego no le caben funciones que acrezcan de ese carácter técnico. Finalmente, la norma refiere las condiciones del Contralor General, y aspectos asociados a su renuncia. ${ }^{3}$

$3 \quad$ ARTICULO 267. El control fiscal es una función pública que ejercerá la Contraloría General de la República, la cual vigila la gestión fiscal de la administración y de los particulares o entidades que manejen fondos o bienes de la Nación.

Dicho control se ejercerá en forma posterior y selectiva conforme a los procedimientos, sistemas y principios que establezca la ley. Esta podrá, sin embargo, autorizar que, en casos especiales, la vigilancia se realice por empresas privadas colombianas escogidas por concurso público de méritos, y contratadas previo concepto del Consejo de Estado.

La vigilancia de la gestión fiscal del Estado incluye el ejercicio de un control financiero, de gestión y de resultados, fundado en la eficiencia, la economía, la equidad y la valoración de los costos ambientales. En los casos excepcionales, previstos por la ley, la Contraloría podrá ejercer control posterior sobre cuentas de cualquier entidad territorial.

La Contraloría es una entidad de carácter técnico con autonomía administrativa y presupuestal. No tendrá funciones administrativas distintas de las inherentes a su propia organización.

Modificado por el art. 22, Acto Legislativo 02 de 2015. El nuevo texto es el siguiente: El Contralor será elegido por el Congreso en Pleno, por mayoría absoluta, en el primer mes de sus sesiones para un periodo igual al del Presidente de la República, de lista de elegibles conformada por convocatoria pública con base en lo dispuesto en el artículo 126 de la Constitución y no podrá ser reelegido ni continuar en ejercicio de sus funciones al vencimiento del mismo.

Texto original

El Contralor será elegido por el Congreso en pleno en el primer mes de sus sesiones para un período igual al del Presidente de la República, de terna integrada por candidatos presentados a razón de uno por la Corte Constitucional, la Corte Suprema de Justicia y el Consejo de Estado, y no podrá ser reelegido para el período inmediato ni continuar en ejercicio de sus funciones al vencimiento del mismo. Quien haya ejercido en propiedad este cargo no podrá desempeñar empleo público alguno del orden nacional, salvo la docencia, ni aspirar a cargos de elección popular sino un año después de haber cesado en sus funciones.

Modificado por el art. 22, Acto Legislativo 02 de 2015. El nuevo texto es el siguiente: Solo el Congreso puede admitir la renuncia que presente el Contralor y proveer las faltas absolutas y temporales del cargo. 
La disposición tendría como antecedente remoto las condiciones de la misión Kemmerer (Gavin y Perotti, 1997), la cual habría contribuido de forma contundente a la institucionalización del control fiscal (Buiter, Corsetti y Roubini, 1993).

Mientras que su antecedente inmediato está informado por las discusiones que se dieron en el seno de la Asamblea Nacional Constituyente, cuya fuente primaria informa que hubo la determinación de imprimir al Estado colombiano una condición de control fiscal, como expresión eidética del Estado democrático, social y de derecho (Younes Moreno, 2012).

En general, nunca se discutió si debía o no haber control fiscal. Al respecto el consenso resultó indiscutible. No obstante, las oposiciones podríamos extrapolarlas de la necesidad de un cuarto poder formal, distinguido por la función de control en general, y particularizado e instrumentado a través de unas instituciones especiales, entre las cuales siempre se mencionó la Contraloría General de la Nación o, a la entidad que hiciera sus veces, como el tribunal de cuentas. Lo cual corresponde con las tendencias doctrinales (Wildavsky, 1975).

De la misma forma, aun cuando de alguna propuesta que pretendió radicar la función del control fiscal en la Fiscalía General de la Nación, surgió una relación específica con los derechos humanos, más que por coincidencia funcional que por cualquier convicción fundada, se tendió a considerar y formular el control fiscal en su máxima expresión técnica. Lo cual, como habrá de verse, atendió a una cierta corriente doctrinal que, por demás, en la actualidad tiende a superarse.

También se halló un cierto sentido de complejidad, en el entendido de ser el control fiscal un aspecto que reclama una cierta acción compartida por una red institucional, la cual involucra tanto aspectos administrativos, técnicos, como también económicos y jurídicos (Davoodi y Zou, 1998).

Texto original

Sólo el Congreso puede admitir las renuncias que presente el Contralor y proveer las vacantes definitivas del cargo; las faltas temporales serán provistas por el Consejo de Estado.

Para ser elegido Contralor General de la República se requiere ser colombiano de nacimiento y en ejercicio de la ciudadanía; tener más de 35 años de edad; tener título universitario; o haber sido profesor universitario durante un tiempo no menor de 5 años; y acreditar las calidades adicionales que exija la Ley.

No podrá ser elegido Contralor General quien sea o haya sido miembro del Congreso u ocupado cargo público alguno del orden nacional, salvo la docencia, en el año inmediatamente anterior a la elección. Tampoco podrá ser elegido quien haya sido condenado a pena de prisión por delitos comunes.

En ningún caso podrán intervenir en la postulación o elección del Contralor personas que se hallen dentro del cuarto grado de consanguinidad, segundo de afinidad y primero civil o legal respecto de los candidatos. 
Así mismo surgió que el control fiscal podía ser preventivo o reactivo, aun cuando los fundamentos no fluyeron como se hubiese esperado de una discusión demasiado sólida.

También surgió, con la misma falta de hondura, la relación género-especie de la vigilancia y el control fiscal, siendo ésta apenas una variación de aquélla.

No podemos despreciar que redactores de algunas de las fórmulas eran expertos en el tema. Con todo, las discusiones, al menos en lo que puede rescatarse de las respectivas actas, no se apreció un curso de discusiones basada en la fundamentación copiosa, ni en estudios científicos sobre el tema, que se hubiesen invocado.

Que no fue una discusión tranquila lo evidencian no menos de 16 proyectos asociados al control fiscal. ${ }^{4}$

Una disímil concepción se evidencia en todos estos textos, algunos abogando por un control ex post, selectivo y a instancia de la ya existente Contraloría General de la República, como fue el caso de las fórmulas de Jesús Pérez González-Rubio y de Diego Uribe Vargas. Mientras que otros, como por ejemplo el formulado por Antonio Navarro, se inclinaron en favor de un control ex ante, y verificado por un organismo distinto.

Pero también se presentaron alternativas como la de integrar un poder paralelo que conglobara la función de control -entre ellos la fiscal, según la propuesta de María Teresa Garcés Lloreda, Guillermo Plazas Alcid, Lorenzo Muelas, Misael Pastrana Borrero o la de Antonio Yepes Parra quienes -a diferencia de aquélla, incluía una amplia participación social. Algunas de las cuales apenas se distinguían por sustituir la Contraloría General de la Nación por un Tribunal de Cuentas, lo cual ya había sido formulado como alternativa para el control fiscal en América Latina (Eichengreen, Hausmann y Von Hagen, 1999).

Alfredo Vásquez y Aida Abello estuvieron muy cerca de esta alternativa, aun cuando prefirieron, más que un poder específico, unas instituciones señaladas como de fiscalización del Estado.

Juan Gómez Martínez y Eduardo Londoño se inclinaron por incorporar la función a la Fiscalía General de la Nación.

Incluso, Luis Guillermo Nieto Roa sin oponerse a la figura del Contralor General de la Nación, pretendió asignar el control fiscal a entidades privadas.

No se cuestionó la descentralización así que algunas propuestas estuvieron dirigidas al ejercicio de esa función a nivel distrital, como fue el caso de Lemos Simmonds y la propuesta

\footnotetext{
4 Al efecto pueden consultarse las Gacetas 4, 5, 5, 7, 22, 27, 30, 31, 33 y 77, de la Asamblea Nacional Constituyente.
} 
de Rodrigo Lloreda Caicedo.

La reconstrucción fidedigna de la institución de la vigilancia y control fiscal en Colombia, puede y debe ser contrastada con el desarrollo doctrinal que ha adquirido la misma institución, vista desde la perspectiva científica, lo cual evidencia más coincidencias que distancias y, particularmente la ocasión de una aproximación hacia una posibilidad que empieza a perfilarse.

La importancia del patrimonio público no requiere ser demostrada. Su condición fundante hace que la vida social sea posible, conforme a la organización adquirida por las comunidades humanas (Galves, 2007).

De donde se tenga claro que la supervivencia misma depende dicho patrimonio, más precisamente, de la administración de dicho patrimonio.

El control fiscal es temáticamente un género que involucra toda incursión en la macroeconomía. No obstante, el propósito temático de este proyecto se cifra en un aspecto, vinculado concretamente a lo que es específicamente identificado como control del gasto público.

Así, bajo el acápite de hacienda pública suele desarrollarse su estudio, con algún tipo de énfasis, frecuentemente en cuanto tiene que ver aspectos de manejo tributario (del Carmen Bolaños, 2017, pp. 54-81), el gasto público dentro del régimen económico (Herrera Robles, A., 1993, pp. 29-46), y también como un asunto de justicia social asociado a las posibilidades de un Estado social y de derecho (Astudillo Moya, M., 2002, pp. 18-23). Durante el Siglo XX, particularmente con las experiencias de posguerra vividas en Estados Unidos y en el Reino Unido, surgió el control fiscal como método de administración de los fondos públicos. Y poco después empezó a adquirir connotaciones científicas, particularmente con la aparición de la teoría keynesiana (Musgrave, R. A., 1988, pp. 113-119).

De donde podamos predicar que en la actualidad el control fiscal se estima no sólo necesario, sino una condictio sine qua non del Estado y del gobierno de los mismos. De hecho, existe la tendencia a asociarlo como una característica esencial de ciertos modelos, principalmente los del Estados de derecho, conforme se ha entendido que ningún gobierno democrático puede sustraerse legítimamente de él, por suerte que la entidad democrática de los gobiernos apareja necesariamente la demostración de un modelo de control fiscal, cuanto más eficiente más democrático (Díaz, E. 2011).

Incluso las más exultantes teorías que desde lo filosófico explican la constitución fundamental de los Estados, admiten como elemento sistémico inevitable, los procesos de control sobre la ejecución del gasto público (Habermas y Jiménez, 1998). Por lo cual ha llegado a adquirir identidad dentro de las construcciones teóricas generales del control, algunas veces 
asociado con el control jurídico (Plazas-Gómez y Moreno-Guzmán, 2017, pp. 325-375), otras con el control político-económico (Cruz y Lapa, 2012, pp. 95-116).

Oscilación no del todo superada y antes bien acentuada por lo menos dados ciertos momentos historiográficamente discernibles, o a propósito de circunstancias favorables, pues las medidas de control fiscal han suscitado inquietudes acerca de la intervención jurisdiccional como condición fundante de su sostenibilidad. Es así que la especialidad del control fiscal ha inquietado acerca de la competencia para conocer de la pertinencia constitucional de las disposiciones, y si bien hay preferencia por los más altos tribunales, también se han dado razones para que de ello conozcan los jueces más cercanos a la realidad social, tal y como lo revela Álvarez García (2018), al detenerse sobre la sentencia del Tribunal Constitucional $118 / 2016$, conforme con la cual la constitucionalidad del régimen normativo de control fiscal debe compartirse entre la jurisdicción constitucional y la ordinaria (pp. 219-228).

Cuando no, ha generado la toma de posiciones políticas que incluso llega a justificar medidas favorables a cierto tipo de gobierno hegemónico con una temporalidad que ratifica el retorno hacia la plenitud democrática. Así, en Noruega, por ejemplo, los hallazgos fiscales a nivel local implican la pérdida de autonomía, hasta tanto se recupera la confianza, la que suele provenir de una disminución de gastos (Hopland, 2013, pp. 185-203).

Podríamos sostener para términos del estado de la cuestión, que el grueso de la discusión se ha orientado más hacia los modelos e intensidad del dicho control, antes que a explicarlo y mucho menos que a justificarlo.

Por supuesto, sirve de variable, cuando no de indicador, del nivel de independencia y acaso de soberanía de un Estado dentro del contexto internacional. Así, lo registra Rosa Rosado (2017) respecto de la Junta de Control Fiscal impuesta a Puerto Rico mediante la Promesa Bill Act. 114th Congress, 2nd session. H.R. 4900, (pp. 331-355).

El discurso técnico del control fiscal, por su parte, se ha inclinado a erigir científicamente las características generales que un sistema debe adquirir, de cara a su eficiencia y a su entronización con el modelo de Estado al que hemos venido haciendo recurrente referencia.

Es así que hoy sabemos que el control fiscal debe ser central, en el entendido de existir como modelo explícito, claro y no susceptible de modificaciones intempestivas, tal y como lo dejó claro Tudor, F. (2009, pp. 99-106). De donde sabemos que aun cuando se cuente con procedimientos de control fiscal rígidos, la ausencia de uno inequívoco $y$, la posibilidad de asalto mediante reformas y contrarreformas ocasionales e incidentales, dan al traste con la filosofía política y el significado tanto jurídico como económico conque surgió.

Así que la estabilidad de un procedimiento fiscal claro y preciso, es condición para que dicho 
control cumpla sus cometidos democráticos.

De la misma forma se ha establecido que el control fiscal no puede ser entendido como independiente, en el entendido que se estructura en relación con otros coeficientes, que bien pueden ser el régimen cambiario, como también el constitucional interno, y su relación sistémica con el internacional (Vuletin, 2013).

Ahora bien, el movimiento estructural funcionalista adquirió en la teoría de los juegos de Nash, su máxima expresión en materia económica, con hondas repercusiones sobre la concepción del control fiscal, dando por resultado su resignificación como sistema, cuya esencia consiste en direccionarlo hacia los indicadores esenciales. Como era de esperarse, surgió la tendencia a comprender el control fiscal como un asunto estrictamente económico, aun cuando nunca ha podido desprenderse de las repercusiones de su eficacia sobre la convivencia pacífica, tal y como lo advirtieron Valieva, Milova, Dozhdeva, Lukin y Chapaev (2016).

Pensamiento que condujo a formular hipótesis econometristas como que a mayor flexibilidad en cuanto a la política de inversión, debe corresponder un mayor control fiscal (Savoskina y Kukanova, 2015).

De alguna manera esta tendencia estructural radicalizó el funcionalismo del control fiscal, conduciendo hacia modelos exageradamente tecnificados, al punto que pareciera que cualquier camino se justificaba si conducía a la eficiencia absoluta del mismo, de donde apareció como contestario de dicha opción la respuesta del control fiscal mito (Allen, 2011, pp. 619-621).

Con esta novedad vino una muy importante reflexión, conforme con la cual, todo tipo de control fiscal, por eficientista, o democrático y robusto que pueda ser concebido, siempre va a depender de la confianza que deposita la sociedad en los ejecutores del gasto, de todos modos, los modelos cuanto más complejos producen menos resultados esperados (Grüner, 2017).

Posición que condujo a concluir que el control fiscal no es apenas un asunto de Estado, sino de la sociedad, aun incluso en sus manifestaciones técnicas, tal y como lo demuestran Haranguş y Dudă-Dăianu, (2013, pp. 34-43). Postura reafirmada por Cilibiu (2016, pp. 397403)

Por consecuencia, se encuentran investigaciones en la materia metodológicamente diseñadas con base en criterios como la zonificación fiscal, en consideración a las restricciones al uso de la tierra por parte de las familias vs. la inversión de bienes públicos para favorecer la explotación, y el nivel de escolaridad, 
considerados indicadores acertados acerca de lo que debe ser el control fiscal (Hanushek y Yilmaz, 2015, pp. 559-585).

Lo cual podemos entender como una tendencia que arraiga en sus orígenes en la importancia otorgada a la educación como factor determinante de la eficacia del control fiscal, unos diecisiete años atrás (Eastaugh, 2000).

(...) As policymakers debate national healthcare reform options, greater attention is being paid to other national systems. Important lessons can be learned from the last nation (South Korea, 1989) and the first nation (Germany, 1883) to pass national health insurance. The reciprocal problems of access and cost control can be addressed by implementing three initiatives: global budgets, promotion of primary care, and improvement of health education. Any plan that does not comprise all three initiatives (BCE-budgets, care, and education) will fail to achieve the two bedrock objectives of reform: universal access and cost containment (...) (9). ${ }^{5}$

Y que la educación social en materia de control fiscal se manifiesta en efectos profundamente asociados a la democracia y sus efectos (Heymann y Navajas, 1989), lo acreditan investigaciones que dan cuenta de cómo cuando una comunidad aprende a rastrear el desempeño fiscal de un gobierno, tal conocimiento que al cabo se desenvuelve como consciencia, tiene un efecto determinante en las subsiguientes elecciones (Porto \& Porto, 2000).

En el mismo sentido ya se habían hecho algunos estudios como el de Eribes y Hall (1981, pp. 107-121), en donde se evidenció la relación entre la madurez política de las sociedades y su conocimiento acerca del control fiscal, pues a mayor conocimiento de éste resulta más probable la intervención democrática.

Pero sigue siendo la eficiencia del control fiscal un criterio determinante, no sólo en condición de baremo, sino como condición eidética, de la cual depende una característica del Estado en su concepción más actualizada (Galves, 2007, pp. 246).

Lo que no obsta a una concepción en que sistemas y principios de control fiscal se integran en una interdependencia cualitativa (Restrepo, 2015, pp. 478-481).

De hecho, se tiende a justificar la complejidad del control fiscal en la complejidad social a la 5 Tomado de http://web.b.ebscohost.com.bdatos.usantotomas.edu.co:2048/ehost/detail/ detail?vid=19\&sid=8cc695ea-13ff-4d30-907a-78f612ff588c\%40pdc-v-sessmgr01\&bdata $=J \mathrm{mxhbmc} 9 \mathrm{Z}$ XMmc2l0ZT1laG9zdC1saXZl\#AN=4317537\&db=bth. Consulta del 07/03/2018. 
que se refiere (Barrios, 2011, pp.48-62).

Dado que ha venido suscitándose un movimiento favorable a una cierta amplitud de interpretación del sistema internacional de DDHH, hoy en día se tiene que no son sólo un discurso a la manera como se registró culminando el Siglo VIII y a comienzos del decimonónico, sino que se aprecia su realidad arraigada en la cotidianeidad asumida por los ciudadanos con ocasión de los gobiernos de turno, con muchas de sus expresiones administrativas. (Steiner y Uribe, 2014).

De hecho, se sabe que las deficiencias en el control fiscal traen consecuencias de tipo bola de nieve, que termina traspasando las fronteras, y dificultando la realización de los DDHH a nivel nacional como internacional (Salvador, 2007).

Apenas diez años después de haber entrado en vigencia la Constitución de 1991, ya evidenciaba dificultades características, que daban razón a las investigaciones que sobre este punto se producían poco tiempo después (Ochoa Díaz y Charris Rebellón, 2003, pp. 13-42).

Al fin y al cabo, es común a las organizaciones políticas permeadas por tendencias antidemocráticas, con especial afectación en términos de violaciones al sistema de DDHH, la ausencia de control fiscal o al menos, la presencia de uno completamente ineficiente, inadecuado o falso (Buteler, 2013, pp. 23-43).

De donde en la actualidad podamos postular lo que llamaríamos, la humanización en la concepción del control fiscal, lo que nos ha permitido empezar a considerar su vínculo instrumental con los $\mathrm{DDHH}$, cuyo su presupuesto es que sin control fiscal no es posible garantizarlos. Línea a la cual se adscribe claramente la OCDE, conforme a la aproximación que se hizo respecto de su posición en materia de control fiscal.

La reciente doctrina entiende el control fiscal como un asunto que supera los límites de la economía, pues posibilita significativamente los fines esenciales del Estado (Gómez Lee, 2006).

Por esencia no desafía la libertad que asiste al gobierno en la ejecución del gasto público, ni siquiera las políticas públicas del control fiscal pueden superar este límite, al cual más bien contribuyen con los resultados de sus evaluaciones (Blöchliger, 2006).

Es característico del control fiscal evitar la generalización. Luego demanda un mecanismo racional de selección de los objetos de control (Eichengreen, 1994). La selectividad atiende criterios de priorización y racionalización de los recursos, todos enfocados hacia el bien común (Auerbach, 2006).

De dicho bien común hacen parte significativa la plena vigencia de los Derechos 
Fundamentales, entre los que deben resaltarse los Derechos Humanos, por lo que puede considerarse el ingreso de disposiciones internacionales asociadas al control fiscal, a través del bloque de constitucionalidad (Cukierman, 1989).

Pese a la tendencia a involucrar entidades privadas en el ejercicio del control fiscal (Lane, (2003), en Colombia sigue siendo una función pública ejercida predominantemente por entidades de esta naturaleza (Alesina, 1999).

\section{La perspectiva de los Derechos Humanos: hacia la justicia fiscal.}

La justicia es no sólo un derecho fundamental, sino adicionalmente, el sentido mismo del derecho (Moya, 2018, 2017a, 2017b, 2015a, 2015b, 2013, 2012, 2010, 2007). Por tal sentido entendemos la construcción social de lo que se asocia como justo e injusto.

En efecto, las comunidades experimentan como condición que promueve constituir el sentido correspondiente, derivado del asocio de unas representaciones orientadas hacia la experiencia de la justicia y de la injusticia, cuyo recorrido indica un curso cuyos orígenes se vinculan los socráticos, pero no parece tener fin (Atienza, 2001).

Aún cuando algunos experimentos parecieran ponerlo en entredicho, sobre la base de la tecnicidad (Bourdieu y Teubner, 2000), cuestionada en sus fundamentos al pretender reducir el derecho a su expresión jurisdiccional, dejando a un lado todo cuanto depende de la sociedad (Moya, 2007).

Los Derechos Humanos se encuentran integrados el sentido de justicia, así como inevitablemente a la experiencia de lo que es representado como justo e injusto.

De hecho, la nominación se encuentra manifiesta en clave de signos jurídicos, la decirse "Derechos" y a continuación "Humanos", es inevitable una significación de naturaleza jurídica, entendida no sólo como acción social en el entendido tradicional (Ferrari, 2002), sino como identidad de las comunidades que los invocan, así sea desacertado en su concreción sígnica, como presupuesto de justicia y de constitucionalidad (Luhmann, 2005). Precisamente, dijo Carl Schmidt -citado por Vita, que (...) la Constitución es una estructura política, requiere además la toma de decisiones políticas esenciales (...) (2015, pp. 206).

Sin que lo controvierta el que las mayorías puedan adoptar determinaciones que involucran a otros, de las cuales no participan. Más que un dispositivo de poder, o un pretexto de dominación, se trata de un modelo de construcción del sentido. De donde no deduzcamos que inevitablemente los Derechos Humanos hagan parte de un consenso absoluto, pero, sea que provenga o no de mayorías, hace parte del sentido social de justicia, bien no pueda descartarse en su nombre, algún tipo de violencia simbólica, como la referida por Nussbaum, 
(...) En las democracias siempre hay una mayoría que logra que sus ideas y sus tradiciones culturales y religiosas se encarnen en el sistema. Una mayoría que determina, por ejemplo, cuáles son los días de fiesta, qué drogas son legales, etc. Por ejemplo, en los países cristianos, el día de descanso es el domingo y las personas cuyas religiones las conmina a descansar el sábado, como los judíos o los adventistas del sétimo día, son discriminadas a no ser que acepten perder su trabajo. (...) (2011, pp. 74).

Cono lo cual se deriva que los Derechos Humanos no aparecen de estimativos estrictamente jurídicos, sino también de otros de orden político, moral, religioso, ideológicos, etc. No obstante, puedan adquirir una cierta completitud discursiva en el campo del derecho, tal y como ha sucedido con la vida, la libertad, el medio ambiente, la paz, (Rodríguez Palop, 2018), y ahora mismo, el control fiscal.

De donde haya resultado como necesario estimar al ritmo de sus contenidos, su nivel de eficacia, lo que no es otra cosa que la garantía jurídica de su observancia, (...) Los derechos, como los deberes y las demás situaciones jurídicas, no son los que como en el iusnaturalismo eran definidos como respuesta a exigencias de justicia, de razón, de eficacia o, incluso, de concreta posibilidad de satisfacción. Son, por el contrario, los derechos, y sólo los derechos que, performativamente, han sido producidos por las leyes, tanto constitucionales como ordinarias, independientemente de su coherencia o incoherencia, de su plausibilidad o de su implausibilidad y de su mayor o menos efectividad. (...) (Ferrajoli, 2009, pp. 106).

Siendo esta la orientación, la protección de los Derechos Humanos terminó determinando su consolidación (Bingham, 2018).

Lo cual ha facilitado reconsiderar su origen individualista por oposición a su carácter social, como la de Ignatieff, que para Zolo, (...) Tiene poco sentido suponer que la doctrina occidental de los derechos humanos pueda ser acogida universalmente, más allá de los procesos de occidentalización del mundo con los cuales la globalización coincide en gran parte. (...) (2007, pp. 102).

Lo cual, en términos de protección desbordó lo típicamente occidental, es decir, su naturaleza individual, para acceder a la garantía social, estando actualmente la discusión en cuanto a qué tanto es una imposición que proviene de afuera, o siendo igualmente una imposición del sentido de justicia, convienen a una construcción predominantemente interna, tal y como lo plantea de Sousa Santos, (...) mientras que los derechos humanos sean concebidos como derechos humanos universales, tenderán a operar como localismo globalizado, una forma de globalización desde arriba. Para poder operar como una forma cosmopolita y contrahegemónica de globalización, los derechos humanos deben ser reconceptualizados como multiculturales. (...) (1998: 352). 
Si inquieta la multiculturalidad, por ejemplo, en cuanto tiende a relativizar el control fiscal $y$, con ello, a frenar los avances de la comunidad internacional, es determinante insistir que hacen parte del sentido social de justicia y, que aquello orientado a su debilidad, es decir todo cuanto se tramite como contra-DDHH, hace parte de la experiencia de la injusticia.

No obstante, es preciso advertir que involucrar los Derechos Humanos como criterio de justicia, como por ejemplo está ocurriendo con la justicia fiscal, implica la reconsideración de estereotipos constitucionales, que van desde la soberanía absoluta, hasta el control posterior predominante (Clérico, 2017).

Un modelo teórico basado en el sentido, semióticamente deducido o deducible, no agota la justicia en una secuencia meramente retórica y abstracta de los Derechos Humanos, ni siquiera en su asociación al control fiscal, pese a lo técnico que aparentemente resulta. Porque en su identidad con la justicia, surge una composición más humana y menos técnica que designamos precisamente, justicia fiscal.

Es sin duda una reconfiguración basada en su encuentro con los Derechos Humanos, tal y como respecto de la libertad entendida como un modo de ser de la justicia, fue propuesto por Hannah Arendt (Delgado Parra, 2017).

Se trata de una justicia orientada a la experiencia de los Derechos Humanos (Hierro, 2016), pues sin control fiscal son tan improbables que, es inevitable concluir que el control fiscal es en sí mismo un derecho fundamental y, en tanto tal, es tan partícipe de él el Estado como la sociedad.

Si implica una resignificación integral del control fiscal, al menos en cuanto a su constitucionalidad, es evidentemente orientado tanto a su plenitud y eficacia, como la humanización misma del sistema en que se basa la integración social (Luhmann, 2013).

\section{Conclusiones}

La construcción de un estado del arte es en sí mismo un proceso investigativo. Por esta razón demanda un presupuesto metodológico de partida que, en este caso, es el semiótico. No lo desarrollamos dentro de este mismo capítulo puesto que ya fue objeto de tratamiento específico en el precedente, con la amplitud y el detenimiento suficiente.

La consideración introductoria señala que un estado del arte no responde nada más que a una relatoría de la situación teórica de un tema. Sino que se trata de algo más complejo, en tanto debe ser fundamentado y orientado, lo cual realza que su construcción es en sí mismo un proceso de producción de conocimiento. 
De tal suerte, este estado del arte implicó la derivación del sentido del control fiscal, situado sobre dos realidades. Por un lado, el desarrollo técnico del tema, pero en consideración a los orígenes constitucionales del control fiscal. Y por otro, su relación con los Derechos Humanos.

Respecto del primer aspecto, el estado del arte nos permite precisar que a partir de 1991 Colombia tendió a contemporizar con la construcción más técnica de la vigilancia y el control fiscal. De tal suerte, la Asamblea Nacional Constituyente tendió hacia la solidificación de este aspecto, adhiriendo, como se dijo, a la tendencia que tecnificaba el control fiscal.

No obstante, si bien quienes orientaron en tal dirección la fundamentación constitucional, contaban con una experiencia importante, las modificaciones no surgieron de estudios científicos que enaltecieran las condiciones reales y pragmáticas de la sociedad colombiana.

En consecuencia, se recayó en esta materia sobre algo que sido característico del país, consistente en propiciar cambios predominantemente inconsultos del estado real y latente del país.

Es tanto como señalar un cambio propiciado en el propósito de satisfacer expectativas importantes, pero con base en presupuestos azarosos e intuitivos, pese ser muy bien intencionados. En otros términos, se pretendió solucionar un problema del cual apenas se conocieron sus manifestaciones, pero no sus presupuestos, condiciones o causas.

Que no haya habido avances significativos, 27 años después, tal y como lo dejó en evidencia el último informe del Auditor General de la República, se puede acreditar en cuanto a que los propósitos manifiestos y justificadores de la reforma de 1991, siguen siendo en la actualidad expectativas defraudadas, que en muchos aspectos se han venido profundizando, tal y como ocurre con la corrupción.

En cuanto al segundo aspecto, el estado del arte fue construido en consideración al que se considera el dilema actual de los Derechos Humanos.

Al respecto, lo que se halló fue una especie de antinomia, en cuanto la universalidad de los mismos, no sólo no se cuestiona, sino que se reclama necesaria, pero se ha tendido a una cierta pretendida hegemonía occidental, en cuyo seno los Derechos Humanos se explican por razones individuales y no sociales.

Dicha racionalidad tendió a imponerse, hasta la negación de cualquier otra posibilidad, lo cual desafía claramente a los pueblos orientales.

Una respuesta se basa en la multiculturalidad la cual, no obstante, registra la inquietud 


\section{OPPCF}

por la relativización que implica la lectura de cada uno de los pueblos, conforme a sus presupuestos culturales.

La semiótica ofrece una alternativa, en cuanto a la derivación del sentido de los Derechos Humanos, pues atiende a la condición social de base, en consideración a una construcción de sentido informada, al tiempo, por una comunidad supranacional.

Específicamente en materia de control fiscal, podría ser estimado en sí mismo un Derecho Fundamental, del cual es titular la sociedad, como mecanismo de salvaguardia de cumplimiento de los fines del Estado, en tanto tengan que ver con la ejecución del gasto público. Y, complementariamente, es una garantía igualmente fundamental, en tanto y cuanto hace posible la realización de otros Derechos.

Por manera que, por un lado, los Derechos Humanos constituyen una condición del sentido de justicia. Considerado incluso su origen metajurídico, y su dirección hacia la protección jurídica.

Siendo un elemento del sentido general de justicia, es propicio a la experiencia de lo que es justo y de lo que no lo es, considerados los códigos supranacionales en donde reposan tanto signos como significados.

Por otro lado, frente al control y vigilancia fiscal, los Derechos Humanos permiten postular la existencia de una justicia fiscal, basada no sólo en el contenido técnico que implica el proceso fiscal, sino en su transformación como Derecho y Garantía fundamental.

De tal suerte, este estado del arte sirve de fundamento al OPPCF, como mecanismo de desarrollo de una política pública basada en conocimiento real y científico, y orientada hacia la realización de los Derechos Humanos, estimando la configuración de una justicia fiscal.

\section{Referencias bibliográficas}

Alesina, A., Hausmann, R., Hommes, R., \& Stein, E. (1999). Budget institutions and fiscal performance in Latin America. Journal of development Economics, 59(2), 253-273. En, https://www.sciencedirect.com/science/article/pii/S0304387899000127.

Álvarez García, S. (2018) Comentario a la sentencia del Tribunal Constitucional 118/2016 Constitucionalidad de los Preceptos Legales que Establecen un Control de las Normas Forales Fiscales Compartido entre la Jurisdicción Constitucional y la Ordinaria. Crónica Tributaria [serial online]. July 2017;(164):219-228. Available from: Business Source Complete, Ipswich, MA. Accessed March 7, 2018. 
Álvarez-Gayou, J. L. (2004). Cómo hacer investigación cualitativa. Fundamentos y metodología. Cómo hacer investigación cualitativa: fundamentos y metodología. http:// www.ceppia.com.co/Herramientas/Herramientas/Hacer-investigacion-alvarez-gayou.pdf

Allen, R. (2011). Legislatures and the Budget Process: The Myth of Fiscal Control - By Joachim Wehner. Governance, 24(3), 619-621. doi:10.1111/j.1468-0491.2011.01538_2.x

Álvarez García, S. (2018) Comentario a la sentencia del Tribunal Constitucional 118/2016 Constitucionalidad de los Preceptos Legales que Establecen un Control de las Normas Forales Fiscales Compartido entre la Jurisdicción Constitucional y la Ordinaria. Crónica Tributaria [serial online]. July 2017;(164):219-228. Available from: Business Source Complete, Ipswich, MA. Accessed March 7, 2018.

Angulo Marcial, N. (2009) ¿Qué Son los Observatorios y Cuáles son sus Funciones? Innovaciónn Educativa, volumen 9, número 47 abril-junio de 2009, pp. 17. México: Instituto Politécnico Nacional.

Arbonies, Ángel, (2005). Observatorios, www.angelarbonies.com/pdfs/observatorio.pdf

Arroyo Muñoz, Ana, Esther Martínez Somolinos e Izaskun Álvarez Meaza, (2006). "La vigilancia tecnológica fuente de generación de conocimiento", Revista Vigilancia Tecnológica, www.robotiker.com/revista/articulo.do;jsessionid=3151DD49D67CB3168659D C175B2FADD6? method $=$ detalle\&id $=42$

Astudillo Moya, M., 2002. Algunas Consideraciones Sobre Hacienda Pública ¿Distributiva?. Momento Económico, (119), 18-23.

Atienza, M. 2001. El Sentido del Derecho. Ariel. Barcelona (España).

Auerbach, AJ (2006). Ventanas de presupuesto, puestas de sol y control fiscal. Journal of Public Economics , 90 (1-2), 87-100. En, https://www.sciencedirect.com/science/article/abs/ pii/S0047272705000423.

Balcázar Nava, P., González-Arratia López-Fuentes, N. I., Gurrola Peña, G. M., \& Moysén Chimal, A. (2013). Investigación cualitativa. Ministerio de Educación. Lima.

Barrios, A. Z. (2011). Planificación estratégica, presupuesto y control de la gestión pública. Universidad Catolica Andres.

Barrios, Diego, et al., (2006), "Matriz conceptual y operativa de un Observatorio Mercosur Cooperativo" (OMERCOOP), uniRcoop, vol. 4, núm. 1, s/p., http://www.unircoop.org/ unircoop/files/revue/Release/03.Barrios.pd 
Batthyány, K., Cabrera, M., Alesina, L., Bertoni, M., Mascheroni, P., Moreira, N., ... \& Rojo, V. (2011). Metodología de la investigación para las ciencias sociales: apuntes para un curso inicial. Universidad de la Repùblica. Montevideo.

Beltrán Villalba, M. (2016), Dramaturgia y Hermenética. Centro de Investigaciones Sociológicas (Madrid).

Bernal Torres, C. A. (2006). Metodología de la investigación para administración, economía, humanidades y ciencias sociales. Pearson Educación.

Bernal Torrez, C. A. (2010). Metodología de la investigación, administración, economía, humanidades y ciencias sociales.

Bingham, T. (2018). El Estado de Derecho. Tirant lo blanch. México D.F. (México).

Blöchliger, H., \& King, D. (2006). Fiscal autonomy of sub-central governments. En, https://www. oecd-ilibrary.org/taxation/fiscal-autonomy-of-sub-central-governments_5k97b127pc0t-en.

Bonilla-Castro, E., \& Sehk, P. R. (2005). Más allá del dilema de los métodos: la investigación en ciencias sociales. Editorial Norma. https://s3.amazonaws.com/academia.edu. documents/34596841/ELSSY-BONILLA-Mas-Alla-Del-Dilema-de-Los-MetodosIntroduccion-y-Cap-1.pdf?AWSAccessKeyld=AKIAIWOWYYGZ2Y53UL3A\&Expires=15 $17957340 \&$ Signature $=$ qoEIJTF5AEzQIOKPhS0alT5\%2BWaU\%3D\&response-content disposition=inline\%3B\%20filename\%3DUnidad I Tema 2.pdf

Bourdieu, P. y Teubner, G. (2000). La Fuerza del Derecho. Traductor Carlos Morales de Setién Ravina. Ediciones Uniandes, Siglo del Hombre. Bogotá (Colombia).

Buiter, W., Corsetti, G., \& Roubini, N. (1993). Excessive Deficits: Sense and Nonsense in the Treaty of Maastricht,[in:] The Political Economy of Monetary Union.

Buteler, A. (2013). El control de la corrupción en el Derecho Comparado-Los casos de Argentina, Brasil y España. A\&C-Revista de Direito Administrativo \& Constitucional, 13(53), 23-43.

Caribenet.info, (2006), Qué es el observatorio del Caribe colombiano, www.caribenet.info/ conoscere 06 ocaribe.asp?!=

Cilibiu, O. (2016). Public Servants with Powers of Financial and Fiscal Control. Annals Of The Constantin Brancusi University Of Targu Jiu-Letters \& Social Sciences Series, 397-403.

Cruz, M., \& Lapa, J. (2012). Crisis y Recuperación Económica. El papel de la política fiscal. Problemas Del Desarrollo. Revista Latinoamericana De Economía, 43(168), 95-116. 
Cukierman, A., Edwards, S., \& Tabellini, G. (1989). Seigniorage and political instability (No. w3199). National Bureau of Economic Research. En, http://www.nber.org/papers/w3199.

Dammert, L., Gutiérrez, M., Isabel, M., Martin, G., Paternain, R., \& Peña, N. (2014). ¿ Qué observan los que observan el delito?: Pasado, presente y futuro de los observatorios del crimen y la violencia en América Latina y el Caribe. Inter-American Development Bank. En, https:// publications.iadb.org/bitstream/handle/11319/6670/ICS\%20DP\%20Qu\%C3\%A9\%20 observan\%20los\%20que\%20observan\%20el\%20delito.pdf?sequence=1\&isAllowed=y.

Davoodi, H., y Zou, HF (1998). Descentralización fiscal y crecimiento económico: un estudio comparativo entre países. Revista de economía urbana , 43 (2), 244-257. En, https://www. sciencedirect.com/science/article/pii/S0094119097920428.

del Carmen Bolaños, L. (2017). Justicia tributaria como principio constitucional en el Estado social de derecho. Revista De Derecho, (48), 54-81. doi:10.14482/dere.44.7167.

Clérico, L. (2017). "Derecho Constitucional y Derechos Humanos: haciendo manejable el análisis de estereotipos". Revista de Derechos en Acción (REDEA). № 5, diciembre de 2017. 206-241, disponible en, http://ar.vlex.com/vid/derecho-constitucional-derechoshumanos-738453437.

Delgadoo Parra, M.C. (2017). "El Concepto de Libertad en Hannah Arendt Paa el Ejercicio de los Derechos Humanos". Tla-Melaua. Volume 10, $\mathrm{N}^{\circ}$ 41: 6-26. Puebla (México). Disponibe en http://www.scielo.org.mx/scielo.php?script=sci_ arttext\&pid=S187069162017000100006\&lng=en\&tlng=en.

Díaz, E. (2011). Estado de derecho y sociedad democrática. Taurus.

Donovan, A. R., Bravo, M., \& Oppenheimer, C. (2012). Co-production of an institution: Montserrat Volcano Observatory and social dependence on science. Science and Public Policy, 40(2), 171-186. In, https://doi.org/10.1093/scipol/scs078.

Eastaugh, S. R. (2000). National Healthcare Spending and Fiscal Control: Comparisons among 15 Countries. Hospital Topics, 78(4), 9.

Education-Observatories (2009), www.education-observatories.net/eduobs

Eichengreen, B., \& Bayoumi, T. (1994). The political economy of fiscal restrictions: implications for Europe from the United States. European Economic Review, 38(3-4), 783-791. En, https:// www.sciencedirect.com/science/article/pii/0014292194901147.

Eichengreen, B., Hausmann, R.,yVonHagen,J.(1999). Reformarlasinstituciones presupuestarias en América Latina: el caso de un consejo fiscal nacional. Open Economies Review , 10 (4), 
415-442. En, https://link.springer.com/article/10.1023\%2FA\%3A1008337818753.

Enjunto, Natividad (2008), "Razón de ser de los observatorios", Jornada Observando observatorios: ¿nuevos agentes en el tercer sector?, http://blog.plataformavoluntariado. org/category/general/actualidad-pve/ observatorio-del-voluntariado/page/2/

Eribes, R. A., \& Hall, J. S. (1981). Revolt of the Affluent: Fiscal Controls in Three States. Public Administration Review, 41(1), 107-121.

Ferrajolli, L. (2009). Derechos y Garantías. La ley del más débil. Traducción de Andrea Greppi. Trotta. Madrid (España).

Ferrari, V. (2002). Acción Jurídica y Sistema Normativo. Introducción a la sociología del derecho. Dykinson. Madrid (España).

Fonseca, F., \& Beuttenmuller, G. (2011). Democracia, Información y Control Social: reflexiones conceptuales y el papel de los observatorios locales. El Control Social de la Administración Pública, 71. En,https://n9.cl/o8g9

Frausto Oscar, Thomas Martínez y Berenice González Matú (2008), “Observatorios e indicadores de violencia social y de género", Revista Digital Universitaria, vol. 9, núm. 7, julio, UNAM, www.revista.unam.mx/vol.9/num7/art44/int44.htm

Galves, R. N. (2007). Eficacia del control fiscal en Colombia: derecho comparado, historia, macroorganizaciones e instituciones. Universidad del Rosario.

Gavin, M., \& Perotti, R. (1997). Fiscal policy in latin america. NBER macroeconomics annual, 12, 11-61. En, https://www.journals.uchicago.edu/doi/abs/10.1086/654320.

Gobierno Vasco, Departamento de Empleo y Asuntos Sociales, (2008), Observatorio vasco de previsión social, www.juslan.ejgv.euskadi.net/r45-5159/es/contenidos/informacion/ presentacion_observatorio_ssc/es_9837/observatorio_ssc.html

Gómez Lee, I. D. (2006). Control fiscal y seguridad jurídica gubernamental. Universidad Externado de Colombia.

Gregorio, Carlos G. (2007), Observatorios ciudadanos de la administración de justicia penal: ¿cómo incidir desde un observatorio?, www.iijlac.org/docs/observatorios.htm

Grüner, H. P. (2017). Mechanisms for the control of fiscal deficits. Journal Of Economic Behavior \& Organization, 144133-152. doi:10.1016/j.jebo.2017.09.019.

Habermas, J., \& Jiménez Redondo, M. (1998). Facticidad y validez: sobre el derecho y el 
Estado democrático de derecho en términos de teoría del discurso (No. 1Habermas). Trotta,.

Hackenberg, R. A. (1970). The social observatory: Time series data for health and behavioral research. Social Science \& Medicine (1967), 4(3), 343-357. En https://n9.cl/4wn

Hanushek, E. A., \& Yilmaz, K. (2015). Land-use Controls, Fiscal Zoning, and the Local Provision of Education. Public Finance Review, 43(5), 559-585. doi:10.1177/1091142114524618

Haranguş, D., \& Dudă-Dăianu, D. (2013). Impact assessment of Public Relations in the Fiscal Control Management of the National Agency for Fiscal Administration. Journal Of Economics \& Business Research, 19(2), 34-43.

Herrera Damas, S. (2006), “Los observatorios de medios en Latinoamérica: elementos comunes y rasgos diferenciales", Revista Razón y Palabra, núm. 51, junio-julio, www.razonypalabra. org.mx/anteriores/n51/sherrera.html

Herrera Robles, A. (1993). Regimen económico y de hacienda pública en la nueva Constitución. (1993). Revista de Derecho, (2), 29-46.

Heymann, D., \& Navajas, F. (1989). Conflicto distributivo y déficit fiscal. Notas sobre la experiencia argentina, 1970-1987. Desarrollo Económico, 309-329. En, http://www.jstor.org/ stable/3466877?seq=1\#page_scan_tab_contents.

Hierro, L. (2016). Los Derechos Humanos: una concepción de justicia. Marcial Pons. Madrid (España).

Hopland, A. (2013). Central government control and fiscal adjustment: Norwegian evidence. Economics Of Governance, 14(2), 185-203. doi:10.1007/s10101-013-0124-3

INTOSAI. (2016). ISSAI 9400. Copenhgen: INTOSAI. Obtenido de www.issai.org

Kornblit, A. L. (Coordinadora) (2007). Metodologías cualitativas en ciencias sociales: modelos y procedimientos de análisis. Buenos Aires: Biblos.

Lafuente Ibáñez, C., \& Marín Egoscozábal, A. (2008). Metodologías de la investigación en las ciencias sociales: Fases, fuentes y selección de técnicas. Revista Escuela de Administración de Negocios, (64).http://www.redalyc.org/html/206/20612981002/.

Lane, PR (2003). El comportamiento cíclico de la política fiscal: evidencia de la OCDE. Journal of Public Economics , 87(12), 2661-2675.

Luhmann, N. (2013). La Paradoja de los Derechos Humanos: tres escritos sobre política, derecho y derechos humanos. Traducción de Nuria Pastor Muñoz. Colección Estudios Nº 43. 


\section{OPPCF}

Universidad Externado de Colombia. Bogotá (Colombia).

Luhmann, N. (2007). La sociedad de la sociedad. Traducción de Rafael Torres Nafarrate. Herder. México D.F. (México).

Luhmann, N. (2005). El derecho de la Sociedad. Traducción de Rafael Torres Nafarrate. Herder. México D.F. (México).

Marradi, A., Archenti, N., \& Piovani, J. (2007). Metodología de las ciencias sociales. Buenos Aires.

Martínez Miguélez, M. (2006). Ciencia y arte en la metodología cualitativa (No. Sirsi) i9789682475689).

Moreno, D. Y. (2006). Derecho del control fiscal: vigilancia para una gestión transparente de lo público. Club de Abogados-Academia.

MOYA VARGAS, M.F. (2018). "Sentido de Justicia y Proceso Penal". Utopía y Praxis Latinoamericana. Año I, N 1: 50-63. Interlocuciones. Maracaibo (Venezuela).

MOYA VARGAS, M.F. (2017a). Semiótica de la Justicia: opción metodológica del derecho. En Teoría del Derecho Contemporáneo. Universidad La Gran Colombia. Bogotá.

MOYA VARGAS, M.F. (2017b). Fundamentos Semióticos Para la Investigación Jurídica. Universidad Católica de Colombia. Bogotá

MOYA VARGAS, M.F. (2015a). Producción Probatoria de la Verdad. Universidad Católica de Colombia, Bogotá (Colombia).

MOYA VARGAS, M.F. y BERNAL CASTRO, C. (2015b). Libertad de Expresión y Proceso Penal. Universidad Católica de Colombia. Bogotá (Colombia).

MOYA VARGAS, M.F. (2013). “Óntica, Episteme y Orígenes del Principio de Congruencia en el Proceso Penal". Rivista Sociologia del Diritto. Fascículo 2: 37-64. Milano (Italia).

MOYA VARGAS, M.F. (2012). La Verdad y El Espacio Procesal Penal. Universidad Católica de Colombia. Bogotá.

MOYA VARGAS, M.F. (2010). Una Manifestación De Política Penal Aplicada: El Procesamiento De Personas Ausentes en la Ley 906 De 2004. Defensoría del Pueblo-Imprenta Nacional, Bogotá (Colombia).

MOYA VARGAS, M.F. (2008). “La Transvaluación: sus posibilidades como categoría de análisis en la investigación sociojurídica. Novum lus. Universidad Católica de Colombia. V.2. N. 1: 33- 


\section{Bogotá (Colombia).}

MOYA VARGAS, M.F. (2007). Los Fallos Penales por Inasistencia Alimentaria. Un desfase entre la ley y la práctica judicial. Universidad Santo Tomás, Bogotá (Colombia).

MOYA VARGAS, M.F. (2010). La Investigación del Derecho Penal en Colombia. En Diez Años de Investigación Jurídica y Sociojurídica. En Colombia. Balances Red Sociojurídica. Bogotá: Red Sociojurídica.

Musgrave, R. A., (1988). La política fiscal de Estados Unidos, Keynes y la economía keynesiana. (Spanish). Boletín Del CEMLA, 34(3), 113-119.

Nussbaum, M. (2011). Libertad de Conciencia: el ataque a la igualdad de respeto. Centro de Cultura Contemporánea de Barcelona. Traducción de Patricia Soley-Beltrán. Barcelona (España).

Ochoa Díaz, H., \& Charris Rebellón, S. (2003). Propuesta de un modelo de control fiscal para el estado colombiano: El sistema de control fiscal nacional. Estudios gerenciales, 19(89), $13-$ 42. En, http://www.scielo.org.co/scielo.php?pid=S0123-59232003000400001\&script=sci_ arttext\&tlng=es.

Ortí, A. (2008). Encuestación cualitativa y praxis socioinstitucional: de la configuración de «subjetividades sociales» a la de «discursos virtuales». En: Arxius de Ciències Socials, 2014, No. 31: 27-56Paton, Robert A., and James McCalman. Change management: A guide to effective implementation. Sage, 2008.

Parker, D., Charlton, J., Ribeiro, A., \& D. Pathak, R. (2013). Integration of project-based management and change management: Intervention methodology. International Journal of Productivity and Performance Management, 62(5), 534-544.

Plazas-Gómez, C. V., \& Moreno-Guzmán, D. M. (2017). Impacto Económico de las Acciones de Tutela en Salud en Colombia. Vniversitas, 66(135), 325-375. doi:10.11144/Javeriana.vj135. ieat.

Porto, A., \& Porto, N. (2000). FISCAL DECENTRALIZATION AND VOTERS'CHOICES AS CONTROL. Journal Of Applied Economics, 3(1), 135.

Restrepo, J.C. (2015). Hacienda Pública, 10. U. Externado de Colombia. Bogotá.

Rodríguez, I. S., Martínez, J. B., \& Pedreño, M. H. (2011). El papel de los observatorios en el conocimiento de los procesos de exclusión social. Zerbitzuan: Gizarte zerbitzuetarako aldizkaria = Revista de se In, http://ieeexplore.ieee.org/abstract/document/6547975/ metricsrvicios sociales, (50), 57-69. file:///C:/Users/manue/Downloads/Dialnet-ElPapelDeLo 


\section{OPPCF}

sObservatoriosEnElConocimientoDeLosProc-3876864.pdf

Rodríguez Palop, M.E. (2018). La Nueva Generación de Derechos Humanos. Origen y justificación. Dykinson. Madrid (España).

Rosa Rosado, J. F. (2017). Promesa y la Junta de Control Fiscal: Aspectos contractuales y constitucionales. (Spanish). Revista De Derecho Puertorriqueño, 56(2), 331-355

Sancho, J. M. (2005). Los observatorios de la Sociedad de la Información: evaluación o política de promoción de las TIC en educación. Revista Iberoamericana de Educación (OEI), 2005, num. 36, p. 37-68. En http://diposit.ub.edu/dspace/handle/2445/57003.

Salvador, S. (2007). Los paraísos fiscales y la lucha contra el fraude fiscal. Cuadernos de Formación. Colaboración, 14(07). En https://portal.uah.es/portal/page/portal/epd2 asignaturas/asig360050/informacion_academica/Trabajo\%202.Art.4.Estudio\%20sobre\%20 paraios\%20fiscales.2006.IEF.pdf

Savoskina, E. V., \& Kukanova, N. V. (2015). FISCAL CONTROL AND CONTROL ARRANGEMENTS. In The World Of Scientific Discoveries / V Mire Nauchnykh Otkrytiy, 65(5.4), 1330-1347.

de Sousa Santos, B. (1998). De la mano de Alicia. Lo social y lo político en la posmodernidad. Traducción de Consuelo Berna y Mauricia García Villegas. Ediciones Uniandes-Siglo del Hombre Editores. Bogotá (Colombia).

Steiner, C., \& Uribe, P. (2014). Convención América sobre derechos humanos.

Tiropanis, T., Hall, W., Shadbolt, N., De Roure, D., Contractor, N., \& Hendler, J. (2013). The web science observatory. IEEE Intelligent Systems, 28(2), 100-104.

Tudor, F. (2009). Some Considerations Regarding the Principle of the Uniqueness of Fiscal Control. Juridical Current, 12(3), 99-106.

Turner, D. M., Hallencreutz, J., \& Haley, H. (2009). Leveraging the value of an organizational change management methodology. In 9th International Conference on Knowledge, Culture and Change in Boston. The International Journal of Knowledge, Culture and Change Management (Vol. 9, No. 9, pp. 1-34).

Vessuri, H. (2002). El ejercicio de la observación sociotécnica... a propósito de los observatorios de ciencia y tecnología. Cuadernos del CENDES, 19(51), 2-17. En, http://www.scielo.org.ve/ scielo.php?pid=s1012-25082002000300002\&script=sci_arttext.

Vandenbroucke, F., Hemerijck, A., \& Palier, B. (2011). The EU needs a social investment pact. Observatoire Social Européen Paper Series, Opinion Paper, 5. In, https://pure.uva.nl/ws/ 
files/2781101/179011_OpinionPaper5_Vandenbroucke_Hemerijk_Palier_2011.pdf

Vuletin, G. (2013). Exchange Rate Regimes and Fiscal Discipline: the role of capital controls. Economic Inquiry, 51(4), 2096-2109. doi:10.1111/ecin.12019

Walker, Alan, and Tony Maltby. (1997). "Ageing Europe." En https://www.popline.org/ node/268158.

Valieva, E. N., Milova, L. N., Dozhdeva, E. E., Lukin, A. G., \& Chapaev, N. K. (2016). Development of Scientific Understanding of the Essence of the Fiscal Control in Russia over the Past 100 Years. International Journal Of Environmental \& Science Education, 11(15), 7763-7781.

Vita, L. (2015). Prusia Contra el Reich ante el Tribunal Estatal. La sentencia que enfrentó a Hermann Heller, Carla Schmitt y Hans Kelsen en Weimar. Univeridad Externado. Bogotá (Colombia)

Wildavsky, A. (1975). Budgeting: A comparative theory of budgetary processes. Little Brown and Company.

Younes Moreno, D. (2012). Las Reformas del estado y de la Administración Pública: de la misión Kemmerer al gobierno de Juan Manuel Santos. Instituto de Estudios del Ministerio Público. Bogotá, Colombia.

Zolo, D. (2007). La Justicia de Los Vencedores. De Nüremberg a Bagdad. Traducción de Elena Bossi. Editorial Trotta. Madrid (España). 


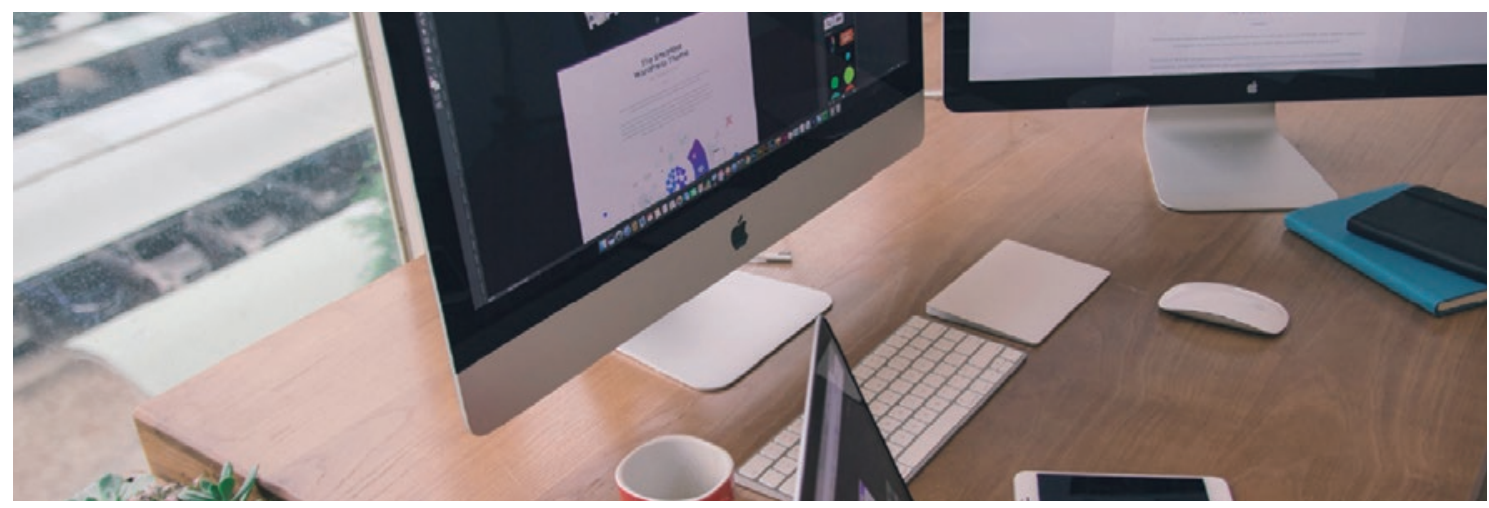

\section{CAPÍTULO III}

\section{METODOLOGÍA}

\section{Methodology}

\section{Manuel Fernando Moya Vargas ${ }^{6}$}

Temario: Introducción. I. Caracterización del OPPCF. 1. Características generales. 2. Características específicas. 3. ¿Qué es el OPPCF? 4. Objetivos. 5. Misión. 6. Visión. 7. Justificación. 8. Resultados esperados. 9. Productos esperados. II. Identificación del método de producción de conocimiento. 1. Signos. 2. Comunicación. 3. Sentido. Conclusiones. REFERENCIAS BIBLIOGRÁFICAS.

\section{Resumen}

El Observatorio de Politica Pública del Control Fiscal surge para el país y la comunidad, como una herramienta de investigación cientifica y de divulgación. Su caracterización lo distingue de todos los demás existentes, en cuanto a su vocación científica. El método en que se basa es el semiótico, pues a diferencia de otros, cubre aspectos asociados a los signos, ala comunicación y al sentido, siendo éste último su principal cualidad.

\section{Abstract}

The Observatory of Public Politics of Fiscal Control is for Colombia and the community, as a tool of scientific research and dissemination. Its characterization distinguishes it from all other existing ones, in terms of its scientific vocation. The method on which it is based is the semiotic, because unlike others, it covers aspects associated with the signs, communication and sense, the latter being its main quality.

Investigador Senior de la Universidad Santo Tomás y de la Auditoría General de la República. 


\section{Palabras clave}

Metodología, Método semiótico, Observatorio de Política Pública del Control Fiscal.

\section{Keywords}

Methodology, Observatory of Public Politics of Fiscal Control, Semiotics methodology

\section{Introducción}

Podríamos sostener de forma sencilla, que un observatorio es un dispositivo que permite hacer seguimiento a un fenómeno, obtener y procesar la información pertinente asociada a él, y por esta vía, servir de fuente de información para la producción de conocimiento en relación con ese mismo fenómeno.

No obstante, ser adecuada la anterior descripción, el observatorio no es en sí mismo una metodología, sino como se dijo un dispositivo, que en la medida con que cuente con una metodología propia, facilita los procesos de producción de conocimiento que se sirven de él.

Esto significa que el observatorio debe disponer de un cierto método de obtención de información, como quiera que un fenómeno es susceptible de ser observado desde distintas perspectivas epistemológicas, y con distintos fines.

Al respecto resulta insuficiente mantener que los hay cuantitativos, cualitativos o mixtos. Pues lo determinante es establecer claramente cuál es el punto de partida epistemológico, y cuál es el destino al que se apunta para aclarar el trasfondo epistemológico, y con ello, hacer presente a la conciencia el saber en que se empeña.

Ya en el capítulo sobre la cuestión epistemológica, ampliamente se indicó que ciertamente hay un método para la constitución del OPPCF, y que proyecta los procesos de investigación a los que sirve de fundamento.

Esa construcción metodológica es la comúnmente conocida como semiótica. Es ella por cuanto se presta, como ninguna otra, para involucrar a la sociedad, y con ella, los procesos de producción y circulación del sentido.

Así, por ejemplo, el OPPCF sirve para producir conocimiento asociado a una disfunción del control fiscal que se materializa en lo que es referido bajo la consideración de corrupción.

Semióticamente surge una serie de inquietudes. Por ejemplo, ¿cuál es el sentido social que permite catalogar algo como corrupto? ¿Qué influencia tiene esa representación social respecto del modelo de control fiscal que debe implementarse? ¿Puede una política pública 
en materia de control fiscal satisfacerse en presupuestos meramente técnicos, prescindiendo de las representaciones sociales, pese a que la Constitución Política la habilita no sólo para participar, sino también para ejercerla, pues al fin y al cabo se trata de su propio patrimonio?

Con el fin de sentar los presupuestos metodológicos, se procede a que retomando las generalidades con que se concluyó la relación de la epistemología con los métodos, en el primer capítulo sobre la cuestión epistemológica, se describirán inicialmente las características más generales de los observatorios, para proceder a la descripción del OPPCF $y$, finalmente la base semiótica de producción de conocimiento en que se fundamenta.

\section{Aspectos generales}

Para referirnos a la metodología es preciso considerar algo que pueda no ser tradicional en Colombia -más no por ello cuestiona la esencialidad científica que envuelve este proceso, consistente en crear un observatorio como objetivo principal de un proyecto de investigación, cuando lo que se acostumbra es que sea un resultado de una investigación. En este caso es un objetivo, dado que como se informó en la justificación, el país lo requiere tanto para propiciar las condiciones hasta ahora inexistentes, para generar investigación científica en materia de vigilancia y control fiscal, así como hacer real en la inmediatez la intervención social en esta misma materia.

La observación es la forma de aproximación a un fenómeno, distinguida por la corriente positivista de las ciencias exactas, que reconociendo o no la participación determinante del observador, hace posible producir conocimiento y con ello, conciencia, respecto de algo (ANGULO MARCIAL, 2009, pp. 6).

Es característico de los dispositivos que llevan el mismo nombre de su método, pues en general, un observatorio es un lugar dispuesto o adecuado para hacer cualquier análisis. Se trata de una estructura que posibilita una amplia visión de lo que es y repercute sobre el fenómeno observado (SANCHO, 2005, pp. 39)

Angulo, citando al Instituto Interamericano de Cooperación para la Agricultura, señala que la sistematicidad y permanencia en la captura de información es lo más característico del dispositivo (2009, pp. 7).

Los observatorios se distinguen por su vocación a la acción, es decir, si bien la creación del observatorio puede ser el objeto de una investigación científica, él mismo tiene una vocación innata al dinamismo, pues a partir de él debe poderse hacer algo más. De hecho, los observatorios constituyen dispositivos de investigación por excelencia,

(...) en términos amplios, un observatorio consiste en la organización sistemática y ordenada 
deactividades relacionadas con la recopilación, análisis einterpretación de toda la información veraz, actualizada y disponible sobre un conjunto de fenómenos de interés particular, cuya distribución y comportamiento debe ser analizado con el fin de tomar decisiones u orientar acciones. Es por ello que conocemos desde antaño el concepto de "información para la acción" como expresión de la intención de quien recopila sistemáticamente la información con el fin de conocer y evaluar indicadores que permitan concluir sobre el comportamiento de ciertas variables o condiciones de interés y tomar decisiones según ellas se comporten (...) Citando a la Superintendencia Nacional de Salud, texto de 2007, (ANGULO MARCIAL, 2009, pp. 8).

Todos los observatorios son acopios de información dispuesta a ser empleadas para la generación de conocimiento específico. De donde pueden clasificarse, al menos en su versión analógica, como un metacódigo, es decir lo que semióticamente implica la fuente de las significaciones o, lo que es igual, el centro de donde se desprenden la condición sintagmática de los signos.

En palabras de Ortuño, citado por Angulo, el observatorio es una especie de panóptico que permite no sólo la aproximación científica al fenómeno, sino que hace probable un esquema de seguimiento dispuesto al constante monitoreo.

(...) el observatorio es un punto de mira, un punto de enfoque, una atalaya digital desde la cual se observa un objeto o una situación. Al mismo tiempo, se le concibe como un mecanismo de monitoreo de tendencias detectables en su ámbito de observación. Un buen observatorio, de acuerdo con Gregorio (2007), establece de manera precisa su tema de interés, su posición con respecto al tema y principios, define también la metodología y se compromete a brindar un servicio (...) (ANGULO MARCIAL, 2009, pp. 7).

De ahí que el observatorio se erija en un dispositivo que por excelencia tiene la vocación democrática de servicio social, pues le es característico estar abierto a un público más o menos abierto, según la tipología de servicio con que se concibe, y las funciones que a nivel científico e institucional puede prestar. Así que es válido predicar que se trata más bien de "un servicio científico especialmente equipado para detectar y recopilar fenómenos científicos naturales. Aunque existen los observatorios geológicos y meteorológicos, el término se suele aplicar a los observatorios astronómicos".7

Desde este punto de vista, es preciso concluir que todo observatorio, científicamente concebido, debe poder cumplir dos funciones esenciales, la de investigar y la de informar (ANGULO MARCIAL, 2009, pp. 8).

Varias son las taxonomías a las que corresponden, por ejemplo, técnicamente se han $7 \quad$ Tomado de https://cup.columbia.edu/. 


\section{OPPCF}

clasificado en observatorios analógicos, simbólicos y digitales, conforme al mecanismo de sistematización de la información y a la base instrumental que sirva al procesamiento de la información (SANCHO, 2005).

De otra parte, se encuentran señalados los observatorios como centros de documentación. Se trata de dispositivos que sirven a la captura de información, pero cuyo procesamiento deriva en un modelo de acopio y sistematización en bruto de los datos. Por otro lado, existen los observatorios caracterizados por capturar la información, sistematizarla y producir algún tipo de análisis. Son comúnmente identificados como centros de análisis de datos. Otros son del tipo espacios de información, cuya vocación es servir de unificación de información especializada, apropiada para comunidades específicas que pueden permitir a sus integrantes algún tipo de interacción, o al menos, actualización en cuanto a los estados del arte. Y también se tienen observatorios determinados por el intercambio y colaboración, mediante los cuales se convoca a comunidades abiertas o cerradas, especializadas o legas, a proporcionar información apropiada para la divulgación (ANGULO MARCIAL, 2009, pp. 7-8)

Si bien pueden clasificarse en cuantitativos, cualitativos y mixtos, los hay sociales o de ciencias exactas, dependiendo el objeto de observación, y la metodología de observación. Lo cierto es que cuando se orientan a fenómenos u objetos de las ciencias sociales o humanas, sociales, tiene por vocación acentuar el carácter social del fenómeno observado, ya que según Urdapilleta citado por Angulo (2009, pp. 7), el observatorio sirve a la creación de sentido social respecto del fenómeno.

De donde resulte característico de estos observatorios el no poder controlar lo que socialmente pueda llegar a hacerse con la información que generan. De donde la importancia que han venido adquiriendo, y la determinante condición de producción científica en cuanto al recaudo, procesamiento y análisis de la información -cuando es el caso conforme a la modalidad del observatorio.

(...) A pesar de que en los últimos años hemos asistido a una considerable proliferación de observatorios cuya misión es realizar el seguimiento de la evolución de fenómenos humanos, no nos ha sido posible encontrar evidencia escrita sobre su origen y conceptualización. Una visión de conjunto, necesariamente «a vuela de buscador» de los diferentes observatorios accesibles a través de Internet relacionados con los ámbitos político, cultural y social (existen observatorios de los derechos humanos, de la justicia juvenil, de los derechos y protección de la infancia, de la promoción de la no violencia, del fin del cuidado de la vida on End of Life Care-, de la discapacidad, de los medios, de la infancia y la adolescencia, de la alimentación, y un largo etcétera), nos indican que su principal misión consiste en informar sobre los derechos de determinados individuos, en documentar y en dar publicidad a las 
violaciones de los mismos; en evaluar las intervenciones que se realizan en el ámbito de observatorio, o en reflexionar y debatir los temas controvertidos. (SANCHO, 2005, pp. 41).

Conforme a esta concepción, estos dispositivos deben propender por vincular distintos sectores sociales, normalmente a la comunidad científica con la sociedad, debiendo involucrar cuando es el caso, a las instituciones públicas. De ahí el carácter social e integrador, facilitado ampliamente en los modelos constitucionales democráticos, sociales y de derecho (RODRÍGUEZ, 2011, pp.66).

Particularmente, (...) los observatorios de políticas públicas nacen, generalmente, de las acciones de las instituciones de la sociedad políticamente organizada que, al recoger, producir y difundir informaciones estratégicas, pretenden ayudar a la participación de los actores sociales implicados en determinada política pública (...) (FONSECA \& BEUTTENMULLER, 2011, pp. 80).

Lo cual no obsta que eventualmente el observatorio pueda ser un lugar de encuentro de los actores interesados, es decir, el observatorio viabiliza la democratización del conocimiento, pero no hace necesariamente que haya una conducción absolutamente democrática hacia él, pues propicia la libertad con que los miembros de una comunidad asumen el conocimiento, en particular, el que ofrece el observatorio (FONSECA \& BEUTTENMULLER, 2011, pp. 82).

En cambio, en el proceso de consolidación de los observatorios, deben adquirir la condición de influir efectivamente en la consolidación de políticas públicas, siendo este grado de incidencia el baremo que permite recabar su razón de ser.

(...) Es característico de los observatorios el acopio y análisis de datos, pero en su madurez su razón de ser se determina por su grado de participación o influencia en la producción de políticas públicas (...) (DAMMER, GUTIÉRREZ, ISABEL, MARTIN, PATERNAIN, \& PEÑA, 2014, pp. 11-12)

El origen de los observatorios puede ser institucional, lo cual es muy frecuente cuando las instituciones públicas se empeñan en darle un tratamiento científico a su accionar. Pero es siempre recomendable conservar un vínculo estrecho con la comunidad científica (DAMMER, GUTIÉRREZ, ISABEL, MARTIN, PATERNAIN, \& PEÑA, 2014, pp. 60).

Metodológicamente los observatorios atienden a una selección cuidadosa de variables e indicadores. Las variables se caracterizan por su nivel de abstracción, mientras que los indicadores propician su especificidad. Es una relación dinámica y constantemente dialéctica entre los connotativo y denotativo, que permite centrifugar la objetividad epistemológica de la información (WALKER and MALTBY, 1997). 
De donde el mecanismo de procesamiento de la información adquiera una muy particular relevancia, según indica Hackenberg (1970).

Adicionalmente los observatorios pueden prestar un servicio social de alertas tempranas, acerca de fenómenos cuya repercusión se traduzca en realidad predecibles y que, por lo mismo, son susceptibles de impacto social alterado. Como consecuencia, el observatorio puede tener una incidencia significativa en la construcción de la realidad social (TIROPANIS, HALL, SHADBOLT, De ROURE, CONTRACTOR and HENDLER, 2013) sirve para predecir, alertas tempranas

\section{Caracterización del OPPCF}

\section{Características generales}

Con base en lo anterior, el diseño metodológico del observatorio de Política Pública del Control Fiscal es de naturaleza predominantemente cualitativa, sin que pueda incorporar información de tipo cuantitativo.

Definición tipológica:

1. Captura y procesa información mixta. Es decir, tanto cualitativa como cuantitativa.

2. Desde su propia enunciación está dispuesto a la formulación, análisis y mejoramiento de la política pública en materia de control fiscal.

3. Tiene cobertura nacional y naturaleza pública.

4. Su vocación compromete dos dinámicas, por un lado, servir a la producción de conocimiento científico en materia de control fiscal; por otro, facilitar la participación ciudadana en la vigilancia y el control fiscal.

5. Las fuentes de información son predominantemente primarias, esto es:

a. Documentación original de la producción normativa, por ejemplo, las Actas de la Asamblea Nacional Constituyente sobre creación del control fiscal.

b. Documentación de las fuentes legales nacionales, inclusive actas legislativas, de impacto sobre el control fiscal en general, y las funciones de la Auditoría en particular.

c. Documentación de las fuentes legislativas internacionales.

d. Doctrina del control fiscal, al menos considerada en los últimos 
cinco años.

e. Observación a través de las auditorías regionales.

f. Información procesada de la jurisprudencia nacional.

g. Información cuantitativa de los SIA

6. Obedece a un régimen de planeación estratégica anual de funcionamiento, orientada a la formulación de proyectos de investigación, su ejecución y la publicación de resultados.

Por cuanto el observatorio será de acceso público a través de la página web de la Auditoría General de la República, podemos concretar que se trata de un espacio científico, integrado a la comunidad académica, regido por los criterios de ciencia y tecnología de Colciencias, con vocación de servicio público.

Adicionalmente, el OPPCF considera la producción de investigaciones de carácter cualitativo, cuyo principal objetivo sea establecer, cómo se construyen escenarios de corrupción en Colombia.

A tal fin se guiará por la metodología de la semiótica, la cual estima la construcción social del sentido, mediante el rastreo de las representaciones sociales acerca de corrupción, para lo cual considerará cuando menos:

a. Construcciones a través de los medios de comunicación

b. Discursos oficiales

c. Análisis de casos emblemáticos

d. Foros abiertos acerca del uso social de las representaciones sobre corrupción

e. Entrevistas estructuradas y semiestructuradas a expertos en el tema

EI OPPCF se dispondrá en la página web de la Auditoría General de la República, e incorporará los siguientes contenidos:

a. Documentación y orígenes constitucionales y legales del control fiscal y DDHH. En esta ventana se podrá verificar las fuentes en que se revela la concepción constitucional y legal del control fiscal, documentada por las actas de la Asamblea Nacional 
Constituyente y los debates legislativos de todo el sistema o subsistema normativo de control fiscal. Servirá para hacer seguimiento a los ritmos de las reformas en Colombia sobre la materia. Se analizará la información de cara a la concepción social y democrática de los DDHH, en busca de formular la naturaleza del control fiscal como Derecho y/o Garantía fundamental.

b. Doctrina científica del control fiscal. En esta ventana se construye y alimenta el estado de arte en materia de control fiscal, tanto a nivel nacional como internacional.

c. Jurisprudencia Nacional. En esta ventana se construirán, documentarán y mantendrán actualizadas las líneas y precedentes que en materia de control fiscal produzcan la Corte Constitucional, el Consejo de Estado y la Corte Suprema de Justicia.

d. Proceso auditor y tendencias internacionales. En esta ventana se describe el proceso auditor, para que sirva de referente en respecto de las fuentes de información públicas que permitan al interesado actualizarse que en materia de control fiscal registrado por organismos internacionales como la OCDE o la CEPAL.

e. Intervención ciudadana y Red Interinstitucional. En esta ventana se facilitará el acceso a la información de los SIA, se analizarán las variables e indicadores seleccionados, con la periodicidad que se disponga en el reglamento interno del Observatorio. Así mismo, se identificarán y analizarán casos emblemáticos informados por las Auditorías regionales, las Contralorías regionales, la Procuraduría General de la Nación, la Contaduría General de la Nación y la Fiscalía General de la Nación, manteniendo la debida reserva cuando a ello haya lugar. Así mismo, de conformidad con el reglamento, se abrirá el foro ciudadano de discusión, conforme a los temas propuestos por el Observatorio.

Cada una de ellas constituye una ventana específica de observación, como se ha venido planteando para hacer seguimiento permanente al control fiscal, sobre la base de sus dinámicas internas.

La política de administración del Observatorio de Política Pública del Control Fiscal estará informado de los siguientes descriptores: 
1. Calidad de la información y los análisis. Existirá una metodología incorporada al estatuto del OPPCF, que responda a las exigencias de ciencia y tecnología de Colciencias, avalada por a comunidad científica nacional e internacional.

2. Cobertura. Nacional.

3. Participación ciudadana, academia e instituciones. El OPPCF es público e integra a la academia, sociedad y a las instituciones cuyo fin constitucional es el control.

4. Alertas tempranas a través de análisis predictivos. Tanto la información como su procesamiento y análisis, considerará siempre el impacto sobre un mecanismo de alertas tempranas que redunde en un control preventivo.

5. Incidencia en políticas públicas relacionadas control y vigilancia fiscal, y anticorrupción. Esta es la utilidad práctica del OPPCF.

6. El OPPCF tiene por propósito impactar la política pública del control fiscal.

7. Apertura internacional. El OPPCF abrirá sus ventanas de observación a la comunidad internacional, mediante redes científicas de estudio.

8. Divulgación. Los resultados serán divulgados a la ciudadanía a través de su acceso a las fuentes de información y documentos.

9. Sostenibilidad. El OPPCF tiene vocación de permanencia, es un dispositivo de investigación científica e intervención ciudadana que dispondrá de los recursos humanos y materiales que garanticen su sostenibilidad.

10. Fortalecimiento. En consideración a la importancia de contar con este tipo de herramientas, toda decisión que se tome en relación con el OPPCF será dispuesto a su mejora.

11. Autoevaluación. A través de un sistema de variables e indicadores, anualmente el OPPCF será autoevaluado a fin de adoptar acciones de fortalecimiento y mejora continua.

12. Plan Estratégico. Anualmente el OPPCF será administrado con fundamento en un plan estratégico, producto de la autoevaluación interna y de necesidades que en materia de control fiscal evidencie el País.

\section{Características específicas}

¿Qué es el OPPCF? 
Por regla general, se entiende que un observatorio es un dispositivo de seguimiento a un fenómeno observable, que puede ser de naturaleza social. Normalmente están diseñados para prestar servicios de procesamiento y divulgación de cierto tipo de información, que puede ser de carácter cuantitativo, cualitativo o mixto.

Sus posibles estructuras oscilan entre as básicas y complejas, dependiendo de los objetivos que se propongan, aun cuando existe a tendencia hacia la complejidad, en cuanto se busca que presten servicios de ciencia y tecnología avanzados.

El OPPCF es un dispositivo complejo, por cuanto está dirigido tanto a la comunidad en general, como a la comunidad científica interesada en servirse de él para adelantar procesos de investigación que satisfagan los estándares nacionales e internacionales de ciencia y tecnología.

Por ello, servirá de línea de base a la producción científica del Grupo de Investigación que se encuentra conformando la Auditoría General de la República.

\section{Objetivos}

Como objetivo general el OPPCF se propone producir a través de un dispositivo de captura y procesamiento científico de la información pertinente, las condiciones de análisis científico y de seguimiento ciudadano al control fiscal sobre la ejecución de los recursos públicos por parte de los ejecutores del gasto público en Colombia, en procura de una política de control fiscal y anticorrupción, afín a los principios constitucionales y muy especialmente al sistema general de los Derechos Humanos, facilitadora de la convivencia pacífica, la justicia y la concordia nacional.

Como objetivos específicos se prevén:

3.a. Obtener de fuentes predominantemente primarias y, en tanto sea necesario, secundarias, la información apropiada a la alimentación de las ventanas de observación.

3.b. Procesar y analizar la información de conformidad con una metodología científica dispuesta a la generación de conocimiento acerca del control fiscal, mediante la publicación de resultados de análisis fruto de investigaciones científicas.

3.c. Formular desde la Auditoría General de la República los presupuestos de una política de control fiscal orientada a la integración sinérgica y en red funcional de los organismos constitucionales encargados del control: Auditoría General de la República, Contraloría General de la Nación, Procuraduría General de la República, Contaduría General de la Nación y, Fiscalía General de la Nación. 
3.d. Establecer la naturaleza de Derecho y/o Garantía Fundamental del control fiscal, y su condición de Garantía Fundamental respecto de los Derechos Humanos, precursores de la convivencia pacífica.

3.e. Facilitar el control ciudadano sobre la ejecución del gasto público, contribuyendo al proceso de vigilancia y control fiscal.

\section{Misión}

El OPPCF es una herramienta científica con vocación de permanencia, orientada a tres propósitos fundamentales: la producción de conocimiento sobre el control fiscal, servir de mecanismo de divulgación y formación en materia de control fiscal, y a posibilitar la intervención social en la eficacia y eficiencia del Estado democrático, social y de derecho en cuanto tiene que ver con el control fiscal.

Por consiguiente, a través del OPPCF se vincula el sector público, con el sector académico y el sector social, en busca de consolidar la condición del control fiscal como derecho y garantía fundamental, que sirve de base a la eficiencia y eficacia de otros derechos y garantías fundamentales, así como de los Derechos Humanos, la convivencia pacífica y la justicia social.

\section{Visión}

El OPPCF se proyecta como un recurso necesario en la producción de conocimiento para la generación, evaluación y consolidación de la política pública del control fiscal en Colombia, y como referente obligado a nivel regional e internacional, en cuanto al tratamiento científico del control fiscal, nucleando al sector público, al sector académico y al sector social, como fuentes de la política pública del control fiscal, en busca de resignificar su naturaleza hacia un derecho y garantía fundamental, necesario en la consolidación de otros derechos y garantías fundamentales, de los Derechos Humanos y de la convivencia pacífica, y de la justicia social.

\section{Justificación}

Los observatorios han venido siendo desarrollados de tiempo atrás, y se consideran herramientas importantes no sólo para la investigación, sino que benefician al Estado democrático, social y de derecho, porque facilita el control social de la función pública, al tiempo que democratiza el conocimiento pues hace posible su acceso a la generalidad de la población.

Es importante así mismo destacar que promueven la integración de las naciones, puesto que se erigen en herramienta de análisis científico y seguimiento ciudadano al ejercicio 


\section{OPPCF}

del gobierno. En efecto, no sólo contribuyen a la comprensión científica de un fenómeno socialmente importante, sino que también hacen más probable la realización de principios y valores en que se fundamenta el Estado democrático, social y de derecho, puesto que involucra en torno al conocimiento, a la sociedad con la academia y con el Estado.

Como consecuencia, la creación del OPPCF se justifica en dos ejes. Por un lado, el servicio de difusión del conocimiento de la vigilancia y el control fiscal, en su conexión con el sistema de DDHH y el efecto sobre patologías sociales como la corrupción. Y por otro, en cubrir una necesidad latente en el país.

i. En primer lugar, se encuentra que en los fundamentos mismos de la democracia se halla el control fiscal. Sin él, la gobernabilidad en términos de democracia, convivencia pacífica y plenitud de los DDHH, no es posible. A lo cual debe agregarse que, en ausencia de un régimen de responsabilidad derivada de la ejecución del gasto público, no es posible la realización de los derechos y garantías fundamentales de las personas. La historia abunda en ejemplos de regímenes caracterizados por la violación sistemática de los $\mathrm{DDHH}$, en que los gobiernos ejecutaban el gasto púbico sin una política de control.

ii. En segundo lugar, encontramos que en Colombia no existe un observatorio de política pública del control fiscal. Esto por cuanto si bien existen se refieren al menos tres observatorios asociados al tema fiscal, no satisfacen ninguno de los objetivos propuestos mediante el OPPCF, y exhiben las deficiencias que suelen atribuirse a estos dispositivos cuando no cumplen sus funciones.

En general, las deficiencias referidas por los expertos señalan marginarse completamente de la acción social, es decir cuando no sirven al mejoramiento de la función pública. Cuando carecen de consistencia científica, o simplemente cuando no cumplen las funciones para las cuales fueron concebidos.

Desde este punto de vista son afines a una concepción de Estado democrático, social y de derecho, porque facilita el control social de la función pública. cuentan:

- Carencia de impacto sobre la realidad social

- Ausencia de solidez científica

- Un deficiente proceso de análisis de información

- Recurso exclusivo a fuentes secundarias

- Carencia de planes estratégicos que garanticen su actualización y operatividad

Recursos humanos y materiales insuficientes 
Varias de las cuales puede predicarse de los ejercicios aproximados a un observatorio de control fiscal que existen actualmente en el País. Así, por ejemplo, a nivel nacional tenemos:

La Contraloría General de La República en su página web (https://www.contraloria.gov. co/web/participacion-ciudadana/observatorio-de-control-fiscal-participativo) refiere un observatorio de control fiscal participativo. Lo primero que se advierte al intentar accesar, es que el ícono que lleva su nombre no permite el ingreso, sin que pueda establecerse si es una deficiencia técnica o, no es posible, o sencillamente se emplea la expresión para referir información pública de la entidad.

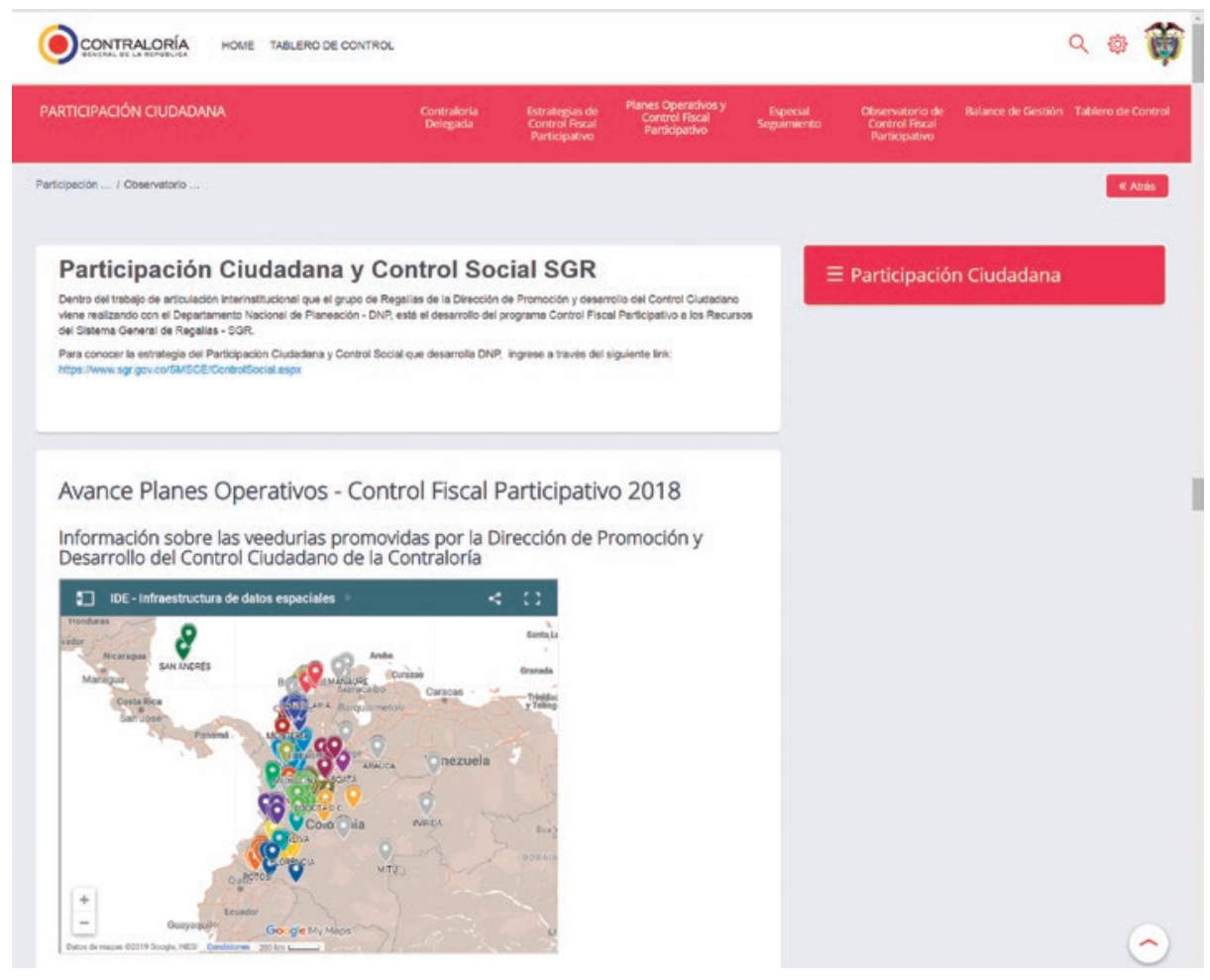

Por suerte que pese a insistir en acceder a una información especial tipo observatorio, no ofrece ninguna otra posibilidad distinta a "Avance Planes Operativos", "Control Fiscal Participativo 2017", "Veedurías Ciudadanas Promovidas por la Contralría General de la República".

Bajo ellos aparece un mapa, luego otro regional y, finalmente uno sobre educación. Más adelante se registra como observatorios: Observatorio Educación, con una opción de acceso en "más información", que al cliquear no ofrece sino una pantalla sin contenido: 


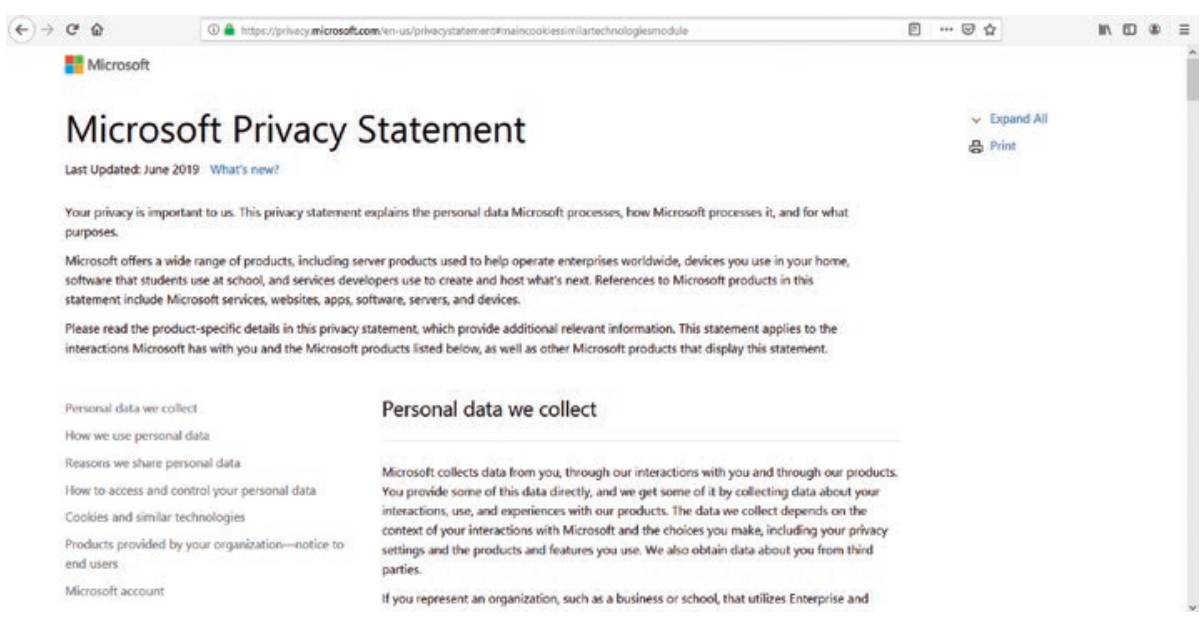

También se encuentra el "Observatorio Salud", el cual no registra ningún tipo de acceso.

A continuación, se hallan 6 documentos bajo la designación "Observatorio 2016", de contenido simplemente sin explicación, que conduce a gráficas en formato pdf, sin análisis, ni siquiera referencia a fuentes.:

\begin{tabular}{|l|c}
\hline Mapa de Calor Promovidas y activas 2014 - 2015.pdf & $\underline{141 \mathrm{k}}$ \\
\hline y activas 2004 - 2015.pdf & \\
\hline N_Número de veedurías del promovidas y activas por regiones & $\underline{110 \mathrm{k}}$ \\
\hline 2014 - 2015.pdf & \\
\hline \begin{tabular}{|l}
\hline Número de Veedurías por Sector Delegado 2014 - 2015.pdf \\
\hline Participantes de las veedurías del país promovidas y activas
\end{tabular} \\
\hline 2014 - 2015.pdf & $\underline{116 \mathrm{k}}$ \\
\hline
\end{tabular}


Veedurías Ciudadanas promovidas y activas 2004 - 2015.pdf

1. El Observatorio de Transparencia y Anticorrupción. Aparece descrito como "El Observatorio de Transparencia y Anticorrupción es una herramienta para la medición y análisis del fenómeno de la corrupción, a partir de la interacción entre entidades, ciudadanos, y organizaciones públicas y privadas del orden nacional y territorial, para contribuir a elevar el nivel de transparencia en la gestión pública."

Señala como ejes "Observar", "educar" y "dialogar".

Se señala su historia a partir de 2012 y, anuncia que sus indicadores son determinados por una mesa técnica.

Dentro del eje Observar se incorporaron indicadores con tres rangos: crítico, en alerta y adecuado. Los cuales describen el punto de cumplimiento por parte de las entidades públicas en cuanto a la política anticorrupción, transparencia, sanciones y gobierno abierto. A cada indicador le es especificado su objeto y su descripción. Incorporó un índice de indicadores de desempeño fiscal con dos ventanas, una de datos abiertos y otra de informes.

El último año completo es el 2014, al verificar la información de la primera ventana arroja una base Excel, sin ningún tipo de análisis, ni siquiera de explicación de la información consignada:

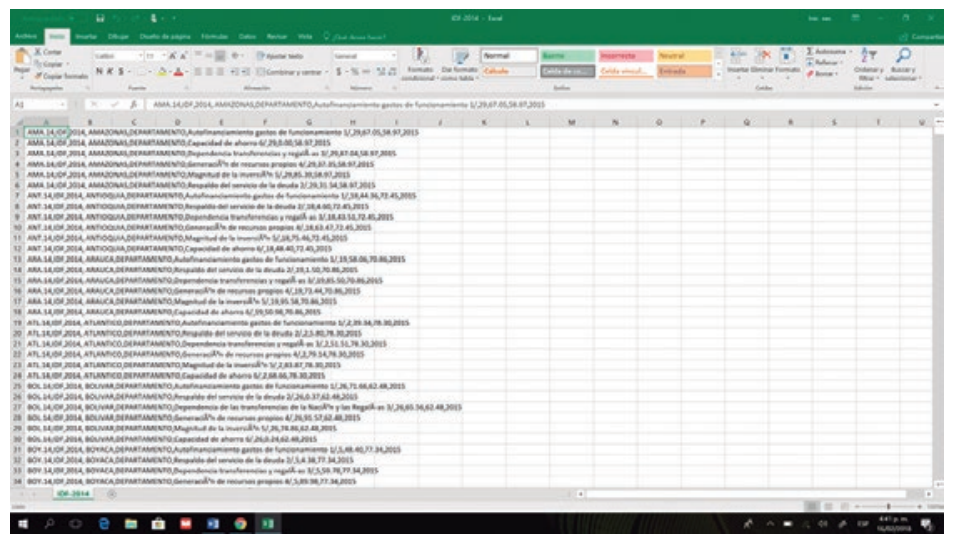

En la segunda ventana se incorporan los informes de desempeño que presenta anualmente Planeación Nacional: 


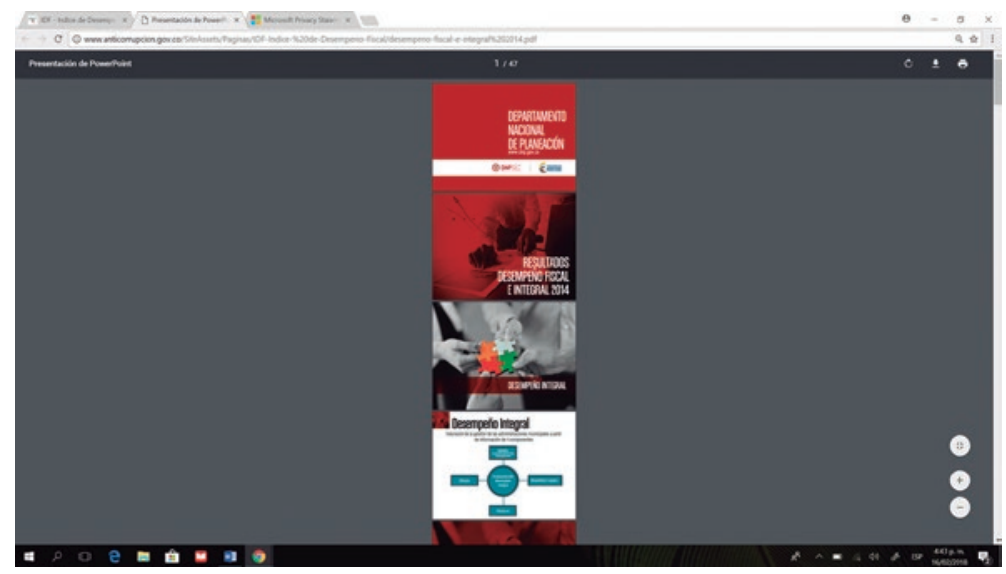

Es decir, teniendo en cuenta que no hay otro análisis en unto específico al control fiscal, el Observatorio en tanto tal no es aportante, puesto que la misma información analítica se hallaría en Planeación Nacional. La cual, por cierto, no registra sino comparaciones numéricas, o contraste.

Recientemente la Contraloría General de la Nación adhirió a esta herramienta que sigue siendo liderada por la Secretaría de Transparencia de la Presidencia, proporcionándole apoyo a través del Área de Sistemas e Información de la Contraloría.

Es importante resaltar que sigue estando contraído a uno de los subtemas asociados al control fiscal, como es el de la corrupción.

Siendo esta la gran diferencia, es decir, mientras el Observatorio de Política Pública del Control Fiscal (OPPCF), no se contrae a un subtema sino que asume la integridad del tema general que es el control fiscal, otras características diferenciadoras emergen con claridad:

1. El OPPCF es fruto del trabajo investigativo de naturaleza científica de un grupo de investigación que, con vocación de permanencia, ha diseñado una herramienta de investigación científica, de divulgación y control ciudadano.

2. A tal finalidad se ejecutó un proceso cuyos pasos fueron:

a. Inscripción de la Auditoría General de la República ante Colciencias.

b. Integración de un Grupo de Investigación conformado tanto por investigadores reconocidos y categorizados por Colciencias, y funcionarios de la Auditoría General de la República.

c. Diseño de un proyecto de investigación para la creación del Observatorio.

d. Conclusión de un Convenio de investigación con una universidad 
institucionalmente acreditada por el Ministerio de Educación, para la ejecución del Observatorio.

e. Diseño del Observatorio de Política Pública del Control Fiscal, integrado por ventanas de observación.

Con base en el OPPCF se suscita un espacio investigativo, consulto de las condiciones de otros reconocidos -como el de la CEPAL, en busca de satisfacer los estándares internacionales de ciencia y tecnología, con el fin de realizar los presupuestos de la política pública de ciencia, dirigida a producir conocimiento científico verificable que, basado en una metodología apropiada, permita en torno al control fiscal, vincular la participación del sector público, el sector privado y la comunidad científica.

La hipótesis sobre la cual fue construido el OPPCF radica en que del control fiscal depende la realización de los Derechos y Garantías Fundamentales de las personas, y que ha adquirido en sí mismo, la categoría de derecho fundamental.

Las ventanas de observación que integran el OPPCF se encuentran pensadas para cubrir todas las condiciones de producción científica de conocimiento, lo cual implica que a partir de él puede generarse conocimiento del tema general del control fiscal, y las subespecies derivadas de él.

Más particularmente, su misión está orientada a servir de cabecera para la generación de la política pública del control fiscal, y constituir la base de la adecuación constitucional y legislativa que demanda la actualización del Estado colombiano.

En consecuencia, se propone, sobre presupuestos de ciencia y tecnología, diagnosticar el control fiscal y sus subtemas, para sobre esta base construir mecanismos de optimización y mejora, a partir del conocimiento real y verificable.

Todo el OPPCF se dirige no sólo a la investigación científica, asumiendo las bases sobre las cuales debe construirse una investigación científica sobre el tema y sus subtemas, sino que busca hacer realidad el derecho constitucional del control social sobre la ejecución del patrimonio público.

De esta forma el OPPCF, como se indicó asocia los sectores público, privado y académico, con el fin de generar conocimiento científico, cultura ciudadana y, desarrollo del control fiscal, entendido como un derecho fundamental, de cuya eficacia dependen otros tradicionalmente entendidos como esenciales a la naturaleza humana, y que dan soporte a todo el sistema de Derechos Humanos, como presupuesto de convivencia pacífica.

La Contraloría del Valle del Cauca refiere un Observatorio, sin otro título, en cuyo espacio 
http://www.cdvc.gov.co/publicaciones.php?id=39676, se registran dos ventanas, una de vigencia 2017 y otra 2018, la segunda no tiene acceso y, la primera trae una ventana que dispuesta a presentar las Auditorías Municipales, los Municipios, los memorandos de asignación, los planes de trabajo y los informes finales de cada auditoría.

No hay análisis de la información.

A nivel internacional sin duda descuella el Observatorio Fiscal de Latinoamérica y el Caribe OFILAC, el cual funciona con las bases de datos de CEPAL, CIAT, IDB-OECD-CEPAL-CIAT, IEF y $\mathrm{OCDE}$, las cuales corresponden a las ventanas de observación.

Fue descrito como, "El Observatorio Fiscal de América Latina y el Caribe (OFILAC) surge como una iniciativa de la Comisión Económica de América Latina y el Caribe por contribuir al mejoramiento de la política fiscal a través de la difusión de estudios y del debate con los diversos actores, aunando los esfuerzos de los distintos organismos que participan de este observatorio, como la GIZ, AECID, OCDE, CIAT, entre otros.

OFILAC constituye un ámbito de análisis, discusión y seguimiento de la política fiscal en los países de la región, fomentando el debate de temas fiscales entre funcionarios de organizaciones internacionales, autoridades fiscales y otros expertos en la materia." (https:// www.cepal.org/cgi-bin/getProd.asp?xml=/ofilac/noticias/paginas/3/42013/P42013. xml\&xsl=/ofilac/tpl/p18f.xsl\&base=/ofilac/tpl/top-bottom.xsl)

Registra una variedad amplia de publicaciones y sus actividades son acentuadamente académicas.

Sin duda, este es un observatorio sólido, que debe servir de referente para la generación de los observatorios nacionales, si bien su vocación aborda todo el tema fiscal, en punto al control debe ser enriquecido a través de observatorios locales como el OPPCF, mediante el cual se pretenderá establecer sinergias de desarrollo y complementación.

\section{Resultados esperados}

El principal resultado al cual apunta el OPPCF se inclina al impacto directo sobre la construcción de la política pública que, en materia de control fiscal, se implante en Colombia, así como respecto de la construcción de programas de control fiscal, dispuestos en desarrollo y con ocasión de las mismas políticas.

Como resultados específicos el OPPCF se dispone impactar directamente sobre la producción científica de conocimiento en materia de control fiscal, proporcionando un dispositivo de investigación que pueda ser utilizado por los investigadores del país y de fuera de él. 
Así mismo, generar cultura ciudadana en materia de control fiscal, contribuyendo a que la sociedad se empodere de su función fiscalizadora sobre la ejecución del gasto público, conforme a la Constitución y a las leyes.

\section{Productos esperados}

Los productos previstos a partir del OPPCF, son:

a. Como producto principal, con carácter permanente, el Observatorio.

b. Por periodicidad bimensual:

i. Al menos un documento de análisis por cada ventana, incorporado como paper investigativo a cada una en el ícono análisis.

ii. Contenido mismo de cada una de las ventanas

iii. Foro ciudadano

c. Periodicidad anual

1. Revista Indexada (en proceso de indexación)

2. Congreso Internacional de Control Fiscal y Anticorrupción

3. Memorias del Congreso

Contribución del proyecto al cumplimiento de la misión institucional: (Se pueden consultar en la página de la Unidad de Investigación)

1. Con qué líneas del PIM se vincula el proyecto. Aun cuando las líneas son interdependientes, este proyecto puede contribuir transversalmente a nutrirlas todas, dado que se propone hacer una contribución específica sobre el control fiscal, urgente y descuidada por otras instancias académicas y del Estado. Misionalmente, como es ampliamente conocido, la justicia como punto de partida para la convivencia pacífica y la dignificación del ser humano, es uno de los pilares del pensamiento tomista.

No obstante, apreciamos una particular correspondencia la línea Proyección social e investigación pertinentes. Por un lado, estamos abordando un tema de impacto específico sobre el actuar de una entidad pública en particular como es la Auditoría General de la República, de una función pública como es la vigilancia y el control fiscal.

Por otro, la investigación se orienta hacia la generación d emejores condiciones de 


\section{OPPCF}

investigación científica en materia de control fiscal y, de intervención ciudadana en cuanto al control social que sobre el gasto público debe y puede ejercer la sociedad conforme se lo atribuyen la Constitución y las leyes

Con qué acciones del Plan General de Desarrollo Bogotá, se articula el proyecto: Si bien el proyecto se dirige a todo el país, tiene efectos específicos en los olanes locales anticorrupción. Como consecuencia la capital se vería beneficiada por la generación de una base conceptual de acción frente a su política anticorrupción.

\section{Identificación del método de producción de conocimiento}

A todo método es característico aproximarse de una u otra forma al sentido de los fenómenos. Tener esto claro permite precaverse de conformarse -cuando no engañarse, nada más que con la periferia del sentido. Es decir, confundirlo con la orientación, el significado, la esencia, la caracterización o, la descripción del fenómeno. Lo cual, por juicioso que sea el investigador, no pasa de ser una cierta aproximación a esa completitud que es el sentido.

La diferencia crucial entre los distintos métodos radica en dónde o a partir de qué proceden a ubicar el sentido en que se empeñan. Así, mientras la hermenéutica lo busca en las interioridades de los textos, la dogmática lo establece a partir de los fundamentos de los sistemas, el método sociológico en los usos sociales y, la semiótica en la dinámica de los signos, esto es, en los procesos comunicativos de los cuales se sirve una comunidad de hablantes para circular o producir el sentido, de donde signos y comunicación sean sus precursores.

Algunos investigadores, sin embargo, no se disponen a alcanzar plenamente el sentido, sea porque no lo requieren para efecto de sus objetivos, sea porque no lo tienen demasiado claro o, sea por error, y prefieran o se conformen con aproximaciones como las que referimos.

No podemos detenernos a señalar los distintos accidentes a que se exponen los procesos investigativos, y por ello preferimos estimar las condiciones del OPPCF, en consideración a las ventajas del método que lo caracteriza.

Optar por un método no se explica por considerarse mejor o más desarrollado que otros. Sin embargo, cuando la investigación quiere considerar la participación social como algo realmente importante, y decididamente está orientada hacia el sentido, la opción por el semiótico evidencia unas ventajas manifiestas en sus cualidades distintivas:

a. Su busca del sentido parte de cómo se produce y, de las opciones de circulación que lo caracterizan. En consecuencia, se orienta hacia los procesos de producción del sentido o, lo que es igual, aquello que en la fenomenología con origen en Husserl es 
conocido como sinngenesis (RAINER, 1973); por otro, hacia los procesos de circulación del sentido. Lo cual conduce a ocuparse de su óntica, implicando necesariamente su descripción. Mientras que los métodos restantes, al no ocuparse de la génesis del sentido, lo asumen como algo dado; es decir, como si se tratase de un producto espontáneo o "natural", desarraigado de los procesos de su constitución, y con ello contribuyendo a enrarecer lo que es el sentido.

b. No divide a la sociedad entre expertos y legos, sino que, entendiéndolos como miembros de una comunidad de hablantes, admite que la capacidad antepredicativa de habla autoriza la creación y circulación del sentido, cuyo origen es invariablemente social. En cambio, la hermenéutica en sí misma entraña la división, de hecho, ella misma es privativa de los expertos. En lo cual no hay mayor distancia con la dogmática, pues apenas la distingue una visión más holística que hace del experto el único dogmatista autorizado. El sociológico, así también, encuentra a la sociedad previamente dividida, clasificada, llegando a formular la más absoluta exclusión de los legos mediante constructos como la teoría de los campos (BOURDIEU, 2000). Esto implica una especie de mutilación, puesto que el sentido es en sí mismo indiferente a la profesionalización, al fin y al cabo, para hablar de algo no se requiere ser experto en ese algo -en cambio sí para otros eventos como, por ejemplo, explicar científicamente las relaciones derivadas de ese algo. De la misma forma como se requiere beber agua tanto por químicos como por legos de la química, lo cual no implica poder explicar su composición, y del sentido social respecto del agua participan unos y otros, siendo normalmente al menos más numerosos los legos que los expertos. La participación determinante de aquellos en la producción de sentido, no es siempre considerada, lo que tiende a invisibilizarla, pero no deja de sorprender en sus dimensiones una vez descubierta. Por ejemplo, dogmática, hermenéutica y sociológicamente se creyó que la producción de la justicia era patrimonio de los expertos, la semiótica del derecho demuestra que el derecho en su versión técnica es de proporciones muy modestas frente a ese otro derecho de donde brota la justicia y se la comparte a aquél, designado en las investigaciones como alterius. ${ }^{8}$

c. Consecuencia de todo lo anterior es que la semiótica se ocupa de los procesos comunicativos en todas sus posibilidades, hallando que los más recurrentes acontecen en la cotidianidad social, otros menos transigentes empleando canales que ciertamente plantean exclusiones, pero no se agotan en sí mismos, ni son los más determinantes del sentido, el cual sigue siendo fruto de la comunidad indiferenciada. Esto es repelente a la hermenéutica y a la dogmática, por sus propias cualidades de

$8 \quad$ MOYA VARGAS, Manuel Fernando (2007): Los Fallos Penales Por Inasistencia Alimentaria. Un desfase entre a ley y la práctica judicial. (Bogotá: Universidad Santo Tomás). 


\section{OPPCF}

ilustración que reclama de hermeneutas y de dogmatistas. La sociología proyecta en sus variables esas mismas exclusiones, como condición de sus propias posibilidades.

d. La semiótica acoge la existencia de sistemas sígnicos, los cuales posibilitan unos ciertos procesos comunicativos, pero no agota el sentido en dichos procesos ni en dichos sistemas, de los cuales infiere su cualidad de precursores. Los métodos restantes se caracterizan por identificar los leguajes especializados con el sentido, frecuentemente con los significados, a los cuales apenas acceden los expertos.

Ahora bien, siendo esta la opción metodológica, es conveniente para efectos de aclarar los fundamentos en que descansa el OPPCF, las características que la identifican.

Para empezar, debemos señalar que el estatuto científico de la semiótica tiene tres manifestaciones, por un lado, los signos, por otro, los procesos comunicativos y, también así el sentido.

Si bien resultan conceptualmente discernibles, en tanto objeto de conocimiento, no lo son. Es decir, una auténtica investigación basada en el método semiótico considera los tres aspectos.

Tal vez el fenómeno que mejor manifiesta la unidad del objeto es la semiosis, porque mediante ella sucede la función sígnica (GREIMÁS, 1991). Sincrónicamente ello ocurre cuando mediante el representamen del signo, se asocia en la conciencia la representación a la cual atiende con la significación que le ha sido asignada.

(...) Para un mejor entendimiento propongamos un ejemplo sencillo. Consideremos el elemento manifiesto como una forma hexagonal, con fondo rojo y, en su centro un carácter blanco correspondiente a la letra P. Esa forma, es el representamen del signo /pare/, /alto/ o /detener la marcha/, y aparece en una esquina de cierta vía pública, siendo suficientemente perceptible por peatones y conductores. La semiosis de ese signo sucede cuando logra generar en la conciencia:

vincularlo al significado [detener la marcha], cuyo efecto es que «todos los que se movilizan por esa vía conduciendo un vehículo deben detener la marcha o al menos disminuir la aceleración, para evitar chocar con otro vehículo o transeúnte que circula con una orientación distinta»;

Crear la expectativa de los demás conductores y de los transeúntes, en cuanto a que los primeros procederán a detenerse o a desacelerar.

Al suceder eso podemos declarar que la función sígnica de /pare/ se ha realizado. Como puede apreciarse, la semiotización evidencia una operación comunicativa, pues una comunidad de hablantes hizo uso del signo conforme a su propia constitución sistémica. Pero 
adviértase algo muy importante, y es que la semiotización compromete un cierto sentido, que puede ser cuestión de \{subordinación\}, de \{orden\}, de \{auto y hetero-protección\}, o quizás de \{condescendencia para con los demás\}, o acaso un poco de todo. Lo cierto es que en ese momento la comunidad de hablantes realizó el sentido y, por ello mismo no sólo se comunicó, sino que reafirmó algo que tiene que ver con su propia identidad. Ahora bien, si un transeúnte no atiende la señal, de ahí no surge necesariamente que la semiotización se haya interrumpido. Pues seguramente /su acción/ será significativa de «incumplimiento», en referencia a [lo que no debe hacerse] y, activará un sentido de \{desorden\}, o de \{ligereza\} o \{desafío\} quizás (...) (MOYA VARGAS, 2018).

El control fiscal en sí mismo cumple una función sígnica que, aplicado genera una serie de experiencias, por ejemplo, la existencia de hallazgos, que de inmediato conduce la experiencia de una irregularidad fiscal.

De hecho, todo el sistema de control fiscal está compuesto de signos, lo cual es propicio al suceso de unas ciertas operaciones comunicativas, cuya realización genera una cierta experiencia de control, de funcionalidad o de disfuncionalidad, que es una forma de crear realidad social, a la cual hemos llamado semiosis (WERNER, 1995).

La conservación de esa tríada que se manifiesta en la semiosis, impide reducir el proceso investigativo a la expresión aislada de los signos, pudiendo por esta vía superar disputas innecesarias, como la planteada en algún momento entre semiótica y hermenéutica (RICOEUR, 1990). Lo cierto es que los manuales tienden a distinguir las tres expresiones, y algunas veces son muy ligeras con el sentido, sugiriendo una cierta atenuación de su importancia y, aparejada, una superinflación de los signos o sistemas sígnicos (ECO, 1991). Es importante considerar que la dinámica revela el uso de un sistema sígnico para comunicarse, y comunicarse para crear y circular el sentido, pese a las contingencias históricas ala s que se ha sujetado la semiótica (CASTAÑARES, 2014).

\section{Signos}

Lo que mejor identifica a un signo es una cualidad consistente en su referencialidad, es decir, su capacidad para remitir a algo diferente a su propia expresión sintáctica. Podríamos precisar que el signo invariablemente representa algo distinto a sí mismo.

Esa referencialidad es lo que hace posible la semiosis, puesto que como se consideró, cuando se produce es ejecutada esa remisión e que consiste la representación. En términos de Peirce se trata de, (...) algo, de cualquier modo de ser, que media entre un objeto y un interpretante, ya que es determinado por el objeto en relación al interpretante, y determina a su vez al interpretante en referencia al objeto, de tal modo como para hacer que el interpretante sea determinado por el objeto a través de la mediación de ese «signo» (...) (PEIRCE, 2008). 
No es muy difícil advertir, por ejemplo, que el control fiscal en sí mismo cumple una función sígnica, puesto que remite a un cierto orden en cuanto a la ejecución del gasto. Si, por ejemplo, se designa el control posterior, la referencia indica que dicho control puede ser ejercido por las autoridades competentes, una vez la ejecución presupuestal ha sido realizada, con el fin de verificar qué tanto se cumplió el régimen existente.

Importa mucho señalar la construcción de la realidad social que se opera mediante la semiosis, pues en el caso el gasto ha sido satisfactorio al control fiscal, se genera una realidad asociada con cierta regularidad, en tanto se predica que el recurso público tuvo el fin que le correspondía, conforme con el régimen aplicable (SHÜTZ, 1966).

Ahora bien, para alcanzar esa construcción, se han realizado una serie de actos de habla practicados con los signos pertinentes (CARNERA, 2012), no todos los cuales deben corresponde a la modalidad de locutorios, pues muchos perfectamente no implican locución (Van den HOVEN, 1988). A través de dichos desarrollos procesuales se genera un cierto sentido (IZZO, 2012).

La tipología de función que cumplen los signos corresponde a regulativas y constitutivas. Las funciones regulativas hacen referencia a fenómenos ya dados, por ejemplo, cuando se refieren vigencias futuras, necesariamente está dando por hecho la existencia de unas ciertas partidas presupuestales. En cambio, las de tipo constitutivo hacen que el fenómeno surja en su propio ejercicio (SEARLE, 1980), por ejemplo, la declaración de renta surge en el acto mismo de semiotizarse el signo correspondiente.

El orden normativo vinculado al derecho, con independencia de su especialidad, evidencia desde sus propios fundamentos la existencia de los dos tipos de signos con reglas y funciones del mismo origen. De donde se predique la posibilidad de hacer análisis semióticos del tipo jurídico (MOYA VARGAS M. F., 2017).

En la tradición semiótica se refiere bajo la expresión semiosphera, el medio ambiente que en general se requiere para que acontezca la semiosis. Al respecto es preciso señalar que se precisa de unas condiciones especiales para que acontezca, puesto que se precisa poder, por ejemplo, decodificar los signos, lo que a su turno conlleva el poder asir su significado. Pero, además, se necesita el poder comunicarse, y esto implica la existencia de una comunidad de hablantes cuyos integrantes puedan hacer todo esto, y otras cosas, por ejemplo, escuchar, expresar, experimentar el sentido, etc.

Ese medio ambiente en sus especiales condiciones sucede sin mayor conciencia por parte de los hablantes, de forma semejante como se suele no ser demasiado consciente de las condiciones del cuerpo en términos de salud. 
Por suerte que, así como dijera Sigerist, la salud es la vida en el silencio de sus órganos, podríamos también declarar que la semiosphera es el escenario donde danza el sentido, embebiendo con donaire de realidad ingenua a las creencias sociales.

Para la semiosis de los signos normativos acostumbramos a precisar como iusphera a ese medio ambiente que se precisa para suceder.

En consideración a que los signos que conforman el sistema de control fiscal son predominantemente normativos, mantendremos la designación iusphera, puesto que está implicando un cierto sentido al que designamos justicia fiscal.

En consecuencia, conviene así mismo advertir que la semiótica asociada a los fenómenos normativos no se agota con los estudios lingüísticos, error recurrente que sin duda puede desviar la orientación del método (KALINOSWSKI, 1975). Precisamente el semiótico, si bien estima la constitución de narrativas y discursos, considera otros aspectos desplegados mediante la utilización de todo el sistema de signos, justamente en los procesos de comunicación que de ellos se sirven (LANDOWSKI, 1973).

De donde la taxonomía de los signos pueda servir de orientador para establecer el tipo de función que cumplen en concreto y, con ello, el uso del cual son susceptibles a través de los actos de habla (KLINKENBERG, 2006).

Esta misma connotación apareja que los signos no existen asilados, sino que forman parte de sistemas de mayor o menor densidad, siendo algunos fundamentales a ciertos actos de habla (PEIRCE C. S., 1883), lo cual condujo a Peirce precisamente a referir un elemento adicional de los signos al cual designó como interpretante, esto es, un signo hecho de otros signos (PEIRCE C. S., Collected Papers of Charles Sanders Peirce, 1960).

Así, las pruebas -afines tanto a procesos judiciales, disciplinarios como fiscales- hacen parte de una variedad sígnica, y evidencian todo un proceso constitutivo, del cual da cuenta la semiótica, pero no así la lingüística (Den BOER, 1994).

También sucede con los hechos asociados a los casos, al adquirir la condición de objeto del proceso, lo cual conviene a una cierta funcionalidad sígnica (MESSNER, 2012).

Otro tanto acontece con las decisiones procesales. Comúnmente reconocidas como sentencias -la designación varía en la modalidad procesal, es un símbolo, cuya función constitutiva resignifica a la persona contra quien es dirigida en condición -igualmente sígnica, de responsable o, todo lo contrario (ALLARD, 2002).

El método semiótico demanda al investigador establecer el sistema sígnico mediante el cual se construyen los procesos comunicativos, haciendo posible el sentido, sea en su tránsito o en su generación. 


\section{OPPCF}

\section{Comunicación}

Podríamos sugerir una especie de definición que nos sirva de sortilegio para conjurar la dificultad proveniente de la complejidad característica de las operaciones comunicativas.

De tal suerte, por comunicación se entiende todo proceso manifiesto en actos de habla que suceden en una comunidad de hablantes, para cuya ejecución son semiotizados los signos de un sistema, con el propósito de circular o producir sentido.

Como puede apreciarse, no se trata de un concepto asentado completamente en los presupuestos de las teorías de Luhmann (Speaking and Silence, 1994), o de Habermas (Conciencia Moral y Acción Comunicativa, 1994), tanto menos en las de Jackobson (HÉBERT, 2011). Se trata más bien de una descripción que intenta conservar la ratio del fenómeno de la comunicación, con un máximo de objetividad epistemológica, fruto de lo que arrojan las exploraciones basadas en la semiótica.

Necesariamente implica que unos signos nucleados en un sistema particular resulten semiotizados a través de actos de habla y que al ser ejecutados entre actantes, demanda de éstos una disposición conveniente al proceso comunicacional, como condición antepredicativa necesaria a los estados intencionales de función de diálogo (AUSTIN, 1998).

Un acto de habla es cualquier intervención de los hablantes, ónticamente susceptible de ser presente a la conciencia de otro hablante, y que conlleva a la semiotización de los signos. Pero, pese ser necesario para que haya comunicación, por sí solo no implica la comunicación. Así, por ejemplo, cuando una persona se estremece al contacto con el agua fría, o canta bajo la ducha sin ser escuchada por más nadie o, simplemente el otro no escucha o, no advierte el estremecimiento, por no disponerse al diálogo. Podríamos decir que para ese efecto se trata de un extraneus, cuya relación con la semiosphera no es sino de proximidad, lo que es tanto como decir que no está haciendo parte de ella.

Ahora bien, dados los actos de habla, la semiosphera y en ella, la semiotización de aquéllos con la intervención de al menos otro hablante, el cual dispone de las condiciones antepredicativas precisas y su disposición de habla -lo que le confiere condición de actante, podemos concluir que hay comunicación, a condición del suceso de transitar o producir sentido.

La naturaleza del sentido implica su circulación entre actantes, bien que sea generado entre ellos, o que nada más -como suele ocurrir, sea vehiculado a través de la semiosis. La comunicación implica un segundo actante, pues hace parte de la misma ratio del sentido el ser social, tal y como ocurre con los actos de habla. 
De ello no provendrá la imposibilidad de sentido para alguien en particular. Pero, sin embargo, le es óntico poderse compartir, de forma similar a como debe poder participar la comunidad del mismo acto de habla. De otro modo, un acto de habla que sólo puede entender una persona, no sirve para comunicarse, lo que confluye en un contrasentido. Mientras que hay sinsentido cuando no puede compartirse.

Eso no conlleva a que los actos de habla -así como el sentido, resulten ser fungibles, pues mediante su uso se reafirma la comunidad, es decir, el sentido ni el acto de habla son agotados para la comunidad de hablantes en el ejercicio del diálogo.

Por otra parte, en manera alguna la comunicación implica la existencia de acciones invariablemente locutivas, pues aún sin voces o expresiones perceptibles por los sentidos habituales, puede haber semiotización y con ello, circulación de sentido o, acaso, sinngenesis.

Lo característico del acto de habla con vocación comunicativa es ser capaz sígnicamente de hacer presente a la conciencia el referente.

Para ello los actantes semiotizan, más que un signo, los signos que le frece un sistema. Al cabo, el destino de la comunicación es el sentido, tal y como lo exhibe el método semiótico -e insistimos en ello con tanta fuerza en cuanto nos resistimos a la tendencia lamentable a ignorarlo o darlo por supuesto. Los signos son precursores de la comunicación, de forma semejante como ésta lo es del sentido. Unos y otros son en sí posibilidades latentes para los actantes, dispuestas a realizar el propósito del sentido.

Desde esta consideración es que preferimos describir la comunicación conforme a un significado procesual, entendiendo que bien puede haber un solo acto de habla, y lograr mediante él todo cuanto tiene que ver con el sentido. Pero los actos de habla precisan registrar la posibilidad de integrarse a otros, de cuyas sinapsis emergen las narrativas. Y suele ocurrir que la comunicación adquiere la suficiente complejidad procesual, para precisar consolidarse a través de la narrativa que la contenga.

La característica sutilidad del sentido lo implica, siendo para ello necesario desplegar unas operaciones comunicativas de cierta complejidad, tanto más, cuanto se vean exigidos los actantes para alcanzar el sentido.

La comunicación es por ello un proceso de interacción entre actantes, para lo cual se sirven de los signos, de cuya semiosis emerge la expresión y, a cuyo efecto, son articulados a través de los actos de habla. En la narrativa el proceso encuentra su mejor sintaxis, mientras que semánticamente depende de su capacidad para proyectar el sentido, sea en su tránsito, sea en su sinngénesis. 
De donde la trascendencia de establecer los procesos comunicativos que, en el caso del OPPCF, se dirige a inferir el sentido mismo del control fiscal, manifiesto en su circulación o en su generación. A tal efecto, el método orienta hacia el sistema sígnico, los actos de habla y finalmente, el sentido.

\section{Sentido}

El propósito de la semiótica es el sentido, y lo indaga a través de los procesos comunicativos que se realizan con los signos de un sistema.

Lo que busca la semiótica del control fiscal es el sentido constituido por la justicia fiscal, que se genera o recorre a través de los procesos comunicativos que se operan con los signos del sistema de control fiscal.

No obstante, ser el sentido el objeto último de todo método, el semiótico no ha sido completamente ajeno a la salida fácil de ignorarlo, o simplemente complacerse con cierto tipo de aproximación.

No obstante, reafirmamos que para el método semiótico trasciende tanto como en ningún otro, puesto que es la semiótica responsable de proporcionar el conocimiento científico del sentido, teniendo en cuenta que es el pináculo de su estatuto. De donde no resulte excusable al semiotista permitirse indulgencias al respecto. Lo que, en cambio, al hermeneuta, al dogmatista y al sociólogo no es tan comprometedor -al menos aparentemente, en cuanto no hace parte de la declaración de su estatuto científico.

Uno de los grandes engaños ha consistido en refugiarse en las nada despreciables indagaciones que respecto del sentido hicieran grandes pensadores como Frege o Wittgenstein, sugiriendo un "nada más hay que decir". O tal vez, el parte de derrota sugerido por Greimas y Courtes, cuando no el enrarecimiento de su naturaleza, tal como puede hacerse surgir de Frege respecto del sentido (Von KUTSCHERA, 1979).

Disponer de una teoría fundamental del sentido es el punto de partida para su asunción. Y quizás un primer paso en favor de su constitución consista justamente en desprenderse de la idea peregrina del "sentido común", como negación misma del sentido, pues una auténtica teoría descansa sobre presupuestos totalmente distintos.

En efecto, la idea del sentido común parte de una especie de condición natural, algo que emerge espontáneamente y, de la cual poco o ninguna participación tiene la intervención social.

Mientras que una teoría del sentido admite como presupuesto, que es creado por las comunidades de hablantes, sin que la desafíe el que su producción resulte invariablemente consciente o voluntaria. Una gran parte de la realidad sucede por una especie de aparente abducción. 
El sentido es imprescindible, como lo es su movimiento y permanente actualización. Sin ser la adequatio rei et intellectus aristotélica, pueda resultar ser lo que probablemente muchos filósofos y científicos atribuyeron a la verdad única, permanente y supra-humana, en que empeñaron sus esfuerzos.

No obstante, la teoría del sentido descarta cualquier asociación con la verdad. Como tampoco lo agota en el significado. De hecho, la asociación provenga de identificar la ausencia de significado o el ser inaprehensible, con la falta de sentido.

Según WITTGENSTEIN, (...) cualquier proposición legítimamente formada tiene que tener un sentido; y si no tiene, esto sólo puede ser consecuencia de que no hemos dado un significado a alguna de sus partes constituyentes. Así pues, «Sócrates es idéntico» no dice nada porque no hemos dado a la palabra «idéntico» ningún significado como adjetivo (...) (WITTGENSTEIN, 2002).

Que haya convergencias no autoriza su identificación, (...) el significante tiene en cierto modo dos caras: una cara llena que es el sentido... y una cara vacía que es la forma... lo que el concepto deforma es la cara llena, el sentido (...) (BARTHES, 2010).

El sentido no procede de atribuciones de significado, sino de proyectar -conscientemente o no, un fenómeno sobre el trasfondo constituido por unas representaciones en que se manifiesta el ser social.

Por ejemplo, si una sociedad proyecta el trabajo en una relación de sacrificio de unas personas en favor de otras, seguramente adquiere el sentido de una pesada carga, en donde unos mandan y otros obedecen. El significado que puede adquirir el trabajo en un metacódigo laboral puede tener muchas coincidencias, pero seguramente bien lejos estaría de descifrar el sentido adquirido.

Por el contrario, las representaciones sociales tienen más que ver con un encuentro entre valores, principios, deseos, frustraciones, aspiraciones, etc., que con una asignación deliberada de significado. Así, cuando una sociedad se representa la riqueza como un poder hacer lo que se quiera por encima de la ley y de los derechos de los demás, la abundancia termina siendo la ocasión de negar a los demás, la fuerza y el capricho como posibilidad negada a quienes carecen de ella. Este el sentido probable, no el significado.

Es así mismo recurrente vincular el sentido con la esencia de los fenómenos. Sin embargo, pudieran tener coincidencia, el sentido no es su característica definitoria, sino una asociación, si se quiere, una proyección del fenómeno más allá de sus cualidades.

Merleau-Ponty mantuvo que (...) Nada nos autoriza a decir que las esencias que encontramos 
le dan al Ser su sentido primitivo, que son lo posible en sí, todo lo posible, que lo que no obedece a su leyes es imposible y que el Ser y el mundo son sus consecuencias; en realidad sólo son su modo de ser, su estilo, el Sosein y no el Sein, y si podemos decir con fundamento que todo pensamiento las respeta, como las respeta el nuestro, si tienen valor universal, es únicamente en cuanto otro pensamiento fundado en otros principios, para darse a conocer a nosotros, para entrar en comunicación con nosotros, tendría que presentarse a las condiciones del nuestro, de nuestra experiencia, y ocupar un sitio en nuestro mundo, y porque, en definitiva, todo pensante $u$ toda esencia posible se refieren a una única experiencia y a un mismo mundo (...) (MERLEAU-PONTY, 1970).

Si por esencial o eidético entendemos lo que caracteriza un fenómeno respecto de cualquier otro, adquiriendo identidad con ocasión de las coincidencias, como del agua estar molecularmente conformada por el encuentro de dos moléculas de hidrógeno con una de oxígeno, el sentido conformado por ser fuente de vida, el bien más valioso o, un indicador de decadencia o sostenibilidad de la naturaleza, dejan claramente discernir que hay una diferencia crucial.

Si llegaren a converger en algo, no evidencia más que la inagotable fuente de posibilidades característica del sentido.

No menos se ha hallado la tentación de vincular el sentido con la orientación. De hecho, es frecuente escuchar "sentido norte, sur, oriental, occidental". Cuando claramente una brújula poco o nada informará acerca del sentido de pobreza, riqueza o condición de clase media, que pueden adquirir los puntos cardinales en una ciudad, por sugerir apenas un ejemplo.

Sentido y utilidad (COLOMER, 1987) tampoco resultan ser correspondientes, teniendo en cuenta que pueden adquirir contenidos acentuadamente paralelos.

Si la tierra es fuente de riqueza, utilitariamente hablando, es profundamente distinto a la asociación que emerge de la fuente materna de la vida, sentido que muchas comunidades indígenas le confieren bajo a designación madre tierra, sin que importe demasiado la utilidad derivada de su fertilidad. Es tan madre tierra la selva como el desierto, o cualquier dehesa conforme a tal sentido.

Los orígenes, las causas, los efectos y los destinos, pueden extraviar no menos el sentido. Por ejemplo, es recurrente hacer referencia a una "quimioterapia" para inducir a través de un acto de habla, el sentido de una grave enfermedad que aqueja a una persona. Obsérvese cómo ese sentido es tan distante del origen -se sugiere algo completamente artificial en los medicamentos, que se pierde vista que las plantas, el agua, las estrellas -de rigen "natural", también tienen composición química, y que un tratamiento a base de ingerir infusiones, no 
es menos una quimioterapia.

La química farmacéutica, origen de las medicinas para enfermedades como el cáncer, dice bastante poco acerca del sentido que se involucra en la locución.

No es difícil advertir que el sentido involucra unos encuentros de las representaciones sociales, los cuales terminan por generarlo. De hecho, se ha advertido su existencia, tal y como lo sugirió HALLIDAY al referirse a, (...) algún nivel superior de significado extralingüístico (...) (HALLIDAY, 1994).

De donde hayamos preferido utilizar la expresión metarrepresentación, cuando en algunos textos hemos querido distinguir esos encuentros de representaciones, con respecto a las que habitualmente son referidas por la sociología y la filosofía del lenguaje.

En el sentido se condensa lo más importante de una comunidad para sí misma. De donde no deje de ser paradójico que se prefiera evitarlo, como poco más o menos se evita conocer las interioridades más profundas de los demás. Lo mejor y lo peor de las sociedades se halla en sentido que construyen. Con razón dijo Saint-Exupéry, Morirás por el sentido del libro, no por la tinta ni el papel (De SAINT-EXUPÉRY, 1998).

Como cualidad social, el sentido no puede ser individual o personal, es quizás lo que hace de una comunidad una hermandad, una unidad, conforme lo ha expuesto la antropología que identifica las culturas como sentido compartido, (...) Si te gusta conocer la aventura de otro para acrecentar la tuya -pues entonces adquiere un sentido- vas a golpear a la puerta de un amigo (...) (De SAINT-EXUPÉRY, 1998, pp. 440).

De hecho, el sentido está llamado a transitar en medio de las comunidades, las cuales lo requieren como manifestación de su propia existencia, de donde Warley comentando un artículo de Peirce, ${ }^{9}$ haya expuesto, (...) En cualquier caso, se trata de la vida de los hombres entendida como ese flujo de sentido que se crea y se recrea y que nunca se detiene (...) (WARLEY, 2007)

De donde resulte mucho más sencillo apreciar, por ejemplo, por qué ser padre es la representación del padre, pero ser un buen padre o un mal padre hace parte del sentido que adquiere esa representación en su encuentro con otras (LÉVI-STRAUSS, 1985).

Como se ha manifestado, el sentido del control fiscal es la justicia fiscal, esto es, el resultado de unas condiciones antepredicativas que hace posibles los estados intencionales e intensionales de función fiscal a una comunidad de hablantes.

$9 \quad$ El artículo apareció en 1878 en el Popular Science Monthly, bajo el título How to Make Our Ideas Clear. 


\section{OPPCF}

\section{Conclusiones}

El semiótico es un método cuya principal característica consiste en seguir el sentido a través de los procesos comunicativos, gestados en uso de los signos de un sistema.

Todo acto de comunicación compromete la semiotización de los signos, para actualizar su referente en la conciencia de los hablantes. Hay un efecto perlocucionario cuando mediante el uso de los signos, es decir, la comunicación, se logra asociar en la conciencia el referente con el significado, enervando el representamen.

El sistema de signos que conforma el control fiscal hace probables los actos de habla que conforman los procesos comunicativos en la materia, a través de los canales pertinentes.

Al sostener la existencia de un sistema de signos se afirma la existencia de unos elementos integrados por un representamen, un referente y un significado, lo cual se verifica en una amplia tipología de expresiones.

Las operaciones comunicativas dan paso al surgimiento de narrativas, en las cuales se exhibe el sentido de justicia fiscal, lo cual es en últimas el objetivo de la semiótica fiscal, del cual participan tanto por legos como expertos.

108 La semiótica descubre el sentido como elemento de su estatuto científico. A diferencia de los signos y la comunicación, también expresiones del estatuto, el sentido suele ser el aspecto más difícil de ese su objeto, en cuanto es en sí mismo difícil de aprehender y, se requiere de un fundamento teórico como soporte, que permita anticipar confundirlo con la verdad, el significado, la esencia, la orientación, las causas o las consecuencias de los fenómenos, en el caso particular se trata específicamente del control fiscal.

El sentido es social, compartido, que está asociado con la identidad de las comunidades, en cuanto se constituye a partir de unos encuentros entre los aspectos que definen lo que una comunidad pretende ser.

Se trata del encuentro de unas representaciones sociales que arrojan la identidad de las comunidades, al menos, en cuanto tiene relación con el fenómeno informado.

El OPPCF prefiere el método semiótico, por sobre el hermenéutico, el dogmático y el sociológico, en consideración a que involucra a la comunidad científica, al estamento público, pero muy especialmente a la sociedad.

Precisamente en cuanto se empeña el dispositivo en la construcción social que emerge del control fiscal, encuentra propicio en el método semiótico un camino hacia el sentido, por cuya naturaleza tiene su génesis en la sociedad. 


\section{Referencias bibliográficas.}

ALLARD, J. (. (2002). La Justice Peut-elle se Passer de Mise en Scène? Quelques Réflexions sur le Cadre Symbolique du Procès. Review of Antoine Garapon's “Bien Juger. Essai sur le Rituel Judiciaire". Inyernational Journal for the Semiotics of Law, 15(3), 203-215.

AUSTIN, J. (1998). Cómo Hacer Cosas con Palabras. Barcelona: Paidós.

BARTHES, R. (2010). Mitologías. (H. Schmucler, Trad.) México: D.F.: Siglo XXI.

BOURDIEU, P. y. (2000). La Fuerza del Derecho. (C. m. Ravina, Trad.) Bogotá: Sigo del Hombre, Ediciones Uniandes, Instituto Pensar.

CARNERA, A. (2012). Freedom of Speech as an Expressive Mode of Existence. International Journal for the Semiotics of Law, 25(1), 57-69.

CASTAÑARES, W. (2014). Historia del Pensamiento Semiótico. Madrid:Trotta.

COLOMER, J. M. (1987). El Utilitarismo: Una Teoría de la Elección Racional. Barcelona: Montesinos.

De SAINT-EXUPÉRY, A. (1998). Ciudadelaa. (H. Ferro, Trad.) Barcelona: Alba Editorial, S.L.

Den BOER, M. (1994). Deictic References to Space and Time in Criminal Evidence. International Journal For The Semiotics of Law, 7(3), 295-310.

ECO, U. (1991). Tratado de Semiótica General (5ed.). (C. Manzano, Trad.) BarcelonaLumen.

GREIMÁS, A. y. (1991). Semiótica. Diccioonario razonado de la teoria del lenguaje. (E. B. Carrión, Trad.) Madrid: Gredos.

HABERMAS, J. (1994). Conciencia Moraly Acción Comunicativa. (R. G. Cotalero, Trad.) Barcelona: Planeta.

HALLIDAY, M. (1994). (1994): El Lenguaje Como Semiótica Social. La Interpretación Social del Lenguaje y del Significado. (J. F. Santana, Trad.) Bogotá: Fondo de Cultura Económico.

HÉBERT, L. (2011). The Functions of Language. SignoSemio. Quebec, Canadá. Obtenido de http://www.signosemio.com/jakobson/functions-of-language.asp

IZZO, V. (2012). Beyond Consensus: Law, Disagreement and Democracy. International Journal for the Semiotics of Law, 5(4), 563-575.

KALINOSWSKI, G. (1975). Lógica del Discurso Normativo. (J. Capella, Trad.) Madrid: Tecnos. 


\section{OPPCF}

KLINKENBERG, J. (2006). Manuel de Semiótica General. (G. B. Heredia,Trad.) Bogota:Universidad Jorge Tadeo Lozano.

LANDOWSKI, E. (1973). La Sociedad Figurada: Ensayos de Sociosemiótica. México D.C.: Univ. Autónoma de Puebla: Fondo de Cultura Económica.

LÉVI-STRAUSS, C. (1985). Las Estructuras Elementales del Parentesco (II). Barcelona: Barcelona: Planeta Agostini.

LUHMANN, N. a. (1994). Speaking and Silence. New German Critique(61), 25-37.

MERLEAU-PONTY, M. (1970). Lo Visible y lo Invisible. (J. Escudé, Trad.) Barcelona: Seix Barral, S.A.

MESSNER, C. (2012). "Living" Law: Performative, Not Discursive. International Journal For The Semiotics of Law, 25(4), 537-552.

MOYA VARGAS, M. (2018). Dimensión Comunicativa del Proceso Penal. (pág. 10). Buenos Aires: Universidad Católica de Colombia.

MOYA VARGAS, M. F. (2017). Fundamentos Semióticos para la Investigación Jurídica. Bogotá: Universidad Católica de Colombia.

PEIRCE, C. S. (1883). Studies in Logic. Boston: Johns Hopkins University.

PEIRCE, C. S. (1960). Collected Papers of Charles Sanders Peirce. Cambridge: Charles Hatsborne/ Paul Weise Harvard University Press.

PEIRCE, C. S. (2008). El pragmatismo . (S. Barrena, Trad.) Madrid: Ediciones Encuentro, S.A.

RAINER, F. (1973). Kontingenz und Sinngenesis; zum problem von entfrendung und geschichte bei Maurice Merleau-Ponty. Munster: Westfalischte Wilhelms-Universitat.

RICOEUR, P. (1990). Between Hermeneutics and Semiotics. International Journal for the Semiotics of Law, 3(2), 115-132.

SEARLE, J. (1980). Actos de Habla. (L. V. Villanueva, Trad.) Madrid: Ediciones Cáteedra.

SHÜTZ, A. (1966). Fenomenología del Mundo Social. Introducción a la Sociología Comprensiva. Barcelona: Paidós.

Van den HOVEN, P. (1988). Legal argumentation as an illocutionary act complex: A critical analysis. . International Journal for the Semiotics of Law, 1(I), 29-45.

Von KUTSCHERA, F. (1979). Filosofía del Lenguaje. (T. d. Álvarez, Trad.) Madrid: Gredos. 
WARLEY, J. (2007). Semiótica de los Medios. Signo, representación, ideología, política. Buenos Aires: Biblos.

WERNER, W. G. (1995). Legal Signs and Legal Science. International Journal for the Semiotics of LaW., 8(2), 207-218.

WITTGENSTEIN, L. (2002). Tractatus Logico-Philosophicus (3 ed.). (L. V. Villanueva, Trad.) Madrid:Tecnos.

\section{Referencias adicionales}

Alesina, A., Hausmann, R., Hommes, R., \& Stein, E. (1999). Budget institutions and fiscal performance in Latin America. Journal of development Economics, 59(2), 253-273. En, https://www.sciencedirect.com/science/article/pii/S0304387899000127.

Álvarez-Gayou, J. L. (2004). Cómo hacer investigación cualitativa. Fundamentos y metodología. Cómo hacer investigación cualitativa: fundamentos y metodología. http:// www.ceppia.com.co/Herramientas/Herramientas/Hacer-investigacion-alvarez-gayou.pdf

ALLEN, R. (2011). Legislatures and the Budget Process: The Myth of Fiscal Control - By Joachim Wehner. Governance, 24(3), 619-621. doi:10.1111/j.1468-0491.2011.01538_2.x

Angulo Marcial, N. (2009) ¿Qué Son los Observatorios y Cuáles son sus Funciones? Innovaciónn Educativa, volumen 9, número 47 abril-junio de 2009, pp. 17. México: Instituto Politécnico Nacional.

Arbonies, Ángel, 2005, Observatorios, www.angelarbonies.com/pdfs/observatorio.pdf

Arroyo Muñoz, Ana, Esther Martínez Somolinos e Izaskun Álvarez Meaza, 2006, "La vigilancia tecnológica fuente de generación de conocimiento", Revista Vigilancia Tecnológica, www.robotiker.com/revista/articulo.do;jsessionid=3151DD49D67CB3168659D C175B2FADD6? method $=$ detalle\&id $=42$

Auerbach, AJ (2006). Ventanas de presupuesto, puestas de sol y control fiscal. Journal of Public Economics , 90 (1-2), 87-100. En, https://www.sciencedirect.com/science/article/abs/ pii/S0047272705000423.

Balcázar Nava, P., González-Arratia López-Fuentes, N. I., Gurrola Peña, G. M., \& Moysén Chimal, A. (2013). Investigación cualitativa. Ministerio de Educación. Lima.

Barrios, A. Z. (2011). Planificación estratégica, presupuesto y control de la gestión pública. Universidad Catolica Andres. 
Barrios, Diego, et al., (2006), "Matriz conceptual y operativa de un Observatorio Mercosur Cooperativo" (OMERCOOP), uniRcoop, vol. 4, núm. 1, s/p., http://www.unircoop.org/ unircoop/files/revue/Release/03.Barrios.pd

Batthyány, K., Cabrera, M., Alesina, L., Bertoni, M., Mascheroni, P., Moreira, N., ... \& Rojo, V. (2011). Metodología de la investigación para las ciencias sociales: apuntes para un curso inicial. Universidad de la Repùblica. Montevideo.

Beltrán Villalba, M. (2016), Dramaturgia y Hermenética. Centro de Investigaciones Sociológicas (Madrid).

Bernal Torres, C. A. (2006). Metodología de la investigación para administración, economía, humanidades y ciencias sociales. Pearson Educación.

Bernal Torrez, C. A. (2010). Metodología de la investigación, administración, economía, humanidades y ciencias sociales.

Blöchliger, H., \& King, D. (2006). Fiscal autonomy of sub-central governments. En, https://www. oecd-ilibrary.org/taxation/fiscal-autonomy-of-sub-central-governments_5k97b127pc0t-en.

Bonilla-Castro,E.,\&Sehk,P.R.(2005).Másalládeldilemadelosmétodos:Iainvestigaciónenciencias sociales. Editorial Norma. https://s3.amazonaws.com/academia.edu.documents/34596841/ ELSSY-BONILLA-Mas-Alla-Del-Dilema-de-Los-Metodos-Introduccion-y-Cap-1.pdf?AWSAcce ssKeyld=AKIAIWOWYYGZ2Y53UL3A\&Expires $=1517957340 \&$ Signature $=$ qoEIJTF5AEzQIOKPh S0alT5\%2BWaU\%3D\&response-content-disposition=inline\%3B\%20filename\%3DUnidad I Tema_2.pdf

Buiter, W., Corsetti, G., \& Roubini, N. (1993). Excessive Deficits: Sense and Nonsense in the Treaty of Maastricht,[in:] The Political Economy of Monetary Union.

Buteler, A. (2013). El control de la corrupción en el Derecho Comparado-Los casos de Argentina, Brasil y España. A\&C-Revista de Direito Administrativo \& Constitucional, 13(53), 23 43.

Caribenet.info, (2006), Qué es el observatorio del Caribe colombiano, www.caribenet.info/ conoscere 06 ocaribe.asp?|=

Cukierman, A., Edwards, S., \& Tabellini, G. (1989). Seigniorage and political instability (No. w3199). National Bureau of Economic Research. En, http://www.nber.org/papers/w3199.

Dammert, L., Gutiérrez, M., Isabel, M., Martin, G., Paternain, R., \& Peña, N. (2014). ¿ Qué observan los que observan el delito?: Pasado, presente y futuro de los observatorios del crimen y la violencia en América Latina y el Caribe. Inter-American Development Bank. En, https:// 
publications.iadb.org/bitstream/handle/11319/6670/ICS\%20DP\%20Qu\%C3\%A9\%20 observan\%20los\%20que\%20observan\%20el\%20delito.pdf? sequence=1\&isAllowed=y.

Donovan, A. R., Bravo, M., \& Oppenheimer, C. (2012). Co-production of an institution: Montserrat Volcano Observatory and social dependence on science. Science and Public Policy, 40(2), 171-186. In, https://doi.org/10.1093/scipol/scs078.

Education-Observatories (2009), www.education-observatories.net/eduobs

Eichengreen, B., \& Bayoumi, T. (1994). The political economy of fiscal restrictions: implications for Europe from the United States. European Economic Review, 38(3-4), 783-791. En, https:// www.sciencedirect.com/science/article/pii/0014292194901147.

Enjunto, Natividad (2008), "Razón de ser de los observatorios", Jornada Observando observatorios: ¿nuevos agentes en el tercer sector?, http://blog.plataformavoluntariado. org/category/general/actualidad-pve/ observatorio-del-voluntariado/page/2/

Eribes, R. A., \& Hall, J. S. (1981). Revolt of the Affluent: Fiscal Controls in Three States. Public Administration Review, 41(1), 107-121.

Fonseca, F., \& Beuttenmuller, G. (2011). CAPÍTULO 3 DEMOCRACIA, INFORMACIÓNY CONTROL SOCIAL: REFLEXIONES CONCEPTUALES Y EL PAPEL DE LOS OBSERVATORIOS LOCALES. EL CONTROL SOCIAL DE LA ADMINISTRACIÓN PÚBLICA, 71. En, https://bit.ly/2X5WoTw

Frausto Oscar, Thomas Martínez y Berenice González Matú (2008), “Observatorios e indicadores de violencia social y de género", Revista Digital Universitaria, vol. 9, núm. 7, julio, UNAM, www.revista.unam.mx/vol.9/num7/art44/int44.htm

Gobierno Vasco, Departamento de Empleo y Asuntos Sociales, (2008), Observatorio vasco de previsión social, www.juslan.ejgv.euskadi.net/r45-5159/es/contenidos/informacion/ presentacion_observatorio_ssc/es_9837/observatorio_ssc.html

Gregorio, Carlos G. (2007), Observatorios ciudadanos de la administración de justicia penal: ¿cómo incidir desde un observatorio?, www.iijlac.org/docs/observatorios.htm

Hackenberg, R. A. (1970). The social observatory: Time series data for health and behavioral research. Social Science \& Medicine (1967), 4(3), 343-357. En https://bit.ly/2FA4HfB

Herrera Damas, Susana (2006), “Los observatorios de medios en Latinoamérica: elementos comunes y rasgos diferenciales", Revista Razón y Palabra, núm. 51, junio-julio, www. razonypalabra.org.mx/anteriores/n51/sherrera.html

Kornblit, A. L. (Coordinadora) (2007). Metodologías cualitativas en ciencias sociales: modelos y 


\section{OPPCF}

procedimientos de análisis. Buenos Aires: Biblos.

Lafuente Ibáñez, C., \& Marín Egoscozábal, A. (2008). Metodologías de la investigación en las ciencias sociales: Fases, fuentes y selección de técnicas. Revista Escuela de Administración de Negocios, (64).http://www.redalyc.org/html/206/20612981002/.

Marradi, A., Archenti, N., \& Piovani, J. (2007). Metodología de las ciencias sociales. Buenos Aires.

Martínez Miguélez, M. (2006). Ciencia y arte en la metodología cualitativa (No. Sirsi) i9789682475689).

(a) Moya V, (2017). Fundamentos Semióticos Para la Investigación Jurídica. Bogotá: Universidad Católica de Colombia.

(b) Moya V, (2017). Semiótica de la Justicia. Opción Metodológica del Derecho. En Teoría del Derecho Contemporánea. Bogotá: Universidad La Gran Colombia.

Moya V, (2010). La Investigación del Derecho Penal en Colombia. En Diez Años de Investigación Jurídica y Sociojurídica. En Colombia. Balances Red Sociojurídica. Bogotá: Red Sociojurídica.

Ortí, Alfonso. Encuestación cualitativa y praxis socioinstitucional: de la configuración de «subjetividades sociales» a la de «discursos virtuales». En: Arxius de Ciències Socials, 2014, No. 31: 27-56Paton, Robert A., and James McCalman. Change management: A guide to effective implementation. Sage, 2008.

Rodríguez, I. S., Martínez, J. B., \& Pedreño, M. H. (2011). El papel de los observatorios en el conocimiento de los procesos de exclusión social. Zerbitzuan: Gizarte zerbitzuetarako aldizkaria = Revista de se In, http://ieeexplore.ieee.org/abstract/document/6547975/ metricsrvicios sociales, (50), 57-69. file:///C:/Users/manue/Downloads/Dialnet-ElPapelDeLos ObservatoriosEnEIConocimientoDeLosProc-3876864.pdf

Sancho, J. M. (2005). Los observatorios de la Sociedad de la Información: evaluación o política de promoción de las TIC en educación. Revista lberoamericana de Educación (OEI), 2005, num. 36, p. 37-68. En http://diposit.ub.edu/dspace/handle/2445/57003.

Steiner, C., \& Uribe, P. (2014). Convención América sobre derechos humanos.

Tiropanis, T., Hall, W., Shadbolt, N., De Roure, D., Contractor, N., \& Hendler, J. (2013). The web science observatory. IEEE Intelligent Systems, 28(2), 100-104.

Tudor, F. (2009). SOME CONSIDERATIONS REGARDING THE PRINCIPLE OF THE UNIQUENESS 
OF FISCAL CONTROL. Juridical Current, 12(3), 99-106.

Turner, D. M., Hallencreutz, J., \& Haley, H. (2009). Leveraging the value of an organizational change management methodology. In 9th International Conference on Knowledge, Culture and Change in Boston. The International Journal of Knowledge, Culture and Change Management (Vol. 9, No. 9, pp. 1-34).

Vessuri, H. (2002). El ejercicio de la observación sociotécnica... a propósito de los observatorios de ciencia y tecnología. Cuadernos del CENDES, 19(51), 2-17. En, http://www.scielo.org.ve/ scielo.php?pid=s1012-25082002000300002\&script=sci arttext.

Vandenbroucke, F., Hemerijck, A., \& Palier, B. (2011). The EU needs a social investment pact. Observatoire Social Européen Paper Series, Opinion Paper, 5. In, https://pure.uva.nl/ws/ files/2781101/179011 OpinionPaper5 Vandenbroucke Hemerijk Palier 2011.pdf

Walker, Alan, and Tony Maltby. (1997). "Ageing Europe." En https://www.popline.org/ node/268158.

Valieva, E. N., Milova, L. N., Dozhdeva, E. E., Lukin, A. G., \& Chapaev, N. K. (2016). Development of Scientific Understanding of the Essence of the Fiscal Control in Russia over the Past 100 Years. International Journal Of Environmental \& Science Education, 11(15), 7763-7781. 


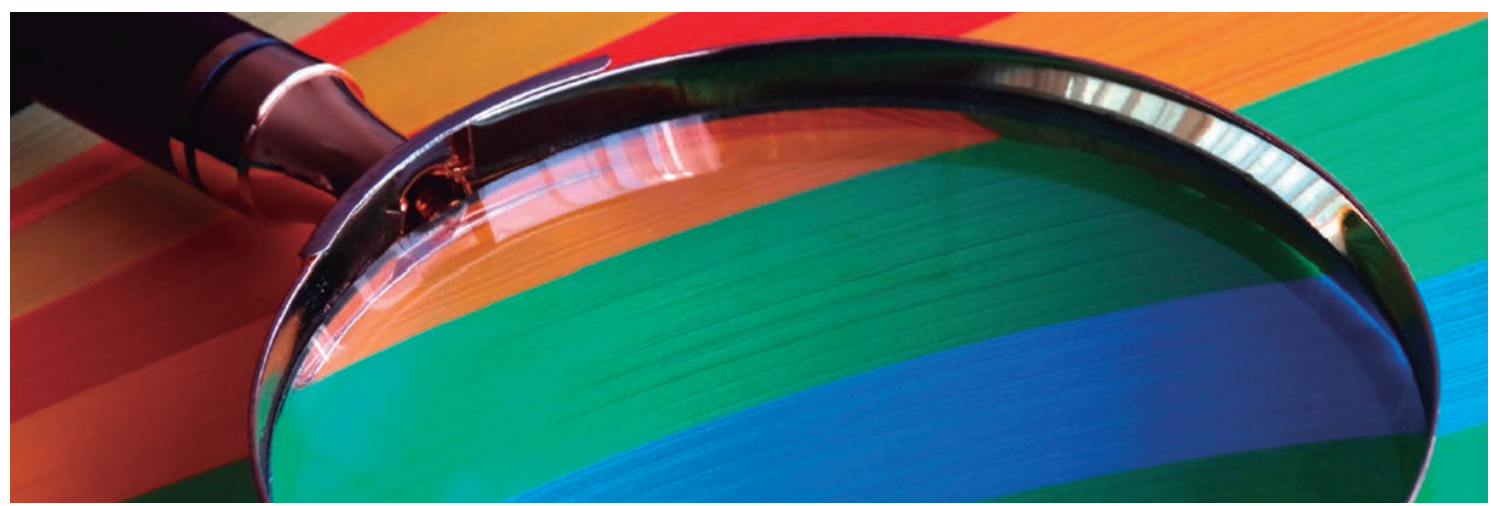

\section{CAPÍTULO IV}

\section{EL ESPÍRITU CONSTITUYENTE DEL CONTROL FISCAL}

Transformaciones y continuidades en las instituciones de control fiscal en Colombia

\section{The constituent spirit of fiscal control}

Transformations and continuities in fiscal control institutions in Colombia

Alexandra González Zapata ${ }^{10}$

\section{Temario:}

Estructura del Estado y equilibrio de poderes públicos

Democracia y elección de la rama fiscal

Estructura y mandato del Control Fiscal

El control fiscal de las entidades territoriales

El control del control: el espíritu de la Auditoría General de la República

Referencias

\section{Resumen}

En este capítulo se aborda la compleja discusión dada por la Asamblea Nacional Constituyente

10 Politóloga y Magister (c) en Políticas Públicas de la Universidad Nacional de Colombia. Investigadora del grupo "Altos estudios en control fiscal, derechos humanos y convivencia pacífica" de la Auditoría General de la República y de la Universidad Santo Tomás -según convenio. Este capítulo es producto de la investigación desarrollada por el Observatorio de Política Pública del Control Fiscal adscrito al grupo. 
de Colombia de 1991 sobre el funcionamiento del control fiscal en el nuevo estado social de derecho. Por un lado, se analiza el proceso a través del cual el constituyente centró su atención en la división de poderes, tratando de comprender los procesos que se presentaron en otros países del mundo en los cuales se superó la división clásica de las tres ramas del poder público, para crear así los pilares del equilibrio de poderes y ramas autónomas que existe actualmente en Colombia. Por otro lado, se trata de analizar las posturas e intereses que promovieron la discusión sobre los mecanismos de elección de los representantes de la rama fiscal a nivel nacional y territorial, la cual fue atravesada por una profunda reflexión sobre la democracia participativa, representativa, y el ejercicio de derechos de la ciudadanía frente al control fiscal. En tercer lugar, se presenta la discusión desarrollada en la Asamblea sobre la estructura que debían tener las entidades encargadas del control fiscal, atendiendo a debates internacionales relativos a la corte de cuentas o estructura unipersonal, y la propuesta presentada por algunos sectores políticos de privatizar el control fiscal para blindarlo, según ellos, de la corrupción. Finalmente, se presenta una de las innovaciones - a pesar de su previa existencia legal- del proceso constituyente, la Auditoría General de la República. Se analizará las competencias que le confirió el constituyente, los límites de su temporalidad y por qué se limitó su mandato.

Palabras claves: Control fiscal, Asamblea Nacional Constituyente, equilibrio de poderes.

\section{Summary}

This chapter addresses the complex discussion given by the National Constituent Assembly of Colombia of 1991 on the operation of fiscal control in the new social state of law. On the one hand, the process through which the constituent focused its attention on the division of powers is analyzed, trying to understand the processes that occurred in other countries of the world in which the classical division of the three branches of power public was overcome, to create the pillars of the balance of powers and autonomous branches that currently exists in Colombia. On the other hand, this chapter tries to analyze the positions and interests that promoted the discussion on the election mechanisms of the representatives of the fiscal branch at the national and territorial levels, which was crossed by a deep reflection of participatory democracy, representative, and the exercise of citizenship rights against fiscal control. Likewise, the discussion developed in the Assembly about the structure that should have the entities in charge of fiscal control is presented, taking into account international debates related to the court of accounts or unipersonal structure, and the need presented by some political sectors to privatize the control prosecutor to shield him from corruption. Finally, one of the innovations - despite its previous legal existence - of the constituent process, the General Audit of the Republic, is presented. The competences conferred by the constituent, the limits of its temporality and why its mandate was limited will be analyzed. 


\section{OPPCF}

Keywords: Fiscal control, National Constituent Assembly, balance of powers.

\section{Introducción}

La Asamblea Nacional Constituyente (ANC) y la Constitución Política de 1991 fue la síntesis de un proceso de transformación que años atrás venía reformulando los principios sobre los cuales se había edificado el estado colombiano.

La carta magna de 1991 pretendió, entre otros aspectos, reorientar los órganos que tienen competencias en la política de control fiscal en el país, creando nuevas entidades como la Fiscalía General de la Nación (1991), la Contaduría General de la Nación (1996) y la Auditoría General de la Republica (1992); y reformulando el carácter y mandato legal de otras que existían en el país hace décadas, como la Procuraduría General de la Nación (1819) y la Contraloría General de la República (1923).

Siguiendo la tradición latinoamericana que generó una oleada de reformismo y reformulación constitucional desde la década de los 80's, la ANC buscó "reforzar las instancias estatales de control, fortaleciendo la autonomía y la capacidad fiscalizadora de las mismas" (Uprimmy, 2011, pág. 118).

La Asamblea tuvo cinco comisiones permanentes que se ocuparon de diversos temas. Comisión Primera: principios, derechos, deberes y garantías fundamentales, mecanismos e instituciones de protección, participación democrática, sistema electoral, partidos políticos, estatuto de la oposición, reformas a la Constitución. Comisión segunda: ordenamiento territorial del Estado, autonomía regional y local. Comisión Tercera: Gobierno y Congreso, hacienda pública y control fiscal. Comisión Cuarta: administración de justicia y ministerio público. Comisión Quinta: asuntos económicos, sociales, de hacienda y control fiscal.

A pesar de esta separación, se generaron propuestas y debates relativos a las instituciones que ejercerían el control fiscal y su mandato en las cinco comisiones de trabajo.

Este capítulo presentará los hallazgos realizados por el Observatorio de Política Pública de Control Fiscal de la Auditoría General de la República. Durante el proceso de estructuración del Observatorio se utilizaron técnicas cualitativas para el análisis de la información que reposa en las actas de la ANC (fuentes primarias). A partir de un proceso investigativo utilizando el método descriptivo, se realizó un proceso de análisis documental de todas las actas de la ANC que hacían algún tipo de referencia al control fiscal, identificándose 52. Posteriormente, se extrajo la información allí recopilada y se agrupó por unidades temáticas afines que se fueron configurando al momento del análisis de los contenidos. Esas unidades temáticas son los subcapítulos de este documento. 
Se identificaron 35 propuestas distribuidas en los siguientes temas: estructura del Estado y separación de poderes (6); democracia y elección de los representantes de la rama de control fiscal (11); estructura y mandato del control fiscal (11); el control fiscal en las entidades territoriales (5); y el control del control y la creación de la Auditoría General de la República (2).

Lograr identificar los fundamentos constitucionales y legales del control fiscal permite establecer cuál fue el horizonte que se le pretendió dar a esta función pública, para así comprender si los cambios presentados posteriormente se deben a un proceso de actualización, reformulación o transformación de lineamientos. Lo anterior, permitirá que el Observatorio de Política Pública de Control Fiscal establezca las trayectorias del control fiscal en Colombia, y gestione la información relativa a las reformas actuales, generando insumos efectivos para la toma de decisiones de las autoridades competentes sobre esta materia.

\section{Estructura del Estado y equilibrio de poderes públicos}

El modelo de frenos y contrapesos surgió como una apuesta de un tipo ideal del constitucionalismo que funda el Estado Moderno, en el cual se pretende imponer límites al poder soberano ${ }^{11}$. El pensamiento de Montesquieu es uno de los primeros referentes sobre la división de poderes, a pesar de existir antecedentes desde la época aristotélica (Castro, Andrés, \& Moya Vargas, 2015).

Montesquieu atribuyó las distintas funciones estatales a órganos separados entre sí, pero independiente y en posición equilibrada (Echavarría, 1981, pág. 221; Vile, 2012, págs. 83 85). En la obra de este filósofo francés del siglo XVIII se identifican las diversas funciones del estado: el poder legislativo, ejecutivo y judicial.

Durante el proceso de configuración de los estados nación del continente americano, se buscó adoptar dicho modelo de separación de poderes, evitando de manera especial la concentración del poder en el órgano ejecutivo, dado que se tenía como referente anterior el gobierno monárquico que ejercía un control absoluto y concentrado sobre toda la población (Echavarría, 1981, pág. 224).

En el caso colombiano puede identificarse el espíritu de separación de poderes desde la primera constitución de 1.810, la Constitución del Socorro. Este texto es el primero de las antiguas provincias del Virreinato de la Nueva Granada que iniciaron su emancipación.

11 La obra del Leviatán es una síntesis del deber ser del nuevo estado moderno, el cual irrumpe ante los modelos totalitarios. Se caracteriza por generar consenso con los ciudadanos, evitando así gobernar de forma arbitraria e irracional, dado que ello terminaría debilitando al Estado y al poder soberano. (Múnera Ruíz, 2005, pág. 42; Vitale, 2007, pág. 107). 


\section{OPPCF}

Esta carta estableció la división en dos poderes. El poder legislativo lo tenía la Junta de Representantes y el poder ejecutivo estaba a cargo de los Alcaldes Ordinarios y en los Cabildos, los cuales ejercían a principalmente funciones judiciales, dado que, como se lee en su numeral diez, estas autoridades debían hacer "apelación al Pueblo en las causas que merezcan pena capital, y en las otras, y civiles de mayor cuantía a un tercer Tribunal que nombrará la Junta en su caso" (Constitución Política de 1810).

Posteriormente, se promulgó la Constitución de Cundinamarca, la primera de alcance nacional, en 1.811. Instauró en el territorio una monarquía constitucional fiel al rey Fernando VII, a pesar de establecer la constitución libre, constituida por elección y consentimiento del pueblo. En dicho texto se consagro por primera vez en nuestra trayectoria como estadonación la división de los tres poderes públicos, ejecutivo, legislativo y judicial, "aunque con el derecho de objetar el poder ejecutivo lo que estime conveniente a las libertades del legislador en su caso y lugar" (Constitución de Cundinamarca, 1811).

Ocho meses después se promulgó el Acta de Federación de las Provincias de la Nueva Granada, la cual eliminó los derechos de gobernante al rey Fernando VII y creó una organización política de corte federalista, atendiendo a las independencias que habían promulgado otras provincias y evitando así la segregación en naciones diferentes. Esta constitución estableció que cada provincia tenía

La facultad de darse un gobierno como más convenga a sus circunstancias, aunque siempre popular, representativo y análogo al general de la Unión, para que así resulte entre todas la mejor armonía, y la más fácil administración, dividiendo sus poderes, y prescribiéndoles las reglas bajo las cuales se deben conducir (Acta de la Federación de las Provincias Unidas de Nueva Granada, 1811).

La disposición establecida en el Acta de Federación se reafirma en el texto promulgado en la Constitución de la República de Tunja, sancionada el 9 de diciembre de 1811. Allí se explicitó que

La reunión de los tres poderes legislativo, ejecutivo y judicial, es origen de la tiranía, por esta razón en un gobierno libre deberán estar separados. La garantía social, no puede existir, si no se halla establecida la división de los poderes, si sus límites no están fixiados (1811).

El 30 de agosto de 1821 es proclamada la Constitución de Cúcuta, la cual tuvo el objetivo principal de crear la Gran Colombia mediante la unificación de la Nueva Granda. Dicha 
constitución estuvo vigente hasta la disolución dada en 1830, y establecía un "gobierno popular representativo, y cuyos poderes, Legislativo, Ejecutivo y Judicial, exactamente divididos, tienen sus atribuciones marcadas y definidas, formando, sin embargo, un todo de tal suerte combinado y armonioso" (Constitución de 1821).

Posterior a la separación de las provincias de Venezuela y Quito, se promulgó una ley que suprimió los departamentos y las provincias centrales de la Gran Colombia formando el Estado de Nueva Granada. Su constitución fue sancionada en 1832, y allí se definió que "el poder supremo estará dividido para su administración, en legislativo, ejecutivo, y judicial, y ninguno de ellos ejercerá las atribuciones que conforme a esta constitución corresponden a los otros, debiendo mantenerse cada uno dentro de sus límites respectivos" (Constitución política del Estado de Nueva Granada de 1832).

Las siguientes cuatro constituciones $(1.843,1.853,1.858$ y 1.863), a pesar de variar en su redacción, establecieron la división clásica de los tres poderes del estado, legislativo, ejecutivo y judicial, y consagraron que cada poder debía mantenerse dentro de sus límites respectivos. Esto a pesar de que las distintas cartas establecieron modelos de gobierno distintos. Por ejemplo, la de 1.843 fortaleció el poder del presidente, mientras que la de 1.853 dio paso al federalismo. Sin embargo, todas respetaron el principio que rige los estados modernos, la separación y equilibrio de poderes.

En la Constitución de 1.853 es la primera vez que se hace alusión al Ministerio Público, el cual tenía la función de acusar, por solicitud del poder ejecutivo, a los Gobernadores de las provincias y a otros funcionarios nacionales o municipales del orden administrativo, 0 judicial, por infracción a la ley (artículo 54).

Dicha disposición cambio cinco años después, en la Constitución de 1.858, en la cual se estableció que el Ministerio público sería ejercido por la Cámara de Representantes, por un funcionario denominado "Procurador general de la Nación" (artículo 55), el cual también tendría funciones judiciales.

En 1.863 se profundiza y aclaran las funciones del Ministerio Público, estableciendo que éste se ejerce por la Cámara de Representantes, y tiene como atribuciones cuidar de que todos los funcionarios públicos al servicio de la Unión desempeñen cumplidamente sus deberes, y acusar ante el Senado o la Corte Suprema federal a los funcionarios justiciables por estas corporaciones.

Posteriormente se promulgó la Constitución de 1.886, la cual permaneció vigente por más de cien años. Dicho texto mantuvo la trayectoria consagrada en los anteriores cuerpos constitucionales, reconociendo los tres poderes públicos, legislativo, judicial y ejecutivo, y 


\section{OPPCF}

señalando que éstos eran limitados, y ejercían separadamente sus respectivas atribuciones.

En dicho texto constitucional, el Ministerio Público sería ejercido, bajo la suprema dirección del Gobierno (artículo 142), asimilando lo adoptado inicialmente por la carta magna de 1.853. Sin embargo, es la primera vez que se hace referencia al control fiscal. Se estableció que la Cámara de Representantes ejercía determinadas funciones fiscales, sin especificar cuáles.

Durante más de cien años se llevaron a cabo distintas reformas que profundizaron la idea de la separación de poderes y especializaron la funciones relativas al control fiscal en instituciones con cierto nivel de independencia. No obstante, no fue hasta 1.991 que se crearon constitucionalmente los organismos de control con independencia y autonomía de las tres ramas del poder público.

Según el constitucionalista Rodrigo Uprimmy:

Una de las características de los procesos constitucionales recientes en América Latina a nivel institucional fue la tendencia a reconocer la existencia de organismos estatales autónomos, encargados de funciones técnicas de regulación, en especial en materia económica, y que no encajaban dentro de la división clásica de poderes. Esos desarrollos no han implicado un abandono de la idea de la división de poderes como un elemento esencial del constitucionalismo sino la posibilidad de prever otras ramas de poder o la existencia de órganos autónomos que no pertenecen a ninguno de los poderes clásicos del Estado. (2011, pág. 121).

En el seno de la constituyente este debate no fue dado sin controversia. Se presentaron seis propuestas alrededor de la independencia de los poderes públicos y el control fiscal, las cuales se pueden resumir de la siguiente manera. En primer lugar, quienes consideraban que debería existir una rama autónoma del poder público ${ }^{12}$, aludiendo a la doctrina de Luis Carlos Sáchica, quien señalaba: "Hay que advertir que, hoy las funciones del Estado son múltiples y de la más variada naturaleza y que, por tanto, la enumeración de las tres fundamentales (...) es anacrónica" (Sachica, 1987, pág. 80).

El sector que estaba a favor de la creación de una rama independiente del poder para el control fiscal manifestó que la teoría contemporánea del derecho constitucional supone la existencia de varias ramas del poder, tantas cuantas vayan surgiendo como complejos

12 Esta perspectiva fue defendida por Antonio Yepes Parra, quien proponía rama autónoma del Poder Público; Antonio Galán Sarmiento, que propuso crear la rama fiscalizadora del poder público; por su parte Jaime Álvaro Fajardo Landaeta y Darío Antonio Mejía Agudelo impulsaron la creación de la rama del poder de control fiscal popular. 
orgánicos que, por desarrollar una función específica y básica en la vida del Estado, deben ser dotadas de independencia en el desempeño de sus tareas propias (Yepes Parra, 1991).

Bajos estas mismas nociones, la doctrina internacional ha establecido que la división clásica en las tres ramas del poder debe actualizar bajo las nuevas necesidades del Estado:

We should take the new bodies as a whole and view them as composing a new branch of government and forming the basis of a new separation of powers. Just as the old separation of powers, between legislatures, executives and the judiciary, added to the overall strength of democratic systems of government, so too can the new separation of powers (Vibert, 2007, pág. 2).

La segunda propuesta impulsó la creación de la categoría de órganos independientes, sin que ello significara la creación de una cuarta rama del poder ${ }^{13}$. Consideraban que, si se dotaba de la autonomía necesaria a dichas instituciones, no era imperativo crear un poder más.

La tercera propuesta pretendía que la vigilancia del control fiscal recayera en el poder legislativo, el cual ejercería dicha función a través de un instrumento técnico, la Contraloría General de la Nación ${ }^{14}$, como estaba contemplado en la Constitución de 1886. Según los ponentes de esta iniciativa, al ser el Congreso el órgano que nombra al Contralor, significa que es a éste a quien se debe, y por tanto, si bien debía ser una entidad técnica con niveles de autonomía, debía ser parte de la rama de control legislativo.

La literatura institucionalista fiscal generalmente considera que, si el control fiscal emana del poder legislativo, se generaría riesgos para las funciones que debe desarrollarse en dicha materia. Los cuerpos legislativos son fiscalmente peligrosos dado que promueven normas que centralizan la toma de decisiones en manos de los ministerios, lo cual afecta la independencia de poderes y aumenta la capacidad del ejecutivo para ejercer control fiscal (Wehner, 2010).

Finalmente fue aprobado el artículo 267 de la Constitución Política de 1991 el cual establece que: El control fiscal es una función pública que ejercerá la Contraloría General de la República, la cual vigila la gestión fiscal de la administración y de los particulares o entidades que manejen fondos o bienes de la Nación.

Cómo se resalta en el artículo, el control fiscal es una función pública, lo que se traduce en una

13 En esta postura se identificaron los constituyentes Hernando Herrera Vergara, Carlos Lleras de la Fuente, Antonio Navarro Wolf, José Matías Ortiz y Abel Rodríguez.

14 Esta propuesta fue presentada Manuel Francisco Becerra, Contralor General de la República, y respaldada por el constituyente Carlos Noriega Rodado. 
actividad que se realiza como parte de los fines propios del Estado. La Corte Constitucional de Colombia ha señalado que esta función no es exclusiva de las ramas del poder público, también la realizan los órganos autónomos e independientes, y las demás entidades o agencias públicas, en orden a alcanzar sus diferentes fines (Sentencia C563, 1998).

\section{Democracia y elección de la rama fiscal}

Producto de la crisis de representación que aquejaba a Colombia, no sólo por el precedente del Frente Nacional, sino por la restringida participación de la ciudadanía en la conducción de los asuntos públicos, el proceso constituyente de 1991 buscó fortalecer la democracia participativa, creando derechos de participación política distintos del voto, como la iniciativa legislativa, el referéndum, la consulta popular, la revocatoria de mandato, entre otras figuras.

Se consideró, por parte de algunos sectores de la ANC, que una de las restricciones democráticas era la ausencia de participación ciudadana en la elección de los designatarios de las autoridades públicas que ejercían control político y fiscal a los entes territoriales y del orden ejecutivo nacional. Lo cual no solo era considerado una restricción a la participación, sino que se configuraba como un mecanismo que propiciaba la corrupción y concentración del poder al interior de los partidos políticos.

124 Por lo anterior, el mecanismo de elección del contralor nacional y los contralores regionales fue un punto neurálgico de discusión en las distintas comisiones de la ANC. Y como se ha visto en la historia reciente del país, continúa siendo un debate inconcluso.

Una de las propuestas sobre este asunto fue impulsada por los constituyentes Juan Carlos Esguerra y Jaime Arias López de la Alianza Democrática $M$ - 19, quienes presentaron un proyecto sobre democracia participativa, en el cual ésta era concebida como un instrumento para combatir las patologías del sistema político: "Ahora se busca superar la simple representación y, avanzando en la participación democrática, crear a través de ella un medio, entre otros, eficaz para superar el clientelismo y la corrupción en que ha caído gran parte de la administración" (Macedo Rizo, 2011).

Dicho proyecto proponía la creación de un artículo nuevo en el que se establecía que en cada municipio existiría un personero elegido por voto popular. Otros constituyentes ${ }^{15}$ estuvieron de acuerdo con el desarrollo de esta propuesta, e incluso impulsaron la elección popular de los representantes nacionales del Ministerio Público.

Dicha propuesta aludía a la idea de soberanía popular que primo en la ANC. La soberanía reside en el pueblo, y no en la Nación, como lo postulaba la Constitución de 1886. Por ello, argüían los constituyentes, si se entiende que el control fiscal se ejerce sobre los recursos

\footnotetext{
15 Antonio Yepes Parra, Guillermo Plazas Alcid y Antonio Galán Sarmiento.
} 
de la ciudadanía, ésta se convierte en titular del derecho y por ello se propone la elección directa con voto popular -y no delegataria- de los representantes del Ministerio Público, dado que las entidades que hacen parte de éste deben representar la voluntad popular de controlar los recursos del pueblo (Carreño Dueñas \& Valencia Villamizar, 2016).

Enrique Silva, doctrinante venezolano, señalaba que:

La Contraloría representa a la sociedad en cuanto que es ella, la titular de sus finanzas en último término, pues en principio lo son del Estado. Vela porque los recursos que le proporciona al Estado estén lo correctamente manejados. El Ministerio Público entonces actúa en función de la sociedad, como la Contraloría para velar porque sus intereses no estén comprometidos. La función fiscalizadora es al mismo tiempo una función de control, ésta es de la esencia y está íntimamente vinculada a un régimen democrático de gobierno. Un gasto no puede ejecutar daño al patrimonio público o perjudicar el interés legítimo de un particular. (Silva Cimma, 1976).

La función fiscalizadora es una función que emana del pueblo, dado que, según los ponentes de esta iniciativa, es éste quien está interesado en conocer si las rentas públicas y los bienes del Estado han sido administrados eficientemente. Por lo anterior, esa función fiscalizadora que emana del pueblo tiene que ser definida no por una democracia derivada, sino por una democracia directa. Con esta designación popular se evitaría la politización de la función fiscalizadora, y se obligaría a los funcionarios, al ser elegidos popularmente que respondan ante el pueblo por la moralidad pública, la eficacia y la eficiencia con que se están administrando los recursos.

La elección popular de los representantes del Ministerio Público se enmarcó en una narrativa que promovía dicho mecanismo como antítesis de la maquinaria de clientelización y politización que existía, dada la elección del Contralor que hacía la Cámara de Representantes, la cual había adoptado la nociva costumbre de elegir para ese cargo a uno de sus miembros.

Además de ese hábito instalado, la función eminentemente fiscalizadora que la Constitución y la ley le habían asignado a la Contraloría se había visto notoriamente cuestionada y deformada por el hecho de que el Contralor, elegido por el partido mayoritario, perteneciera a la misma filiación del jefe del Gobierno al cual debía fiscalizar. Por esta razón, algunos constituyentes $^{16}$ plantearon como conveniente y democrático que el Contralor fuera de filiación política distinta de la del Presidente de la República; es decir, que la función fiscalizadora estuviera en manos de la oposición. No obstante, la elección la podía hacer, según los ponentes, el Congreso o las altas cortes.

16 Hernando Herrera Vergara y Augusto Ramírez. 
La tercera propuesta ${ }^{17}$ fue aquella que signaba que al Contralor General y los Contralores Departamentales los debían elegir una corte de lo contencioso administrativo, de acuerdo a la jurisdicción territorial, bien sea esta el Consejo de Estado o el Tribunal Administrativo de cada departamento.

Finalmente, como cuarta iniciativa, se identificó aquella que promovía que el Congreso mantuviera la elección, pero que lo hiciera de una terna enviada por la rama judicial ${ }^{18} \mathrm{o}$ la ejecutiva.

Esta propuesta planteaba que esta designación debe pertenecer al Congreso porque es el supremo fiscalizador de las finanzas nacionales, $y$, por tanto, la potestad decisoria del Congreso debe estar matizada, obligándolo a que este organismo decida sobre una lista de candidatos, conformada por alguna otra instancia del Estado que garantice la independencia del Contralor.

Finalmente, quedó aprobado por 49 votos el inciso 5 del artículo 267 de la Constitución Política:

El Contralor será elegido por el Congreso en pleno en el primer mes de sus sesiones para un período igual al del Presidente de la República, de terna integrada por candidatos presentados a razón de uno por la Corte Constitucional, la Corte Suprema de Justicia y el Consejo de Estado, y no podrá ser reelegido para el período inmediato ni continuar en ejercicio de sus funciones al vencimiento del mismo. Quien haya ejercido en propiedad este cargo no podrá desempeñar empleo público alguno del orden nacional, salvo la docencia, ni aspirar a cargos de elección popular sino un año después de haber cesado en sus funciones.

De igual forma, se aprobó el artículo 272 de la Constitución que establece que:

Corresponde a las asambleas y a los concejos distritales y municipales (...) elegir contralor para período igual al del gobernador o alcalde, según el caso, de ternas integradas con dos candidatos presentados por el tribunal superior de distrito judicial y uno por el correspondiente tribunal de lo contencioso-administrativo.

Lo aprobado por la ANC buscó generar una relación y equilibrio entre las ramas del poder público. Sin embargo, la tesis de la democracia directa no fue acogida, y en los registros

17 Promovida por Iván Marulanda Gómez, Gustavo Zafra Roldan y Carlos Fernando Giraldo.

18 Luis Guillermo Nieto Roa; Jorge Humberto Botero, integrante de los gremios económicos y Álvaro Cala. 
de las actas de las sesiones no se encuentra mayor información sobre el porqué de su hundimiento.

El debate sobre la elección del Contralor continuó siendo objeto de modificaciones por parte del legislativo. En el año 2015, el Congreso de la República aprobó el acto legislativo 02/15 por medio del cual se adopta una reforma de equilibrio de poderes y reajuste institucional y se dictan otras disposiciones. En la exposición de motivos de esta norma se planteó que el mecanismo idóneo de elección de contralor debía ser a través de una convocatoria pública, con la finalidad de definir un número indeterminado de candidatos, siendo el Congreso quien elija al Contralor General de la República, “mediante un mecanismo prístino y coherente con las funciones de representación ciudadana que le atañen" (Bustos \& Reyes, 2014).

Se eliminó la postulación que hacían las altas cortes y los tribunales del distrito en los artículos 267 y 272, y este mecanismo fue sustituido por una lista de elegibles conformada por convocatoria pública. Así mismo, eliminó la prohibición de desempeñar empleo público durante el año posterior al mandato, y solo dejó la restricción de reelección.

En el primer debate dado en el Senado de la República se arguyó que la fórmula de elección que se propone, mezcla un elemento meritocrático y un elemento político, considerando así que la elección que hacia la rama judicial no permitía cumplir con la amplitud, la participación y la meritocracia.

Una de las propuestas fue que dicha convocatoria fuera realizada por la Comisión Nacional del Servicio Civil, no obstante, en el trámite de este Proyecto en la Cámara de Representantes se eliminó dicha disposición, dado que se consideró que el Congreso de la República tiene un poder derivado para controlar la manera como se dispone de los recursos del erario que tienen origen en los tributos que pagan sus contribuyentes. Para esta corporación, todo el proceso de elección de los contralores debe tener lugar al interior de los cuerpos colegiados correspondientes para que se preserve la independencia del Contralor respecto del ejecutivo quien es el llamado, de manera preferente, a ejecutar los recursos públicos. Por tanto, no resulta adecuado que sea una comisión que pertenece a la Rama del Poder Público respecto de la cual se va a ejercer la vigilancia fiscal, quien postule los candidatos para ocupar dicho cargo (Gaceta 694, 2014).

Así mismo, se planteó que entregar a la ciudadanía la posibilidad de encargarse de la función fiscal a través del proceso de convocatoria pública implicará que esta función se ejecute con rigurosidad y transparencia (Gaceta 585 y 602, 2014).

Finalmente, se aprobó la modificación del inciso quinto del artículo 267, el cual quedó así:

El Contralor será elegido por el Congreso en Pleno, por mayoría 
absoluta, en el primer mes de sus sesiones para un periodo igual al del Presidente de la República, de lista de elegibles conformada por convocatoria pública con base en lo dispuesto en el artículo 126 de la Constitución y no podrá ser reelegido ni continuar en ejercicio de sus funciones al vencimiento del mismo.

De igual forma, el cuarto inciso del artículo 267 quedó así:

Los Contralores departamentales, distritales y municipales serán elegidos por las Asambleas Departamentales, Concejos Municipales y Distritales, mediante convocatoria pública conforme a la ley, siguiendo los principios de transparencia, publicidad, objetividad, participación ciudadana y equidad de género, para periodo igual al del Gobernador o Alcalde, según el caso.

Este proceso de selección debía ser en todo caso regulado por una ley posterior que aprobara el Congreso de la República. Lo anterior no se dio hasta el mes de junio de 2018, en el cual se aprobó la Ley 1904.

Dicha Ley establece las reglas de la convocatoria pública previa a la elección del contralor general de la república. En el artículo 5 de dicha norma, se estableció que:

La Convocatoria Pública se hará por conducto de la Mesa Directiva del Congreso de la República, a la cual se faculta para seleccionar en el acto de convocatoria a una institución de educación superior, pública o privada y con acreditación de alta calidad, con quien se deberá suscribir contrato o convenio a fin de adelantar una convocatoria pública con quienes aspiren a ocupar el cargo.

La institución de educación superior debe diseñar y aplicar unas pruebas de conocimiento las cuales se dirigen a establecer la capacidad, idoneidad y aptitud del aspirante frente al cargo. Las temáticas a evaluar deben girar en torno a la Gerencia Pública, control fiscal, organización y funcionamiento de la Contraloría General de la República y las relaciones del ente de control y la administración pública.

El Acto Legislativo había ordenado que la lista de elegibles surgiera de una Convocatoria Pública reglada, no de un concurso público de méritos. Son constitucionalmente diferentes estas dos figuras. En el caso de la Convocatoria no existe un orden específico dentro de la lista, aunque esto no significa que el Congreso de la República tenga una absoluta discrecionalidad en la elección, sino que, por el contrario, debe hacerlo de conformidad con los resultados de la Convocatoria: la selección de los mejores candidatos para la provisión 
del cargo de Contralor General de la República (Gaceta 227, 2018).

Uno de los álgidos debates que se presentaron en la discusión del proyecto de ley fue precisamente la concepción de convocatoria pública y no de concurso. Sectores de la oposición e independientes, encabezados por el Polo Democrático Alternativo y la Alianza Verde, criticaron que la norma no modificara en lo sustancial el mecanismo de elección de contralor y personeros municipales, dado que la potestad sigue siendo del poder legislativo, el cual, según los críticos de esta iniciativa, práctica la máxima de "yo te elijo tú me cuidas".

A pesar de esta situación, la norma fue aprobada con la noción de convocatoria pública y se aplicó por primera vez en el mes de julio y agosto de 2018. Esta norma estableció en su artículo 11 que las mismas disposiciones contenidas en la ley serán aplicables en lo que correspondan a la elección de los contralores departamentales, distritales, y municipales, en tanto el Congreso de la República expida disposiciones para la materia.

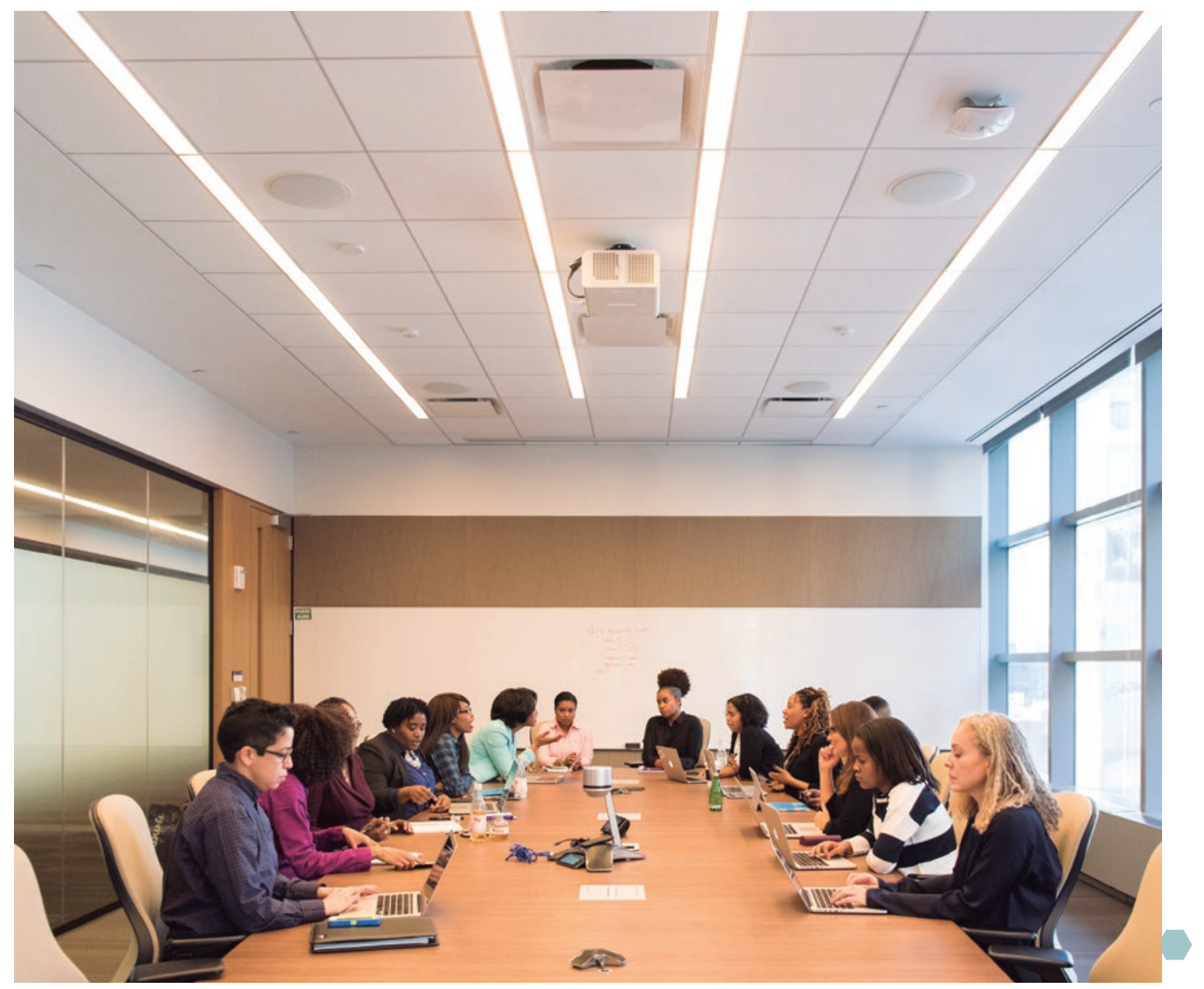




\begin{tabular}{|c|c|c|c|c|c|c|c|}
\hline \multicolumn{8}{|c|}{ Elección de altos designatarios del Estado Colombiano } \\
\hline \multirow{2}{*}{$\begin{array}{l}\text { Tipo de } \\
\text { Autoridad }\end{array}$} & \multirow{2}{*}{ Entidad } & \multirow{2}{*}{ Cargo (s) } & \multicolumn{3}{|c|}{ Elección } & \multirow{2}{*}{$\begin{array}{l}\text { Tipo de } \\
\text { periodo }\end{array}$} & \multirow{2}{*}{ Re-elección } \\
\hline & & & Paso 1 & Paso 2 & Paso 3 & & \\
\hline \multirow{3}{*}{$\begin{array}{c}\text { Órganos de } \\
\text { control }\end{array}$} & $\begin{array}{l}\text { Contraloría } \\
\text { General de la } \\
\text { República }\end{array}$ & $\begin{array}{c}\text { Contralor } \\
\text { General de } \\
\text { la República }\end{array}$ & $\begin{array}{c}\text { La Mesa } \\
\text { Directiva del } \\
\text { Congreso de } \\
\text { la República } \\
\text { realizará una } \\
\text { convocatoria } \\
\text { pública. }\end{array}$ & $\begin{array}{c}\text { Una institución } \\
\text { de educación } \\
\text { superior, con } \\
\text { acreditación } \\
\text { de alta calidad, } \\
\text { realizará una } \\
\text { prueba de } \\
\text { conocimiento } \\
\text { a los inscritos } \\
\text { de la } \\
\text { convocatoria. } \\
\text { Se pre- } \\
\text { seleccionarán a } \\
\text { los } 20 \text { mejores } \\
\text { aspirantes. }\end{array}$ & $\begin{array}{c}\text { Una Comisión } \\
\text { accidental del } \\
\text { Congreso elegirá } \\
\text { una lista de } \\
10 \text { elegibles. } \\
\text { Estos serán } \\
\text { escuchados } \\
\text { en plenaria } \\
\text { del Congreso. } \\
\text { Será elegida } \\
\text { una persona } \\
\text { por mayoría } \\
\text { absoluta. }\end{array}$ & $\begin{array}{l}\text { Periodo de } \\
4 \text { años, el } \\
\text { cual debe } \\
\text { coincidir } \\
\text { con el del } \\
\text { Presidente } \\
\text { de la } \\
\text { República }\end{array}$ & $\begin{array}{l}\text { No es } \\
\text { permitida } \\
\text { la relección } \\
\text { para el } \\
\text { periodo } \\
\text { inmediato. }\end{array}$ \\
\hline & $\begin{array}{l}\text { Procuraduría } \\
\text { General de la } \\
\text { Nación }\end{array}$ & $\begin{array}{l}\text { Procurador } \\
\text { General de } \\
\text { la Nación }\end{array}$ & $\begin{array}{l}\text { Se elaborará } \\
\text { una terna de un } \\
\text { candidato del } \\
\text { Presidente de } \\
\text { la República, } \\
\text { uno del Consejo } \\
\text { de Estado y } \\
\text { otro de la Corte } \\
\text { Suprema de } \\
\text { Justicia. Las } \\
\text { dos altas cortes } \\
\text { realizan una } \\
\text { convocatoria } \\
\text { pública y } \\
\text { realizan una } \\
\text { pre-selección } \\
\text { y entrevista, } \\
\text { y se elige por } \\
\text { votación el } \\
\text { candidato a } \\
\text { ternar. }\end{array}$ & $\begin{array}{l}\text { El Senado de } \\
\text { la República } \\
\text { realiza en } \\
\text { pleno un } \\
\text { proceso de } \\
\text { entrevista a los } \\
\text { tres ternados. }\end{array}$ & $\begin{array}{l}\text { Por mayoría } \\
\text { absoluta, el } \\
\text { Senado elige al } \\
\text { Procurador. }\end{array}$ & $\begin{array}{l}\text { Periodo de } \\
4 \text { años }\end{array}$ & $\begin{array}{c}\text { No puede } \\
\text { ser re- } \\
\text { elegido. }\end{array}$ \\
\hline & $\begin{array}{l}\text { Defensoría } \\
\text { del Pueblo }\end{array}$ & $\begin{array}{c}\text { Defensor del } \\
\text { Pueblo }\end{array}$ & $\begin{array}{l}\text { El presidente } \\
\text { de la República } \\
\text { presenta una } \\
\text { terna a la } \\
\text { Cámara de } \\
\text { Representantes }\end{array}$ & $\begin{array}{l}\text { La cámara de } \\
\text { representantes } \\
\text { realiza en } \\
\text { pleno una } \\
\text { audiencia } \\
\text { pública }\end{array}$ & $\begin{array}{l}\text { La Cámara de } \\
\text { Representantes } \\
\text { elige, por } \\
\text { mayoría } \\
\text { absoluta, al } \\
\text { Defensor del } \\
\text { Pueblo. }\end{array}$ & $\begin{array}{l}\text { Periodo de } \\
4 \text { años }\end{array}$ & $\begin{array}{c}\text { No puede } \\
\text { ser re- } \\
\text { elegido. }\end{array}$ \\
\hline
\end{tabular}




\begin{tabular}{|c|c|c|c|c|c|}
\hline \multirow{2}{*}{$\begin{array}{l}\text { Autoridades } \\
\text { electorales }\end{array}$} & $\begin{array}{l}\text { Registraduría } \\
\text { Nacional del } \\
\text { Estado Civil }\end{array}$ & $\begin{array}{l}\text { Registrador } \\
\text { Nacional del } \\
\text { Estado Civil }\end{array}$ & $\begin{array}{c}\text { Será escogido por los Presidentes de la Corte } \\
\text { Constitucional, la Corte Suprema de Justicia y el } \\
\text { Consejo de Estado, mediante concurso de méritos } \\
\text { organizado según la ley }\end{array}$ & $\begin{array}{l}\text { Periodo de } \\
4 \text { años }\end{array}$ & $\begin{array}{c}\text { No puede } \\
\text { ser re- } \\
\text { elegido. }\end{array}$ \\
\hline & $\begin{array}{l}\text { Consejo } \\
\text { Nacional } \\
\text { Electoral }\end{array}$ & $\begin{array}{c}9 \\
\text { magistrados }\end{array}$ & $\begin{array}{l}\text { Elegidos por el Congreso de la República en pleno, } \\
\text { mediante el Sistema de Cifra Repartidora, previa } \\
\text { postulación de los partidos o movimientos políticos } \\
\text { con Personería Jurídica o por coaliciones entre ellos }\end{array}$ & $\begin{array}{l}\text { Periodo de } \\
4 \text { años }\end{array}$ & $\begin{array}{c}\text { No puede } \\
\text { ser re- } \\
\text { elegido. }\end{array}$ \\
\hline
\end{tabular}

Fuente: Elaboración propia. Se tomó en cuenta la información proporcionada por Elección Visible (Elección Visible, n.d.). Sin embargo, se hizo un proceso de actualización de la información de acuerdo al Acto Legislativo 02 de 2015 y otras normas posteriores.

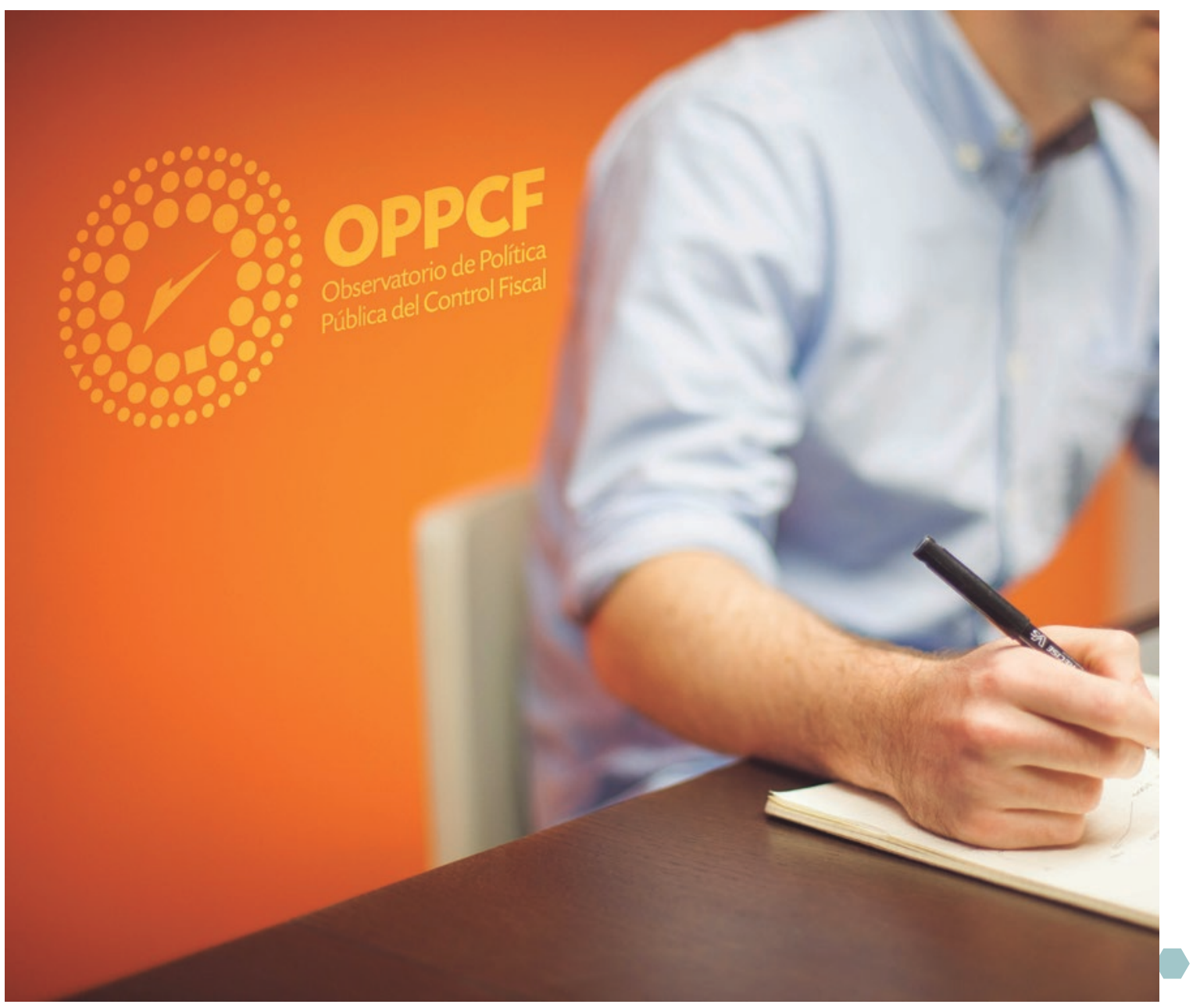




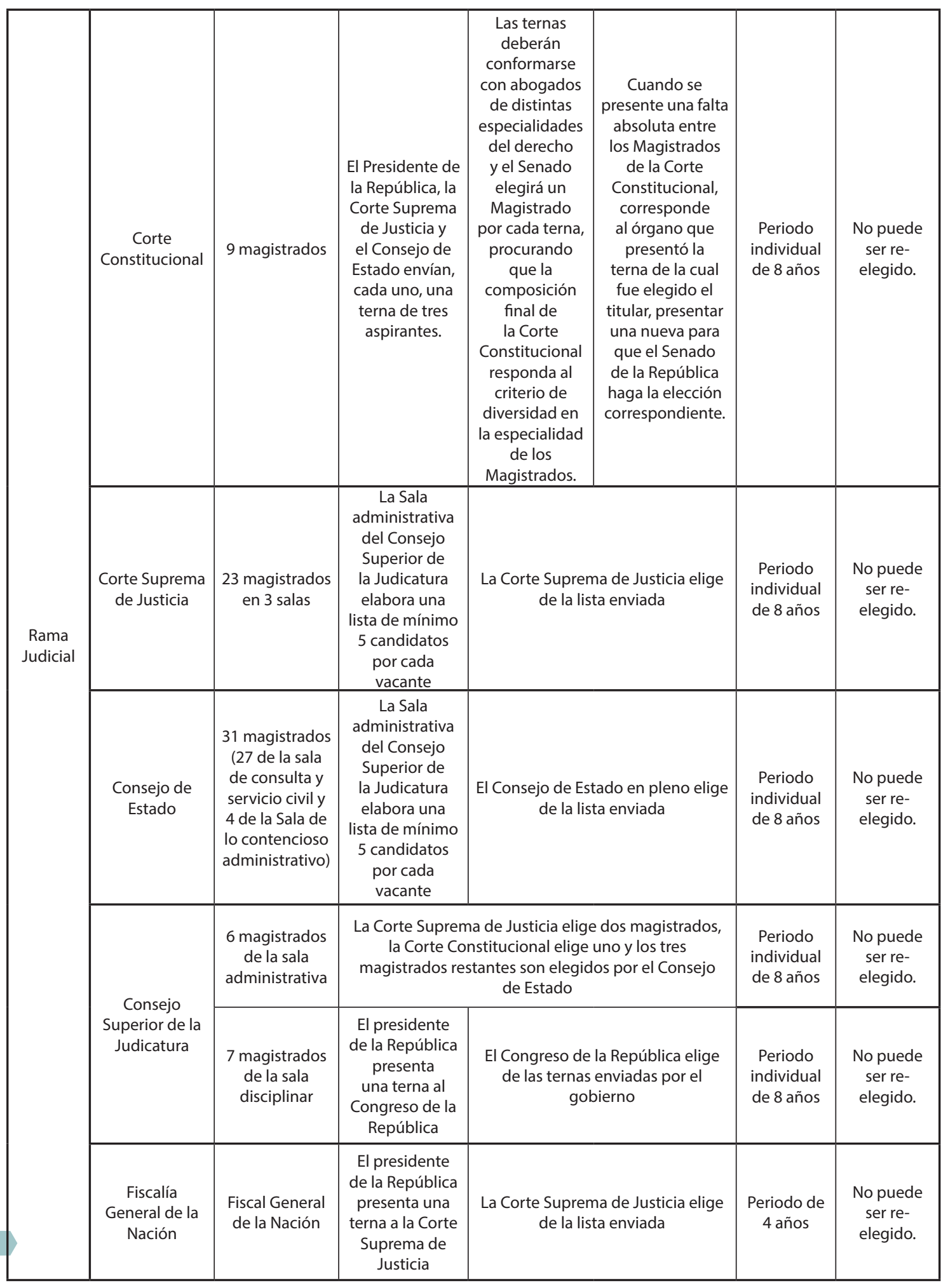




\section{Estructura y mandato del Control Fiscal}

Paralelamente a la discusión sobre la estructura del Estado y los mecanismos de elección que deberían aplicarse para los representantes del Ministerio Público y en especial de la rama de control fiscal, en la ANC se surtió un debate sobre la estructura y el mandato del control fiscal, en el cual se desarrollaron dos discusiones centrales que dieron lugar a la estructura actual de la rama de control fiscal.

La constitución de 1991 amplió de manera significativa el espectro del control fiscal en el país al establecer que la vigilancia fiscal se ejercerá no solamente sobre las entidades públicas, sino también sobre los particulares que manejen fondos o bienes de la nación y de las entidades territoriales (Obregón, 2006, pág. 20). Para llegar a esta conclusión se desarrollaron dos discusiones importantes.

\section{- Corte de Cuentas o Contraloría}

Las entidades fiscalizadoras superiores suelen tener tres modelos básicos de estructura: la corte de cuentas, como órgano colegiado del poder ejecutivo con estatus similar a la independencia de los jueces; la corte de cuentas como órgano colegiado del poder judicial u órgano autónomo de fiscalización; y el Contralor General, como órgano unipersonal ubicado formalmente en la órbita del poder legislativo (Galves, 2007, pág. 42).

En la ANC se discutió sobre la estructura que se debería implementar en el país. Por un lado, constituyentes como Carlos Noriega Rodado ${ }^{19}$ señalaron que una de sus preocupaciones de tener una contraloría unipersonal era que si el Contralor era del mismo partido político del Presidente de la República se tiene la tentación o la tendencia de convertirse en un cómplice, y si es de un partido contrario al del Presidente existiría la tendencia y la tentación de convertirse en un obstáculo de la gestión administrativa. Razón por la cual, para él, un cuerpo de tres o cinco personas, podría ayudar a equilibrar las tendencias políticas y optimizar así la función del control fiscal.

Por otro lado, constituyentes como Gustavo Zafra resaltaron que un Tribunal de Cuentas significaba incluir un mecanismo propio del sistema inquisitivo, dado que la propuesta implicaba que el organismo colegiado podía investigar y suspender funcionarios, es decir, investigar y juzgar, lo cual iba en contravía de la filosofía del proyecto constitucional de 1991, inspirado en el sistema acusatorio (Moya, 2008).

En Colombia se utilizó el sistema de Cortes de Cuentas desde la colonia y una vez obtenida la independencia se siguió utilizando el modelo durante casi un siglo. Posteriormente se creó la Contraloría, bajo el gobierno de Pedro Nel Ospina, mediante la Ley 42 de 1923.

19 De igual forma se pronunciaron los constituyentes Jaime Castro, Germán Rojas y Jesús Pérez. 
Esta Ley adoptó las recomendaciones de la misión Kemmerer, la cual se creó por orientación del Congreso de la República en 1.922. El gobierno contrató una misión de cinco técnicos financieros estadounidenses. La misión fue dirigida por Edwin Walter Kemmerer (Pennsylvania, junio 29 de 1875, Princeton New Jersey, diciembre 16 de 1945), de ahí su nombre, quien era economista y había sido previamente contratado por otros gobiernos de países del sur global para equilibrar sus manejos monetarios. Entre esos países se destaca su participación en Filipinas, México, Sudáfrica, Chile, Perú, Liberia, Guatemala, entre otros.

La misión estuvo en el país entre marzo y agosto de 1.923. Durante estos cinco meses se entrevistó con los representantes de distintas entidades nacionales, miembros de partidos políticos y voceros del sector financiero.

"Su tesis principal era el establecimiento del patrón oro en las economías, la organización de la banca central y el ordenamiento de un sistema apropiado de contabilidad y control fiscal" (Pavas, 2010, pág. 81). La misión presentó 10 proyectos de ley, de los cuales 8 fueron aprobados por el Congreso:

- Ley 20 de 1923, orgánica del papel sellado y del timbre nacional.

- Ley 25 de 1923, mediante la cual se creó el Banco de la República.

- Ley 31 de 1923, que fijaba el número y nomenclatura de los ministerios.

- L Ley 34 de 1923, sobre formación del presupuesto nacional.

- Ley 36 de 1923, sobre la administración y recaudo de rentas nacionales.

- L Ley 42 de 1923, sobre el Departamento de la Contraloría.

- Ley 45 de 1923, que originó la Superintendencia Bancaria.

- Ley 46 de 1923, sobre títulos negociables.

El control previo, fue considerado por la misión Kemmerer como un enfoque básico de control fiscal, a su vez que el control posterior. El primero perduró como único método durante casi 70 años. En el año de 1975, la Ley 20 dio origen a los controles previo, perceptivo y posterior (control numérico legal) (Pavas, 2010, pág. 84).

En su origen la Contraloría no fue un instrumento de lucha contra la corrupción sino de saneamiento de las finanzas públicas, las cuales se consideraban en desorden debido a la ausencia de una estructura institucional clara. A los 22 años de su creación, en la reforma de 1945, se le añadió la función del control fiscal y en la década de los setenta se le sumó el 
control previo (Cuervo, 2014).

En la Constitución de 1.991 se optó por continuar con el modelo de la Contraloría unipersonal, a pesar de que se presentó el debate de retornar a la corte de cuentas, la cual desarrollaría una función muy similar a la de un auditor externo frente a una empresa, haciendo énfasis en lo relativo al control de legalidad y de ejecución del presupuesto, a través de auditorías financieras.

El Gobierno Nacional, en cabeza de Cesar Gaviria, le propuso a la Asamblea Nacional Constituyente que la Contraloría General de la República fuera concebida como un organismo preponderantemente técnico, dedicado a un control de gestión y de resultados, y sin facultades para efectuar un control previo.

Sin embargo, el debate en la ANC sobre la estructura de la Controlaría no se centró precisamente en la idoneidad del mecanismo de acuerdo a las condiciones propias del sistema fiscal colombiano, sino a la cooptación política de las cuales era sujeto la entidad, especialmente en su orden territorial.

Por lo anterior, algunas de las propuestas tornaron hacia la eliminación de esta entidad, y unificar los organismos que realizan control en el país. Es así como Iván Gómez Martínez y Hernando Londoño, constituyentes del partido Conservador, propusieron crear un único órgano nacional de control, el cual realizara el ejercicio de unificar las diversas modalidades del control: disciplinario, judicial, fiscal y para los derechos humanos. Para ello, propusieron crear la Fiscalía General de la Nación, con autonomía administrativa y financiera. El Fiscal General de la Nación, según su propuesta, sería de elección popular. La Fiscalía subsumiría a tres instituciones de la época: la Procuraduría, la Contraloría y la Consejería para los derechos humanos (Londoño \& Gómez, 1991).

Las funciones del "Fiscal Contralor" propuestas fueron:

1. Vigilar la gestión propiamente fiscal de todas las autoridades centrales o descentralizadas del nivel nacional, así como de los particulares que administran bienes o recursos públicos;

2. Establecer los procedimientos para la rendición de cuentas por parte de los responsables del manejo de fondos públicos, de conformidad con la metodología y la contabilidad que elabore el Ministerio de Hacienda.

3. Exigir informes a los empleados públicos nacionales, civiles o militares, sobre su gestión fiscal, así como a los particulares que administran bienes o recursos públicos.

4. Revisar y fenecer las cuentas de los responsables del tesoro nacional, con posterioridad 
a la ejecución de los respectivos gastos.

5. Las demás que le asigne la ley.

La estructura propuesta por los signatarios del partido conservador consistía en un Fiscal Contralor en el nivel nacional, y fiscales departamentales y municipales en sus ámbitos especiales de competencia. El sistema de control fiscal sería único y exclusivamente posterior. El control será técnico y, por tanto, no impedirá el ejercicio de funciones administrativas, salvo las inherentes al servicio.

El control numérico legal, para los ponentes, aparte de las investigaciones y sanciones a que diere lugar, no sería sino un indicador del control de gestión y de resultados que los organismos de planeación respectivos realicen sobre el ente auditado. Si la asignación de recursos realizada conforme a la ley se declara como no eficiente ni eficaz por los organismos de planeación de cada nivel territorial, las autoridades ejecutivas respectivas deberán sancionar, corregir o suprimir al ente evaluado.

Por su parte los constituyentes Jaime Álvaro Fajardo y Darío Antonio Mejía, signatarios del movimiento Esperanza, Paz y Libertad (EPL), eran partidarios de la corte de cuentas. Para ellos, esta entidad sería la encargada del control de presupuesto de gastos e inversiones y demás actividades del Estado relacionadas con los planes de desarrollo económico y social, a su vez de vigilar la gestión fiscal de la administración. La Corte de Cuentas estaría conformada por cinco (5) magistrados elegidos por la Asamblea Legislativa y escogidos por listas que presente el Procurador General de la Nación, con un número no inferior a quince candidatos en donde se respete la composición de los partidos minoritarios de la Cámara.

Otras iniciativas que se encaminaban en esa propuesta, proponían que la Corte de Cuentas estuviese conformada por 9 magistrados elegidos por el Consejo de Estado por un período de 8 años, sin reelección. Las atribuciones de esta entidad eran:

1. Practicar el control presupuestario, financiero y de gestión de la administración en forma selectiva y posterior a la ejecución de las operaciones.

2. Prescribir los métodos de la contabilidad presupuestaria, patrimonial, y financiera de la administración, la manera de rendir cuentas los responsables del manejo de fondos o bienes nacionales, y dictar las normas concernientes al modo de ejercer la auditoría interna.

3. Revisar, fenecer las cuentas de los responsables del erario.

4. Examinar el control interno que ejerce la administración. 
5. Fallar, conforme lo señalará la ley, los casos de responsabilidad patrimonial derivada de la gestión fiscal. La Corte de Cuentas, según el procedimiento que establecerá la ley, tendrá jurisdicción coactiva para hacer efectiva dicha responsabilidad.

6. Auditar el informe anual sobre el Estado de los recursos públicos que presente el Gobierno a la Asamblea Nacional.

En el marco de la discusión, el contralor general de la época, Manuel Francisco Barrera, enunciaba que "no existe un antecedente en el mundo en que una Contraloría General se haya convertido en un corte de cuentas, en cambio en todas partes del mundo hay una tendencia general de transformar las cortes de cuentas en contralorías u auditorías" (Informe de la sesión de la comisión segunda del día 11 de marzo de 1991).

En la historia del control fiscal existen dos ejemplos paradigmáticos de la Corte de Cuentas. El primer es el francés, el cual se caracteriza por estar ubicado en la órbita del poder ejecutivo, y tiene estatus y garantías de independencia similar al de los jueves. El segundo es el alemán y español, el cual funciona como un órgano colegiado unipersonal, se encuentra ubicado en la órbita del poder judicial y tiene la condición de ser un órgano autónomo de fiscalización.

Por su parte, la figura unipersonal del contralor se ha ubicado, históricamente, en el poder legislativo. Ha sido un auxiliar o una extensión de este poder, de quien emana constitucionalmente la función del control fiscal. Los dos modelos más conocidos son los desarrollados por los países norteamericanos: Estados Unidos y Canadá (Galves, 2007, pág. 42).

Finalmente, en sesión del 13 de mayo de 1.991 de la Comisión Quinta, se votó la estructura de la entidad rectora del control fiscal. Siete personas votaron a favor de la sustitutiva de Corte de Cuentas, diez en contra de la misma figura y diez a favor de la estructura del contralor.

No obstante, a la Contraloría se le atribuyo la función de establecer la responsabilidad derivada de la gestión fiscal (artículo 268 de la C.P.), creando así un sincretismo entre la Corte de Cuentas y la figura unipersonal. Sin embargo, esta facultad está limitada en las funciones sancionatorias.

La Contraloría se convirtió en un mecanismo de control posterior que buscaba asegurar la eficiencia, la eficacia, la economía y la valoración de los costos ambientales de la inversión pública. Como dijo Cuervo (2014), la contraloría pasó de ser un ente de control sobre las finanzas públicas a ser un mecanismo de lucha contra la corrupción.

\section{- Control posterior, selectivo y de resultados}


Una de las debilidades del control fiscal en Colombia, según los delegados de la ANC, era la coadministración que existía en el país en cabeza de la auditoría. Esta se debía, según los ponentes por la existencia del control fiscal previo. Razón por la cual, uno de los principios de la Carta Política es que la Contraloría no "tendrá funciones administrativas distintas a las inherentes a su propia organización".

Los constituyentes decidieron excluir la figura del control previo, la cual se aplicaba desde 1.886, por considerarla ineficaz y nociva, dado que se convirtió en un sistema de coadministración arbitraria.

La Comisión Tercera no tardó mucho en decidir que el control fiscal debía ser posterior y selectivo. Esto implicó abandonar el modelo de control previo que se había desarrollado en el país desde la segunda década del siglo XX. Según el poder constituyente:

El control previo, generalizado en Colombia, ha sido funesto para la administración pública pues ha desvirtuado el objetivo de la Contraloría al permitirle ejercer abusivamente una cierta coadministración que ha redundado en un gran poder unipersonal del contralor y se ha prestado también para una engorrosa tramitomanía que degenera en corruptelas (Noriega, González, \& Herrán, 1991).

138 El cambio hacia un modelo de control posterior, también implicaba, según unos constituyentes, avanzar hacia el control de resultados, atendiendo a la necesidad de garantizar el logro de los resultados que la sociedad debe obtener de la utilización de los recursos estatales. No obstante, esta decisión no fue exenta de la discusión y problematización por la Asamblea.

Un ejemplo de ello fue la propuesta de crear un departamento nacional de control resultados impulsada por Pérez González Rubio. Para él el control fiscal y el control de resultados no deben estar a cargo de la misma institución y menos de la contraloría, pues se consideraba una entidad burocratizada, y con una mentalidad procedimental y no de resultados.

El constituyente propuso crear el sistema de Control de Resultados de la Administración Pública Nacional, cuyo objetivo fuese vigilar el cumplimiento del plan de desarrollo económico y social, de obras públicas y de la Administración de Justicia, así como sus programas y proyectos, y verificar los avances y resultados de los mismos en términos de tiempo, costos y prioridades. Para la administración de ese sistema, propuso crear el Departamento Nacional de Control de Resultados como organismo del Estado, de naturaleza jurídica especial.

Este departamento se pensó como una institución por lo menos de tanta jerarquía como la de la Procuraduría o la Contraloría actual. Para González Rubio el control fiscal y el control de resultados no deben estar a cargo de la misma institución y menos aún de la 
contraloría actual, dado que era una entidad, según él, burocratizada y con una mentalidad procedimental y de no resultados.

El control fiscal es muy distinto del control de resultados. El control fiscal refiere al presupuesto, se refiere a sí el funcionario correspondiente encuadra sus gastos dentro del marco de autorizaciones que en otra cosa es el presupuesto aprobado por el Congreso, y así verificará si existe un crédito para determinado objetivo y verificará si la partida todavía alcanza para ejecutar el gasto, es lo que se conoce como el control numérico legal. El control de resultados, por el contrario, hace referencia a las acciones de la administración, a los planes y programas de desarrollo y contrasta los recursos con los resultados obtenidos y los resultados obtenidos con los objetivos y las metas preestablecidas de manera que estamos hablando de cosas que dé común solo tienen la palabra control, fuera de eso no tienen en común absolutamente nada, (...) creo que sería un grandísimo error, un error que probablemente si esta Constitución lo llegará a cometer, no se lo perdonaría en el futuro, pretender entregarle un instrumento nuevo de tanta importancia para lograr la eficiencia del Estado a una institución burocratizada, clientelizada, unos funcionarios que tienen una manera de actuar y una mentalidad determinada, eso es un nicho de clientelismo y vamos a esterilizar ese instrumento formidable del control de resultados (Informe de la sesión de la Comisión Quinta, 1991, pág. 23).

No obstante, el constituyente Alfonso Palacio Rudas consideró que no era conveniente una iniciativa de este alcance, en razón de que estas funciones debían integrarse con las competencias del control fiscal.

De igual forma se pronunció Zafra Roldan:

Solo tengo observaciones digamos tangenciales sobre el sistema de control de resultados que se le asigna a Planeación Nacional pues lo que va a hacer es congestionar aún más a Planeación Nacional. Uno quiere una Planeación Nacional diseñando el futuro del país, pensando diez años hacia adelante y no revisando y auditando como se cumplieron los presupuestos de todo el país como aparentemente se diseña aquí. Por lo demás, eso es una función de la Contraloría. Si estamos fortaleciendo la Contraloría, si la estamos llevando a control posterior y de resultados, pues yo no veo por qué se le va a quitar esa función desarticulando el ente de control (Informe de la sesión plenaria del día 17 de junio, 1991, pág. 80).

Finalmente, los constituyentes optaron por incluir el control de resultados dentro de la rama de control fiscal, atendiendo a que esta función no implicaba sólo la revisión de la no malversación de los recursos, sino que su utilización sea, según los principios de economía, eficiente y eficaz. 
El control previo y perceptivo fue reemplazado por el posterior y selectivo, que comprende: un control financiero, de gestión y de resultados, basado en la eficiencia, la economía, la equidad y la valoración de los costos ambientales. Esta función se desarrolla en los artículos 267 y 272 de la Constitución Política.

El ejercicio del control fiscal en Colombia, según la Ley 42 de 1993, que desarrolla los principios establecidos en la Constitución Política, debe determinar en la administración, en un período determinado, que la asignación de recursos sea la más conveniente para maximizar sus resultados; que en igualdad de condiciones de calidad los bienes y servicios se obtengan al menor costo; que sus resultados se logren de manera oportuna y guarden relación con sus objetivos y metas. Así mismo, que permita identificar los receptores de la acción económica y analizar la distribución de costos y beneficios entre sectores económicos y sociales y entre entidades territoriales y cuantificar el impacto por el uso o deterioro de los recursos naturales y el medio ambiente y evaluar la gestión de protección, conservación, uso y explotación de los mismos.

De forma ilustrada, se puede analizar las funciones de los organismos de control fiscal en otros países de América Latina en la siguiente ilustración

\begin{tabular}{|l|l|}
\hline PAÍS & ATRIBUCIONES DE LA CONTRALORÍA GENERAL \\
\hline Argentina & $\begin{array}{l}\text { Tendrá a su cargo el control de legalidad, gestión y auditoria de toda } \\
\text { la actividad de la administración pública centralizada y descentralizada, } \\
\text { cualquiera fuera su modalidad de organización, y las demás funciones } \\
\text { que la ley le otorgue. Intervendrá necesariamente en el trámite de } \\
\text { aprobación o rechazo de las cuentas de percepción e inversión de los } \\
\text { fondos públicos (artículo 85). }\end{array}$ \\
\hline Bolivia & $\begin{array}{l}\text { Tendrá el control fiscal sobre las operaciones de entidades autónomas, } \\
\text { autárquicas y sociedades de economía mixta. La gestión anual será } \\
\text { sometida a revisiones de auditoría especializada. Anualmente publicará } \\
\text { memorias y estados demostrativos de su situación financiera y rendirá las } \\
\text { cuentas que señala la ley. El Poder Legislativo mediante sus Comisiones } \\
\text { tendrá amplia facultad de fiscalización de dichas entidades (artículo } \\
\text { 155). }\end{array}$ \\
\hline
\end{tabular}




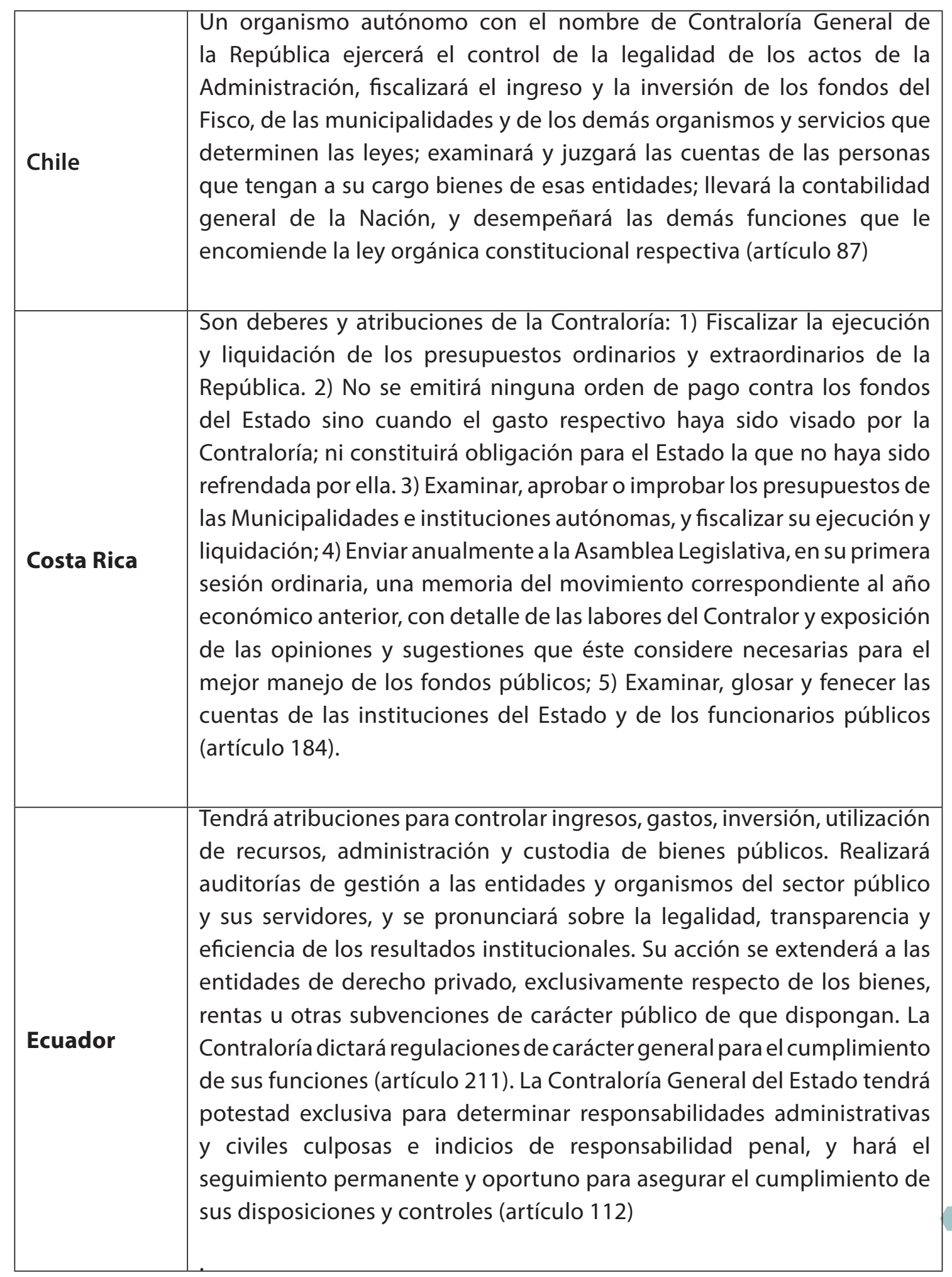




\begin{tabular}{|c|c|}
\hline Perú & $\begin{array}{l}\text { La Contraloría General de la República es una entidad descentralizada } \\
\text { de Derecho Público que goza de autonomía conforme a su ley orgánica. } \\
\text { Es el órgano superior del Sistema Nacional de Control. Supervisa la } \\
\text { legalidad de la ejecución del Presupuesto del Estado, de las operaciones } \\
\text { de la deuda pública y de los actos de las instituciones sujetas a control } \\
\text { (artículo 82). }\end{array}$ \\
\hline Venezuela & $\begin{array}{l}\text { La Contraloría General de la República es elórgano de control, vigilancia y } \\
\text { fiscalización de los ingresos, gastos, bienes públicos y bienes nacionales, } \\
\text { así como de las operaciones relativas a los mismos. Goza de autonomía } \\
\text { funcional, administrativa y organizativa, y orienta su actuación a } \\
\text { las funciones de inspección de los organismos y entidades sujetas } \\
\text { a su control. Sus atribuciones son: 1) Ejercer el control, la vigilancia y } \\
\text { fiscalización de los ingresos, gastos y bienes públicos, así como las } \\
\text { operaciones relativas a los mismos, sin perjuicio de las facultades que } \\
\text { se atribuyan a otros órganos en el caso de los Estados y Municipios, de } \\
\text { conformidad con la ley; } 2 \text { ) Controlar la deuda pública, sin perjuicio de } \\
\text { las facultades que se atribuyan a otros órganos en el caso de los Estados } \\
\text { y Municipios, de conformidad con la ley; } 3 \text { ) Inspeccionar y fiscalizar los } \\
\text { órganos, entidades y personas jurídicas del sector público sometidos a } \\
\text { su control; practicar fiscalizaciones, disponer el inicio de investigaciones } \\
\text { sobre irregularidades contra el patrimonio público, así como dictar las } \\
\text { medidas, imponer los reparos y aplicar las sanciones administrativas a } \\
\text { que haya lugar de conformidad con la ley; } 4 \text { ) Instar al Fiscal o Fiscala y } \\
\text { al Procurador o Procuradora General de la República a que ejerzan las } \\
\text { acciones judiciales a que hubiere lugar con motivo de las infracciones } \\
\text { y delitos cometidos contra el patrimonio público y de los cuales tenga } \\
\text { conocimiento en el ejercicio de sus atribuciones; 5) Ejercer el control } \\
\text { de gestión y evaluar el cumplimiento y resultado de las decisiones y } \\
\text { políticas públicas de los órganos, entidades y personas jurídicas del } \\
\text { sector público sujetos a su control, relacionadas con sus ingresos, gastos } \\
\text { y bienes. }\end{array}$ \\
\hline
\end{tabular}

Fuente: Elaboración propia a partir de la información proporcionada por la Base de datos políticos de las Américas (1998), en su publicación: Atribuciones de la Contraloría General. Análisis comparativo de constituciones de los regímenes presidenciales. 


\section{El control fiscal de las entidades territoriales}

El debate sobre el control fiscal en los territorios se vio permeado por las discusiones alrededor de la corrupción y el clientelismo. En la constituyente se cuestionó la descentralización del control fiscal como un elemento asociado a mayor riesgo de corrupción. Las contralorías departamentales eran percibidas por la opinión pública como escenarios de cooptación de las clientelas políticas regionales. Por ello se propuso la privatización de la función pública del control fiscal en los territorios.

Varios constituyentes, liderados por Luis Guillermo Nieto Roa, propusieran que la vigilancia de la gestión fiscal de la administración se hiciera por empresas privadas especializadas en auditoría y revisoría fiscal, bajo la inspección y vigilancia de la Contraloría General de la República.Como complemento a esta iniciativa, Gustavo Zafra Roldan propuso la contratación de auditores externos, seleccionados por los Tribunales Administrativos, previo registro técnico de personas jurídicas y naturales dedicados al técnico de auditoría. Paralelamente a este mecanismo se permitiría a los Colegios de Profesionales, las Universidades y la Comunidad organizada ejercer también estos controles sociales. Este esquema, según Zafra, permitiría eliminar las Contralorías Departamentales a partir de 1.993.

No obstante, dicha propuesta no fue acogida por la mayoría de la Asamblea, en parte por el argumento esgrimido por la Alianza Democrática M19, quienes señalaban que de esta medida se verían beneficiadas las grandes corporaciones internacionales de auditaje, lo cual afectaría la autonomía y soberanía nacional.

En contrapartida a esta propuesta se impulsó la creación de mecanismos de control que no fueran en contravía de la autonomía de las entidades territoriales, la cual no es ilimitada. Por ello, se consideró que debía existir prevalencia del control fiscal por parte de la Contraloría General de la República en aras de garantizar el adecuado rendimiento de los bienes e ingresos de la nación, pero las entidades y sus cuerpos parlamentarios, como lo son las asambleas, podrían actuar también sobre el control de los recursos que los mismos territorios producen.

Antonio Yepes Parra propuso que los concejos de los municipios cuyo presupuesto anual sea superior a ciento cincuenta millones de pesos, sin incluir el valor de los recursos del crédito ni las transferencias que reciba de la Nación, ni del Departamento, pudiesen crear y organizar contralorías que tengan a su cargo la vigilancia de la gestión fiscal de la respectiva administración. Dentro de la competencia territorial que le corresponde a las Contralorías General de la República, a las Departamentales, Intendenciales, Municipales y Distritales, éstas tendrían, además de las que le asigne la ley, las Ordenanzas y los Acuerdos, ejercer el control sobre la deuda pública y prescribir los métodos de contabilidad de la administración 


\section{OPPCF}

y la forma de rendir las cuentas los responsables del manejo del erario público.

Las Contralorías Departamentales y Distritos Especiales, según la propuesta de Yepes Parra, deberían ser organizadas como entes independientes con personería jurídica y autonomía presupuestal y financiera.

La ANC consideró imperante crear un sistema unificado de control fiscal, en el cual las entidades territoriales puedan ejercer su propio control fiscal, el cual es posterior, de resultados y orientado a la verificación de la eficiencia, la eficacia y la economía en el manejo de los recursos públicos. Para ello, las contralorías de las entidades territoriales no desempeñan funciones administrativas distintas a las inherentes a su propia organización.

Con la discusión dada por el constituyente, y su posterior aprobación, se definió que la Contraloría General de la República realiza un control de excepción sobre los dineros transferidos por la Nación a cualquier título a las entidades territoriales, teniendo en cuenta que este es un órgano superior de control fiscal del Estado y por tanto, los recursos que son transferidos, a pesar de que ingresan al presupuesto de las entidades territoriales, provienen de la nación y su destino no deja de ser inherente a la finalidad del Estado. (Sentencia C-403, 1999).

144 Por su parte, las contralorías de las entidades territoriales deberán hacer el control fiscal de los recursos que generen las propias entidades, los cuales provienen por la explotación de los bienes de su propiedad, entre otras fuentes (Sentencia C-290, 2002).

\section{El control del control: el espíritu de la Auditoría General de la República}

A pesar de que se consideró la Auditoría General de la República como una entidad innovadora en el ordenamiento interno colombiano producto de la ANC de 1991, lo cierto es que cuando se estableció la ley 20 de 1975 se definió la creación de dicha figura. No obstante, nunca se implementó.

Los constituyentes Palacio Rudas y Luis Guillermo Nieto Roa propusieron que la vigilancia de la gestión fiscal de la Contraloría General de la República fuera ejercida por un Auditor, elegido para periodos de dos años por el Consejo de Estado de terna enviada por la Corte Suprema de Justicia. Este artículo fue aprobado por la ANC.

La Auditoría General realizaría un control fiscal de segundo nivel sobre la gestión fiscal de las contralorías del país, pues éstas últimas no eran controladas por nadie. Así mismo, se le facultó para hacer el control correspondiente a la Contraloría General.

Causa sorpresa el periodo dispuesto para el Auditor de dos años, el cual resulta incompatible con los otros cargos de la rama de control fiscal. Al respecto, en las actas de la ANC no se 
encontró información que pudiera dar cuenta del debate dado sobre este asunto.

No obstante, haciendo un análisis de toda la información recolectada, se podría prever que esta situación se debe a un interés no expreso por parte de los sectores políticos, de no generar una carga de pesos al Contralor, reviviendo así, el fantasma de la clientelización y corrupción ligada a la Contraloría en su ordenamiento nacional y territorial.

Los vacíos que sobre la Auditoría General existen en la norma constitucional, implicó que sus desarrollos normativos y misionales fuesen abordados y debatidos de manera posterior en las normas y decretos que la desarrollan, así como en la jurisprudencia que sobre su funcionamiento ha elaborado la Corte Constitucional. Precisamente, según esta alta Corte, la vigilancia de la gestión fiscal de la Contraloría General de la República por parte del auditor, debe producirse con la misma intensidad y de conformidad con los mismos principios que regulan el control fiscal que la Contraloría General de la República realiza frente a las restantes entidades y organismos del Estado. Es por lo anterior que la Auditoría debe contar con todas las garantías de "autonomía que el Estatuto Superior depara a los órganos que llevan a cabo la vigilancia de la gestión fiscal en Colombia para la realización de sus funciones" (Sentencia C-1339, 2000). Esta autonomía debe ser administrativa, presupuestal y jurídica.

Replicando las funciones que el constituyente le otorgó a la Contraloría, la Auditoría según la interpretación de la carta magna debe comprender, además del control numérico legal, la evaluación de la gestión y los resultados de la actividad fiscal que desarrollan las contralorías.

\section{Referencias bibliográficas}

Acta de la Federación de las Provincias Unidas de Nueva Granada. (27 de noviembre de 1811). Nueva Granada. Obtenido de https://bit.ly/2NFluhC

Asamblea Nacional Constituyente. (1991). Gaceta Constitucional NQ 53.

Asamblea Nacional Constituyente. (9 de mayo de 1991). Informe de la sesión de la Comisión Quinta. Gaceta Constitucional. Colombia.

Asamblea Nacional Constituyente. (5 de junio de 1991). Informe de la sesión de la comisión segunda del día 11 de marzo de 1991. Gaceta Constitucional. Bogotá, Colombia.

Asamblea Nacional Constituyente. (17 de junio de 1991). Informe de la sesión plenaria del día 17 de junio. Gaceta Constitucional. Bogotá, Colombia.

Base de datos políticos de las Américas. (1998). Atribuciones de la Contraloría General. Análisis comparativo de constituciones de los regímenes presidenciales. Georgetown University y Organización de Estados Americanos. 
Bustos, J., \& Reyes, Y. (3 de septiembre de 2014). Exposición de motivos del acto legislativo 2 de 2015. Gaceta 458/14. Colombia.

Carreño Dueñas, D., \& Valencia Villamizar, D. (2016). Historiografía, persona y nación. Bogotá: Universidad Santo Tomás.

Castro, B., Andrés, C., \& Moya Vargas, M. F. (2015). Democracia y libertad de expresión. En C. \&. Bernal Castro, Libertad de expresión y proceso penal. Bogotá: Universidad Católica de Colombia.

Constitución de 1821. (30 de agosto de 1821). Villa del Rosario de Cúcuta. Obtenido de https://bit.ly/2uNkvq6

Constitución de Cundinamarca. (30 de marzo de 1811). Santa fe de Bogotá. Obtenido de https://bit.ly/2Oh8pNZ

Constitución de la República de Nueva Granada de 1843. (8 de mayo de 1843). Bogotá, Nueva Granda. Obtenido de https://bit.ly/2Ogl03X

Constitución de la República de Tunja. (9 de diciembre de 1811). de la transformación política del nuevo reyno de granada. Santa fe de Bogotá, Nueva Granada: Imprenta de don Bruno

146 Espinosa. Obtenido de https://bit.ly/2LIPOgQ

Constitución Política de 1810. (15 de agosto de 1810). Acta de la constitución del estado libre e independiente del Socorro. Colombia: Ministerio de Justicia. Obtenido de https://bit. ly/2mlh4MD

Constitución Política de Colombia. (4 de agosto de 1886). Bogotá, Colombia. Obtenido de https://bit.ly/1KkkXcB

Constitución Política de la Nueva Granada. (20 de mayo de 1853). Bogotá, Nueva Granada. Obtenido de https://bit.ly/2JU2Cup

Constitución Política de los Estados Unidos de Colombia. (8 de mayo de 1863). Rionegro, Estados Unidos de Colombia. Obtenido de https://bit.ly/2f3FgFM

Constitución política del Estado de Nueva Granada de 1832. (1 de marzo de 1832). Bogotá, Nueva Granada. Obtenido de https://bit.ly/2mL9qBq

Constitución Política para la Confederación Granadina. (22 de mayo de 1858). Bogotá, Nueva Granada. Obtenido de https://bit.ly/2uNhRjM

Cuervo, I. (2014). Contraloría: reformarla o cerrarla. Razón Pública. Obtenido de https://bit. 


\section{ly/2LTTxTh}

Echavarría, J. J. (1981). Sobre el principio de la separación de poderes. Revista de Estudios Políticos(24), 215 - 234.

Elección Visible. (n.d.). Elección Visible. Obtenido de www.eleccionvisible.com/files/EVElecciones_altos_dignatarios.pdf

Galves, R. (2007). Eficacia del control fiscal en Colombia: derecho comparado, historia, macroorganizaciones e instituciones. Bogotá: Universidad del Rosario.

Informe de ponencia para primer debate al proyecto de acto legislativo 153 de 2014 cámara. (10 de octubre de 2014). Gaceta 694. Colombia.

Informe de Ponencia para primer debate al Proyecto De Ley 211 De 2018 Senado, 232 De 2018 Cámara. (8 de mayo de 2018). Gaceta del congreso 227. Colombia: Imprenta Nacional.

Jaime, A., \& Esguerra, J. (8 de marzo de 1991). Proyecto de Acto Reformatorio de la Constitución Política de Colombia No. 73. Democracia Participativa. Bogotá: Asamblea Nacional Constituyente.

Londoño, H., \& Gómez, I. (14 de febrero de 1991). Proyecto de articulado para una Constitución Política de Colombia. Asamblea Nacional Constituyente(Gaceta No. 9). Bogotá, Colombia.

Macedo Rizo, M. (2011). La participación ciudadana en la Constitución del 91 Citizen participation in Constitution 1991. Pensamiento jurídico(30), 129 - 160.

Moya, M. F. (2008). La transvaluación: su posibilidad como categoría de análisis en la investigación sociojurídica. Novum Jus: Revista Especializada en Sociología Jurídica y Política, 2(1), 33-68.

Múnera Ruíz, L. (2005). Poder (trayectorias teóricas de un concepto). Colombia internacional(62), 32 - 49.

Noriega, C., González, J., \& Herrán, H. (18 de abril de 1991). Informe de la comisión quinta de hacienda pública y presupuesto. Gaceta constitucional. Bogotá.

Obregón, C. (2006). Control fiscal territorial: fundamentos de reforma. Bogotá: Universidad del Rosario.

Pavas, D. (2010). La Misión Kemmerer y el control estatal. Apuntes contables(12), 79 - 90.

Ponencia segundo debate, segunda vuelta, al proyecto de acto legislativo 153 de 2014 cámara, 18 de 2014 senado. (2014). Gaceta 585 y 602. Colombia. 
Sachica, L. (1987). Constitución Política de Colombia. Medellin: Biblioteca jurídica Dike.

Sánchez, T., López, C., Peña, E., \& Aldana, D. (2006). Control fiscal territorial. Diagnóstico y perspectivas. Estudios Socio-Jurídicos,, 8(2), 44-84.

Sentencia C-1339 (Corte Constitucional 4 de octubre de 2000).

Sentencia C-290 (Corte Constitucional 23 de abril de 2002).

Sentencia C-403 (Corte Constitucional 29 de junio de 1999).

Sentencia C563 (Corte Constitucional de Colombia 7 de octubre de 1998).

Silva Cimma, E. (1976). El Control Político, filosofía -principios. Caracas: Contraloría General de la Republica de Venezuela.

Uprimmy, R. (2011). Las trasformaciones constitucionales recientes en América Latina: tendencias y desafíos. En C. Rdriguez Garavito, El derecho en América Latina, un mapa para el pensamiento jurídico del siglo XXI. Buenos Aires: Siglo XXI Ed. .

Vibert, F. (2007). The rise of the unelected: democracy and the de separation of powers (Vol. 3). Cambridge University Press.

Vile, M. J. (2012). Constitutionalism and the separation of powers. Indianapolis: Liberty Fund.

Vitale, E. (2007). Hobbes y la teoría del Estado moderno. La lectura de Bobbio. Isegoría(36), $105-124$.

Wehner, J. (2010). Legislatures and the budget process: the myth of fiscal control. Palgrave Macmillan.

Yepes Parra, A. (7 de marzo de 1991). Proyecto de reforma constitucional. Asamblea Nacional Constituyente(Acta 48). Bogotá, Colombia. 


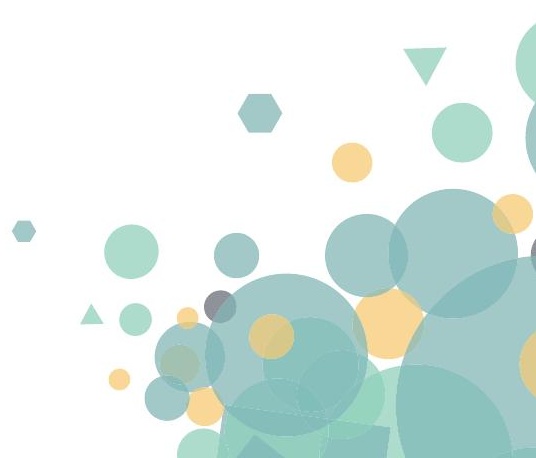




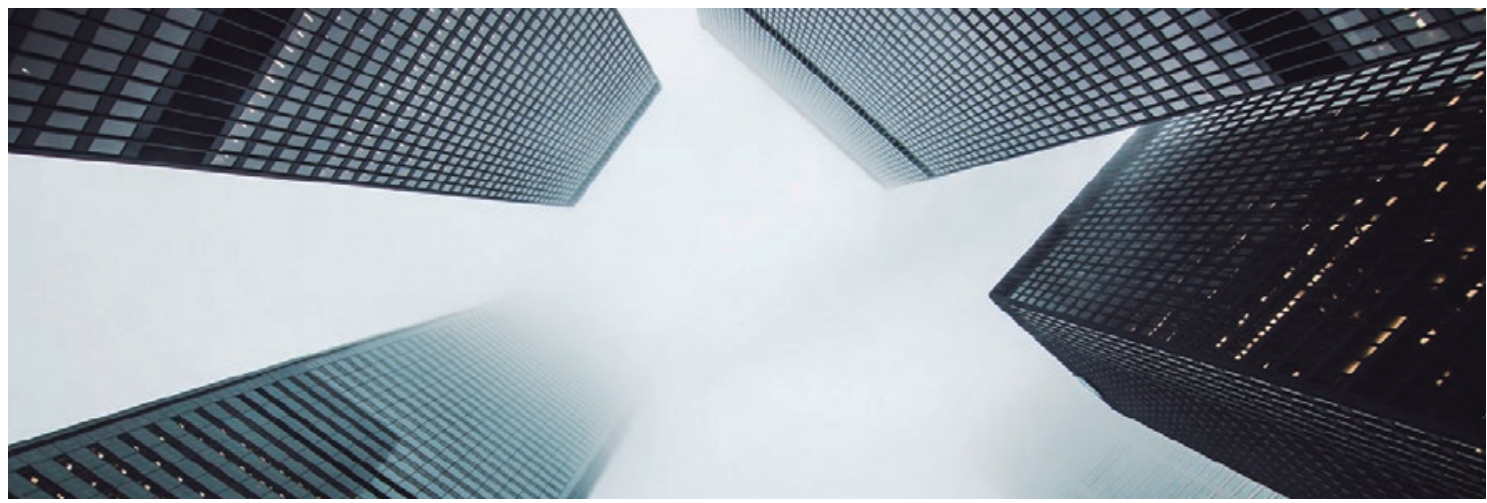

\section{CAPÍTULO V}

\section{LEGISLACIÓN INTERNACIONAL EN MATERIA DE CONTROL INTERNO Y FISCAL - INTOSAI}

\section{INTERNATIONAL ESTANDARS: THE TERMS OF INTERNAL AND FISCAL CONTROL - INTOSAI}

\section{DIANA MAITE BAYONA ARISTIZABAL ${ }^{20}$}

SUMARIO: 1. INTRODUCCIÓN. 2. NORMAS DE CONTROL INTERNO. 2.1. Generales. 2.2. Específicas. 3. CONTROL INTERNO. 3.1. Componentes del control interno. 3.2. Actividades de control. 4. ESTRUCTURAS. 5. AUDITORÍA INTERNA. 6. AUDITORÍA EN EL SECTOR PÚBLICO 7.. AUDITORÍA FINANCIERA DEL SECTOR PÚBLICO. 8. CONCLUSIONES. 9. BIBLIOGRAFÍA.

SUMMARY. 1. INTRODUCTION. 2. INTERNAL CONTROL STANDARS. 2.1. Generals. 2.2. Specific. 3. INTERNAL CONTROL. 3.1. Components of the internal control 3.2. Internal control activities 4. ESTRUCTURES. 5. INTERNAL AUDITING. 6. PUBLIC-SECTOR AUDITING. 7. FINANCIAL AUDITING IN THE PUBLIC-SECTOR. 8. CONCLUSIONS. 9. BIBLIOGRAPHY.

Resumen: El presente capítulo pretende abordar los estándares internacionales producidos por la Organización Internacional de Instituciones Fiscalizadoras superiores (INTOSAI), conocida como una organización no gubernamental con un status especial con el Consejo Económico y Social de las Naciones Unidas, autónomo, independiente y apolítico que

20 Abogada, especialista en ciencias penales y criminológicas de la Universidad Externado de Colombia. Investigadora la Universidad Santo Tomás de Bogotá. Proyecto vinculado en las líneas de investigación: Francisco de Vittoria e investigación socio-humanística del derecho adscritas a la Facultad de Derecho. Producto de Proyecto de investigación "Observatorio de Política Pública del Control Fiscal" adscrito-según convenio.- a la Auditoría General de la República y la Universidad Santo Tomás de Bogotá. 
agrupa más de un millar de países del mundo. Tiene como finalidad, mejorar a nivel mundial la fiscalización pública exterior con miras a fortalecer el desempeño y las competencias de las Entidades Fiscalizadores Superiores (EFS), en general, y de los procedimientos de fiscalización pública adelantados por entidades gubernamentales de los Estados miembro, en particular.

Abstract. This chapter aims to address the international standards produced by the International Organization of Supreme Audit Institutions (INTOSAI), known as a nongovernmental organization with a special status with the United Nations Economic, Social and Economic Council, autonomous, independent and apolitical that brings together more from a thousand countries of the world. Its purpose is to improve worldwide public external auditing with a view to strengthening the performance and competencies of the Supreme Audit Institutions (SAIs), in general, and of the public inspection procedures carried out by government entities of the member states, in particular.

Palabras Clave: Control interno, Control fiscal, auditoría, INTOSAI.

Keywords. Internal control, fiscal control, auditing, INTOSAI.

\section{Abreviaturas.}

EFS: Entidades Fiscalizadoras Superiores.

INTOSAI: Organización Internacional de Instituciones Fiscalizadoras Superiores.

IIA: Instituto de Auditores Internos.

NIA: Normas Internacionales de Auditoría.

\section{Introducción}

La legislación internacional, entendida esta como el conjunto de disposiciones yorientaciones construido sobre la base de buenas prácticas estatales en el desarrollo económico, social y de control tanto a nivel latinoamericano como a nivel global, constituye un valioso instrumentos para la construcción de políticas públicas, así como, de los lineamientos y procedimientos pertinentes en materia de control fiscal.

En esta última materia son referentes tres (3) organismos internacionales principales, a saber, i) La organización para la cooperación y el desarrollo económicos (OCDE), propende por la promoción de políticas que mejore el bienestar económico y social de las personas alrededor del mundo(«La OCDE - OECD», s. f.). Colombia ratificó la adhesión ante este organismo el pasado 30 de mayo de 2018 en París, Francia, ii) La comisión económica para América Latina y el Caribe (CEPAL), es una de las cinco comisiones regionales de las Naciones 
Unidas. Su objetivo es contribuir al desarrollo económico y social de América Latina y el Caribe, mediante la coordinación y el refuerzo de las acciones conjuntas en estos asuntos (Caribe, 2014), y la Organización Internacional de Instituciones Fiscalizadoras superiores (INTOSAI), es una organización no gubernamental con un status especial con el Consejo Económico y Social de las Naciones Unidas, autónomo, independiente y apolítico que agrupa más de un millar de países del mundo. Tiene como finalidad, mejorar a nivel mundial la fiscalización pública exterior con miras a fortalecer el desempeño y las competencias de las Entidades Fiscalizadores Superiores (EFS), en general, y de los procedimientos de fiscalización pública adelantados por entidades gubernamentales de los Estados miembro, en particular («INTOSAl.org: Acerca de nosotros», s. f.)

Las disposiciones contenidas en la legislación internacional, sobretodo las relacionadas con procesos de auditoría interna o control interno (proceso auditor) son un referente importante para el diseño y ejecución de las políticas locales en esta materia. Su fortalecimiento contribuye al perfeccionamiento del sistema con miras a evitar la presencia de situaciones irregulares que puedan implicar errores sustanciales, fraudes o delitos relacionados con la inversión de los dineros públicos.

Sobre este último aspecto, existe y se incrementa un sentimiento de desconfianza colectiva -sobre todo en los países latinoamericanos- en el que los ciudadanos contribuyen al sostenimiento del Estado a través de, entre otros, el pago de los tributos, sin recibir, por lo menos de la forma adecuada, la reinversión de esos dineros en planes o políticas que contribuyan a la consolidación de los derechos fundamentales básicos en un Estado Social y Democrático de Derecho. Es menester entonces crear y fortalecer mecanismos idóneos, eficientes y eficaces en el seguimiento al manejo de los recursos públicos en cabeza de las instituciones que el Estado ha creado para tal fin.

El Marco de Normas Profesionales de la INTOSAI tiene cuatro niveles. El Nivel 1 contiene los principios fundamentales del marco. El Nivel 2 (ISSAIs 10-99) establece los requisitos previos para el funcionamiento apropiado y la conducta profesional de las EFS, en términos de consideraciones organizacionales, que incluyen independencia, transparencia y rendición de cuentas, ética, y control de calidad, las cuales son relevantes para todas las auditorías llevadas a cabo por las EFS. Los Niveles 3 y 4 se refieren a la conducción de auditorías individuales e incluyen principios profesionales generalmente reconocidos que respaldan la fiscalización eficaz e independiente de las entidades del sector público. (INTOSAI P. d., 2013, p. 1).

El presente escrito consolida el contenido de más de un centenar de documentos que reglamentan el control fiscal a nivel internacional. Cuenta con ejemplos concretos de 
implementación y desarrollo de actividades del control, así como, con consideraciones propias del fisco como las auditorías internas y externas en el sector público y los principios que orientan de la labor de auditoría. Está dirigido principalmente a las instituciones y funcionarios encargados del proceso auditor a nivel gubernamental, con miras a que evalúen la idoneidad y aplicabilidad de los procesos nacionales del control fiscal, así como, a la comunidad en general para que conozca, en términos muy generales, los conceptos, protocolos, procedimientos y fines que, bajo estándares de calidad, persigue el proceso de auditoría en el sector público.

Es así como el presente documento contribuye a los objetivos del Observatorio de Política Pública de Control Fiscal - OPPCF, creado por la Auditoría General de la República, en tanto que, involucra a la ciudadanía en los procesos de seguimiento, monitoreo y control de los dineros públicos, mediante la consideración de que el control fiscal constituye un derecho y garantía en poder de la comunidad, dotada de las herramientas que contribuyan a la comprensión del mismo en todas sus dimensiones.

\section{Normas De Control Interno.}

Cualquier construcción de políticas debe cimentarse sobre un cuerpo normativo que fije los lineamientos teleológicos del proceso que se pretende implementar. La gestión del control interno no es la excepción y por tanto la INTOSAI (INTOSAI S. -c., 1998) ha establecido aquellas que son propias en procesos de esta naturaleza.

\section{Generales.}

La INTOSAI, ha considerado la existencia de por lo menos cinco (5) normas generales en las entidades públicas que orienten la construcción del proceso y la estructura del control fiscal, a saber, i) garantía razonable; ii) respaldo; iii) integridad y competencia, iv) objetivos de control y, v) vigilancia de los controles (issai.org, 1998).

\subsection{Garantía razonable.}

Las estructuras de control interno de las entidades públicas deben proveer a todos los estamentos, un nivel de confianza razonable en que los objetivos propuestos por la entidad se van a cumplir. Se trata de una confianza fincada en la valoración de costos, beneficios y riesgos propios de las actividades del organismo (INTOSAI S. -C., 1998).

En la experiencia de algunos países miembros de la INTOSAI, esta norma se garantiza a partir de múltiples frentes. En Nueva Zelanda por ejemplo, a partir del trabajo y subsecuente informes de cada uno de los líderes de Departamentos en la rendición de cuentas de la información financiera. Así, la responsabilidad de controlar el manejo de los fondos públicos, 
no recae únicamente en el funcionario general encargado de los asuntos administrativos y financieros, sino en cada uno de los directores que tienen relación directa o indirecta con el gasto de los recursos. Esto permitirá obtener una visión global del sistema financiero a partir de la sumatoria de los análisis parcializados de su ejecución (nivel micro de garantía). Por su parte la constitución japonesa contempla la obligación anual de rendición de cuentas en la que el Consejo de Ministros presentan - soportados en informes de auditoría anuallas cuentas de ingresos y gastos del Estado (nivel macro de garantía) (INTOSAI S. -c., 1998). Para conocer en detalle el proceso de rendición de cuentas en la administración, consulte el documento de la INTOSAI: Internal Control: Providing a Foundation for Accountability in Government (INTOSAI S. C., 2001).

En otros países como la República de Sudáfrica, la norma general no se garantiza en tanto que los cambios periódicos a nivel gubernamental tanto en la delegación de las actividades, como en la asignación de responsabilidades dificultan su eficacia. No obstante se reconoce la necesidad de consolidación y se implementan estrategias que, desde lo particular, puedan impactar la confianza en la consecución de los objetivos de las entidades públicas (INTOSAI S. -C., 1998)

\subsection{Respaldo.}

La segunda regla de oro para el eficiente funcionamiento del control fiscal lo constituye la actitud positiva (no idealista) y de apoyo a los controles internos por parte de todas las personas que intervienen en las actividades de la entidad. El interés individual, y la suma de estos para consolidar un interés colectivo del control deberán mantenerse en todo momento. Esta norma inicia con los gerentes y administradores y se distribuye a todo el personal a cargo, de modo tal, que se evidencie el compromiso institucional (INTOSAI S. -C., 1998).

Esta norma es de especial importancia en tanto que, del compromiso y consistencia de las funciones de los miembros de una organización dependerá la consecución de los objetivos de la misma. Algunos países miembros de la INTOSAI (Estados Unidos e Islandia por ejemplo), han identificado la falla en la implementación de la norma de respaldo, cuando se evidencia la indiferencia o falta de compromiso de sus miembros en el desarrollo de las actividades cotidianas al punto de generar graves crisis económicas y operativas. Para hacer frente a ello ambos países promulgaron leyes encaminadas a controlar y auditar actividades financieras, indispensables para el desarrollo y mantenimiento nacional (INTOSAI S. -C., 1998).

\subsection{Integridad y competencia.}

Todo el personal de una entidad, sobre todo si se trata de una entidad pública, debe estar cualificado ética y profesionalmente para el cargo que ocupa. Aunque parezca un elemento 
insignificante, la integridad personal y la capacidad de comprender y utilizar controles para el desarrollo de las funciones constituye un requisito sine qua non para la efectividad de la actividad de control interno. Contar con personal cualificado ética y profesionalmente evita de antemano la presencia - por lo menos de manera masificada - de fenómenos como el fraude, los errores y la corrupción (INTOSAI S. -c., 1998).

Igual tratamiento merece la competencia, entendida esta como los conocimientos procedimentales, técnicos, operativos, entre otros, necesarios para el ejercicio del cargo asumido. La capacitación constante de los funcionarios, la evaluación de resultados obtenidos y el sistema de premios por rendimiento laboral son métodos adecuados para garantizar el cumplimiento de esta norma. En China por ejemplo, se ha implementado el procedimiento de "certificación para el cargo" como requisito de procedibilidad para asumir determinada actividad al interior de una entidad pública. (INTOSAI S. -C., 1998).

Las EFS, en tanto que fungen como modelo de confianza y credibilidad a nivel nacional, deben tener un código de ética que guíe los procedimientos de auditorías del sector público. Para mayor información sobre este aspecto consulte el documento, código de ética de la INTOSAI (issai.org, 1998).

1.4 Objetivos del control.

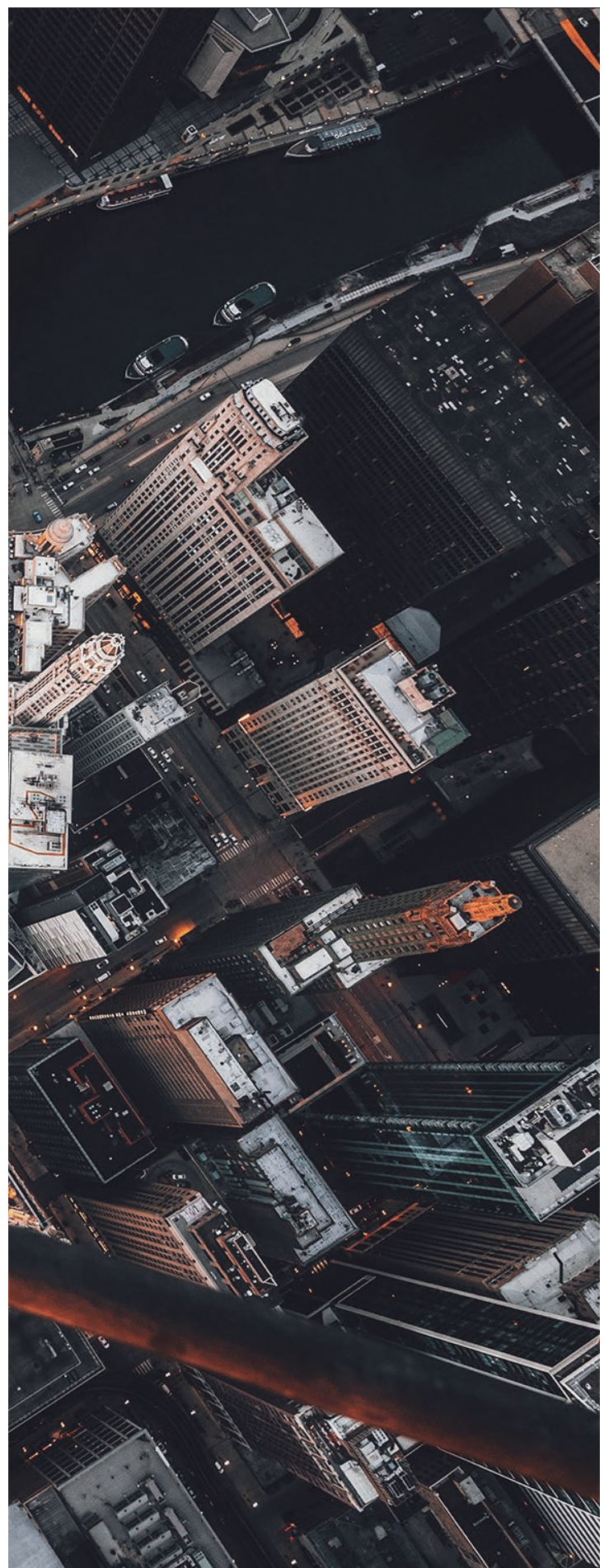


Para poder comprender e implementar el control interno, al punto de interiorizarlo y ajustarlo a las actividades desplegadas por los funcionarios de las entidades públicas, es muy importante que tanto su definición, como sus objetivos, se encuentren definidos de manera clara, completa y comprensible en todos los estamentos de la entidad. No es suficiente con reiterar el compromiso institucional con el control interno si el personal no conoce los motivos por los cuales este es importante.

Muchos de los riesgos generados en las entidades públicas se producen porque los procedimientos o actividades desplegados no son claros, o se contradicen, o son confusos y/o porque sus objetivos no han sido lo suficientemente difundidos para que el conjunto de funcionarios que los materializan puedan identificar los eventos que pudiesen resultar perjudiciales para su consecución. Por tanto, la definición de objetivos alcanzables, sencillos y comprensibles por todos los intervinientes debe ser el punto de partida de la implementación del control interno en las entidades públicas. No importa que se vean obvios o redundantes, lo importante es que se entienda la razón de su existencia y exigencia con claridad (INTOSAI S. -C., 1998).

\subsection{Vigilancia de los controles.}

Puede ocurrir que los objetivos y sistemas del control interno estén perfectamente diseñados en el papel y que hayan sido perfectamente instalados en cada uno de los estamentos de la entidad que los requieren pero que no pasen de ser una mera formalidad contractual. $\mathrm{Si}$ los directivos encargados del control en cada una de sus dependencias no efectúan labores de supervisión constante a las actividades de control, este puede devenir en ineficiente y/o ineficaz en la medida que, i) la actividad de control no se aplica en el funcionamiento de la dependencia, ii) no se identifican eventos constitutivos de riesgo para la consecución de los objetivos, iii) no se toman medidas tendientes a mitigar o controlar el riesgo, etc (INTOSAI S. -C., 1998).

El Reino Unido como experiencia en la implementación de esta norma ha recomendado hacer pública la identificación de deficiencias en los controles internos con miras a que el personal encargado de su supervisión tome medidas correctivas con rapidez (INTOSAI S. -C., 1998).

\section{Específicas.}

Algunos aspectos de la entidad merecen la determinación de normas específicas, por la importancia que su estabilidad constante representa para la existencia y mantenimiento de la institución. INTOSAI ha considerado que son seis (6) los elementos que merecen reglamentación específica, a saber: i) la documentación, ii) registro oportuno y adecuado 
de las transacciones y hechos, iii) autorización y ejecución de las transacciones y hechos, iv) división de las tareas, v) supervisión y vi) acceso a los recursos y responsabilidad ante los mismos.

\subsection{Documentación.}

La documentación de las transacciones o sucesos adelantados por la entidad no solo es muestra de buenas prácticas corporativas, sino que sirve para evidenciar la trazabilidad de las actividades adelantadas por la entidad pública. Aunque este objetivo específico debería exigirse en toda clase de persona jurídica, en las entidades públicas, sobre todo, por el manejo de fondos y recursos públicos debe ser una obligación. La información documentada debe dar fe de la transparencia de las operaciones desde su generación hasta su finalización de manera clara, completa y veraz. Así, se cuenta con el soporte necesario para evidenciar el manejo del gasto y la vez, se fortalece la confianza ciudadana en que los tributos están siendo bien distribuidos (INTOSAI S. -C., 1998)

\subsection{Registro oportuno y adecuado de transacciones y hechos.}

Todas las actividades desplegadas por la entidad pública deben además registrarse en las circunstancias de tiempo, modo y lugar, y según las condiciones particulares en que se generan. El registro tardío o incompleto de las transacciones y sucesos puede conllevar errores de contenido y como consecuencia de ello, a eventos nefastos a la luz de la vista pública. La falta de registro oportuno y correcto de las transacciones pueden desencadenar un sin número de eventos riesgosos para la entidad en tanto que, la falta de registro o el registro incompleto o erróneo de determinada actividad amenaza la fiabilidad de las operaciones. En Estados Unidos por ejemplo, la falta de registro del personal que dejó de pertenecer al ejército norteamericano, conllevó al pago de salario a más de 2.200 personas en el transcurso de varios meses, lo que generó pérdidas alrededor de 7.8 millones de dólares (INTOSAI S. -C., 1998).

\subsection{Autorización y ejecución de transacciones y hechos.}

Las transacciones y sucesos relevantes, además de estar debida y oportunamente registradas, deberán contar con el aval o autorización de las personas encargadas del manejo de recursos en determinada dependencia dentro de la entidad. La responsabilidad en el manejo del gasto conlleva a la revisión sobre la pertinencia, necesidad y justificación de la transacción o evento a adelantar. No obstante, en la experiencia de países miembro de la INTOSAI como Islandia y Costa Rica, pese a la existencia de esta norma, la autorización de transacciones en actividades innecesarias, impertinentes o aplicadas en intereses individuales se vislumbra con bastante frecuencia. Ejemplo común en ambos Estados, es el uso de vehículos oficiales 
para adelantar propósitos personales, en horarios no laborales o por parte de personas ajenas a los beneficiados. China por su parte, ha implementado un proceso de control de las autorizaciones para hacer frente a estas hipótesis (INTOSAI S. -C., 1998).

\subsection{División de tareas.}

Según INTOSAI, para evitar el riesgo de error, derroche o actos ilícitos en actividades de autorización, tratamiento, registro, revisión y ejecución de transacciones o sucesos es indispensable que el proceso sea manejado por varias personas, así, las fases decisivas serán controladas por quienes intervengan en su realización mediante la segregación de labores. En casos en los que esta norma es de difícil concreción, por ejemplo, tratándose de entidades pequeñas con un número limitado de funcionarios, la recomendación es rotar a los encargados de tal manera que el manejo y control de la actividad no permanezca en cabeza de una sola persona por un largo periodo de tiempo (INTOSAI S. -C., 1998).

En la experiencia adelantada por países miembros de la INTOSAI se ha reconocido la validez de esta norma aunque países como Nueva Zelanda manifiestan que debe manejarse con moderación porque un número grande de personas en procedimientos relativamente sencillos pueden desencadenar otra clase de riesgos como la demora en los procedimientos (INTOSAI S. -c., 1998).

\subsection{Supervisión.}

Todas las actividades de control interno deben estar en constante monitoreo por parte de los encargados de las dependencias sobre las que este opera. Aunque se ejemplificará en detalle la labor de supervisión en los apéndices subsiguientes, es menester resaltar que un seguimiento constante de las actividades de control garantiza que los procedimientos se desarrollen de manera correcta, oportuna y eficiente. Los supervisores deben implementar estrategias de comunicación con sus empleados así como orientar y formar a su equipo de trabajo para reducir al mínimo la posibilidad de cometer errores o realizar movimientos incorrectos. La aplicación de esta norma es trascendental, por ejemplo, en asuntos como los de ejecución contractual con terceros (INTOSAI S. -c., 1998).

2.6 Acceso a los recursos y responsabilidades ante los mismos.

Algunos aspectos neurálgicos al interior de entidades públicas, sólo pueden ser conocidos y consultados por un número limitado de personas que a su vez, garantizarán la idoneidad e integridad de los mismos. El riesgo de uso inadecuado, o de pérdida o daño de información relevante para la institución podría conllevar a sucesos de malversación o pérdida de recursos públicos. La información confidencial debe ser consultada con una periodicidad promedio y cotejada con la documentación de los procedimientos adelantados. En la experiencia de los 
países miembros de INTOSAI, Estados Unidos alertó sobre la falta de controles en los sistemas de información digitales en tanto que estos pueden ser burlados por medios informáticos y reiteró que autorizar a un número plural de funcionarios para realizar operaciones podría facilitar fenómenos como el fraude (INTOSAI S. -c., 1998).

\section{li. Control Interno.}

(...)El control interno es un proceso integral efectuado por la gerencia y el personal y está diseñado para enfrentarse a los riesgos y para dar una seguridad razonable de que en la consecución de la misión de la entidad, se alcanzarán los objetivos generales (...) (INTOSAI S.-c. d., 2004, p. 6).

Las instituciones Públicas, encargadas de velar por el cumplimiento de los propósitos estatales y de garantizar los derechos, la prestación periódica y efectiva de servicios y el acceso a la administración de justicia, están llamadas imperiosamente a crear y mantener políticas, mecanismos, procedimientos, protocolos, guías y actividades de control interno tendientes a la maximización de los recursos públicos pero sobre todo, a garantizar la vocación de servicio hacia el interés general en un Estado Social y Democrático de Derecho. La gestión del control interno implica la identificación oportuna de riesgos que permitan mantener la estabilidad en la prestación de los servicios y la previsibilidad de su ocurrencia con miras a adelantar acciones de mejoramiento, contención y/o eliminación de los mismos.

Dicho control será positivo en la medida que los eventos detectados, guíen a la institución a actualización, mejora y eficiencia de sus procedimientos. Se trata de minimizar los riesgos y maximizar las oportunidades (INTOSAI S.-c. d., 2007).

Como proceso intrínseco a las actividades propias de una entidad, el control interno debe construirse, alimentarse, implementarse y mantenerse desde la organización. Todos los procesos deben estar permeados por él. Así, el personal, desde el último en la cadena de producción hasta el gerente, emplearán el control interno en cada una de sus labores, con independencia del rol que desempeñen y/o con la intensidad que el control se manifieste en ellas. Por ejemplo, el Gerente tiene la responsabilidad global del diseño, implantación y supervisión del sistema de control interno - de conformidad con la teleología y los objetivos de la institución - y con miras a evitar la concreción de riesgos presentes o sobrevinientes en la actividad pública (nivel de seguridad razonable, no absoluta), mientras que un miembro del personal determinado sólo deba verificar la ejecución del mismo (INTOSAI S.-c. d., 2004).

Como cualquier proceso dependiente del factor humano, el control interno no puede 
garantizar una seguridad absoluta. A la par, existen situaciones que escapan al ámbito de aplicación de este que se tornan imposibles de manejar como el cambio en el personal, la disminución de los recursos en la entidad y los cambios en las políticas, planes y procedimientos gubernamentales y/o locales. Ello implica que el control como actividad dinámica, deberá estar en constante adaptación, actualización y difusión para hacer frente a los riesgos que deba enfrentar (INTOSAI S.-c. d., 2004).

En las instituciones del sector público, los riesgos pueden provenir de fuentes externas a la entidad, condicionando incluso el ajuste de los objetivos generales en un corto periodo de tiempo. Algunos riesgos típicos en las entidades gubernamentales son, cambios generales en la economía que implican menor crecimiento y por tanto menor asignación de recursos para la entidad, reducción en capacidad de ofrecer mayor cantidad y/o cobertura de bienes y servicios, pérdida o malversación de fondos por fraude o corrupción, falla adecuada de la medición del riesgo, falla de contratistas o socios de otras agencias gubernamentales que proporcionan insumos a la entidad, riesgo tecnológicos, falta de herramientas o procesos técnicos inadecuados o desactualizados, retrasos en la ejecución de los proyectos por sobrecostos derivados de recesiones económicas, etc (INTOSAI S.-c. d., 2007).

Lo importante es que el control interno se identifique en cada una de las actividades adelantadas por la organización sin que este sea excesivo o superficial en unas u otras operaciones. Así, deberán implementarse controles altos en actividades que requieran el movimiento de dinero en tanto que de ello deriva la confianza de la ciudadanía en la auditoría del gasto, mientras que en procedimientos administrativos el exceso puede ser perjudicial para el oportuno desarrollo de las actividades de la entidad (INTOSAI S.-c. d., 2004).

Según la administración de riesgos del COSO ERM - Organismo de reconocimiento internacional que establece los marcos reguladores en materia de riesgos y las guías de control interno- citado por INTOSAI, el proceso global del control interno se conoce como Gestión del Riesgo, entendido este como,

(...) Proceso efectuado por la junta directiva de una entidad, la gerencia y el personal, que aplica en el planteamiento de la estrategia y a lo largo de la Entidad, está diseñado para identificar eventos potenciales que podrían afectar a la entidad y permite administrar el riesgo dentro de los límites aceptados, proveyendo la seguridad razonable para la consecución de los objetivos de la entidad (...) (2007, p. 11).

1. Componentes del control interno. 
Fincado sobre los objetivos generales ya descritos, la gestión de riesgos a partir de procesos de control interno se compone de ocho (8) ítems relacionados entre sí que, a su vez, transversalizan a las dependencias y personas que pertenecen a la institución. INTOSAI, ha denominado dichos componentes así, i) Entorno del control o ambiente interno; ii) Establecimiento de objetivos; iii) identificación de eventos; iv) Evaluación del riesgo; v) Respuesta a los riesgos; vi) actividades de control; vii) información y comunicación y viii) seguimiento (INTOSAI S.-c. d., 2004) Cfr. (INTOSAI S.-c. d., 2007).

\subsection{Entorno del control o ambiente interno.}

El entorno del control interno es el espacio físico y organizacional que fija la identidad de la organización dando disciplina y estructura a la misma. Define la filosofía de la gestión del riesgo desde la gerencia hacia cada una de las dependencias de la entidad. Sus elementos comprenden la base de las relaciones personales y profesionales de la organización y guía las actividades cotidianas. (INTOSAI S.-c. d., 2004) Cfr. (INTOSAI S.-c. d., 2007).

Se caracteriza por, i) integridad personal y profesional con valores éticos: identificar en el colectivo (entidad) y en el personal (funcionarios) - con independencia de la ubicación jerárquica dentro la institución- una integridad ética individual y profesional que enaltezca los códigos de conducta dispuestos y el apoyo hacia los objetivos institucionales; ii) competencia: garantizar en el personal un nivel de conocimientos y habilidades acordes con sus responsabilidades individuales y la relación de estas con el control interno. Para ello las capacitaciones en el campo ético como profesional son una herramienta de actualización y potenciación de las competencias; iii) "tono de los superiores": Liderar mediante una actitud de apoyo permanente el compromiso institucional con el control interno a través de actividades, políticas, dependencias y evaluaciones; iv) estructura organizacional: definir ordenadamente la asignación y delegación de funciones y los procesos de rendición de cuentas. Para ello es importante contar con una oficina o unidad de control interno; v) Políticas y prácticas de recursos humanos: fijar procedimientos claros de contratación, promoción y evaluación del personal como aspecto importante del control interno mediante procesos transparentes y públicos con miras a garantizar en el personal un sentido de compromiso que le haga competente y confiable (INTOSAI S.-c. d., 2004).

Se trata entonces, de un criterio de cultura organizacional que guía el comportamiento profesional mediante actividades que garantizan el buen ambiente laboral y el sentido de pertenencia con la misión, los objetivos y el control de la institución.

1.2 Establecimiento de objetivos. 
Cualquiera que sea la forma de implementar el control interno en las instituciones, este, deberá construirse sobre la base de unos objetivos generales y específicos propios de un proceso de esta naturaleza. Se consideran objetivos generales los inherentes a la funcionalidad de la entidad, en tanto que serán objetivos específicos aquéllos que se refieran exclusivamente a procedimientos, funciones y personal determinados (INTOSAI S.-c. d., 2004).

La claridad de objetivos generales de toda entidad, sobre todo, de entidades de naturaleza pública son un prerrequisito para un proceso efectivo de control interno y se encaminan principalmente hacia, i) La fijación de metas de alto nivel que se corresponden con la misión institucional (objetivos estratégicos); ii) la ejecución las operaciones de manera ordenada, ética, económica, eficiente y efectiva (objetivos operacionales); iii) la satisfacción de las obligaciones con sentido de responsabilidad por las decisiones y acciones adelantadas en el marco de la transparencia de la información completa, financiera y no financiera (objetivos de información); iv) el cumplimiento de las disposiciones legales y reglamentarias. En algunos casos se exige también el seguimiento de regulaciones internacionales (objetivos de cumplimiento); v) y la salvaguarda de los recursos públicos. Aunque este último objetivo corresponde a una derivación de los objetivos operacionales, merece especial tratamiento en tanto que comprende flujo de dineros, activos, pasivos e información física y digital indispensables para el funcionamiento, incluso, para la existencia de la entidad pública. Fortalecer los controles relacionados con la prevención, corrección y malversación de fondos público evita la presencia de fenómenos como el abuso o el fraude (INTOSAI S.-c. d., 2004) Cfr. (INTOSAI S.-c. d., 2007).

\subsection{Identificación de eventos.}

El proceso de identificación de eventos se caracteriza por analizar el funcionamiento y concreción de objetivos en el marco de la cotidianidad de la entidad. Estos eventos, entendidos como incidentes o acontecimientos que alteran la implantación de estrategias o la consecución de los objetivos generales y específicos y que pueden provenir de factores externos o internos, no pueden interpretarse per se como riesgos, sino que, por el contrario, puede tratarse de fenómenos que impliquen una oportunidad de mejora para la institución o ser de naturaleza mixta (que impliquen una oportunidad o un riesgo según como sean manejados) (INTOSAI S.-c. d., 2007).

No existe una metodología específica para la identificación y valoración de eventos. Ello dependerá de multiplicidad de factores tales como, la periodicidad de las actividades de la institución, cantidad de procedimientos existentes, multiplicidad de vías de manejo de las operaciones, etc. No obstante, es importante que ese proceso se realice sobre eventos pasados y futuros. Es más sencillo sobre eventos pasados en tanto que se cuenta con los 
insumos para su interpretación: auditorías, historial de contabilidad, informes, comités, pero es indispensable proyectar el impacto de los eventos para evitar, bien que se conviertan en riesgo, bien que se concreten en resultados negativos para la consecución de los objetivos. Sobre todo es importante considerar las variables de factores externos que escapan al control de la entidad pero que pueden ser determinantes para su funcionamiento, incluso para su subsistencia. Cambios económicos, políticos, ambientales son un ejemplo de ello (INTOSAI S.-c. d., 2007).

\subsection{Evaluación del riesgo.}

"(...) La evaluación de riesgo es el proceso de identificación y análisis de los riesgos relevantes para el logro de los objetivos de la entidad y para determinar una respuesta apropiada (...)" (INTOSAI S.-c. d., 2004, p. 24).

Superadas las fases de identificación, clasificación de eventos y la consecuente determinación del riesgo, la entidad deberá efectuar su proceso de identificación y clasificación según el ciclo de evaluación de la siguiente manera,

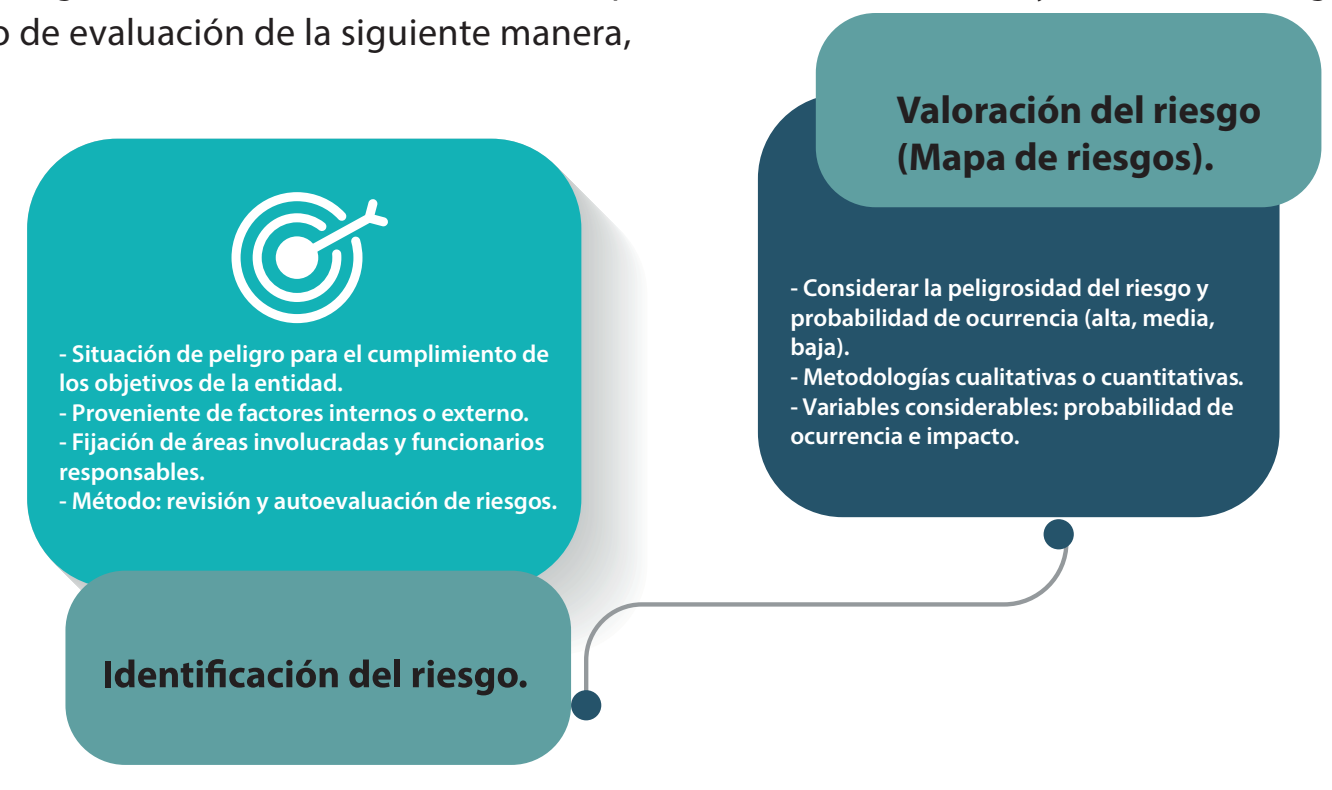

(INTOSAI S.-c. d., 2004)

(...)El objetivo de la evaluación de riesgos es identificar eventos suficientemente importantes y significativos que concentren la atención de la gerencia (...) (INTOSAI S.-c. d., 2007, p. 33)

Tampoco existe una metodología definitiva para evaluar los riesgos de la entidad, en tanto que su identificación y clasificación obedece a la misión, objetivos y procedimientos de cada institución de manera individual. Los métodos cualitativos, cuantitativos, objetivos 
o subjetivos deberán realizarse de manera independiente según las necesidades de la Institución. Lo que sí es cierto, es que el proceso de valoración del riesgo deberá enmarcarse en términos de probabilidad e impacto. Así, dependiendo de si la probabilidad de ocurrencia e impacto es alta, moderada o baja, se definirá si se trata de un riesgo tolerable o si requiere la implementación de acciones de contención, trasferencia, eliminación, etc. Los riesgos más importantes son aquéllos con una alta probabilidad de ocurrencia y de alto impacto (riesgos prioritarios), los demás podrán categorizarse como inherentes o residuales. (INTOSAI S.-c. d., 2007).

Dado que las condiciones económicas, políticas, fiscales, normativas y operacionales fluctúan constantemente, igualmente, el proceso de evaluación de riesgo ha de ser permanente (INTOSAI S.-c. d., 2004).

\subsection{Respuesta a los riesgos.}

(...) La probabilidad representa la posibilidad de que un evento determinado ocurra en un periodo de tiempo dado, mientras que el impacto representa el tamaño y efecto que tendría en la capacidad de la entidad para alcanzar sus objetivos (...) (INTOSAI S.-c. d., 2007, p. 33)

Categorizados los riesgos, la gerencia definirá la implementación de una de las siguientes respuestas atendiendo a las variables de probabilidad - impacto y de costo - beneficio,

(INTOSAI S.-c. d., 2007)

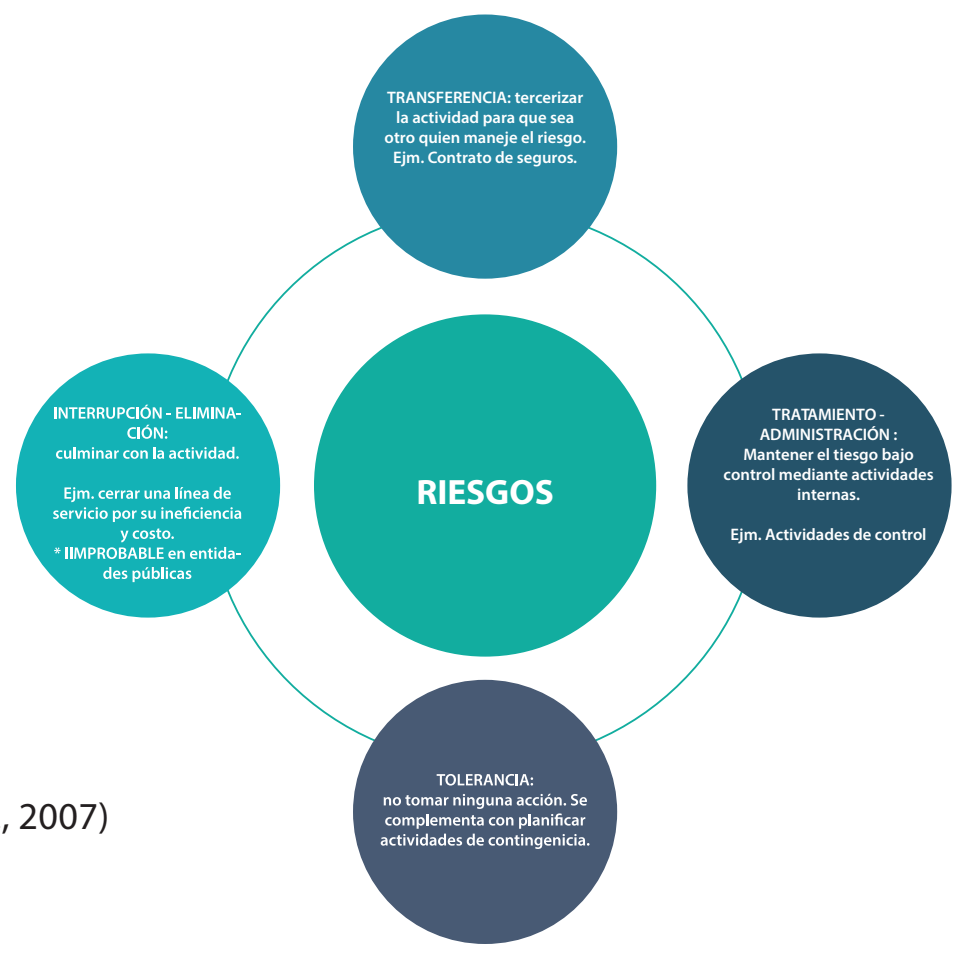




\section{Actividades de control.}

Construido el mapa de riesgos y la valoración de los mismos en probabilidad de concreción en alta, media o baja, surge la necesidad de crear, fortalecer, modificar o eliminar políticas, procedimientos y/o dependencias de la organización. Esto se logra a través de actividades de control que pueden ser a su vez de detención o prevención y mediante acciones correctivas en los casos en que el riesgo se muestre como una realidad latente de materialización (INTOSAI S.-c. d., 2004).

“(...) Las actividades de control son políticas y procedimiento establecidos para enfrentar los riesgos y lograr los objetivos de la entidad. Los procedimientos que una organización ejecuta para tratar el riesgo se llaman actividades de control interno. Las actividades de control interno son la respuesta al riesgo en tanto que son diseñadas para contener la parte poco certera del resultado que ha sido identificado (...)" (INTOSAI S.-c. d., 2004, p. 62)

Para cumplir con las finalidades, dichas actividades de control deberán ser temporales (por un lapso de tiempo determinado), cuantificables (con un costo contemplado sin que exceda el beneficio que se pretende obtener con su implementación), claras (en relación con el procedimiento aplicable así como con las dependencias y personas encargadas de su ejecución) y comprensibles (creadas en un lenguaje accesible a los funcionarios) (INTOSAI S.-c. d., 2004).

Entre las actividades de control preventivas se destacan los procedimientos de autorización y aprobación, entendidos estos como el aval requerido para la realización de transacciones en condiciones y términos específicos para que sean válidos. Dicha autorización deberá estar en cabeza de funcionarios con rango de autoridad para orientar los procedimientos hacia los objetivos de la institución. También se encuentran la segregación de funciones en un número plural de personas que tengan funciones específicas y rotatorias en la revisión de las actividades y los controles de acceso a recursos y archivos en aras de garantizar la integralidad y existencia de los mismos (INTOSAI S.-c. d., 2004).

Por su parte, las actividades de control de detección, están encaminadas a identificar riesgos en el desarrollo de los objetivos de la institución. Entre ellas se resaltan las verificaciones, entendidas como el seguimiento a las transacciones antes y después de ser procesadas, las conciliaciones, caracterizadas por el cotejo de la información sobre una base regular y la revisión de desempeño operativo en términos de efectividad y eficiencia de la funcionalidad de la entidad (INTOSAI S.-c. d., 2004). 
Fungen como actividades de control preventivas y de detección, la revisión periódica de operaciones, procesos y actividades en concordancia con las políticas y lineamientos institucionales y la supervisión constante de las mismas, mediante la utilización de guías, acompañamiento presencial, capacitación y revisión sistemática (INTOSAI S.-c. d., 2004).

Merecen un tratamiento diferenciadolas actividades de control sobrelossistemasinformáticos y la información digital por cuanto gran parte de las actividades de funcionamiento de las instituciones se realizan sobre software y programas de computación. Para hacerle frente a los riesgos tecnológicos como el acceso abusivo a bases de datos, sistemas de comunicación, programas, la implantación de virus o la modificación o anulación de datos en sistemas digitales, es menester contar con controles generales y de aplicación que blinden los programas y la información contenida en sistemas virtuales de comunicación. Los controles generales se componen de programas de seguridad de planificación y gerencia, mecanismos para el desarrollo, mantenimiento y cambio de software (ej. Controles de acceso y funciones a los funcionarios), segregación de funciones y continuidad en el servicio. Los controles de aplicación se construyen sobre la base de actividades específicas en sistema digital que identifiquen y corrijan errores e inconsistencias en un ciclo que comprende tres (3) procesos fundamentales: entrada, procesamiento y salida de información. El éxito de los controles de aplicación depende de la solidez y efectividad de los controles generales de información digital (INTOSAI S.-c. d., 2004).

Los controles directivos son transversales a la aplicación eficiente y efectiva de las actividades de control preventivas, detectivas y/o correctivas. Buscan asegurar que el resultado querido sea alcanzado sobre todo mediante actividades de confiabilidad (INTOSAI S.-c. d., 2007)

\subsection{Información y comunicación.}

Todas las actividades de funcionamiento y desempeño del control interno deben estar permeadas por labores claras y periódicas de información y comunicación. La información correcta y oportunamente identificada, archivada, organizada, categorizada, consolidada y analizada constituye un factor esencial para que la gerencia pueda identificar la presencia de riesgos al interior de la entidad. Con ella, se asegura la sostenibilidad de la institución, se facilita a los procesos de rendición de cuentas, se garantiza el seguimiento a las operaciones y se identifican las responsabilidades. La comunicación efectiva y constante entre la gerencia y el personal facilita la interiorización de las actividades adelantadas como organización, así como el rol y responsabilidades de cada uno de los funcionarios. Es indispensable contar con canales de comunicación entre los miembros de la entidad y con el sector externo (Entidades fiscalizadores superiores, auditores externos, beneficiarios, proveedores, etc.) para orientar la creación de acciones puntuales de seguimiento (INTOSAI S.-c. d., 2004). 


\subsection{Seguimiento o monitoreo.}

Cualquier sistema de control interno debe contener procedimientos de seguimiento y monitoreo que validen su efectividad con el transcurrir del tiempo. Existen procedimientos generales de seguimiento, entendidos como las operaciones rutinarias que se adelantan al interior de la institución, por ejemplo, las labores de supervisión y evaluaciones puntuales que se realicen sobre una actividad o función determinada dependiendo de los riesgos existentes sobre ese asunto en particular y la efectividad o no de los controles generales. Ambos procedimientos se realizan mediante labores de auditoría que pueden ser internas o externas. Las unidades de auditoría interna al interior de la organización monitorean la efectividad del sistema de control interno. Debe garantizarse su imparcialidad e independencia. (INTOSAI S.-c. d., 2004)

El seguimiento al sistema de control interno permite identificar hallazgos que facilitan a la gerencia la evaluación de los mismos, la determinación de acciones correctivas, si hay lugar a ello, y la implementación de acciones que corrijan o resuelvan los asuntos que generan alerta. Así, se efectúa una revisión constante y pertinente sobre las actividades propias de la organización y toman las medidas pertinentes en relación con los hallazgos reportados (INTOSAI S.-c. d., 2004).

La relación existente entre objetivos, dependencias y componentes de la gestión del control interno en una entidad, podría graficarse de la siguiente manera,

(INTOSAI S.-c. d., 2004)

Cfr. (INTOSAI S.-c. d., 2007)

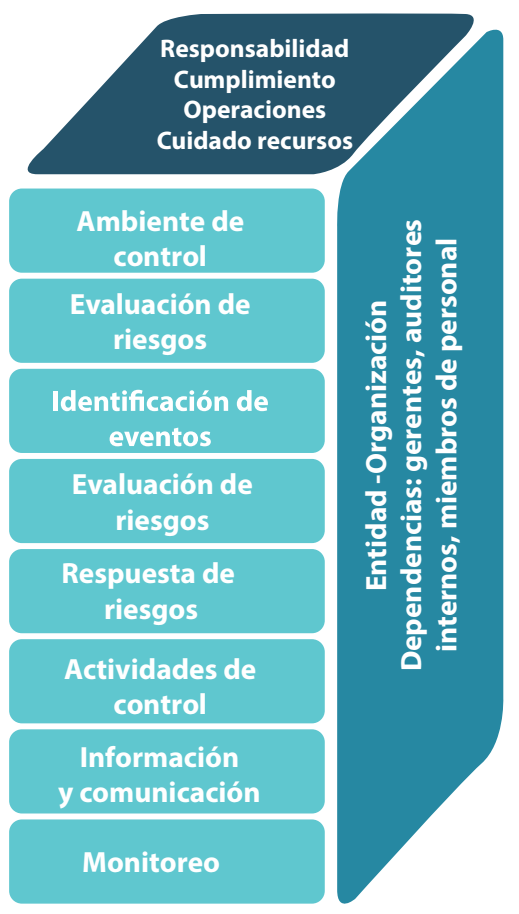




\section{OPPCF}

\section{Estructuras.}

Para que el control interno pueda tener el impacto que requiere, debe estar respaldado por una serie de elementos jurídicos, administrativos y funcionales que lo garanticen. La estructura del control interno alude a la base sobre la que este se construye, alimenta, y complementa. Son decisivos como garantía de eficacia los siguientes elementos,

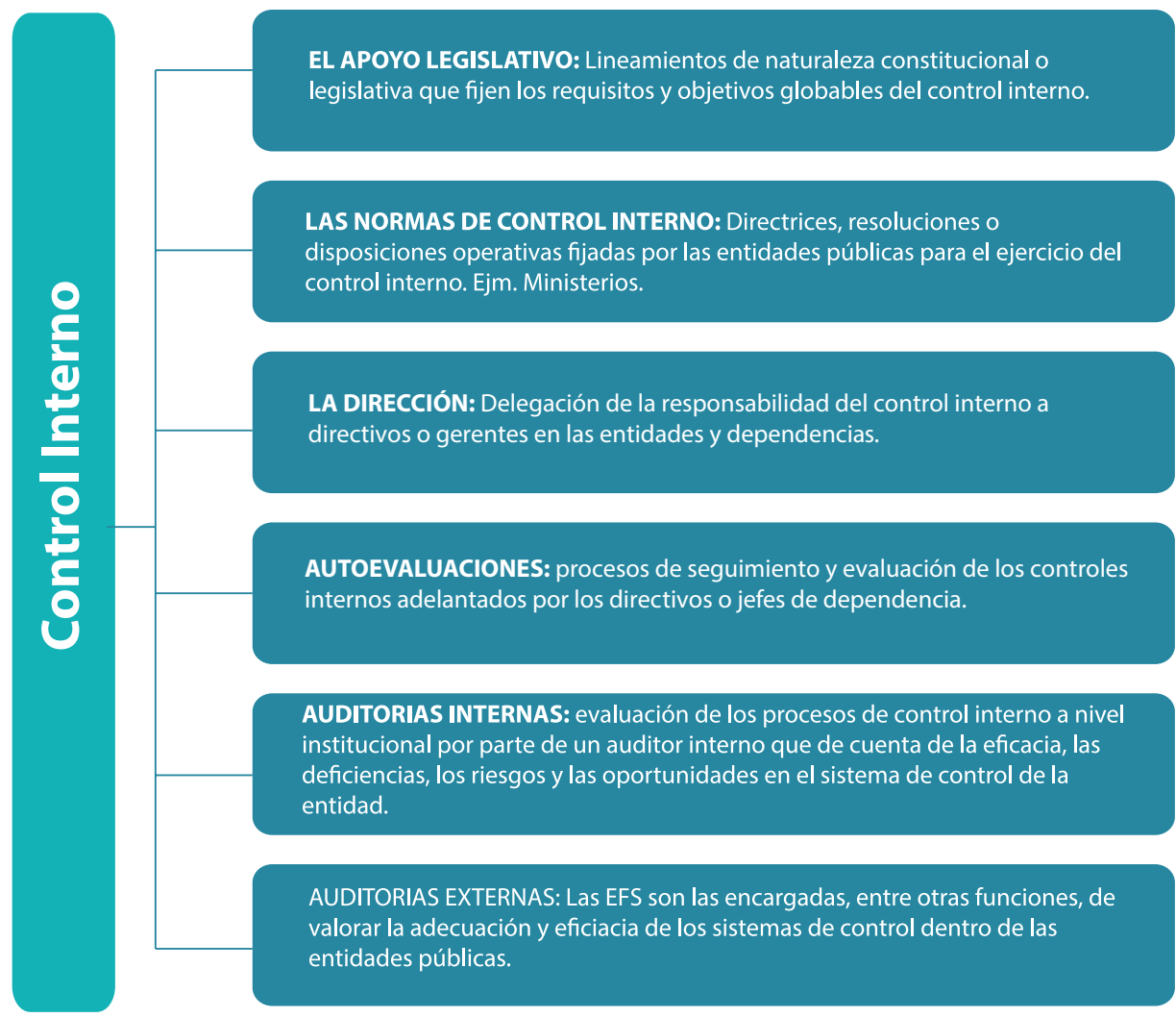

(INTOSAI S. -C., 1998)

\section{Auditoria en el Sector Público.}

En términos generales, el control interno constituye la columna vertebral del seguimiento y mejoramiento de las actividades desplegadas por las entidades del sector público al interior de su estructura personal, funcional y operativa. Por su parte, el proceso de auditoría se caracteriza por la verificación y eficacia de dicho control interno (entre otros aspectos) y su coherencia con las leyes, normas, reglamentos y procedimientos estatalmente fijados. Dicho proceso es efectuado, por regla general, por las entidades fiscalizadoras superiores 


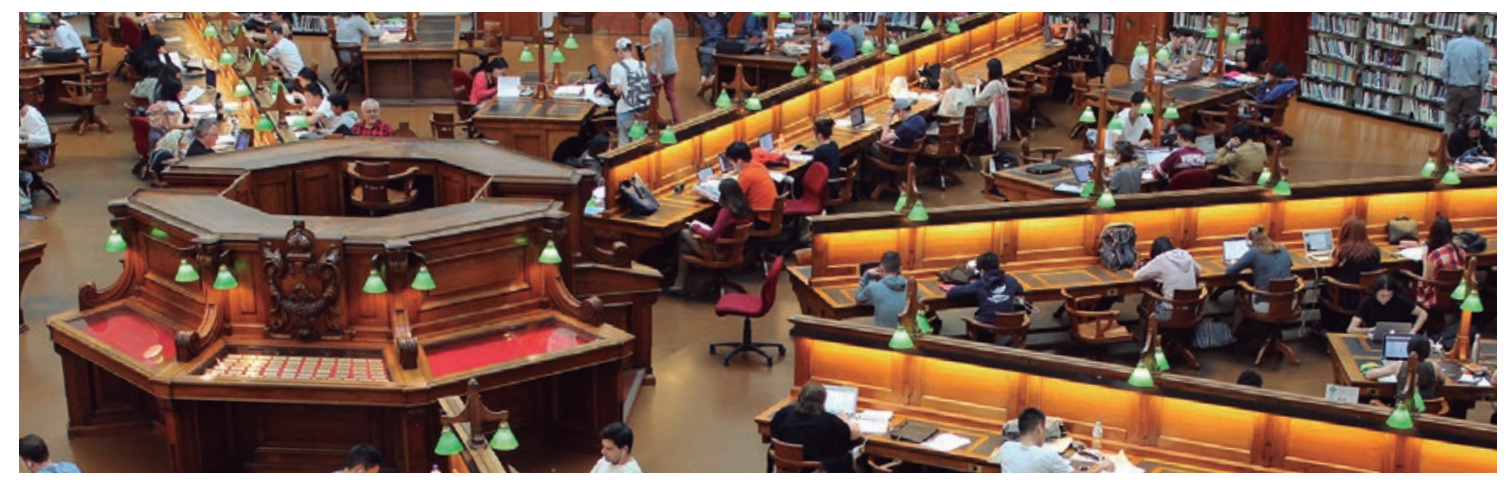

$(E F S)^{21}$ entendidas com los organismo estamentales que tienen por objeto, intervenir en los asuntos que sean de interés para la administración y los encargados de la gobernanza. En materia fiscal, se enfocan en la auditoria de los encargados de la gestión y el uso apropiado de los bienes y dineros públicos. Ocasionalmente este proceso es adelantado por entidades particulares e incluso, por auditores internos.

Según la guía de los principios fundamentales de Auditoría del sector público, (...) La auditoría del sector público puede describirse como un proceso sistemático en el que de manera objetiva se obtiene y se evalúa la evidencia para determinar si la información o las condiciones reales están de acuerdo con los criterios establecidos. La auditoría del sector público es esencial, ya que proporciona, a los órganos legislativos y de supervisión, a los encargados de la gobernanza y al público en general, información y evaluaciones independientes y objetivas concernientes a la administración y el desempeño de las políticas, programas u operaciones gubernamentales (...) (INTOSAI P. d., 2013, p. 4)

En el marco de un Estado Social y Democrático de Derecho, los procesos de auditoría, tanto interna como externa, en el sector público constituyen un valioso instrumento para la ciudadanía en tanto que, i. Obliga a las instituciones del Estado a rendir cuentas sobre la gestión y el desempeño de los dineros públicos, provenientes de la tributación u otras fuentes; ii. Dan fe de la situación real de la inversión de los fondos públicos en la prestación de los servicios públicos esenciales, sociales, económicos, etc, mediante el análisis de información de manera independiente, objetiva y confiable iii. Evidencian las problemáticas procedimientales que afectan la eficiencia y eficacia en la prestación de los servicios iv. Identifican fenómenos como el fraude y la corrupción con miras a su erradicación, iv. Contribuyen al perfeccionamiento y fortalecimiento de los los mecanismos que materializan 21 Organismo público de un estado que, con independencia de su designación, constitución u organización, ejerce en virtud de la ley la más importante función de auditoría pública de dicho Estado. En algunas Entidades fiscalizadoras Superiores existe un único Auditor General designado que desempeña una función similar a la de "socio responsable del encargo'"'!' (SIC) y que es el principal responsable de las auditorías del sector público. Otras entidades Fiscalizadoras Superiores pueden estar organizadas como Tribunal de Cuentas o con arreglo a un sistema colegiado. (INTOSAI C. d.-c., 2010, P. 59) 
los derechos fundamentales de los ciudadanos mediante el erario público, promoviendo la mejora continua y la confianza de los usuarios del sistema v. Proponen fórmulas para corregir u optimizar las actividades de las entidades del sector fincadas sobre principios de gobernanza y operatividad (INTOSAI P. d., 2013).

En ese sentido, (...) Los objetivos de la auditoría interna son diferentes a los de auditoría externa. Sin embargo, ambos tipos de auditoría promueven la buena gobernanza al contribuir a la transparencia y a la rendición de cuentas sobre el uso de los recursos públicos, así como sobre la economía, eficiencia y eficacia de la administración pública. Esto brinda oportunidades de coordinación y cooperación, así como la posibilidad de eliminar la duplicación de esfuerzos (...) (INTOSAI P. d., 2013, p. 12)

\section{Principios de la Auditoría en el sector público.}

Así como el control interno en las entidades públicas se cimienta sobre unos principios generales y específicos, el proceso auditor en el sector público también lo hace. Existen principios generales a la labor de auditoría y principios llamados, procedimientales, propios de proceso de auditoría.

\subsection{Principios generales de auditoría en el sector público.}

Toda entidad fiscalizadora superior debe establecer y mantener sus procedimientos con arreglo a altos estándares de calidad que le permitan legitimar la labor que adelanta en la auditoría de entidades del sector público. Ello por cuanto, es el organismo sobre el que reposa la confianza de los grupos de interés en el control y seguimiento de las actividades desplegadas por los organismos estatales, sobre todo, en lo concerniente al manejo e inversión de los dineros comunes. Por ello, los funcionarios adscritos a las EFS deben garantizar en su proceder profesional, el cumplimiento de cualidades éticas y el seguimiento fiel a los protocolos y lineamientos legales y regulatorios existentes para el desarrollo de su labor (INTOSAI P. d., 2013). Para conocer en detalle la construcción del sistemas de control de calidad por las EFS consulte el documento de la INTOSAI, Control de Calidad para las EFS, producido por el Consejo de Normas Internacionales de Auditoría y Aseguramiento IAASB, la Federación Internacional de Contadores IFAC, y el Grupo de Trabajo de la EUROSAI en colaboración con expertos de distintas EFS y del Tribunal de Cuentas Europeo bajo la presidencia de la EFS de Hungría (Consejo de Normas Internacionales de Auditoría y Aseguramiento IAASB, 2010)

Como principios generales de la labor de auditoría (presentes en cualquier momento y no sólo en el proceso de auditoría) en el sector público se destacan,

i. La ética e independencia del auditor (guía de conducta general). La independencia 
garantiza la imparcialidad y objetividad en los hallazgos derivados del proceso de auditoria.

ii. La actitud del auditor: escéptica, juiciosa y diligente. El excepcitismo profesional ha sido definido por la INTOSIA como (...) Actitud que implica una mente crítica y alerta con respecto a circunstancias que puedan indicar la existencia de incorrecciones por fraude o error, así como una valoración crítica de la evidencia de auditoría (...) (Introducción General a las Directrices de Auditoría financiera, 2010, p. 44). Por su parte, el juicio profesional es entendido como la aplicación de los conocimientos profesionales y técnicos acordes con las necesidades del proceso, oportunos y acertados. Dichas cualidades deberán aplicarse en el ámbito de la materialidad de lo auditado, que puede consistir en aspectos cuantitativos o cualitativos, individuales o analizados en contexto. (INTOSAI P. d., 2013)

iii. Control de calidad. El proceso de auditoría deben orientarse sobre una dirección de alto nivel y acompañarse de procesos de revisión y supervisión que permitan identificar falencias o equivocaciones durante su realización. Ello evita que el proceso se vicie en su integralidad por la presencia de equivocaciones aunque estas sean supérfluas o inofensivas para el resultado. El proceso de auditoría debe estar lo más garantizado posible desde cualquier punto de vista por lo que, en casos de asuntos difíciles o confusos deben existir los estamentos encargados para solucionarlos al interior de las EFS. Para profundizar en este aspecto en particular consulte, (Consejo de Normas Internacionales de Auditoría y Aseguramiento IAASB, 2010).

iv. Gestión y habilidad del equipo de auditoría. Los miembros del equipo que lleve a cabo una auditoría en el sector público deberán contar con las competencias profesionales, la experiencia necesaria y los conocimientos técnicos o especializados requeridos por el objeto de la auditoría. Ello no implica que todos deban ser expertos en todas las áreas de auditoría. En casos de que se requieran conocimientos especializados y la EFS no cuente con profesionales en la materia, podrá contarse con el apoyo de expertos o auditores externos e incluso del auditor interno de la entidad auditada. Ello no significa que la responsabilidad en cabeza de la EFS se delegue, en tanto que es ella la única responsable y garante de la información producto de la auditoría.

v. Riesgos de auditoría. La auditoría interna no es ajena a los riesgos propios de cualquier actividad. El riesgo latente en estos procedimientos consiste en que el auditor llegue a conclusiones inadecuadas y como consecuencia de ello se genere un informe anpropiado para los fines requeridos. Por tanto, y bajo el presupuesto 
de que nunca podrá haber certeza absoluta sobre el concepto del auditor, este se encuentra en la obligación de implementar todos los mecanismos que considere necesarios para administrar dicho riesgo (INTOSAI P. d., 2013).

vi. Documentación y comunicación. La actividad de auditoría debe estar debidamente documentada desde la preparación hasta sus resultados. En ella debe describirse con detalle el plan de auditoría, la metodología empleada, los procedimientos realizados, la materia en cuestión, la evidencia obtenida y las conclusiones. Durante el proceso de consolidación de la auditoría deberá existir una comunicación constante tanto a nivel interno (con la entidad o persona auditada) como a nivel externo (con los grupos de interés o estamentos de rango superior competentes). Este proceso es indispensable para la consolidación de un trabajo constructivo (INTOSAI P. d., 2013)

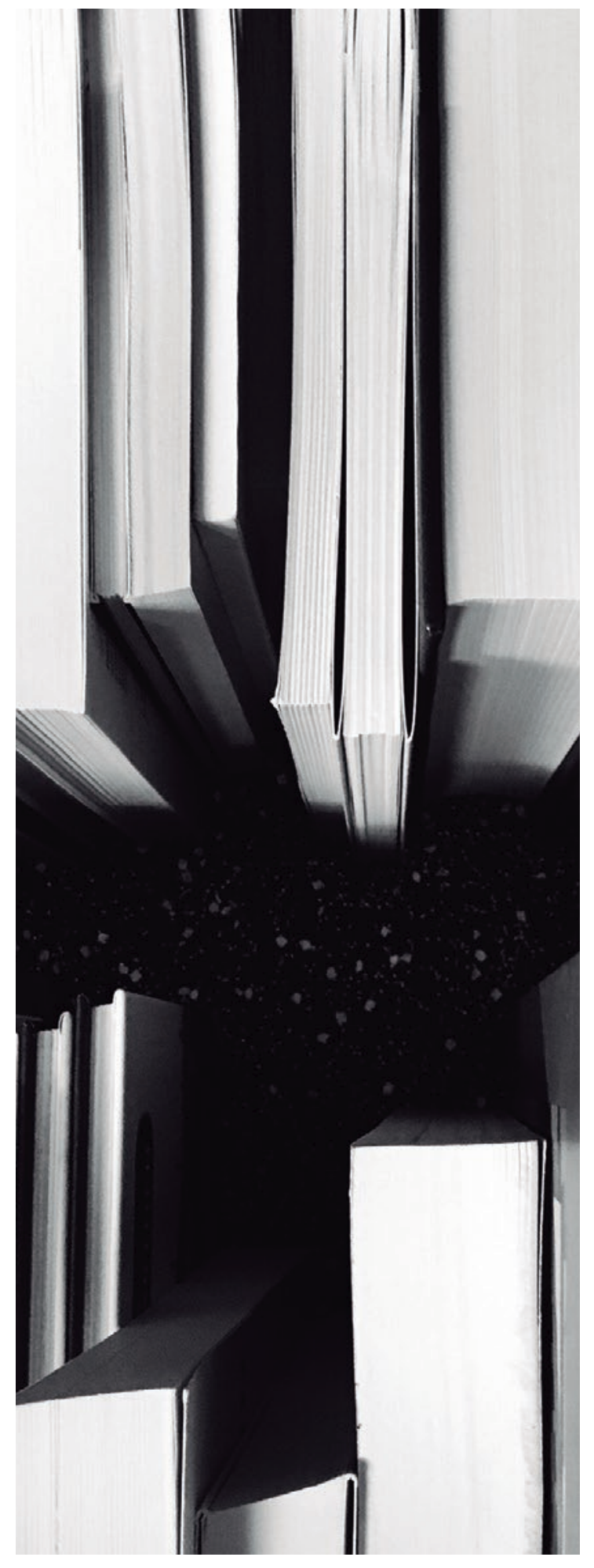




\subsection{Principios relacionados con el proceso de auditoría.}

\section{El proceso de auditoría en el sector público se define a su vez, por principios específicos que}

la orientan,

1. PLANEACIÓN DE AUDITORIA

1.1. Comprensión

clara de la

naturaleza de la

entidado programa

a auditar: objetivos,

operaciones,

entorno regulatorio,

controles internos,

etc. a partir de la

interaccióncon

involucradosy del

uso de expertoso

estudios adicionales

1.2. Establecer con

claridad el objetivo

de la auditoría

(según la clase de

auditoría. Ver 5.2.

1.3. Identificar los

riesgos generales y

específicos, su

impacto yel

tratamiento dado

por la entidad auditada, haciendo

énfasisen los

riesgos de fraude.

1.4. Organización de la auditoría.

1.4.1. Organización estratégica: definir el alcance (materia y

criterios), los

objetivos (lo que se

quiere lograr) yen

enfoque (naturaleza

y alcande de los

procedimientos de

recolección de evidencia).

1.4.2. Organización

operacional:

Cronograma,

asignación de

actividadesal

equipo, solicitud de

recursos adicionales.
2. REALIZACION DEAUDITORIA

2.1. Obtención de

evidencia de

auditoría:

información utilizada

por el auditor para

determinar si el

asunto auditado

cumple con los

criterios aplicables.

esta evidencia se

puede tomar de

diferentes formas

(registros de

operaciones,

comunicaciones,

entrevistas,testimoni

os, etc) y mediante la

aplicación de

variados métodos

(observación,

inspencción, análisis,

recálculo, etc).

Debe ser suficiente (en cantidad): validar los resultadosy

hallazgos y apropiada (en calidad):

relevante, válida y confiable.

2.2. Evaluación de la evidencia: El auditor debe cotejar la evaluación inicial de

la materia de auditoría con la evidencia recaudada para determinar si es necesario realizar procedimiento adicionales. Esta evaluación se realiza con miras a obtener los resultados y hallazgos de la auditoría y tiene en cuentafactores cuantitativos como cualitativos.

\section{ELABORACION DE INFORMES Y SEGUIMIENTO}

3.1.El informe es el documento a través del cual se

comunican los

resultados dela

auditoría. Debe estar

construido en

lenguaje

comprensible, de

manera detallada y

completa. Describir el método utilizado y

los hallazgos del

proceso, esto es explicar la forma en que se usóla evidencia obtenida y la razón de las conclusiones resultantes.

3.2. Si el compromiso de la auditoría es de atestiguamiento, deberá consignarse si la materia cumple o no con los criterios establecidos.

3.3. Si el compromiso es directo, $\mathrm{Se}$ incluyen además recomendaciones.

3.4. Las EFS en su rol de supervisoras, deben realizar seguimiento a las recomendaciones impartidas en el informe. Si no se llevan a cabo acciones de mejora o estas son insuficientes puede incluso elaborar un nuevo informe.

\section{DICTAMEN}

Se realiza en formato estandarizado.

4.1. NO MODIFICADO: Cuando se ha obtenido una seguridad limitada o razoable.

4.2. MODIFICADO: EI auditor deberá expresar claramente las razones en perspectiva de los objetivos de la auditoría (1.2). Este puede ser:

4.2.1. Calificado o con salvedad: El auditor está en desacuerdo o no es capaz de obtener evidencia de auditoría suficientey apropiada en algunos elementos de la materia auditada que podrían ser importantes aunque no generalizados.

4.2.2. Adversa: Cuando el Auditor concluye que las desviaciones o las representaciones erróneas, individuales - colectivas son importantesy generalizadas.

4.2.3. Abstención de opinión:

Imposibilidad del auditor de obtener evidencia de auditoria suficiente y apropiada significante y generalizada. 
2. Clases de auditoría en el sector público.

Aunque el fin último de una auditoría del sector público consiste en identificar, evidenciar y verificar el cumplimiento de las leyes y reglamentos establecidos para el cumplimiento de los fines del Estado, existen en él, tres (3) objetivos específicos que determinarán la clase de auditoría que se requiere. A saber,
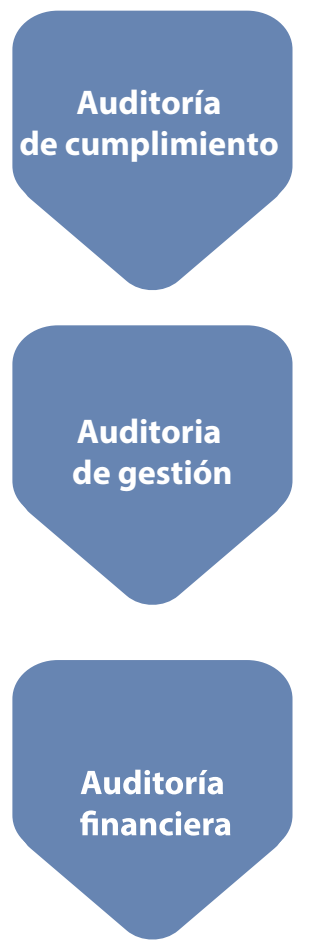

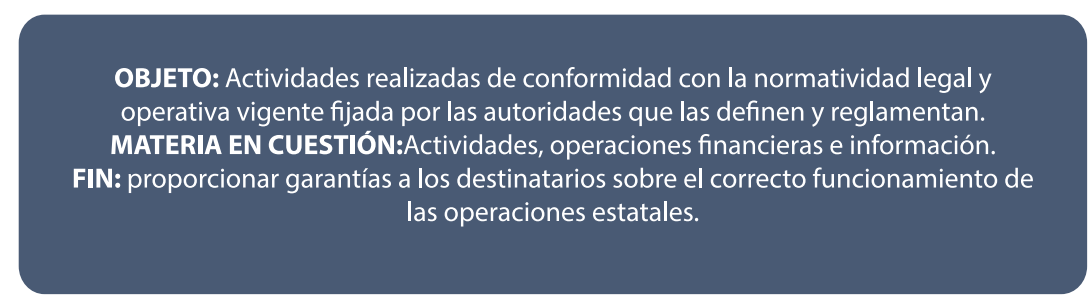

También conocida como auditoria de desempeño, rendimiento o de optimización de recursos

OBJETO: intervenciones, programas e instituciones.

MATERIA EN CUESTIÓN: Programas, entidades o fondos específicos, actividades (productos, resultados e impactos), situaciones existentes (causas y consecuencias), información financiera y no financiera.

FIN: desempeño de conformidad con los principios de eficacia, eficiencia y economía con miras a evitar la malversación o uso indebido de los dineros públicos.

OBJETO: Información financiera de una entidad.

MATERIA EN CUESTIÓN: Situación financiera, resultados financieros, flujo de efectivo, estados financieros.

FIN: Cotejar con el marco de referencia y regulatorio de emisión de información financiera y analizarla a partir de la situación de la entidad, los resultados y el uso de los recursos.

(INTOSAI P. d., 2013) Cfr. (INTOSAI C. d.-C., 2010)

No obstante lo anterior, pueden existir auditorias combinadas que incorporen 2 o más de los aspectos enunciados.

3. Elementos de auditoría en el sector público.

Toda auditoría en el sector público se compone de tres (3) elementos básicos para su materialización, a saber,

3.1. Los sujetos intervinientes.

Existen por lo menos (3) sujetos intevinientes esenciales para adelantar un proeso de 
auditoria. El auditor, definido por la INTOSAI como (...) persona o personas nombradas en virtud de una disposición estatutaria o de un acuerdo que actúan por cuenta de una agencia nacional de auditoría o de un tribunal de cuentas formado por jueces (...) (2010, p. 56); la parte responsable, encargada del objeto de la auditoría. Pueden ser individuos u organizaciones; y los usuarios previstos, entendidos estos como los receptores del los resultados de auditoría. Pueden ser individuos, organizaciones o áreas de las misma. También pueden ser órganos legislativos o de vigilancia/supervisión con facultad de gobernanza y/o toma de decisiones en el sector público. (INTOSAI P. d., 2013)

\subsection{El objeto de auditoría.}

El objeto de auditoría de se define de conformidad con una serie de variables relacionadas entre sí. La materia o asunto en cuestión, entendida como la información, condición, programa o actividad que se evaluará. Los criterios para evaluar el asunto, son los parámetros o puntos de referencia sobre los que se llevará a cabo la auditoría. Estos pueden depende entre otros aspectos, de los objetivos, la clase de auditoria o tipo de compromiso adquirido. Existen criterios generales como las leyes o principios estatales y criterios específicos como los los reglamentos o normas de control interno de entidades del sector público. La información, entendida como el resultado de la evaluación conforme a los criterios establecidos. También varia según el objetivo y clase de auditoría a adelantar. (INTOSAI P. d., 2013)

\subsection{Los compromisos.}

La relación entre la parte responsable y el auditor puede definir el compromiso de auditoría a adelantar. Existen compromisos de atestiguamiento, en los cuales la parte responsable reune y presenta la información de la materia con el ánimo de que el auditor cuente con una base razonable que le permita expresar una conclusión. También existen compromisos directos, en los que el auditor selecciona la materia o asunto en cuestión y la evalúa de conformidad con los criterios. El resultado de esta medición se presenta en el inform de auditoría en forma de hallazgos, conclusiones, recomendaciones o en un dictamen. (INTOSAI P. d., 2013)

\section{Auditoria Interna.}

Desempeña un papel trascendental en el sector público la actividad de auditoría interna, definida por el Instituto de Auditores Internos IIA (por sus siglas en inglés) como,

(...) una actividad independiente, objetiva y consultiva diseñada para agregar valor y mejorar las operaciones de una organización. La auditoría interna ayuda a una organización a cumplir con sus objetivos 
ofreciendo un enfoque sistemático y disciplinado para evaluar $y$ mejorar la eficacia en los procesos de gestión del riesgo, de control y de gobernabilidad (...) (INTOSAI S. c., 2010)

Aunque en la efectividad del control interno debe evidenciarse en todos y cada uno de los eslabones de la entidad pública, es indispensable que exista un órgano o dependencia con dedicación exclusiva a su monitorio y evaluación. Por ello, la actividad de auditoría interna en entidades públicas se ha convertido en un elemento que visibiliza el buen gobierno corporativo y los procesos de rendición de cuentas propios de establecimientos encargados del manejo y uso de dineros públicos (INTOSAI S. C., 2010).

La pretensión de la auditoría interna en las entidades del sector público no puede ser distinta a la de identificar, monitorear y controlar los procedimientos y actividades adelantados por esta, con miras a sostener y actualizar los procesos de control interno que orienten la prestación de servicios públicos en general de manera eficiente y eficaz, consolidar de manera integral la información necesaria para procesos de rendición de cuentas, mejorar las operaciones e inspirar la confianza de los grupos de interés (INTOSAI S. C., 2010). Por tanto, no puede entenderse como un proceso rígido y punitivo de evaluación de las actividades, sino por el contrario, como un mecanismo que propenda por el mejoramiento de la institución.

Dentro de las funciones de la actividad de auditoría interna se encuentran, i) Analizar las debilidades y fortalezas del control interno en relación con los objetivos generales y específicos de la entidad, verificando su coherencia y materialidad, ii) relacionar el control interno con factores como la gobernabilidad y la cultura organizacional, iii) identificar los eventos derivados del control interno para catalogarlo como oportunidades o riesgos, iv) orientar al personal en aspectos que puedan ser peligrosos para las actividades cotidianas de la organización, v) ofrecer soluciones o planes de mejoramiento en los aspectos que impliquen riesgos (INTOSAI S. C., 2010).

Para lograr el cumplimiento efectivo de estas funciones, la auditoria interna deberá estar dotada de una serie de procedimientos y mecanismos que, por un lado, garanticen su autonomía absoluta en el desarrollo de sus actividades (independencia), y por otro lado, contribuyan a la visibilización de la realidad en el análisis de la información suministrada (objetividad). Independencia y objetividad son entonces, los dos (2) elementos que acompañan a la labor de auditoría si se quiere que esta sea un proceso riguroso, confiable y efectivo (INTOSAI S. c., 2010).

La independencia, entendida como (...) la libertad de dependencia, influencia o control por parte de otra persona, organización o estado (...) (INTOSAI S. C., 2010), implica que los auditores 
internos conozcan y se pronuncien sobre la información relacionada con el uso de recursos públicos y los servicios prestados por la entidad auditada sin ninguna clase de restricciones, presiones, controles o manipulaciones. La definición de su rol y funciones en leyes, normas o reglamentos, la ubicación organizacional en un alto estamento de la entidad, el apoyo irrestricto a la gestión por parte de los altos mandos de la entidad, las reuniones periódicas con los cuerpos directivos, la libertad para establecer planes de auditoría, la asignación de recursos físicos, económicos y de personal suficientes, el acceso libre e irrestricto a todas las funciones, expedientes, documentación correspondiente a bienes muebles e inmuebles de uso de la entidad, una remuneración considerable acorde a la cantidad de trabajo y el contacto con el personal constituyen mecanismos eficaces para garantizar una labor autónoma del ejercicio de auditoría (INTOSAI S. c., 2010).

La objetividad por su parte, ha sido definida por el Instituto de Auditores Internos IIA (por sus siglas en inglés) como (...) una actitud mental imparcial que permite a los auditores internos cumplir con sus compromisos de forma tal que tengan una fuerte creencia en la honestidad de su trabajo final y que la calidad de este no se vea comprometida de ninguna manera (...) (INTOSAI S. c., 2010). Esta se garantiza, i) mediante la capacitación sobre las actividades de auditoría y la composición orgánica y funcional de la entidad auditada que evidencie los conocimientos, habilidades y experiencia requerida para el cargo de auditor interno ii) mediante la ubicación organizacional fuera del personas y de la función administrativa de la unidad objeto de auditoría (en aras de evitar conflicto de intereses), iii) a través de rendición de cuentas e informes a la alta dirección dotada de poder de mando, iv) Alejada de cualquier presión de carácter político, económico o personal (INTOSAI S. C., 2010).

La actividad de auditoría interna puede ser desempeñada por varias personas adscritas a una unidad, dependencia u organización independiente según el modelo adoptado por la entidad auditada. Será interna, cuando los servicios de auditoría y la actividad de auditoría son ofrecidos y administrados por empleados de la organización. Será coordinada, cuando los servicios de auditoría son ofrecidos por la combinación de empleados internos y proveedores y la actividad de auditoría es administrada por un empleado de la entidad. Será mixta, cuando los servicios de auditoría sean administrados por proveedores contratados por la entidad para ese propósito pero la actividad de auditoría es administrada por un empleado de la institución y será delegada, cuando tanto los servicios como la actividad de auditoría son ofrecidos por proveedores de servicios contratados para tal fin. En este último caso la supervisión del contrato de prestación de servicios será realizada por un funcionario de la entidad (INTOSAI S. c., 2010). "Para ampliar la información sobre los términos del contrato de auditoría consulte el "Acuerdo sobre los términos del contrato de auditoría" de la INTOSAI (issai.org, 2010). 
En cualquiera de estos casos, un auditor es, (...) la persona o personas que llevan a cabo la auditoría, habitualmente el auditor responsable del encargo u otros miembros del equipo, o cuando proceda, la empresa de auditoría (...) (INTOSAI. C. d.-C., issai.org, 2010, p. 43)

\section{Auditoria Financiera del Sector Público.}

Así como la recolección de la información de sistemas informáticos merece un acápite especial dentro de la documentación como actividad del control, la auditoría financiera amerita un abordaje específico dentro de las actividades de auditoría de las entidades públicas. Ello es así en tanto que estas, como administradoras de los dineros del Estado (dineros públicos) deben mantener políticas, procedimientos, actividades y controles rigurosos sobre el uso y la destinación de los mismos con miras a mantener, y en la medida de lo posible, intensificar la confianza de los grupos de interés (legisladores, proveedores, ciudadanía, beneficiarios) en las labores de las instituciones públicas como garantes de la materialización de sus derechos fundamentales.

Según las NIA, los estados financieros son (...) Una representación estructurada de información financiera histórica incluidas las notas relacionadas con ella, destinada a comunicar los recursos económicos o las obligaciones de una entidad en un momento concreto o los cambios registrados en un periodo determinado de acuerdo con un marco d einformación financiera. Las notas relacionadas ordinariamente comprenden un resumen de las políticas contables más significativas y otra información explicativa. El término "estados financieros" se refiere ordinariamente a un conjunto completo de estados financieros determinado por los requisitos del marco de información financiera aplicable, pero también puede refererise a un solo estado financiero (...) (INTOSAI. C. d.-C., issai.org, 2010, p. 43)

Según la INTOSAI, el objetivo general del auditor al efectuar una auditoría de estados financieros es determinar si estos se encuentran libres de incorrecciones significativas (como fraudes o errores determinantes) y si ofrecen una imagen fiel de la situación real de la entidad en términos financieros (aspectos de cumplimiento, rendición de cuentas y buena gestión financiera) de conformidad con la normatividad legalmente establecida en la materia (issai. org, 2010). Para cumplir dichos fines, las NIA ofrecen una panorámica desde el punto de vista deontológico, procedimental y operativo suficiente para adelantar una auditoría en general, y una auditoría de estados financieros en particular. No constituyen un imperativo de aplicación, en tanto que cada país contiene legislación y reglamentación propia para adelantar los procesos de control y seguimiento, pero sí de complementariedad, sobre todo en aquellos aspectos que no cuentan con una línea legal y procedimental establecida para adelantarlos.

Para lograr dicho objetivo, el auditor financiero, que puede ser un auditor interno o un 
auditor externo, proveniente por ejemplo de entidades fiscalizadoras superiores, deberá, i) Mantener un juicio y un excepticismo profesional en el desarrollo del encargo, ii) Permanecer en el encargo hasta la suscripción del informe final que consigne los hallazgos de la auditoría (salvo que se presenten circunstancias que obliguen al abandono para garantizar objetividad e independencia (ver No. 4 de este documento)), iii) Garantizar la aplicación de controles de calidad durante la inspección, iv) Asegurarse que los insumos otorgados para el cumplimiento de la labor son idóneos y suficientes para soportar las conclusiones, recomendaciones y opiniones expresadas en el informe, v) Efectuar actos de comunicación con los encargados de la gobernanza, entendida esta como (...) la(s) persona(s) u organización(ones) con la responsabilidad en la supervisión de la dirección estratégica de la entidad y con obligaciones relacionadas con la rendición de cuentas de la entidad (...) (INTOSAI. C. d.-C., 2010, p. 29), vi) orientar el plan de auditoría sobre la detección de errores e irregularidades cuantitativamente significativos en los estados financieros, vii) Indagar con la dirección sobre detecciones previas de fraudes y/o errores significativos, viii) velar por la integridad y validez del presupuesto y de las cuentas públicas, ix) Analizar los riesgos internos $y / 0$ externos ligados a la actividad o a la entidad, $x$ ) indicar todas las deficientes identificadas y las desviaciones de cumplimientos legales, reglamentarios y estatutarios, entre otras (INTOSAI. C. d.-C., 2010).

La base de una auditoría financiera son los estados financieros de la entidad auditada. Estos estados financieros constituyen no solo la materialidad sobre la que operan las actividades propias de la entidad pública, sino la guía para la toma de decisiones en materia económica, de órganos públicos de mayor jerarquía (legisladores, ministerios, etc) y de los usuarios del sistema. Esta materialidad se compone no sólo de aspectos cuantitativos, como el gasto, las inversiones, los programas etc, sino cualitativos, en la medida que la decisión de continuar, intensificar, eliminar, ajustar o complementar los programas y financiamientos públicos dependerá del análisis de los estados financieros en particular (entidad auditada) y en conjunto (entidades públicas) en competencia de órganos encargados de la gobernaza a nivel nacional (INTOSAI. C. d.-C., issai.org, 2010)

Por lo anterior, el informe de auditoría de estados financieros constituye un insumo esencialísimo para el seguimiento y la toma de decisiones en materia de control fiscal. El auditor deberá, según los objetivos específicos de su labor, informar de manera fiel la situación de los estados financieros auditados y las consecuencias que de ellos se derivan: constataciones, recomendaciones e incluso respuestas a la dirección. Para conocer en detalle la formación de opinión y elaboración de informes de auditoría de estados financieros, consulte el documento de la INTOSAl: forming an opinion and reporting on financial statements (INTOSAI. C. d.-c., 2010). 


\section{OPPCF}

\section{Conclusiones}

Las disposiciones internacionales de la INTOSAI reglamentan en detalle procesos de control interno (entendido este como un mecanismo de evaluación y seguimiento a las actividades desplegadas por entidades del sector público, con miras a identificar y responder a riesgos que pueden ser perjudiciales para la labor de administración de recursos), de auditoría interna (entendida como una dependencia encargada exclusivamente de la verificación y mejora de los procesos de gestión de riesgo, de control y de gobernabilidad en todos los estamentos de la entidad) y de auditoría externa -que se diferencia del anterior en tanto que, esta se adelanta con miras a evaluar (aunque sería más apropiado hablar de verificar la coherencia) si las actividades de la entidad operan de conformidad con leyes, normas, reglamentos y procedimientos fijados por el Estado.

- El control interno se fundamenta en la aplicabilidad de principios generales y específicos en la totalidad de las actividades y proyectos adelantados por entidades estatales, tendientes a que la gerencia y el personal se encuentren preparados para asumir, gestionar o eliminar riesgos que pongan en peligro la misión de la institución. Para ese efecto, toda entidad pública deberá diseñar un sistema de control que permita que identificar eventos que pueden o no constituir un riesgo, valorar su mayor o menor probabilidad de ocurrencia y tomar las medidas correspondientes (mediante un análisis de costo-beneficio). a todo nivel dentro de la organización.

- Es importante que el control interno cuente con reglamentación clara, sencilla y comprensible (que puede ser general o particular) y con un organismo interno pero independiente que tenga como actividad principal su monitoreo.

- El proceso de auditoría es adelantado por regla general, por las Entidades Fiscalizadoras Superiores - EFS definidas como los organismos estatales encargados de intervenir en el control de las instituciones públicas dependientes del Estado. Ocasionalmente es desarrollado por entidades particulares o auditores internos.

- La auditoría del sector público tiene como fin último identificar si las condiciones reales de funcionamiento de una entidad se corresponden con los criterios fijados a nivel nacional para ello con miras a enterar a los encargados de la gobernanza y/o la toma de decisiones a nivel Estatal.

- La auditoría interna propende por mantener o actualizar los procesos de control interno de una entidad pública con miras a garantizar los objetivos de su existencia y funcionamiento. En términos generales, a orientar la prestación de servicisos públicos de manera periódica, eficiente y eficaz. 
- Reviste especial importancia en labores de auditoría del sector público, la auditoría de esstados financieros, definida como aquella que se realiza sobre el los recursos económicos de que dispone una entidad para el desarrollo de sus actividades. Ello es así en tanto que, para los grupos de interés (entiéndase, organismos encargados de la gobernanza, ciudadanía beneficiaria de la entidad o programa, público en general, etc) es primordial conocer en qué se invierten los dineros del estado y si esa inversión es acorde con las necesidades y/o objetivos de dicha entidad.

- Toda la reglamentación nacional e internacional en materia de control y auditoría podría ser objeto de cuestionamiento desde el punto de vista de un observador profáno. El exceso de controles tanto a nivel interno como externo puede ser perjudicial para el desarrollo de actividades que ameritan un tratamiento especial expedíto e inmediato. La falta de controles tanto a nivel interno como externo contribuyen a la presencia de riesgos de fraude y delitos como la corrupción. La inexistencia de entidades encargadas de auditar a las instituciones públicas evidencian una debilidad estatal en el control de sus operaciones. La existencia de órganos independientes al interior del Estado encargados de auditar a las entidades públicas son una inversión considerable y no representan mayores beneficios en tanto que la labor puede ser desempeñada al interior de la institución. Etc.

Sin embargo, en la práctica, estos procesos, adelantados ética y ordenadamente, contribuyen significativamente al correcto funcionamiento de las entidades estatales. La posibilidad de identificar riesgos que se concreten en daños para la actividad pública, los mecanismos para atender peligros que pueden repercutir en la vulneración de derechos fundamentales de los ciudadanos, la identificación de actividades y/o personas que contribuyan a la corrupción o mal manejo de los recursos, el seguimiento a los planes y programas en términos de eficacia y necesidad, los procesos de rendición de cuentas como símbolo de transparencia gubernamental, entre otros, son escenarios necesarios dentro de un Estado Social y Democrático de Derecho.

Ello desde la teleología de la reglamentación y los protocolos. La perversión del sistema y las coyunturas políticas, económicas, sociales y culturales, sobre todo en países de la región, habrán de ser abordadas en otros escenarios y/o publicaciones.

\section{Referencias Bilbiográficas}

INTOSAI, S. -c. (1998). issai.org. Retrieved 1 de 08 de 2018 from issai.org : http://www.issai. org/en_us/site-issai/issai-framework/intosai-gov.htm

INTOSAI, S.-c. d. (2007). intosai.org. Retrieved 16 de 07 de 2018 from intosai.org: http://www. intosai.org/es/issai-executive-summaries/detail/detail/News/intosai-gov-9130-guia-para- 


\section{OPPCF}

las-normas-del-control-interno-del-sector-publico-informacion-adic.html

INTOSAI, S.-c. d. (2004). intosai.org. Retrieved 2 de 07 de 2018 from intosai.org: http://www. intosai.org/es/issai-executive-summaries/detail/detail/News/intosai-gov-9100-guia-paralas-normas-de-control-interno-del-sector-publico.html

INTOSAI, C. d. (1998). issai.org. Retrieved 3 de 08 de 2018 from issai.org: http://www.issai. org/en_us/site-issai/issai-framework/2-prerequisites-for-the-functioning-of-sais.htm

INTOSAI, S. C. (2001). issa.org. Retrieved 9 de 08 de 2018 from issai.org : http://www.issai.org/ en_us/site-issai/issai-framework/intosai-gov.htm

INTOSAI, S. c. (2010). issai.org. Retrieved 9 de 08 de 2018 from issai.org: http://www.issai.org/ en_us/site-issai/issai-framework/intosai-gov.htm

INTOSAI., C. d.-C. (2010). issai.org. Retrieved 10 de 09 de 2018 from issai.org: http://www. issai.org/es/site-issai/issai-framework/4-directrices-de-auditoria.htm

INTOSAI., C. d.-C. (2010). issai.org. Retrieved 13 de 08 de 2018 from issai.org: http://www. issai.org/es/site-issai/issai-framework/4-directrices-de-auditoria.htm

INTOSAI., C. d.-c. (2010). ISSAl.org. Retrieved 03 de 09 de 2018 from ISSAI.org: http://www. issai.org/es/site-issai/issai-framework/4-directrices-de-auditoria.htm

INTOSAI, P. d. (2013). issai.org. Retrieved 20 de 09 de 2018 from issai.org: http://www.issai. org/en_us/site-issai/issai-framework/3-fundamental-auditing-priciples.htm

INTOSAI, C. d.-c. (2010). issai.org. Retrieved 23 de 09 de 2018 from issa.org: http://www.issai. org/en_us/site-issai/issai-framework/4-auditing-guidelines.htm

Consejo de Normas Internacionales de Auditoría y Aseguramiento IAASB, F. I. (2010). issa. org. Retrieved 25 de 09 de 2018 from issa.org: http://www.issai.org/en_us/site-issai/issaiframework/2-prerequisites-for-the-functioning-of-sais.htm 


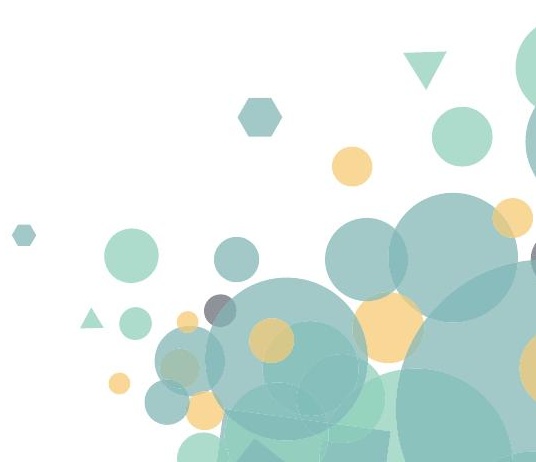




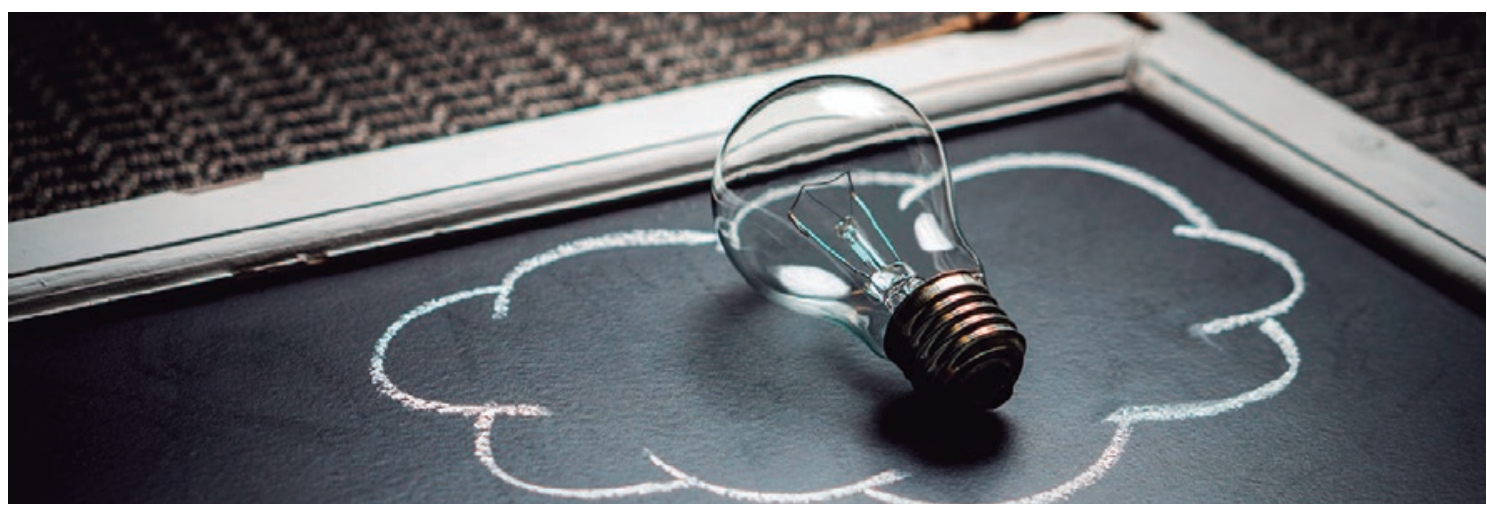

\section{CAPÍTULO VI}

\section{LINEA JURISPRUDENCIAL CONTROL FISCAL EN COLOMBIA \\ JURISPRUDENTIAL LINE FISCAL CONTROL IN COLOMBIA 22 \\ DALIA CARREÑO DUEÑAS ${ }^{23}$}

Temario: introducción, metodología, distribución temática, contribución al Observatorio, lo que viene, abordaje jurisprudencial Corte Constitucional, Corte Suprema, Consejo de Estado, Consejo Superior de la Judicatura, Conclusiones, Referencias

\section{Resumen}

Colombia como Estado social de derecho en tanto proyecto político, social y ético, ha trazado las rutas, los mecanismos y los propósitos necesarios para que se instaure la moralidad pública y la transparencia en el manejo de los recursos públicos, que más allá de la mera vigilancia técnica, se trata de la construcción de una auténtica cultura de la responsabilidad pública y el compromiso social, con un país que cuenta con una población necesitada y desprotegida. Así que el control fiscal se ha de configurar en derecho fundamental, cuyos amparos y salvaguardas propicien la lucha contra la corrupción, contra aquellos que malgastan y se aprovechan de los recursos públicos negando oportunidades de calidad de vida. De ahí que

22 Este capítulo es resultado de investigación del Convenio de colaboración académica, celebrado entre la Universidad Santo Tomás y la Auditoria General de la República, desarrollado en colaboración entre los grupos de investigación Socio Humanística del Derecho, Francisco de Vitoria de la Universidad Santo Tomás, clasificados en COLCIENCIAS en A, dentro de la línea de investigación en Corrupción, y el grupo de Investigación de la Auditoria General de la República dentro del proyecto de Investigación: Observatorio de Política Pública del Control Fiscal. 23 Licenciada en filosofía y letras, licenciada en filosofía y ciencias religiosas, Abogada especialista en derecho penal, magíster en Educación, Doctoranda en Derecho Universidad de Buenos Aires. Líder del grupo de investigación social y humanística, clasificado A en COLCIENCIAS, miembro del Grupo de Investigación Política Pública y Control Fiscal de la Auditoria General de la República. Contacto: daliacarreno@usantotomas.edu.co 
indagar por la forma en que los magistrados de las Altas Cortes han construido y creado el bien jurídico del Control fiscal, su arquitectura en la que han definido los sujetos, los mecanismos, métodos, sistemas y la trascendencia de este como corresponsabilidad de todos, pues es necesario fortalecer una ciudadanía que coadyuve en la labor de vigilancia, control y sin duda eficiencia y eficacia de los recursos públicos que permitan la paz social. Por lo que es necesario y fundamental la creación de un Observatorio en Política pública y Control Fiscal como compromiso en la lucha contra la inmoralidad del manejo del erario, y en alternativa de justicia.

\section{Abstract}

Colombia as a social State of law as an ethical-political project, has traced the routes, mechanisms and purposes necessary for the establishment of public morality and transparency in the management of public resources, which go beyond mere technical surveillance, it is about the construction of an authentic culture of public responsibility and social commitment, with a country that has a needy and unprotected population. So fiscal control must be configured in fundamental law, whose protections and safeguards propitiate the fight against corruption, against those who waste and take advantage of public resources denying opportunities for quality of life. Hence, investigate the way in which the magistrates of the High Courts have built and created the legal right of fiscal control, its architecture in which they have defined the subjects, the mechanisms, methods, systems and the transcendence of this as co-responsibility of all, therefore, it is necessary to strengthen a citizenship that contributes to the work of vigilance, control and undoubtedly efficiency and effectiveness of public resources that allow social peace. For what is necessary and fundamental the creation of an Observatory on Public Policy and Fiscal Control as a commitment in the fight against the immorality of the management of the treasury, and in the alternative of justice.

\section{Palabras clave}

Control fiscal, Observatorio, Jurisprudencia

\section{Key Words}

Fiscal control, Observatory, Jurisprudence

\section{Introducción}

La corrupción marca la decepción de las sociedades posmodernas que advierten, que los propósitos del Estado social de Derecho son una mera aspiración o quizá una frustración, frente a los ideales de una ciudadanía, que advierte como el erario, que representa la 
manera como se pueden garantizar los recursos para que las oportunidades puedan llegar a los menos favorecidos, es dilapidado y de manera injusta apropiado por un grupo de inescrupulosos; cuya conciencia social, no mide la tragedia que causa, bien porque no asume de manera pulcra, es decir con la moralidad cívica, pública, y con transparencia la función del servicio público, que conlleva el manejo de estos recursos.

De ahí que, como expresión de la voluntad política ciudadana, y como compromiso con la lucha contra la corrupción, que origina deterioro general de una nación como la nuestra, que vive el momento histórico del posacuerdo o del posconflicto, como un gran reto (Carreño et al, 2017a). La creación de un Observatorio de Política Pública se configura en un aporte, desde la investigación interdisciplinar del derecho como ciencia social, creadora de conceptos, discursos que implica de manera necesaria una forma de acción práctica política.

No hay duda de que la creación del derecho, en perspectiva crítica contemporánea, reside de manera fuerte también en la jurisprudencia, como expresión de la manera de pensar y decir el derecho. Los magistrados de las Cortes, desde las apuestas por la moralidad pública, han posibilitado la arquitectura de lo que conforma el Control Fiscal, los principios que le son conexos, en tanto él mismo es también principio. Así mismo contempla el tratamiento a los sujetos, procesos, métodos y la gestión que adelantan la Contraloría General, a las contralorías departamentales y municipales.

El control fiscal como creación por vía jurisprudencial ha sido objeto de pronunciamientos de todas las Altas Cortes. Cada Corte ha asumido temas y problemas como expresión de la complejidad de los procesos que adelantan los órganos de control y que, pese a ellos, campea la corrupción, dando la impresión en el conjunto social, que no hay alternativas de solución, ni de posibilidades de superar este mal endémico, que arrastra la nación en formación desde el siglo XIX (Carreño et al, 2016)

La creación de la línea jurisprudencial del Control Fiscal demandó esfuerzos de los grupos de investigación interinstitucional de la Auditoria General de la República y de la Facultad de Derecho de la Universidad Santo Tomás, compuesto por un investigador senior, un asociado y por el grupo de jóvenes pertenecientes al semillero de Política Pública. Esta labor implicó un proceso sistemático, organizado en cuatro momentos, que bajo la denominación de metodología se detalla el paso a paso, de cómo se desarrolló la línea jurisprudencial del Control Fiscal en Colombia.

Una vez la metodología se precisa los hallazgos de la jurisprudencia en cada una de las Cortes, con los abordajes fundamentales, los conceptos y el desarrollo histórico que da cuenta del pensar del Control Fiscal. En esta enunciación al final se adjunta la visualización, la forma gráfica o comprensiva de cada ejercicio, Corte por Corte. 


\section{La metodología de trabajo}

Para la creación de la línea jurisprudencial fue necesario realizar un trabajo sistemático con el equipo de investigadores, que partió en un primer momento de la búsqueda de toda la jurisprudencia en donde el asunto tratado sea el control Fiscal, en la Corte Constitucional, Corte Suprema de Justicia, Sala Penal, Consejo de Estado y Consejo Superior de la Judicatura.

El filtro o la clave en base de datos de la Corte Constitucional permitió la primera selección aproximada que arrojó un total de 642 sentencias discriminadas así: 37 autos, 460 sentencias de constitucionalidad, 9 sentencias de unificación y 137 tutelas. Para el caso de la Corte Suprema Sala Penal, se trabajaron 199 jurisprudencias. Del Consejo de Estado se hallaron en esta primera fase 154 sentencias y 77 conceptos. El análisis inicial reportó 11 sentencias del Consejo Superior de la Judicatura.

Con esta base de jurisprudencia en un segundo momento, se inició la revisión una a una de cada sentencia, con el diseño de instrumentos de captura, y un tutorial para su desarrollo, específicos para cada Corte, así que el instrumento para la recolección de la información aplicado a la Corte Constitucional precisó de los siguientes elementos: tipo de decisión, y de manera importante la descripción fáctica, la norma acusada, el problema jurídico central, los argumentos de la corte, y una discriminación del fundamento asociado con el ejercicio del control fiscal, que podría ser excepcional, atendiendo a la finalidad, a la vigilancia fiscal; al control fiscal a sociedades de economía mixta, a los principios del control fiscal y al proceso de responsabilidad fiscal. Y como aspectos finales si se advierte una contribución específica a la línea jurisprudencial y si hubo salvamentos de voto.

El instrumento de captura para la información de la Corte Suprema de Justicia, Sala Penal en materia de delitos asociados a Control Fiscal, identificando el tipo de decisión de primera, segunda instancia o de casación; así como si se trata de una absolución, una condena u otra. Es importante en este análisis identificar la fuente de la noticia criminal, si reside en los organismos de control, veedurías u otros. Es necesario que se identifique el argumento en términos de por qué la corte concluye que el hecho es irregular, así como la caracterización de la irregularidad, que bien puede ser por el incumplimiento por las personas, o respecto de recursos, de los requisitos, de la obra en sí, del procedimiento contractual, o si es un incumplimiento mixto.

Para el análisis de la Jurisprudencia del Consejo de Estado en materia de Control Fiscal, el instrumento requirió identificar: sí refiere a la sala de consulta, a la sala contenciosa o que sección. Se precisa si la decisión se trata de un concepto, de una sentencia de segunda instancia, única instancia o una tutela. De igual manera si se trata de una absolución, una condena a una persona, o a una persona natural. Es necesario identificar en dónde se desató 
el control fiscal, en los órganos de control, veeduría, auditoría o en otras instancias incluida la ciudadana. Abordar el hecho irregular (la descripción fáctica), el argumento (por qué el Consejo concluye que el hecho es irregular), así como la caracterización de la irregularidad asociado a: personas, recursos, al control fiscal interno, a la Obra, al Procedimiento contractual, o si se trata de un incumplimiento Mixto u otros. Se indaga si el Consejo hizo algún pronunciamiento respecto al control fiscal, y si hizo esta sentencia alguna contribución específica a una línea jurisprudencial, para cerrar identificar si hubo salvamentos de voto.

El instrumento de trabajo para la información del Consejo Superior de la Judicatura en materia de control fiscal está centrado en el tipo de fallo, si se trata de un proceso disciplinario, un pliego de cargos, un conflicto de jurisdicciones, un conflicto positivo de competencia o el conflicto negativo de jurisdicciones. Se indaga en dónde se originó la conducta investigada, el lugar, además si fue impulsada en algún organismo de control, veedurías o en otros. De igual manera el análisis recae en el problema jurídico central, las normas violadas, la calificación de la falta; el fundamento jurídico asociado con misión del cargo, o el conflicto de jurisdicciones, para cerrar con dilucidar si existe una contribución específica a la línea jurisprudencial del control fiscal.

En un tercer momento contando con el grupo jurisprudencias, los instrumentos de captura y de análisis para cada Corte, y sobre el filtro dado en la base de datos LexBase, se procedió a revisar, una a una las sentencias. Como era posible que el buscador según el algoritmo tomará como control fiscal, otra temática, o que abordará el control dentro del contexto semántico, se acordó que se anotará en la ficha que no aplicaba, para dejar reseña o huella de la pesquisa de todos estos fallos que tuviesen que ver con el tema del control fiscal.

Una vez se superó la etapa de recolección, como ejercicio de selección, y sin duda de interpretación porque en cada ficha de análisis los datos buscados, tienen un fin de consolidar la categoría jurídica del control Fiscal, como noción abierta al campo semántico de ser política pública, bien jurídico, derecho fundamental, en todo caso más allá de los aspectos técnicos que este implica.

Se procedió como cuarto momento a consolidar la información relevante que permitiera identificar cuál o cuáles podrían ser tanto la sentencia arquimédica así como la sentencia hito, siguiendo las indicaciones de la propuesta de López (2009), y que posibilitaran la elaboración gráfica de la línea jurisprudencial. Que, de cuenta, bien en forma lineal histórica de la consolidación y creación teórica del Control fiscal, de las consideraciones esenciales, fundantes, de las rupturas y de lo que hasta la fecha se considera como precedente, y que se configura en objeto de estudio, análisis y crítica. Se dejo a los recursos gráficos de los investigadores la manera de visualización de la línea, con la pretensión de que dé cuenta del proceso de selección 
y posterior interpretación.

Y a manera de cierre se realizó un quinto momento, que consistió en la socialización de los aspectos relevantes, de la interpretación, construcción y comprensión de la línea jurisprudencial, en cada una de las Cortes. Quedando con ello abierto el trabajo investigativo acerca del Control Fiscal en Colombia como control integral atendiendo a los postulados ético-políticos del Estado social de derecho.

\section{El telón epistemológico de la política pública del Control Fiscal}

En este capítulo se ubica epistemológicamente desde la teoría crítica del derecho, que asume que la creación del derecho está desplegada en otros escenarios no exclusivos en el legislativo, y por actores esenciales como los jueces, quienes en el día a día de la práctica judicial han de dar respuesta a los desafíos de las sociedades complejas del siglo XXI.

Uno de los temas y problemas que aquejan la paz social y atentan contra los ideales del Estado social de derecho, es la inmoralidad y la injusticia que ocasiona la corrupción por lo que urge pensar y construir la Política Pública del Control Fiscal, para ello es necesario aportar al Observatorio la creación jurisprudencial de los jueces de las Altas Cortes como la Corte Constitucional, la Corte Suprema de Justicia, el Consejo de Estado y el Consejo Superior de la Judicatura.

En cada Corte se profundiza en los aspectos básicos, las categorías de análisis y el abordaje teórico de los aspectos fundantes de la arquitectura del Control Fiscal, con vocación de consolidarse, dado el impacto para el conjunto social, en derecho fundamental, tutelado y salvaguardado por el Estado y la corresponsabilidad ciudadana. También como parte de esta propuesta jurisprudencial, se presenta un esquema que da cuenta de las sentencias de mayor trascendencia, y las que trazado los lineamientos de las exigencias de moralidad y transparencia del manejo de los recursos públicos. Una vez el mapa que conforma la línea jurisprudencial, se advierten por los investigadores unas conclusiones, más como intencionalidades a seguir con la consolidación de la política pública del Control Fiscal en Colombia como compromiso de la paz y la justicia social.

\section{Contribución al Observatorio de la Ventana de línea jurisprudencial}

La contribución de la línea jurisprudencial es un aporte necesario y fundamental al Observatorio de política pública, como quiera que da cuenta de la epistemología del Control Fiscal, de la filosofía y de la teoría del derecho, que subyace a este. Los decires de los jueces (Carreño et al 2007b) se han de comprender como los fundamentos básicos, con los cuales se ha de construir la política pública del Control Fiscal, pues esta labor de discurso 
instaura sentidos y como acción práctica se convierte, en compromiso ético-moral por la transparencia del manejo de los dineros públicos.

La jurisprudencia recoge los aconteceres históricos, la vivencia de lo social frente a lo público, que es percibido por el ciudadano como ajeno y extraño, y por lo tanto corrupto así que los jueces mediante sus fallos han constituido un espacio iusfilosófico, en donde han definido y delimitado, lo que es el control fiscal, los órganos competentes para adelantarlo, los sujetos en quienes recae este, los métodos, sistemas y los principios que le son propios o conexos, que redundan en el cumplimiento de los fines del Estado social de derecho.

Una de las ventanas del Observatorio de la política pública del Control Fiscal está integrada por la línea jurisprudencial, recogida de los fallos de las Cortes, que han dado respuesta a las preguntas, reclamos, demandas y consultas, acerca de la responsabilidad en el manejo del erario, así como las exigencias de moralidad y ética pública que frenen la corrupción que menoscaba la ciudadanía y los ideales democráticos de convivencia pacifica y de igualdad de oportunidades para todos. El grupo de investigadores al adentrarse en la creación jurisprudencial ha abierto las rutas por las cuales se deben trazar el universo de tópicos que consolidan la arquitectura del Control fiscal, en proyecto de ser e instituirse en un derecho fundamental, que garantice la pulcritud y la transparencia de los recursos públicos.

\section{La prospectiva}

Una vez los investigadores han acoplado la jurisprudencia, acerca del Control Fiscal, y han seleccionado, como interpretación también, lo que compone su fundamento, es decir el marco teórico que lo precisa, queda el escenario para que quienes, en la Academia, tengan interés en abordar y profundizar estos temas, de igual manera para los otros investigadores, estudiantes, profesores de las diversas disciplinas, con un interés en profundizar los diversos aspectos, y la multiplicidad de problemas atendidos.

Esta ventana es una herramienta práctica para los funcionarios públicos de todos los niveles, o para aquellos particulares, quienes están dentro del ejercicio público del manejo de recursos públicos, pues en la jurisprudencia de manera expedita y sin duda, cumpliendo su propósito social, dan respuesta clara a las líneas opacas por las cuales transitan quienes desean aprovechamiento para sí del erario. Quizá con ello también, sin que sea su finalidad, sino con la reserva de la interpretación de los investigadores, se trate de cierta prevención general (positiva) para los servidores, en tanto guardas del manejo ético-moral del recurso.

Una de las expectativas de la ventana de la línea jurisprudencial, tiene que ver con la participación de los ciudadanos, que han de asumir el rol de corresponsabilidad de la guarda de los recursos públicos, y sólo en la medida en que accedan a la información, que les 
pertenece como propia, con el compromiso de ilustrase acerca de lo que es la política pública del Control Fiscal, y por lo tanto coadyuvar en su protección como derecho fundamental, y como bien jurídico.

Una ciudadanía mayor de edad es capaz de superar la mera e inactiva opinión para poder consolidar propuestas de justicia y paz social, con la prolija consideración del erario en pro de los desvalidos y los sin oportunidad.

\section{Abordaje jurisprudencial}

\section{Abordaje desde la jurisprudencia de la Corte Constitucional}

La Corte Constitucional ha contribuido con la arquitectura del sistema de Control Fiscal pronunciándose como categoría, naturaleza, principios, sujetos, procesos, y gestión que corresponde a la Contraloría General, a las contralorías departamentales y municipales. Y que se constituye en parte de lo que ha de conformar las nociones que integran el derecho fundamental del Control Fiscal, origen que se halla en los lineamientos de la Misión Kemmerer que se concretaron en la Ley 42 de 1923, que creó el Departamento de Contraloría, con autonomía y cuyo propósito consistía en la fiscalización del manejo de los recursos públicos. (Cfr. Colombia, Corte Constitucional, Sentencia C 103 de 2015, 11/03/2015, Magistrado ponente: María Victoria Calle Correa). Cabe señalar que se comprende como fisco o erario los bienes o fondos públicos, cualquiera sea su origen.

Recoge la Sentencia C 103 de 2015 aspectos centrales del control fiscal, pues según lo consagrado en el artículo 267 de la Constitución, se conforma en una función pública especializada, que consiste en vigilar la gestión fiscal de la administración y de los particulares o entidades que manejan fondos o bienes de la nación atendiendo al imperativo de proteger el patrimonio público, de las irregularidades que se cometen y que redundan en la corrupción como acción inmoral, injusta y sin duda en contra de los ideales del Estado Social de Derecho.

Como parte de la noción está también que el Control Fiscal es un mecanismo de amparo de las finanzas del Estado, según Sentencia C-499 de 1998 "el control fiscal es el mecanismo por medio del cual se asegura "el cabal cumplimiento de los objetivos constitucionalmente previstos para las finanzas del Estado" (Cfr. Colombia, Corte Constitucional, 15/09/1998, Magistrado ponente: Eduardo Cifuentes Muñoz). De igual manera es inherente al Control Fiscal, la vigilancia de la gestión fiscal de la administración y de particulares o entidades que manejen recursos públicos, y que cubre aspectos financieros, de gestión y de resultados según Sentencia C 570 de 1997. Por lo que el carácter de vigilancia tiene que ver con indicar si “las diferentes operaciones, transacciones y acciones jurídicas, financieras y materiales en 
las que se traduce la gestión fiscal se cumplieron de acuerdo con las normas prescritas por las autoridades competentes (...) aplicables a las entidades que administran recursos públicos" (Cfr. Colombia, Corte Constitucional, Sentencia C 529 de 1993, 11/11/1993, Magistrado ponente: Eduardo Cifuentes Muñoz).

La jurisprudencia de la Corte se ha referido, como parte de su arquitectura a los sujetos del control fiscal, según lo preceptuado por el artículo $2^{\circ}$ de la ley 42 de 1993, enumera los sujetos de control fiscal, dentro del carácter de amplio e integral, y por lo tanto se refiere a órganos y organismos del poder legislativo y judicial, así como también particulares (incluidos partidos políticos), que manejen fondos, bienes o recursos del Estado en sentencias tales como las C320 de 1994, C-374 de 1995, C-272 de 1996, C-722 de 2007 y en los últimos pronunciamientos la C 107 de 2006. Así que los sujetos cubren un amplio espectro entre los que están las empresas de servicios públicos domiciliarios "la ley ha trasladado a las empresas de servicios públicos con participación oficial la atribución que de conformidad con la ley corresponde a las contralorías de contratar la vigilancia fiscal con empresas colombianas" (Cfr. Colombia, Corte Constitucional, Sentencia C 374 de 1995, 08/24/1995, Magistrado ponente: Antonio Barrera Carbonell).

Otro sujeto de Control Fiscal recae en las Cámaras de Comercio según lo preceptuado en la C-167 de 1995 (Cfr. Colombia, Corte Constitucional, 04/20/1995, Magistrado ponente: Fabio Morón Diaz). como quiera que estas desarrollan una función pública del registro mercantil, que corresponde al quehacer del Estado, y además esta entidad capta dineros en razón al cobro por el registro mercantil, de comerciantes y establecimientos de comercio, así estas entidades reciben ingresos públicos, y por lo tanto han de ser sujetas a control fiscal en cabeza de la Contraloría General de la República.

También son sujetos de Control Fiscal las entidades territoriales, ya que estas, dentro del régimen de república unitaria, estas "participan de los ingresos nacionales" por lo tanto la Contraloría ejerza el control sobre los fondos o bienes de la Nación, transferidos a "cualquier título" (Cfr. Colombia, Corte Constitucional, Sentencia C 127 de 2002, 26/02/2002, Magistrado ponente: Alfredo Beltrán Sierra) así como también las Sentencias C-403 de 1999 y C-364 de 2001. De igual manera para el Alto Tribunal, es cierto que en el caso de que las entidades territoriales reciban en su erario regalías del Estado, configurándose estas con ello, en fuente exógena de financiación y por lo tanto partícipes de estas, se confirma que la Contraloría debe ejercer el control fiscal sobre estos recursos públicos. (Cfr. Colombia, Corte Constitucional, Sentencia C 541 de 2011, 06/07/2011, Magistrado ponente: Nilson Pinilla Pinilla)

Las sociedades de economía mixta son sujetos de control fiscal, como lo advirtió la Corte 
en sentencias C-722 de 2007 y C-529 de 2006, pues estas están precisadas dentro del sector descentralizado, de ahí que son "organismos vinculados a la administración pública" (Cfr. Colombia, Corte Constitucional, Sentencia C-529 de 2006, 12/07/2006. Magistrado ponente: Jaime Córdoba Triviño) ya que parte del patrimonio social lo conforman recursos del Estado. A consecuencia de ello el control fiscal es legítimo y además debe ser obligatorio por disposición constitucional. Otro de los sujetos sobre el cual recae el Control Fiscal es el Banco de la República, en Sentencia C-529 de 1993, en atención a las funciones Constitucionales que le atribuye el art. 371, y recae frente a los actos que realice como propios de la labor fiscal.

Para la Corte son sujetos de vigilancia entre sí, sin que con ello se establezca una relación jerárquica entre estas entidades de control, pues se trata de aspectos puntuales de vigilancia de la gestión de Control Fiscal, entre la Contraloría y la Auditoria General de la República, como bien se contempló en la Sentencia C-1176 de 2004. Pues el control de la gestión fiscal de la Contraloría General es de resorte de la Auditoria "sin que, por tal circunstancia, ésta pueda convertirse en ente superior de aquella en cuanto al direccionamiento de la vigilancia y control fiscal, pues la atribución constitucional conferida a la Auditoria solo se restringe a la vigilancia de la gestión fiscal de la Contraloría General", ejerciendo vigilancia sobre la Contraloría General y las Contralorías territoriales. Y como quiera que la Auditoría General de la República realiza gestión fiscal, estos recursos y bienes son sujeto de Control por parte de la Contraloría "no puede quedar exento de vigilancia y control fiscal" por lo que corresponde esta vigilancia fiscal a la Contraloría General de la República, así que ha de quedar claro que "solo de manera excepcional, la Constitución autorizó a la Auditoria para la vigilancia de la gestión fiscal de la Contraloría" (Cfr. Colombia, Corte Constitucional, Sentencia, C-1176 de 2004, 24/11/2004, Magistrado ponente: Clara Inés Vargas Hernández)

Para el Alto Tribunal el proceso, los mecanismos del Control Fiscal han de atender y amparar la moralidad, transparencia de la función y de las actuaciones de los servidores públicos, que incluso se extiende a la participación en controversias políticas, la jurisprudencia entre otras la C-0089 de 1994, C-840 de 2001, C1148 de 2001 y reciente la C-794 de 2014.

El Alto Tribunal ha configurado con base en el postulado constitucional del Estado Social de Derecho, y en el principio republicano de la Democracia, la función de control fiscal es armónica con la tributaria y presupuestal otorgada al Congreso. La legitimidad del Control fiscal reside en el principio de legalidad "- trasunto de la soberanía popular -, al cual se adiciona en el momento presente la eficiencia, eficacia y economía (CP art. 268-2, Ley 42 de 1993, arts. 8-13)"y que sustenta los principios de eficiencia, eficacia y economía, principios que atienden el propósito del interés general "que en todo momento debe perseguir la Administración - hasta el punto de que su objeto y justificación estriban en su satisfacción (CP arts. 1 y 2)" en cuanto 
al cuidado del erario es decir de los recursos públicos (Cfr. Colombia, Corte Constitucional, Sentencia C 529 de 1993, 11/11/1993, Magistrado ponente: Eduardo Cifuentes Muñoz).

Los principios de eficacia económica, equidad y valoración de los costos, y protección del patrimonio público, deben estar adosados a esta arquitectura del Control Fiscal como derecho fundamental, cimentado en la absoluta pulcritud y honestidad "abarca toda la gama del comportamiento que la sociedad en un momento dado espera de quienes manejan los recursos de la comunidad y que no puede ser otro que el de absoluta pulcritud y honestidad" (Cfr. Colombia, Corte Constitucional, Sentencia C-046/94, 10/02/1994, Magistrado ponente: Eduardo Cifuentes Muñoz), y que expresan este imperativo ético-jurídico, que consagra el principio de la moralidad como rector de la gestión fiscal, y que tiene que ver con las expectativas ético-morales de la sociedad, respecto de las actuaciones de los servidores, en el manejo de los recursos públicos. Cabe anotar que para la Corte el principio de la moralidad, no se agota en las convicciones personales del servidor público, de ahí que se trate de un auténtico ejercicio ciudadano, de un legítimo derecho a comprobar el comportamiento de quienes manejan el erario; y a su vez el derecho del funcionario a que la sociedad examine su patrimonio: "La sociedad, a través de los órganos de control fiscal, tiene derecho legítimo a comprobar, en cualquier momento, la conducta de sus agentes. También éstos tienen en su favor el derecho, de que la sociedad examine su patrimonio y sus actuaciones" (Cfr. Colombia, Corte Constitucional, Sentencia C-046/94, 10/02/1994, Magistrado ponente: Eduardo Cifuentes Muñoz). En igual sentido las sentencias C-499 de 1998 y C-1176 de 2004, que aluden a los principios que gobiernan el Control Fiscal y que instituyen las bases de su empoderamiento como principio constitucional.

Para la Corte el control Fiscal es de naturaleza constitucional, pública y legal, y su ámbito de aplicación, no se limita "a un mero control numérico y de legalidad, como ocurría bajo el anterior marco constitucional" (Cfr. Colombia, Corte Constitucional, Sentencia C 103 de 2015, 11/03/2015, Magistrado ponente: María Victoria Calle Correa) sino que en su integralidad se refiere las diversas modalidades, que se hallan consagradas en la Ley 42 de 1993, definidos como: el control financiero que se realiza con base en la reglamentación de la Auditoria General de la República, para determinar si los estados financieros de la entidad, dan cuenta del resultado de sus operaciones, y los cambios en esta situación, además de comprobar "que en la elaboración de los mismos y en las transacciones y operaciones que los originaron, se observaron y cumplieron las normas prescritas por las autoridades competentes y los principios de contabilidad universalmente aceptados o prescritos por el Contador General" según art 10 Ley 42 de 1993 (Cfr. Colombia, Corte Constitucional, Sentencia C 716-2002, 03/09/2002, Magistrado ponente: Marco Gerardo Monroy Cabra). También desarrollado en C-557 de 2009, C-167 de 1995, C-402 de 2001, C-736 de 2007 y C-826 de 2013. 
Otro de los controles es el de gestión que examina la eficiencia y eficacia, en la administración de los recursos públicos, por parte de los sujetos auditables, a través del examen de los procesos administración, el empleo de indicadores de "rentabilidad pública y desempeño y la identificación de la distribución del excedente que éstas producen, así como de los beneficiarios de su actividad" según el art. 12 de la Ley 42 de 1993, y en Sentencia C-127 de 2002. Así mismo el control de resultado es el que se recae para evaluar si los sujetos auditables, logran el desarrollo de los objetivos y planes dentro de un periodo, de acuerdo con el art. 13, también en Sentencia C 100 de 1996. Para la Corte el sistema del Control Fiscal debe estar bajo el mandato del control de legalidad, establecido en el art 11, como lo refiere la Sentencia C-438 de 2017. El control Fiscal de igual manera está dirigido a la revisión de cuentas en la Sentencia C-967 de 2012 y a la evaluación del control interno, dejando con estos, completo el esquema de los sistemas que conforman la arquitectura de la vigilancia fiscal.

En la precitada sentencia C-716 de 2002 la Alta Corte sentó las bases históricas acerca de los métodos de control fiscal en Colombia, ya mencionados, teniendo que lo que se prevé es que se verifique un manejo pulcro, correcto del patrimonio público. Afirma que el vocablo actual fiscal proviene del latín fiscus que se traduce como erario o tesoro público, de ahí que control fiscal no es otra cosa que la vigilancia del manejo de los recursos de la República "el control fiscal en Colombia se confiera a una entidad que cuida de la res-publica, es decir, de la cosa pública, denota que el fin primordial del mismo es el de preservar la conservación y buen manejo de los bienes que pertenecen a todos". (Cfr. Colombia, Corte Constitucional, Sentencia C-716 de 2002, 03/ 09/ 2002, Magistrado ponente: Marco Gerardo Monroy Cabra).

También enriquece la Corte la cimentación del Control Fiscal, con vocación de derecho fundamental, pues delinea los elementos que estructuran el modelo en Colombia, resalta 4 aspectos necesarios como el de ser un control posterior, selectivo, amplio e integral, que supera el modelo anterior a la Constitución del 91 que era de forma previa y perceptiva; el carácter amplio esta dado por el manejo de los recursos de la nación, más allá de la calidad del sujeto auditable, y se centra "exclusivamente con fundamento en que su gestión fiscal involucre recursos públicos o patrimonio de estatal" (Cfr. Colombia, Corte Constitucional, Sentencia C-438/2017, 13/07/2017, Magistrado ponente: Gloria Stella Ortiz Delgado). Otro aspecto tiene que ver con la armonización, conservando las diferencias, entre mecanismos del control fiscal externo e interno como exigencia de toda entidad pública, y los alcances del control posterior. Y como cuarto la Corte prohíbe que se atribuyan funciones de carácter organizacional a la Contraloría y que son inherentes a esta misma.

El control selectivo como se considera en la Sentencia C- 716 de 2002, evidencia que no todo ha de ser objeto de inspección, ya que goza la Contraloría del poder de seleccionar 
cuáles operaciones administrativas, por sus efectos sociales, deben ser escrutadas. Con un criterio empresarial, de resultados más que gestión meramente contable, o de contrastación "persigue una visión global de las operaciones o actividades administrativas en una tónica de decidido estilo empresarial que supera los resultados obtenidos por el caduco régimen de control previo" (Cfr. Colombia, Corte Constitucional, Sentencia C-716 de 2002, 03/ 09/ 2002, Magistrado ponente: Marco Gerardo Monroy Cabra).

En la sentencia C 103 de 2015 la Corte estudia la función de advertencia según el Decreto 267 de 2000 artículo 5 numeral 7º por parte de la Contraloría General de la República, y al precisar que esta función temprana, si bien está dentro del contexto de los principios de eficiencia y eficacia como propósitos constitucionales, rompe con el equilibrio de la vigilancia fiscal y de las funciones de fiscalización consagradas en el art 267 de la C.N., así que establece límites a la tarea fiscalizadora de la Contraloría, en cuanto que este debe ser posterior y no previo, con el fin de que esta función no termine siendo una especie de intervención indebida, o incluso en una forma de coadministración, de ahí que para la Corte el Control fiscal desarrolla su función: "justamente cuando la Administración culmina la suya, esto es, cuando ha adoptado ya sus decisiones." (Cfr. Colombia, Corte Constitucional, Sentencia C-113 de 1999, 24/02/1999), Magistrado José Gregorio Hernández Galindo).

La Corte ha reafirmado las dos dimensiones del Control Fiscal, es decir un control externo, el cual es de resorte y ejercicio de la Contraloría, y el otro denominado control interno que deben, por mandato constitucional estar en cabeza de las propias entidades a través de las auditorías internas. Es claro que son diferentes, pero deben ser complementarias. En la sentencia C-534 de 1993 la Corte instituye que la propia administración cuenta con mecanismos de vigilancia y control internos y a su vez está sometida, al control externo "el control interno se entiende como parte del proceso administrativo y corresponde adelantarlo a los administradores; teniendo oportunidades propias en todos los momentos del cumplimiento de la función administrativa, pudiendo serlo previo, concomitante o posterior" (Cfr. Colombia, Corte Constitucional, Sentencia C-534 de 1993, 11/11/1993, Magistrado ponente: Fabio Morón Diaz) con el cual el funcionario asume la total responsabilidad de sus acciones. Y está labor esta también sometida al control fiscal externo, que en ningún momento se trata de un quehacer que implique una labor de coadministración, pues está función es posterior y selectiva.

El control fiscal externo por disposición constitucional según los artículos 117, 119, 267 y 268, reside en cabeza de la Contraloría General de la República, y la vigilancia y control fiscal de las entidades territoriales, le corresponde a las contralorías municipales, distritales y municipales, según el art. 272 de la C.N., y de acuerdo con el artículo 274 de la C.N. la Auditoría General de la República, es titular de la vigilancia de la gestión fiscal de la Contraloría General de la República. 
Así entonces es que se configura el Control fiscal como un sistema integral "procurando que su actividad no implique una interferencia indebida en las competencias de las autoridades para la administración y manejo de los fondos oficiales, pero velando siempre porque el control fiscal se cumpla de manera integral" (Cfr. Colombia, Corte Constitucional, Sentencia C-967 de 2012, 21/11/2012, Magistrado ponente: Jorge Iván Palacio Palacio). Esta integralidad del control fiscal, que se hace posterior se despliega también a los contratos estatales que se realiza una vez se cumpla con la legalización, con su perfeccionamiento, es decir que se hayan ejecutado, terminado o liquidado; así como la administración de los sistemas de información, como lo afirmó la Corte en Sentencias C-623 de 1999, sentencia C-648 de 2002 y sentencia C-716 de 2002.

\section{Jurisprudencia del Consejo Superior de la Judicatura}

La jurisprudencia del Consejo Superior en cuanto al Control Fiscal se ha centrado en dos aspectos básicos: el tema disciplinario y el conflicto de jurisdicciones. Como Alto Tribunal disciplinó a Magistrados que incumplieron con la labor de elección de Contralor Departamental, siendo esta una función que se debe adelantar con suma responsabilidad y cuidado. En Sentencia sancionatoria se profiere pliego de cargos contra los doctores Jorge Eduardo Rodríguez Moreno, María Del Pilar Diaz Guzmán, Jaime Enrique Vargas Moreno, Álvaro Peñuela Delgado, Alberto Romero Romero, Luis Enrique Hernández Palacios y Gloria Isabel Espinel Fajardo en su condición de Magistrados del Tribunal Superior del Distrito Judicial de Villavicencio, como posibles autores de falta disciplinaria.

Como quiera que actuaron de forma descuidada, y de manera particular con negligencia el Dr. Jorge Eduardo Rodríguez Moreno, quien frente al estudio de la hoja de vida del señor Eulises Reyes Diaz, no advirtió que este se hallaba dentro de una causal de inhabilidad para ejercer el cargo "donde figura la constancia laboral que señalaba al rompe la inhabilidad que tenía para aspirar al cargo (Cfr. Colombia, Consejo Superior de la Judicatura, Sala Jurisdiccional Disciplinaria, Radicación No. 11001010200020050128600 del 14 de junio de dos mil seis 2006, Magistrado ponente: Temístocles Ortega Narváez).

Posterior a esta Sentencia, el Consejo Superior disciplina al Magistrado del Tribunal Jorge Eduardo Rodríguez Moreno, quien teniendo el encargo de la postulación de candidatos para integrar las ternas para el cargo de Contralor Departamental, tarea que debió realizar con "supremo celo y cuidado", no cumplió pues en el caso del candidato Eulises Reyes Diaz, realizó de forma negligente, con culpa grave, con lo que ocasionó menoscabo en el servicio público y detrimento de la buena imagen de la administración pública. De ahí que es sancionado, pues afirma el Consejo que la elección del titular Departamental del organismo de Control "es un acto complejo (...) los Magistrados (...) deben velar porque 
los postulados cumplan con los requisitos que la Constitución y la ley han señalado (...) de allí que la gravedad de la falta se potencie además por esta circunstancia" (Cfr. Colombia, Consejo Superior de la Judicatura, Sala Jurisdiccional Disciplinaria, Radicación No. 11001 010200020050128600 del 18 de junio de 2008 Magistrado ponente: Temístocles Ortega Narváez).

El Consejo Superior solventa el conflicto negativo de jurisdicciones originado entre el Juzgado Promiscuo Municipal de San Roque (Antioquia) y el Juzgado Décimo Sexto Administrativo del Circuito de Medellín, respecto del conocimiento del proceso ejecutivo que instaurara la Cooperativa de Municipalidades de Antioquia Ltda, COOMUNICIPIOS en contra del Municipio de San Roque. Para el Consejo "las Cooperativas de Administración Pública, con excepción justamente de la materia referida a los contratos estatales se regula por el derecho privado" con lo cual ha de ser la jurisdicción ordinaria quien conozca el proceso ejecutivo. (Cfr. Colombia, Consejo Superior de la Judicatura, Sala Jurisdiccional Disciplinaria, Radicación No. 110010102000200602048 del enero 31 de 2007. Magistrado ponente: Temístocles Ortega Narváez).

De igual manera el Consejo al resolver conflicto positivo de competencias, entre la Comisión de Investigación y Acusación de la Cámara de Representantes y la Contralora General de la República, en favor de la Comisión. Reitera la función del Contralor General de la República centrada en "establecer la responsabilidad que se derive de la gestión fiscal, imponer las sanciones pecuniarias que sea del caso, recaudar su monto y ejercer la jurisdicción coactiva sobre los alcances deducidos de la misma" en ultimas su intervención lleva a determinar y establecer la "responsabilidad fiscal" de todo el que maneje o administre el erario. (Cfr. Colombia, Consejo Superior de la Judicatura, Sala Jurisdiccional Disciplinaria, Radicación No. 11001010200020120024300 del 29 marzo de 2012. Ponencia Conjunta). Así que no es dable a la Contraloría investigar a los Magistrados del Consejo Superior de la Judicatura, por presuntamente nombrar de magistrados auxiliares por breves periodos, acto que pese a que afecta y menoscaba el patrimonio público como quiera que le fueron reconocidas pensiones, no se trata de un ejercicio fiscal como quiera que no existe disposición material del patrimonio público.

La jurisprudencia del Consejo frente al conflicto de jurisdicciones resuelve el Conflicto de Jurisdicciones, absteniéndose, suscitado entre el Juzgado 52 civil municipal de Bogotá, y el Juzgado 32 Administrativo de la misma ciudad, en razón de la demanda ejecutiva singular de mínima cuantía incoada por la Fiduciaria La Previsora S.A., liquidadora de "ADPOSTAL en liquidación" contra Silvio Alfredo Otero Bula como quiera que impuso sanción dentro de un proceso disciplinario al demandado, consistente en multa de $\$ 640.311$. Afirma que la jurisdicción coactiva es una función que adelanta un organismo del Estado para que haga 
efectiva por vía ejecutiva, las obligaciones expresas, claras y exigibles en favor de la entidad pública, y añade que los organismos de control fiscal "también tienen esta potestad sobre las obligaciones que surgen de los fallos de responsabilidad fiscal y las multas que en el ejercicio del mismo control se impongan"(Cfr. Colombia, Consejo Superior de la Judicatura, Sala Jurisdiccional Disciplinaria, Radicación No. 11001010200020080325000 del 07 mayo de 2009. Magistrado Ponente Henry Villarraga Oliveros)

\section{Jurisprudencia Consejo de Estado}

La jurisprudencia del Control Fiscal desarrollada por el Consejo se Estado ha venido afirmando categorías fundamentales, de la arquitectura del Control Fiscal, en prospectiva de ser e instituirse en derecho fundamental, aborda aspectos como su definición, ámbitos de aplicación, objeto del control fiscal, multas, proceso de responsabilidad, sujetos del control Fiscal, distinción entre control fiscal y gestión fiscal, funciones de los contralores territoriales, función del contralor municipal, además de los aportantes y las tarifas de control fiscal.

Para el Consejo de Estado está definida su arquitectura, en la medida en que se trata de que este es amplio y comprende, diversos ámbitos de aplicación, por lo que afirma que la Contraloría General de la República podrá ejercer control fiscal posterior, en forma excepcional, sobre las cuentas de cualquier entidad territorial, o que conformen estas, como el caso de la gestión fiscal relacionada con la contratación llevada a cabo en el IDU para el sistema Transmilenio, pues son entidades que hacen parte de la entidad territorial denominada Distrito Capital. Este control sin perjuicio del control que les corresponde a las contralorías departamentales, y municipales, según artículo 26 de la Ley 42 de enero 26 de 1993. Y que su ámbito de acción puede iniciar con solicitudes del gobierno departamental, distrital o municipal, de cualquier comisión permanente del congreso de la República o de la mitad más uno de los miembros de las corporaciones públicas territoriales y muy importante por parte de la ciudadanía.

Es claro para el Consejo de Estado, compartiendo jurisprudencia con la Corte Constitucional, afirma que el objeto del control fiscal en cabeza de la Contraloría se ejerce"sobre los recursos provenientes de ingresos de la Nación será prevalente" y reconoce de manera contundente "que en tratándose de recursos endógenos-al ser producidos por la propia entidad territorial-la intervención de la Contraloría General de la República debe ser excepcional" (Cfr. Colombia, Consejo de Estado, Sala de lo Contencioso Administrativo, Sección Primera Radicación No. 11001-03-24-000-2004-00288-01 del 5 de marzo de 2015, Consejero Ponente María Claudia Rojas Lasso)

Para el Consejo, la Contraloría en ejercicio puede imponer dos clases de multas: la primera a manera de sanción pecuniaria que se deriva de la responsabilidad fiscal y su finalidad, de 
acuerdo con la Corte Constitucional, implica el resarcimiento de perjuicios "ocasionados a causa de una gestión fiscal irregular" conlleva la función de recaudo, mediante el ejercicio de la jurisdicción coactiva. La segunda clase de multa de naturaleza no sancionatoria sino correccional. La finalidad de las multas es buscar la afirmación del Control Fiscal "constreñir al funcionario o particular renuente (...) que cumpla ciertos deberes a su cargo sin los cuales no sería posible el control fiscal (...) su finalidad principal es la de "vencer los obstáculos para el éxito del control fiscal" (Cfr. Colombia, Consejo de Estado, Sala de lo Contencioso Administrativo, Sección Primera Radicación No. 41001-23-31-000-1995-08428-01 del 12 de abril de 2012, Consejero Ponente María Claudia Rojas Lasso)

Según jurisprudencia del Consejo el proceso de responsabilidad consiste en un conjunto de actuaciones administrativas encaminadas a determinar y establecer, si los servidores públicos y los particulares, cuando en el ejercicio de la gestión fiscal o con ocasión de ésta causen por acción u omisión, en forma dolosa o culposa, daño al patrimonio del Estado. De ahí que para la jurisprudencia "la responsabilidad fiscal que es de carácter subjetivo tiene por finalidad la protección del Patrimonio Público; en tal sentido, su carácter es netamente resarcitorio y por consiguiente, busca la recuperación del daño cuando se ha causado un detrimento patrimonial al Estado"(Cfr. Colombia, Consejo de Estado, Sala de lo Contencioso Administrativo, Sección Primera Radicación No. 25000-23-24-000-2001-00064-01 del 11 de julio de 2013, Consejero Ponente Guillermo Vargas Ayala). Por lo anterior el propósito de la responsabilidad Fiscal, es resarcitorio y debe tenerse la certeza de que existió el daño ocasionado al patrimonio del Estado, además de la cuantía, este ha de establecerse en cifras concretas y en su real dimensión.

Deja claro la jurisprudencia del Consejo, la distinción entre la función del control fiscal y la de gestión fiscal, que según concepto ${ }^{24}$ de la misma Alta Corporación, el control fiscal es una "función pública que tiene por objeto la vigilancia de la gestión fiscal de la administración y de los particulares que manejan fondos o bienes públicos" (Cfr. Colombia, Consejo de Estado, Sala de lo Contencioso Administrativo, Sección Primera Radicación No. 25000-23-27000-2008-00161-01 del 7 de junio de dos mil doce (2012), Consejero Ponente Marco Antonio Velilla Moreno (e)). La titularidad está en cabeza de la Contraloría General de la República, las contralorías territoriales y la Auditoría General, este se realiza a través de controles como el financiero, el de gestión y el de resultados. Esta función que se afirma también en la jurisprudencia de la Corte Constitucional se cumple desde los principios de eficiencia, economía, equidad y la valoración de costos ambientales. De igual manera el control fiscal como lo reitera la Corporación es posterior y selectivo.

Por otro lado, la gestión fiscal, según el art. 3 de la ley 610 de 2000 la define el Consejo 24 Retoma en esta jurisprudencia el Concepto Núm. 1522 de 2003, de 4 de agosto de 2003, de la Sala de Consulta y Servicio Civil del Consejo de Estado, como Consejero Ponente Flavio Augusto Rodríguez Arce. 
como el desarrollo de actividades de carácter económico, jurídico y tecnológico, adelantada por servidores públicos y las personas privadas que manejen o administren recursos públicos. Con el fin de que se realice correctamente adquirir, planear, conservar, administrar, custodiar, explotar, enajenar, además el "consumo, adjudicación, gasto, inversión y disposición de los bienes públicos, así como a la recaudación, manejo e inversión de sus rentas en orden a cumplir los fines esenciales del Estado, con sujeción a los principios de legalidad, eficiencia, economía" así como con "eficacia, equidad, imparcialidad, moralidad, transparencia, publicidad y valoración de los costos ambientales" (Cfr. Colombia, Consejo de Estado, Sala de lo Contencioso Administrativo, Sección Primera Radicación No. 2500023-27-000-2008-00161-01 del 7 de junio de dos mil doce (2012), Consejero Ponente Marco Antonio Velilla Moreno (e)) y también en: (Cfr. Colombia, Consejo de Estado. Sala de lo Contencioso Administrativo. Sección Primera. Expediente No. 1999-00482. 15 de abril de 2004. Consejero Ponente. Gabriel Eduardo Mendoza Martello) y (entre otras) (Cfr. Colombia, Consejo de Estado. Sala de lo Contencioso Administrativo. Sección Primera. Expediente No 2002-00291 del 6 de diciembre de 2007. Consejero Ponente. Marco Antonio Velilla Moreno). Por lo anterior esta distinción es necesaria y oportuna como quiera que una es función y la otra es objeto de la función.

Para el Consejo de Estado los Contralores de las entidades territoriales en razón al artículo 272 de la Constitución Política poseen "una competencia normativa subsidiaria en materia de control fiscal. Competencia residual de la ejercida por el Contralor General de la República, cuyo válido ejercicio está condicionado a las disposiciones de carácter general que expida dicho funcionario para armonizar los sistemas de control fiscal" (Cfr. Colombia, Consejo de Estado. Sala de lo Contencioso Administrativo. Sección Primera. Expediente CESEC 1-EXP1998-N3880 del 19 de febrero de 1998. Consejero Ponente Libardo Rodríguez Rodríguez) con el propósito de que esta competencia normativa subsidiaria permita al Contralor precisar aspectos, teniendo en cuenta en todo caso que no exista contradicción o desconocimiento de estos.

Desarrolla la Jurisprudencia del Consejo la pregunta acerca de quienes son sujetos del Control fiscal, también en armonía con la jurisprudencia de la Corte Constitucional, afirma que todo empleado oficial de cualquier orden y todo particular, que maneje fondos o bienes del erario. Cabe señalar que los sujetos del control fiscal son del orden nacional y territorial, hacen parte de este la organización de la administración, entidades, sociedades de economía mixta, empresas industriales y comerciales del Estado. Y a nivel territorial "los organismos que integran la estructura de la administración departamental y municipal y las entidades de este orden". (Cfr. Colombia, Consejo de Estado. Sala de lo Contencioso Administrativo. Sección Primera. Expediente 5590 del 20 de enero de 2000. Consejero Ponente Olga Inés Navarrete Barrero). De ahí advierte el Consejo que las entidades descentralizadas se 
configuran en sujeto pasivo del control fiscal.

El Consejo advierte que el Control fiscal se ejerce sobre empresas de servicios públicos si el patrimonio de ésta está conformado por recursos públicos, por lo que es estas se conforman en sujeto de control fiscal: "la Constitución ordena que el control fiscal se adelante frente a entidades de cualquier naturaleza que administren y manejen fondos o bienes de naturaleza pública" por lo que la jurisprudencia del Consejo, en su línea jurisprudencial y compartiendo postura con la Corte Constitucional ha reiterado que "el elemento predominante y decisivo para determinar si una entidad se encuentra sujeta al control fiscal, es que haya recibido para su gestión o administración bienes o fondos del Estado" como el caso de las empresas de servicios públicos que no pierden su naturaleza pública. (Cfr. Colombia, Consejo de Estado, Sala de lo Contencioso Administrativo, Sección Primera Radicación No. 25000-23-24-0002001-00064-01 del 7 de junio de dos mil doce (2012), Consejero Ponente Marco Antonio Velilla Moreno (e))

La jurisprudencia del Consejo afirma que son sujetos del control fiscal los particulares que prestan servicios públicos, como quiera que estos son investidos de autoridad, y por lo tanto ponen en riesgo derechos fundamentales de los usuarios "subyace la prevalencia del interés general (...) de su protección se trata precisamente en garantía del patrimonio del estado, entregando en la modalidad de aportes de capital sin perjuicio de su naturaleza privada, no resulta inmune al control". Por lo tanto, ningún sujeto pasivo del Control Fiscal puede oponerse alegando "válidamente intangibilidad frente al control fiscal". El control Fiscal tiene como sujeto pasivo a las personas jurídicas y cualquier otro tipo de organización o sociedad que maneje bienes o recursos oficiales, sin que se requiera la naturaleza de la entidad o persona, pública o privada, que realiza la función o tarea sobre el cual recae el control, ni su régimen jurídico. Ningún ente, de manera concluyente, por público o privado que sea, puede abrogarse el derecho de no ser fiscalizado cuando tenga que ver directa o indirectamente con los ingresos públicos o bienes de la comunidad. (Cfr. Colombia, Consejo de Estado. Sala de lo Contencioso Administrativo. Sección Segunda Subsección B Expediente: ACU-655 del 25 de marzo de 1999. Consejero Ponente: Silvio Escudero Castro)

En cuanto a la función del Contralor Municipal, afirma el Consejo de Estado que es por medio del Revisor Fiscal, quien realiza el control fiscal en los organismos y las entidades, descentralizadas de la administración municipal. Por lo que ni la Constitución ni la Ley contemplan que corresponda al Consejo municipal la elección del Auditor pues no puede existir un auditor fiscal paralelo y menos autónomo: “Como en Medellín, pues, existía, y existe, Contraloría Municipal, a este organismo correspondía y corresponde, conforme a todo lo expuesto, ejercer el control del municipio y sus entes descentralizados" (Cfr. Colombia, Consejo de Estado. Sala de lo Contencioso Administrativo. Sección Primera Expediente: 2997 
del 28 de octubre de 1994. Consejero Ponente: Libardo Rodríguez Rodríguez).

Señala la Jurisprudencia del Consejo de Estado que las Contralorías gozan de personería jurídica, son sujetos de derecho, de obligaciones y de capacidad de representación judicial y extrajudicial. De ahí que una de las funciones de la Contraloría departamental recae sobre las asociaciones de municipios, ya que estas conforman organismos públicos, es decir cuentan con personería jurídica y recursos propios e independientes. O bien recae la función de control fiscal en la Contraloría existente mediante la Asamblea General, en la misma asociación. (Cfr. Colombia, Consejo de Estado. Sala de lo Contencioso Administrativo. Sección Primera Expediente: 2990 del 26 de enero de 1996. Consejero Ponente: Rodrigo Ramírez González)

La Jurisprudencia del Consejo advierte que han de considerarse como aportantes, para efectos del control fiscal, las empresas industriales y comerciales del Departamento, pues estas entidades descentralizadas están sometidas al control fiscal ejercida por la Contraloría General de la República y en virtud de esta calidad, deben contribuir con los gastos que éste ocasiona. (Cfr. Colombia, Consejo de Estado. Sala de lo Contencioso Administrativo. Sección Primera Expediente: 2468 el 6 de febrero de 1997. Consejero Ponente: Ernesto Rafael Ariza Muñoz)

El Consejo advierte que la Contraloría General de la República cobrará una tarifa de control fiscal a los organismos y entidades fiscalizadas y esta será fijada individualmente para cada organismo o entidad vigilada mediante resolución "la determinación de las cifras correspondientes a los presupuestos tanto de la Contraloría General de la República como de cada entidad y el valor de la sumatoria de todos los presupuestos de las entidades públicas" (Cfr. Colombia, Consejo de Estado, Sala de lo Contencioso Administrativo, Sección Primera Radicación No. 25000-23-27-000-2006-90783-01 del 18 de julio de 2012, Consejero Ponente Marco Antonio Velilla Moreno e.)

La gráfica de la línea jurisprudencial obedece a una temporalidad, y a los temas y problemas que convergen a este. Y que dan cuenta de la descripción precitada una a una.

\section{Jurisprudencia de la Corte Suprema de Justicia, Sala Penal}

La Sala Penal de la Corte Suprema, comparte la jurisprudencia de la Corte Constitucional en que consagra la gestión Fiscal, como ejercicio de control sobre la administración y manejo de bienes y fondos públicos, en las distintas etapas de recaudo o adquisición, conservación, enajenación, gasto, inversión y disposición. La jurisprudencia coincide respecto de lo que es la gestión fiscal, y de cuáles han de ser los sujetos de control fiscal, para lo cual cita sentencias como la Sentencia C-499 de 1998, Sentencia SU-620 de 1996, en las que se afirma 
que el Control fiscal recae en la administración y manejo del erario, en sus diversas etapas. De igual manera es claro que se predica la responsabilidad fiscal, en todos los directivos de entidades, que fungen como ordenadores, controladores, directores y coordinadores del gasto, sean funcionarios públicos, contratistas y particulares que administren recursos públicos, si sus actuaciones lesionan el patrimonio público, verbigracia la que recae en los funcionarios de la Cámara de representantes. "la gestión fiscal no se reduce a la potestad de ordenar el gasto, como se ha sugerido (...) Por el contrario, la Mesa Directiva de la Cámara de Representantes también desempeña gestión fiscal" (Cfr. Colombia, Corte Suprema de Justicia, Sala de Casación Penal, Proceso No 17089 veintitrés (23) de septiembre de dos mil tres (2003). Magistrado Ponente Edgar Lombana Trujillo). Para la Corporación quien despliegue la gestión fiscal en alguna de sus fases está obligado a la trasparencia, cuidado responsable vigilancia y control del erario. Pues la responsabilidad fiscal se extiende a directivos y personas (particulares) dentro de entidades que determinen la gestión fiscal, como el caso del Director Administrativo de la Cámara de Representantes, quien desarrollaba toda la gestión fiscal y concentraba la tarea en materia contractual.

La Corte considera que debido a que el amparo penal no cubre "disfunciones o irritualidades en el sistema de contratación" al bien jurídico de la administración pública, se han creado diversos controles, entre los cuales están el político, el fiscal, el disciplinario, el penal, incluso el ciudadano "Tal coexistencia de controles de la gestión pública, muy afín con la idea de tutela progresiva de bienes jurídicos, permite entender el por qué, desde la Carta, el Estado protege los bienes jurídicos de diversa manera". (Cfr. Colombia, Corte Suprema de Justicia, Sala de Casación Penal, Proceso No 19826 treinta y uno (31) de agosto de dos mil cinco (2005). Magistrado Ponente Mauro Solarte Portilla). Señala el Alto Tribunal que es relevante el control fiscal posterior que recae en el ámbito financiero, de gestión y de resultados, que adelanta la Contraloría, y que recae en los funcionarios públicos que realizan actos de la administración, particulares o entidades que manejan fondos o bienes de la Nación.

Recuerda el alto Tribunal que ostentar la calidad de servidor público, conlleva la responsabilidad fiscal en la celebración de contratos estatales "con cargo a los recursos" del Estado. Y por lo tanto ha de asumir como propia la función contractual que de incumplirla incurre en una conducta penal reprochable "alternativa" que contempla tres hipótesis: tramitar contratos sin el cumplimiento de requisitos legales, celebrar contratos sin acatar requisitos, dentro de la fase precontractual, así como en su liquidación. Esta responsabilidad contractual está respaldada en principios como "la igualdad, moralidad, eficacia, economía, celeridad, imparcialidad y publicidad" integrados al principio de planeación del contrato al que deben estar sometidos los servidores públicos para proteger el erario "significa que el Estado está obligado a actuar con alto grado de eficacia y eficiencia para que se protejan los recursos públicos, fiscales, con sujeción estricta al orden jurídico" (Cfr. Colombia, Corte 
Suprema de Justicia, Sala de Casación Penal, Proceso No 29285 dos (2) de diciembre de dos mil ocho (2008) Magistrado Ponente Alfredo Gómez Quintero). Coincide la Corte con la jurisprudencia del Consejo de Estado al señalar que la contratación "no es, ni puede ser, una aventura ni un procedimiento emanado de un poder discrecional, sino, por el contrario, es un procedimiento reglado en cuanto a su planeación, proyección, ejecución e interventoría, orientado a impedir el despilfarro de los dineros públicos". Así que el Control Fiscal está encaminado a este propósito del Estado social de Derecho (Cfr. Colombia, Corte Suprema de Justicia, Sala de Casación Penal, Proceso No 29285 dos (2) de diciembre de dos mil ocho (2008) Magistrado Ponente Alfredo Gómez Quintero).

Así mismo la Corte advierte de manera clara y expresa, que el régimen de inhabilidades e incompatibilidades que consagra la Ley 80 de 1993, artículo 8, numeral 2º en el que se consagra la prohibición de celebrar contratos públicos con entidades estatales, si quienes están incursos en este proceso de contratación son cónyuge, compañero o compañera permanente del servidor público en los niveles directivo, asesor, ejecutivo, o de un miembro de la junta o consejo directivo, o de quien ejerza funciones de control interno o de control fiscal. Para el Alto Tribunal el régimen legal de inhabilidades e incompatibilidades (artículo 144 del Decreto Ley 100 de 1980) no debe ser obstáculo para su aplicación, incluso si se trata de tipos penales en blanco, que bien el acusador puede completar "el acusador no se detuvo al realizar la calificación provisional en la mera definición típica del punible, sino que también lo completó en su ingrediente normativo jurídico referido al régimen legal de inhabilidades e incompatibilidades y en ese orden acudió al estatuto de contratación o Ley 80 de 1993 , artículo 8, numeral 20" (Cfr. Colombia, Corte Suprema de Justicia, Sala de Casación Penal, Proceso No 21926 treinta (30) de enero de dos mil ocho (2008) Magistrado Ponente Alfredo Gómez Quintero). El régimen de inhabilidad e incompatibilidad incluso cobija a quien ejerza como representante legal, o parte de la Junta Directiva de la entidad, sin que necesariamente este hubiese quien suscribió el contrato.

En Proceso 28760 de 2009 la Corte afirma, que quien ostenta la calidad de servidor público y celebra contratos estatales que implican recursos del Estado, debe atender a principios, como Postulados Superiores, tales como el de "economía, transparencia, responsabilidad, igualdad, moralidad, eficacia, celeridad, imparcialidad, publicidad y selección objetiva" (Cfr. Colombia, Corte Suprema de Justicia, Sala de Casación Penal, Proceso No 28760 del cuatro de febrero de dos mil nueve Magistrado Ponente Julio Enrique Socha Salamanca). Sí falta a estos principios entonces su conducta punible, puede ser como en este caso que se disputa tramitar, celebrar o liquidar contrato sin el cumplimiento de los requisitos legales, que debe observarlos en todas las etapas de la contratación, tramitación, celebración y liquidación. Por lo que todo servidor público al celebrar contratos sin los requisitos legales, desconoce el principio de legalidad que debe tutelarse en toda contratación administrativa 
que salvaguarda los recursos públicos, y por lo tanto le genera responsabilidad penal, disciplinaria y fiscal "como todas las actuaciones de los servidores públicos, es una actividad eminentemente reglada, cuya "transgresión no solo compromete la existencia o validez de los actos contractuales, sino que genera responsabilidad penal, disciplinaria y fiscal de los servidores públicos" (Cfr. Colombia, Corte Suprema de Justicia, Sala de Casación Penal, Proceso No 28760 del cuatro de febrero de dos mil nueve Magistrado Ponente Julio Enrique Socha Salamanca).

La jurisprudencia de la Corte, advierte las diversas modalidades ilícitas frente a la defraudación del erario, en los casos en los que incurre el funcionario público, involucrado en la contratación pública de forma irregular, dentro de estas formas delictivas están las de como contratar sin el cumplimiento de los requisitos legales, fraccionar contratos, planear desfalcos, direccionar recursos a partir de modificaciones en el presupuesto oficial, ubicar personas y establecimientos de comercio reales y ficticios, además permitir "que terceros se apropiaran de los recursos del erario oficial destinados al por demás precario servicio, también estatal de la educación" (Cfr. Colombia, Corte Suprema de Justicia, Sala de Casación Penal, Proceso No 28021 octubre veintiocho (28) de dos mil diez (2010) Magistrado Ponente Alfonso Daza González). El sumo reproche deviene toda vez que este no garantizó, y por demás menoscabo principios esenciales a toda contratación como el de economía, transparencia, responsabilidad y en especial el de selección objetiva, para cumplir los fines del Estado social de derecho, bajo el mandato de que sus actuaciones han de ajustarse a la ética y la justicia. Para la Corte es claro que el vejamen a la administración de justicia es tal, que no puede predicarse siquiera la posibilidad de violentar el principio de doble incriminación, en razón a la simultaneidad de las acciones disciplinaria, fiscal y penal, porque con estas sanciones se atienden diversos ámbitos de la función pública corrupta "las tres encuentran su origen en el ámbito genérico del derecho sancionador y punitivo (...) atienden fines y propósitos diversos, alcances que les permiten coexistir en campos diferentes y ejercer de manera independiente" (Cfr. Colombia, Corte Suprema de Justicia, Sala de Casación Penal, Proceso No 28021 octubre veintiocho (28) de dos mil diez (2010) Magistrado Ponente Alfonso Daza González). Así que, para el Alto Tribunal, según el art 1 de la Ley 42 de 1993, la responsabilidad fiscal que se deriva del sistema de control fiscal y financiero ha de imponerse junto a las demás sanciones, su coexistencia está fundada en los principios de autonomía e independencia.

Para la Corte el control administrativo dentro de la Asamblea lo adelanta la auditoría permanente de la Contraloría General del Departamento en cabeza del Auditor de Hacienda Departamental; además de la oficina de Control Interno con funciones de auditoría previa en lo administrativo y lo fiscal. El manejo del presupuesto en la Asamblea, entre lo que esta solicitar adiciones presupuestales (hubo diputados que a más de éstas contrataron hasta con 
11 contratistas colaborando en sus oficinas) deben estar dentro del marco de la legalidad fiscal y han de respetar los principios que rigen la contratación pública. La Sala no tiene duda que constituye un requisito esencial para el cumplimiento de la contratación estatal la existencia del presupuesto, la disponibilidad presupuestal y el registro en particular. Para la Corte el concepto de presupuesto no se refiere al "certificado de disponibilidad presupuestal y del subsiguiente registro que deben ser previos y específicos para cada uno de los gastos" (Cfr. Colombia, Corte Suprema de Justicia, Sala de Casación Penal, Proceso No 32679 catorce (14) de diciembre de dos mil once (2011) Magistrado Ponente Javier Zapata Ortiz)así como también la disponibilidad presupuestal y el registro "son condiciones de validez del gasto, elementos esencial del contrato administrativo"(Cfr. Colombia, Corte Suprema de Justicia, Sala de Casación Penal, Proceso No 32679 catorce (14) de diciembre de dos mil once (2011) Magistrado Ponente Javier Zapata Ortiz)

La Corte en esta Jurisprudencia afirma que los gobernadores, y los empleados de la gobernación, como servidores públicos, son titulares de la responsabilidad fiscal del erario del Departamento, que conlleva no sólo una transparente ejecución del gasto de rentas, sino que conductas ilícitas violatorias como inhabilidades e incompatibilidades, además del interés indebido en la celebración de contratos y sin el cumplimiento de los requisitos legales, que llevaron a la "ideación y creación de normas reguladoras del procedimiento injustificadamente" (Cfr. Colombia, Corte Suprema de Justicia, Sala de Casación Penal, Proceso No 35022 dos (2) de febrero de dos mil once (2011) Magistrado Ponente Fernando Alberto Castro Caballero), con el propósito de aprovecharse y derrochar “por esta vía el presupuesto en contravía manifiesta de la Constitución y la ley, ya que la citada ordenanza sólo facultaba a los gobernadores para celebrar convenios o contratos con entidades públicas, previo acatamiento de las reglas pertinentes" (Cfr. Colombia, Corte Suprema de Justicia, Sala de Casación Penal, Proceso No 35022 dos (2) de febrero de dos mil once (2011) Magistrado Ponente Fernando Alberto Castro Caballero) son objeto de sanción, penal disciplinaria y fiscal.

Afirma el Alto Tribunal que la complejidad del proceso de contratación estatal, está inmersa en conductas reprochables, objeto de sanción penal, fiscal y disciplinaria como el interés indebido en la celebración de contratos, contratos sin cumplimiento de requisitos legales; el indebido favorecimiento de los contratistas con su selección, manipulación de los pliegos de condiciones elaborados a su medida, el rechazo y habilitación de las propuestas necesarias para convertir en contratistas a quienes ofrecen el pago de las coimas, entre otras. Todas conductas que lo que hacen es quebrantar, los principios fundantes de la contratación pública como los de "moralidad, imparcialidad, transparencia, igualdad y selección objetiva", (Cfr. Colombia, Corte Suprema de Justicia, Sala de Casación Penal, Proceso No 34282 ocho (08) de noviembre de dos mil once (2011) Magistrado Ponente Julio Enrique Socha Salamanca) 


\section{OPPCF}

postura determinante y reiterado por la Corte. Es claro que para la Corte la contratación administrativa pertenece al bien jurídico de la administración pública“ideada como el interés del Estado en que la colaboración de los funcionarios públicos en ella no esté subyugada a los beneficios individuales, sino atada a la estricta obediencia de los principios de la función administrativa". (Cfr. Colombia, Corte Suprema de Justicia, Sala de Casación Penal, Proceso No 34282 ocho (08) de noviembre de dos mil once (2011) Magistrado Ponente Julio Enrique Socha Salamanca)

En esta jurisprudencia la Corte advierte la corrupción ocasionada mediante las conductas ilícitas dirigidas a la defraudación en la contratación "de la Troncal de Transmilenio sobre la Calle 26, adjudicada a un Grupo empresarial, el de los hermanos Nule, con la vista complaciente de las autoridades de control, encabezadas por el Contralor de Bogotá, Miguel Ángel Moralesrussi". (Cfr. Colombia, Corte Suprema de Justicia, Sala de Casación Penal, Proceso No 37322 veintisiete (27) de septiembre de dos mil doce (2012) Magistrado Ponente Fernando Alberto Castro Caballero). Además de violar los principios de la Contratación estatal como el de selección objetiva, el de transparencia y el de igualdad. Estos funcionarios públicos incurrieron en hechos reprochables como pagar coimas, hacer contratos simulados, y de manera oprobiosa la participación ilícita del señor Contralor Distrital con un 2\% de comisión para la participación en la defraudación, cuya labor corrupta consistía en evitar que "interfiriera en el contrato de Transmilenio 137/07, es decir no ejerciera la auditoría y control fiscal ante el atraso de las obras de la calle 26" (Cfr. Colombia, Corte Suprema de Justicia, Sala de Casación Penal, Proceso No 37322 veintisiete (27) de septiembre de dos mil doce (2012) Magistrado Ponente Fernando Alberto Castro Caballero). El señor Germán Alonso Olano Becerra ex Representante a la Cámara, aprovechó sus influencias para lucrarse e incidir en la conducta del Contralor, violando el interés superior de la administración pública, de ahí que la imputación de tipos penales en concurso entre el tráfico de influencias "no requiere para su estructuración de remuneración o lucro, pues indistintamente que se reciba o no un beneficio económico, el comportamiento delictivo se consuma en el mismo instante en que se utiliza indebidamente la influencia" (Cfr. Colombia, Corte Suprema de Justicia, Sala de Casación Penal, Proceso No 37322 veintisiete (27) de septiembre de dos mil doce (2012) Magistrado Ponente Fernando Alberto Castro Caballero) y enriquecimiento ilícito de servidor público, prospera.

En esta jurisprudencia afirma el Alto Tribunal que la labor de la Contraloría General de la República, al ejercer el control fiscal halló que se presentó incumplimiento del contrato, pues este no se cumplió en su totalidad. Señala que el interventor de la obra recibió la obra, sin que esta se hubiese terminado en su totalidad. Por lo que el contratista al "no cumplir con lo pactado sino con menos del 50\%, se apropió de los recursos del Estado" (Cfr. Colombia, Corte Suprema de Justicia, Sala de Casación Penal, Proceso No 38144 mayo siete (7) de dos 
mil catorce (2014). Magistrado Ponente Patricia Salazar Cuéllar). De ahí se desprende la responsabilidad fiscal, además de la sanción penal y disciplinaria.

La gráfica de la línea jurisprudencial está desarrollada como secuencia de tiempo, en donde la Corte Suprema en sala penal, ha abordado la arquitectura del Control Fiscal.

\section{Conclusiones}

La jurisprudencia de la Corte Constitucional conforma la arquitectura del sistema de Control Fiscal, al abordar su naturaleza constitucional, pública y legal, con un ámbito de aplicación más allá del control numérico, al centrarse en la vigilancia de la gestión de la administración y de particulares que manejan el erario. El Control Fiscal como derecho fundamental, es ejercido en tanto titular a la Contraloría General, a las contralorías departamentales y municipales.

Así mismo el Control Fiscal, para la Corte Constitucional se trata de una función pública especializada, que atiende el imperativo de proteger el patrimonio público, de las irregularidades que se cometen y que redundan en la corrupción como acción inmoral, injusta y sin duda en contra de los ideales del Estado Social de Derecho.

Los principios que sustentan la arquitectura del Control Fiscal entre otros están el de eficiencia, eficacia y economía, postulados propios del Estado Social de Derecho, y del principio republicano de Democracia. Vale señalar que para la Corte el principio de legalidad es el garante de la legitimidad del Control Fiscal. Dentro del esquema principiológico la noción del Control Fiscal, de acuerdo con la jurisprudencia Constitucional, está el ser un mecanismo de amparo de las finanzas del Estado, y como tal ha de propender por el acatamiento a principios como el de moralidad, transparencia de la función y de las actuaciones de los servidores públicos, y particulares que manejen recursos del Estado, como propósito del interés general.

La jurisprudencia del Consejo Superior en cuanto al Control Fiscal se ha centrado en dos aspectos básicos: el tema disciplinario y el conflicto positivo y negativo de jurisdicciones. Para el Alto Tribunal, los funcionarios públicos faltan a sus funciones por falta de responsabilidad, cuidado y por negligencia.

Para el Consejo de Estado la arquitectura del Control Fiscal se funda en que este es amplio, lo adelanta la Contraloría General de la República, de manera posterior y selectivo, y en forma excepcional, sobre las cuentas de cualquier entidad territorial, o que conformen estas. Por lo que la Contraloría puede imponer dos clases de multas: la primera a manera de sanción pecuniaria que se deriva de la responsabilidad fiscal y su finalidad, la segunda de naturaleza no sancionatoria sino correccional. Además, cabe señalar que también el órgano de Control 
Superior posee competencia normativa subsidiaria en materia de control fiscal.

Según jurisprudencia del Consejo el proceso de responsabilidad consiste en un conjunto de actuaciones administrativas encaminadas a determinar y establecer, si los servidores públicos y los particulares, cuando en el ejercicio de la gestión fiscal o con ocasión de ésta causen por acción u omisión, en forma dolosa o culposa, daño al patrimonio del Estado. Por otro lado, la gestión fiscal, la define el Alto Tribunal como el desarrollo de actividades de carácter económico, jurídico y tecnológico, adelantada por servidores públicos y las personas privadas que manejen o administren recursos públicos.

Desarrolla la Jurisprudencia del Consejo, la noción de sujetos del Control fiscal, en armonía con la jurisprudencia de la Corte Constitucional, lo define como todo empleado oficial de cualquier orden y todo particular, que maneje fondos o bienes del erario. $Y$ han de ser del orden nacional y territorial, que hagan parte de la organización de la administración, tales como entidades, sociedades de economía mixta, empresas industriales y comerciales del Estado.

La Sala Penal de la Corte Suprema, comparte la jurisprudencia de la Corte Constitucional, toda vez que consagra la gestión Fiscal, como ejercicio de control sobre la administración y manejo de bienes y fondos públicos, en las distintas etapas de recaudo o adquisición, conservación, enajenación, gasto, inversión y disposición.

Para la Corte Suprema coexisten diversos controles a la gestión fiscal entre los cuales están, el político, el fiscal, el disciplinario, el penal e incluso el ciudadano, pues considera que el amparo penal no cubre "disfunciones o irritualidades en el sistema de contratación" al bien jurídico de la administración pública. De ahí que quien ostenta la calidad de servidor público, es responsable fiscalmente por la celebración de los contratos estatales "con cargo a los recursos" del Estado. Y por lo tanto ha de asumir como propia la función contractual que de incumplirla incurre en una conducta penal reprochable "alternativa" que contempla tres hipótesis: tramitar contratos sin el cumplimiento de requisitos legales, celebrar contratos sin acatar requisitos, dentro de la fase precontractual, así como en su liquidación.

La jurisprudencia del Alto Tribunal señala las diversas modalidades ilícitas frente a la defraudación del erario, que son causas de corrupción pues están dirigidas a la defraudación en la contratación: tales como contratar sin el cumplimiento de los requisitos legales, fraccionar contratos, planear desfalcos, direccionar recursos a partir de modificaciones en el presupuesto oficial, ubicar personas y establecimientos de comercio reales y ficticios, entre otros. 


\section{Referencias Bibliográficas}

Carreño et al (2017a) Una Teoría crítica para el posconflicto. En Justicia Constitucional Tomo 1 (2007) Bogotá. Universidad Santo Tomás

Carreño et al (2007b). Adjudicación jurídica política de la vida y argumentación en educación. Bucaramanga. Universidad Santo Tomás

Carreño et al (2016). Historiografía, persona y nación. Bogotá. Universidad Santo Tomás

López, Medina Diego E. (2009). El derecho de los jueces. Bogotá. Legis-Uniandes

Jurisprudencia

República de Colombia, Corte Constitucional, Sentencia C 529 de 1993, 11/11/1993, Magistrado ponente: Eduardo Cifuentes Muñoz.

República de Colombia, Corte Constitucional, Sentencia C-534 de 1993, 11/11/1993, Magistrado ponente: Fabio Morón Diaz

República de Colombia, Corte Constitucional, Sentencia C -0089 de 1994, 03/03/1994. Magistrado Ponente: Eduardo Cifuentes Muñoz

República de Colombia, Corte Constitucional, Sentencia C-046/94, 10/02/1994, Magistrado ponente: Eduardo Cifuentes Muñoz

República de Colombia, Corte Constitucional, Sentencia C-320 de 1994, 14/07/1994 Magistrado Ponente: Fabio Morón Diaz

República de Colombia, Corte Constitucional, Sentencia C 374 de 1995, 08/24/1995, Magistrado ponente: Antonio Barrera Carbonell.

República de Colombia, Corte Constitucional, Sentencia C-167 de 1995, 04/20/1995, Magistrado ponente: Fabio Morón Diaz

República de Colombia, Corte Constitucional, Sentencia C 100 de 1996, 07/03/1996 Magistrado ponente: Alejandro Martínez Caballero.

República de Colombia, Corte Constitucional, Sentencia C-272 de 1996, 0/06/ 1996 Magistrado ponente Antonio Barrera Carbonell.

República de Colombia, Corte Constitucional, Sentencia C 570 de 1997, 06/11/1997 Magistrado ponente: Carlos Gaviria Díaz

República de Colombia, Corte Constitucional, Sentencia C-499 de 1998, 15/09/1998 


\section{OPPCF}

Magistrado ponente Eduardo Cifuentes Muñoz

República de Colombia, Corte Constitucional, 15/09/1998, Magistrado ponente: Eduardo Cifuentes Muñoz.

República de Colombia, Corte Constitucional, Sentencia C-113 de 1999, 24/02/1999, Magistrado José Gregorio Hernández Galindo.

República de Colombia, Corte Constitucional, Sentencia C-623 de 1999, 25/08/1999 Magistrado ponente Carlos Gaviria Díaz

República de Colombia, Corte Constitucional, Sentencia C-403 de 1999, 02/06/1999 Magistrado ponente Alfredo Beltrán Sierra.

República de Colombia, Corte Constitucional, Sentencia C-840 de 2001, 09/08/2001 Magistrado ponente Jaime Araujo Rentería

República de Colombia, Corte Constitucional, Sentencia C1148 de 2001, 31/10/2001 Magistrado ponente Alfredo Beltrán Sierra.

República de Colombia, Corte Constitucional, Sentencia C-402 de 2001, 19/04/2001 Magistrado ponente Clara Inés Vargas Hernández

República de Colombia, Corte Constitucional, Sentencia C-364 de 2001, 02/04/2001 Magistrado ponente Eduardo Montealegre Lynett

República de Colombia, Corte Constitucional, Sentencia C 127 de 2002, 26/02/2002, Magistrado ponente: Alfredo Beltrán Sierra

República de Colombia, Corte Constitucional, Sentencia C-648 de 2002, 13/ 08/2002 Magistrado ponente Jaime Córdoba Triviño

República de Colombia, Corte Constitucional, Sentencia C 716-2002, 03/09/2002, Magistrado ponente: Marco Gerardo Monroy Cabra.

República de Colombia, Corte Constitucional, Sentencia, C-1176 de 2004, 24/11/2004, Magistrado ponente: Clara Inés Vargas Hernández

República de Colombia, Corte Constitucional, Sentencia C-529 de 2006, 12/07/2006. Magistrado ponente: Jaime Córdoba Triviño

República de Colombia, Corte Constitucional, Sentencia C 107 de 2006, 17/02/2006 Magistrado ponente Manuel José Cepeda Espinosa 
República de Colombia, Corte Constitucional, Sentencia C-736 de 2007, 19/09/2007 Magistrado ponente Marco Gerardo Monroy Cabra.

República de Colombia, Corte Constitucional, Sentencia C-722 de 2007, 12/09/2007 Magistrado ponente Clara Inés Vargas Hernández.

República de Colombia, Corte Constitucional, Sentencia C-557 de 2009, 20/08/2009, Magistrado ponente Luis Ernesto Vargas Silva

República de Colombia, Corte Constitucional, Sentencia C 541 de 2011, 06/07/2011, Magistrado ponente: Nilson Pinilla Pinilla

República de Colombia, Corte Constitucional, Sentencia C-967 de 2012, 21/11/2012, Magistrado ponente: Jorge Iván Palacio Palacio

República de Colombia, Corte Constitucional, Sentencia C-826 de 2013. 13/11/2013, Magistrado ponente Luis Ernesto Vargas Silva

República de Colombia, Corte Constitucional, Sentencia C-794 de 2014, 29/10/2014 Magistrado ponente Mauricio González Cuervo

República de Colombia, Corte Constitucional, Sentencia C 103 de 2015, 11/03/2015, Magistrado ponente: María Victoria Calle Correa

República de Colombia, Corte Constitucional, Sentencia C-438/2017, 13/07/2017, Magistrado ponente: Gloria Stella Ortiz Delgado

República de Colombia, Consejo Superior de la Judicatura, Sala Jurisdiccional Disciplinaria, Radicación No. 11001010200020050128600 del 14 de junio de dos mil seis 2006, Magistrado ponente: Temístocles Ortega Narváez.

República de Colombia, Consejo Superior de la Judicatura, Sala Jurisdiccional Disciplinaria, Radicación No. 11001010200020050128600 del 18 de junio de 2008 Magistrado ponente: Temístocles Ortega Narváez.

República de Colombia, Consejo Superior de la Judicatura, Sala Jurisdiccional Disciplinaria, Radicación No. 110010102000200602048 del enero 31 de 2007. Magistrado ponente: Temístocles Ortega Narváez.

República de Colombia, Consejo Superior de la Judicatura, Sala Jurisdiccional Disciplinaria, Radicación No. 11001010200020120024300 del 29 marzo de 2012. Ponencia Conjunta

República de Colombia, Consejo Superior de la Judicatura, Sala Jurisdiccional Disciplinaria, 


\section{OPPCF}

Radicación No. 11001010200020080325000 del 07 mayo de 2009. Magistrado Ponente Henry Villarraga Oliveros

República de Colombia, Consejo de Estado, Sala de lo Contencioso Administrativo, Sección Primera Radicación No. 11001-03-24-000-2004-00288-01 del 5 de marzo de 2015, Consejero Ponente María Claudia Rojas Lasso

República de Colombia, Consejo de Estado, Sala de lo Contencioso Administrativo, Sección Primera Radicación No. 41001-23-31-000-1995-08428-01 del 12 de abril de 2012, Consejero Ponente María Claudia Rojas Lasso

República de Colombia, Consejo de Estado, Sala de lo Contencioso Administrativo, Sección Primera Radicación No. 25000-23-24-000-2001-00064-01 del 11 de julio de 2013, Consejero Ponente Guillermo Vargas Ayala.

República de Colombia, Consejo de Estado, Sala de lo Contencioso Administrativo, Sección Primera Radicación No. 25000-23-27-000-2008-00161-01 del 7 de junio de dos mil doce 2012, Consejero Ponente Marco Antonio Velilla Moreno e

República de Colombia, Consejo de Estado, Sala de lo Contencioso Administrativo, Sección Primera Radicación No. 25000-23-27-000-2008-00161-01 del 7 de junio de dos mil doce 2012, Consejero Ponente Marco Antonio Velilla Moreno e

República de Colombia, Consejo de Estado. Sala de lo Contencioso Administrativo. Sección Primera. Expediente No. 1999-00482. 15 de abril de 2004. Consejero Ponente. Gabriel Eduardo Mendoza Martello

República de Colombia, Consejo de Estado. Sala de lo Contencioso Administrativo. Sección Primera. Expediente No 2002-00291 del 6 de diciembre de 2007. Consejero Ponente. Marco Antonio Velilla Moreno.

República de Colombia, Consejo de Estado. Sala de lo Contencioso Administrativo. Sección Primera. Expediente CE-SEC 1-EXP1998-N3880 del 19 de febrero de 1998. Consejero Ponente Libardo Rodríguez Rodríguez

República de Colombia, Consejo de Estado. Sala de lo Contencioso Administrativo. Sección Primera. Expediente 5590 del 20 de enero de 2000. Consejero Ponente Olga Inés Navarrete Barrero

República de Colombia, Consejo de Estado, Sala de lo Contencioso Administrativo, Sección Primera Radicación No. 25000-23-24-000-2001-00064-01 del 7 de junio de dos mil doce 2012, Consejero Ponente Marco Antonio Velilla Moreno e 
República de Colombia, Consejo de Estado. Sala de lo Contencioso Administrativo. Sección Segunda Subsección B Expediente: ACU-655 del 25 de marzo de 1999. Consejero Ponente: Silvio Escudero Castro

República de Colombia, Consejo de Estado. Sala de lo Contencioso Administrativo. Sección Primera Expediente: 2997 del 28 de octubre de 1994. Consejero Ponente: Libardo Rodríguez Rodríguez.

República de Colombia, Consejo de Estado. Sala de lo Contencioso Administrativo. Sección Primera Expediente: 2990 del 26 de enero de 1996. Consejero Ponente: Rodrigo Ramírez González

República de Colombia, Consejo de Estado. Sala de lo Contencioso Administrativo. Sección Primera Expediente: 2468 el 6 de febrero de 1997. Consejero Ponente: Ernesto Rafael Ariza Muñoz

República de Colombia, Consejo de Estado, Sala de lo Contencioso Administrativo, Sección Primera Radicación No. 25000-23-27-000-2006-90783-01 del 18 de julio de 2012, Consejero Ponente Marco Antonio Velilla Moreno e.

República de Colombia, Corte Suprema de Justicia, Sala de Casación Penal, Proceso No 17089 veintitrés 23 de septiembre de dos mil tres 2003. Magistrado Ponente Edgar Lombana Trujillo

República de Colombia, Corte Suprema de Justicia, Sala de Casación Penal, Proceso No 19826 treinta y uno 31 de agosto de dos mil cinco 2005. Magistrado Ponente Mauro Solarte Portilla

República de Colombia, Corte Suprema de Justicia, Sala de Casación Penal, Proceso No 29285 dos 2 de diciembre de dos mil ocho 2008 Magistrado Ponente Alfredo Gómez Quintero

República de Colombia, Corte Suprema de Justicia, Sala de Casación Penal, Proceso No 29285 dos 2 de diciembre de dos mil ocho 2008 Magistrado Ponente Alfredo Gómez Quintero.

República de Colombia, Corte Suprema de Justicia, Sala de Casación Penal, Proceso No 21926 treinta 30 de enero de dos mil ocho 2008 Magistrado Ponente Alfredo Gómez Quintero

República de Colombia, Corte Suprema de Justicia, Sala de Casación Penal, Proceso No 28760 del cuatro de febrero de dos mil nueve Magistrado Ponente Julio Enrique Socha Salamanca

República de Colombia, Corte Suprema de Justicia, Sala de Casación Penal, Proceso No 28760 del cuatro de febrero de dos mil nueve Magistrado Ponente Julio Enrique Socha Salamanca.

República de Colombia, Corte Suprema de Justicia, Sala de Casación Penal, Proceso No 28021 
octubre veintiocho 28 de dos mil diez 2010 Magistrado Ponente Alfonso Daza González.

República de Colombia, Corte Suprema de Justicia, Sala de Casación Penal, Proceso No 28021 octubre veintiocho 28 de dos mil diez 2010 Magistrado Ponente Alfonso Daza González

República de Colombia, Corte Suprema de Justicia, Sala de Casación Penal, Proceso No 35022 dos (2) de febrero de dos mil once (2011) Magistrado Ponente Fernando Alberto Castro Caballero

República de Colombia Corte Suprema de Justicia, Sala de Casación Penal, Proceso No 32679 catorce (14) de diciembre de dos mil once (2011) Magistrado Ponente Javier Zapata Ortiz República de Colombia, Corte Suprema de Justicia, Sala de Casación Penal, Proceso No 34282 ocho (08) de noviembre de dos mil once (2011) Magistrado Ponente Julio Enrique Socha Salamanca

República de Colombia, Corte Suprema de Justicia, Sala de Casación Penal, Proceso No 37322 veintisiete (27) de septiembre de dos mil doce (2012) Magistrado Ponente Fernando Alberto Castro Caballero

Normatividad

ley 610 de 2000

Ley 80 de 1993

Ley 42 de 1993 


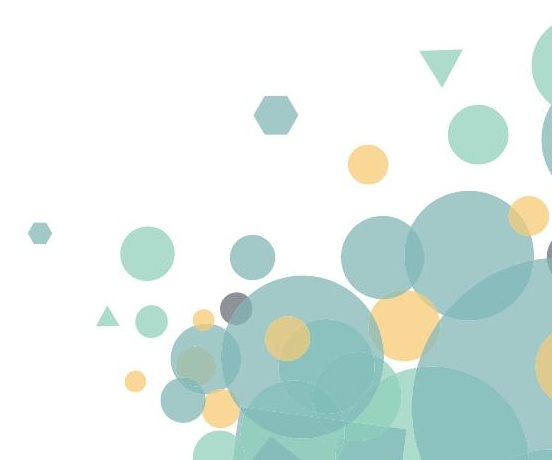




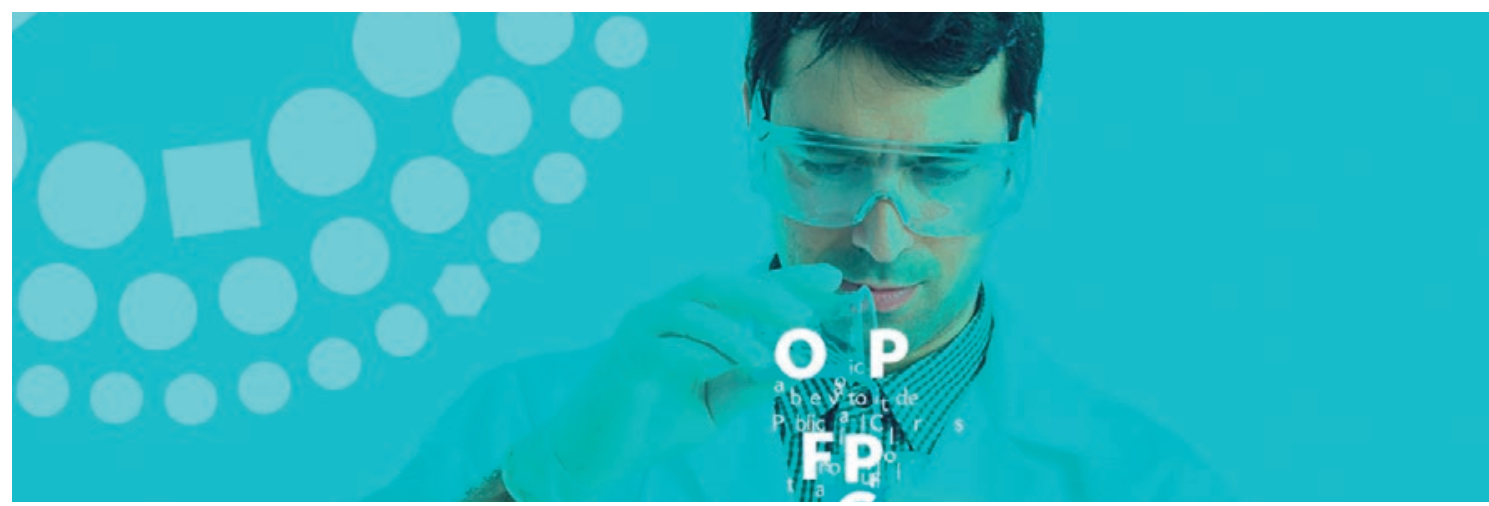

\section{CAPÍTULO VII}

\section{EL CONTROL FISCAL DESDE LA CIUDADANÍA}

\section{Fabio Iván Rey Navas ${ }^{25}$}

Temario: Introducción - Que es el control ciudadano - Como hacer el control ciudadano Que no es control ciudadano - Conclusiones - Bibliografía

\section{Resumen}

El fortalecimiento de la participación ciudadana en el ejercicio del control fiscal permite la democratización de los recursos públicos mediante la injerencia del administrado en la cosas pública. La fiscalización ciudadana puede realizarse en cualquiera de los ámbitos territoriales del estado, a través de los grupos primarios de interés en uno o varios de los temas competencia de la respectiva administración o de la entidad de control fiscal que corresponda. El control ciudadano sobre el recurso público promueve la igualdad en la asignación e inversión, aumentando las posibilidades de satisfacción del interés general y de los grupos menos favorecidos con la repartición de lo público.

Palabras Claves: Control Fiscal - Participación - Ciudadana

\section{Introducción}

La participación de la ciudadanía desde su significado y como se aplica la mismo al control fiscal es una de las inquietudes que trata de resolver la propuesta elaborada a partir del Observatorio de la Política Pública de Control Fiscal, motivando al lector a identificar el mismo como un derecho intrínseco al hecho de vivir en sociedad en una organización estatal.

25 Doctor en Estado de Derecho y Gobernanza Global de la Universidad de Salamanca. Miembro del grupo de investigación de la Auditoría General de la República y de la Universidad Santo Tomás -según convenio, y que el capítulo proviene de la investigación Observatorio de Política Pública del Control Fiscal 
El cómo ejercer control fiscal desde el rol del ciudadano se convierte en eje principal de la propuesta, pues el tratarse de temas especializados de economía, contabilidad y administración pública, exige contar con un conjunto de conocimientos que deben ser proporcionados por las entidades especializadas como la Auditoria General y sus gerencias seccionales, las Contralorías, las veedurías, o mediante convenios colaborativos con las facultades de las universidades y los consultorios de cada área específica, quienes desde su labor social traducen a lenguaje común la técnica aplicada para el manejo de los recursos.

La fiscalización como proceso de participación democrática es un acto de responsabilidad social que debe ser ejercido dentro de los límites propios determinados en la Constitución y la Ley, así como en la finalidad propia de cada institución, cabiendo precisar que no es fiscalizar.

Desde el observatorio se comprende como la fiscalización amplia permite afianzar la competencia ciudadana para ejercer una veeduría activa desde el momento mismo de la ubicación de las fuentes de los recursos públicos, la asignación de los cupos presupuestales y la efectiva aplicación de estos en el interés que se busca satisfacer.

La investigación aplicada es analítica y descriptiva en cuanto recolecta información relacionada con la participación ciudadana y el control ciudadano, así como literatura relacionada con el logro de la igualdad mediante el control fiscal.

De ahora en adelante con estos puntos se pretender promover la participación ciudadana para el control fiscal del estado nacional y local, y las instituciones públicas y privadas que lo acompañan en el ejercicio de satisfacer el interés general de los asociados.

\section{I. ¿Qué es el control mediante la participación ciudadana?}

La participación ciudadana es el derecho que tienen los ciudadanos para ejercer un control directo o indirecto a las decisiones que se van adoptar o las que ya se asumieron por parte del estado o de particulares autorizados por la organización estatal.

Es una expresión de la soberanía popular, para lograr una "real eficacia de la consagración de la soberanía popular" (Corte Constitucional SU-1122/2001), sometiéndose el estado al control ciudadano, permitiendo "el ejercicio de un control político, moral y jurídico de los electores por parte de los elegidos, sin intermediarios, con lo que se sanciona eficazmente la corrupción administrativa y el uso del poder en interés particular" (Corte Constitucional. C-643/2000).

Es necesario indicar que la participación del ciudadano en el control es un derecho deber, derecho porque implica la posibilidad de hacerlo de forma adecuada y una vez lo realice se 


\section{OPPCF}

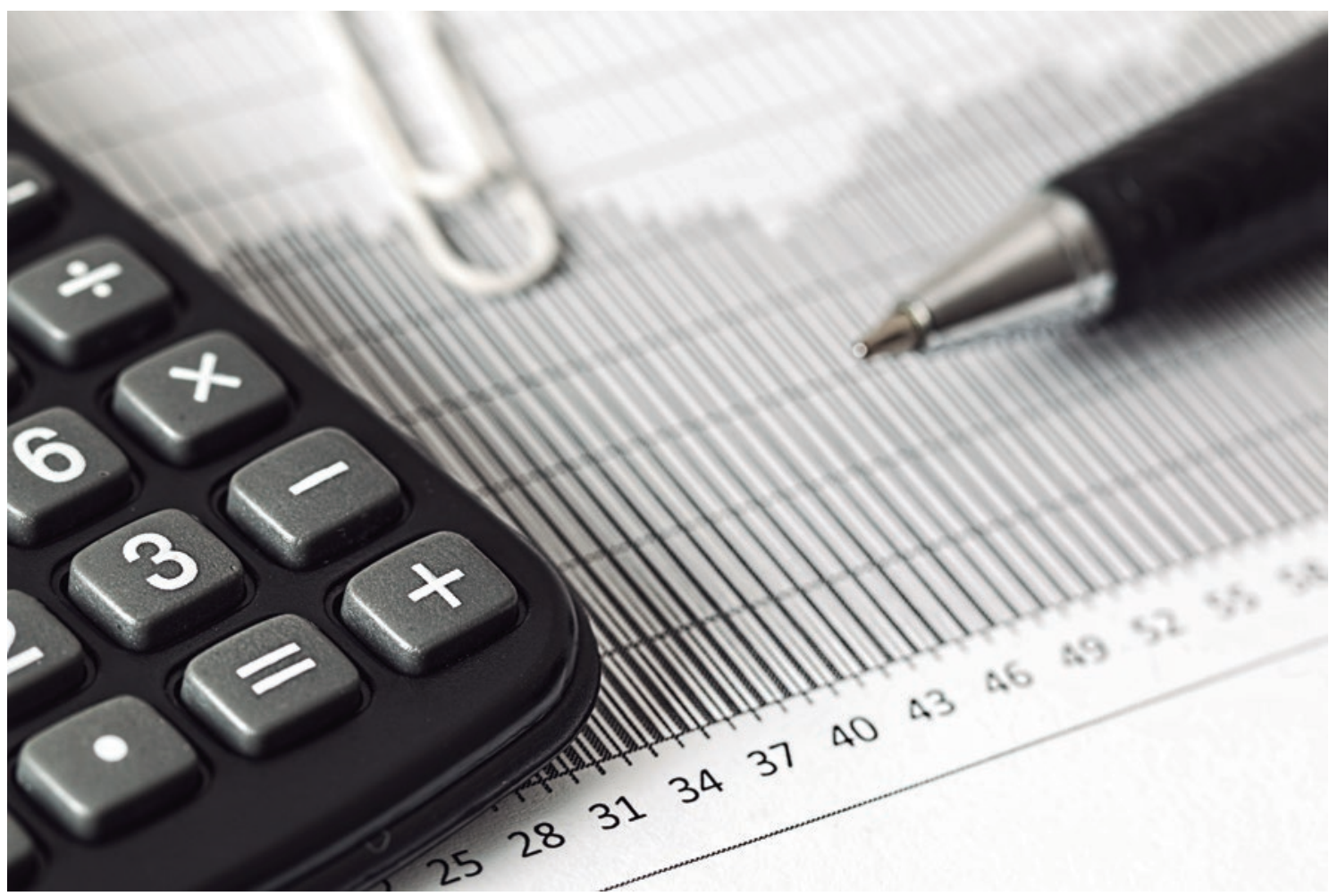

convierte en un deber advertir las irregularidades o aciertos en el manejo de lo público, de tal forma que se convierte en un gestor de la fiscalización de los recursos y en el motivador para que lo público sea bien invertido. Para el estado es igualmente un derecho deber, toda vez que debe abstenerse de limitarlo o retroceder en los niveles de participación, y deber de adoptar medidas que evite que las autoridades pública o los particulares interfieran con el mismo, optimizando el tiempo de respuesta (Corte Constitucional. C-150-15).

El control ciudadano cobija la actividad del estado contractual del estado (antes, durante y posterior a la actividad del estado), la destinación de los recursos públicos (Corte Constitucional. C-150-15), la efectiva inversión de los mismos y la rentabilidad social, financiera o cultural de la inversión (Ortiz Ospino, Eficiencia y eficacia en la asignación y ejecución del presupuesto cultural, 2008) para los ciudadanos que les beneficia o afecta.

La institucionalización del control ciudadano permite que la administración pública cuente con una vigilancia in loco (en el lugar), lo que promueve una activa participación de la ciudadanía en la elaboración del presupuesto y en la inversión del mismo, generando la cultura de austeridad en el gasto, control de la inversión y satisfacción de las necesidades propuestas con el uso de los recursos, "reduciendo las asimetrías de información existentes 
de manera tal que los ciudadanos queden en capacidad de controlar el cumplimiento de las funciones de las entidades públicas (art. 40, 103 y 270 CP)" (Corte Constitucional. C-15015), alcanzando la gerencia del estado mayores niveles de eficiencia (Corte Constitucional T-637/2001).

Todos los aspectos de la administración pública pueden ser objeto de vigilancia, excepto aquellos que estén sometidos a reserva (defensa, seguridad, entre otros temas), lo cual no obsta para indagar sobre inversiones generales.

Con la participación del ciudadano en el control fiscal se democratiza la gestión pública, en la búsqueda de una optimización de los recursos públicos y la actividad del estado, al dirigirla hacia donde el interés general lo requiere.

\section{II. ¿Cómo hacer control ciudadano al control fiscal?}

Cuando el entrenador de futbol está dirigiendo a los futbolistas lo hace para que estos puedan aprovechar mejor la fuerza que tienen, ubicándolos donde mejor funcionen para el equipo, de tal manera que puedan llegar a convertir goles, defenderse y atacar al contrario. Esto mismo hace el ciudadano cuando controla la administración, le dice donde hacer las inversiones públicas para que produzcan más riqueza social, cultural, administrativa, financiera o humana, y además le advierte a los ordenadores del gasto y su equipo como cubrir los espacios para evitar que el otro equipo (la corrupción) le haga goles o le ponga en peligro (Cashin, 1989).

El estado es una gran empresa de satisfacción de lo público y a quien se dirige es igualmente parte ella, por lo tanto todos pueden tomar parte activa en el manejo de lo público y su fiscalización.

Para realizar la actividad de control fiscal no son necesarios otros conocimientos más especiales que la lógica común y el sentir como propio aquello que es de todos. Para realizar un buen proceso auditor desde lo público se debe contar con el interés de los ciudadanos en ejercer el control fiscal a una determinada actividad pública, por ejemplo por programa o una determina obra específica o a una labor integral, como el logro del plan de gobierno en cifras u otras relacionadas.

*El grupo de interés pueden ser asociaciones de vecinos, juntas de acción comunal, cooperativas, corporaciones o fundaciones de interés público, grupos culturales, ecológicos o educativos, etc... : 


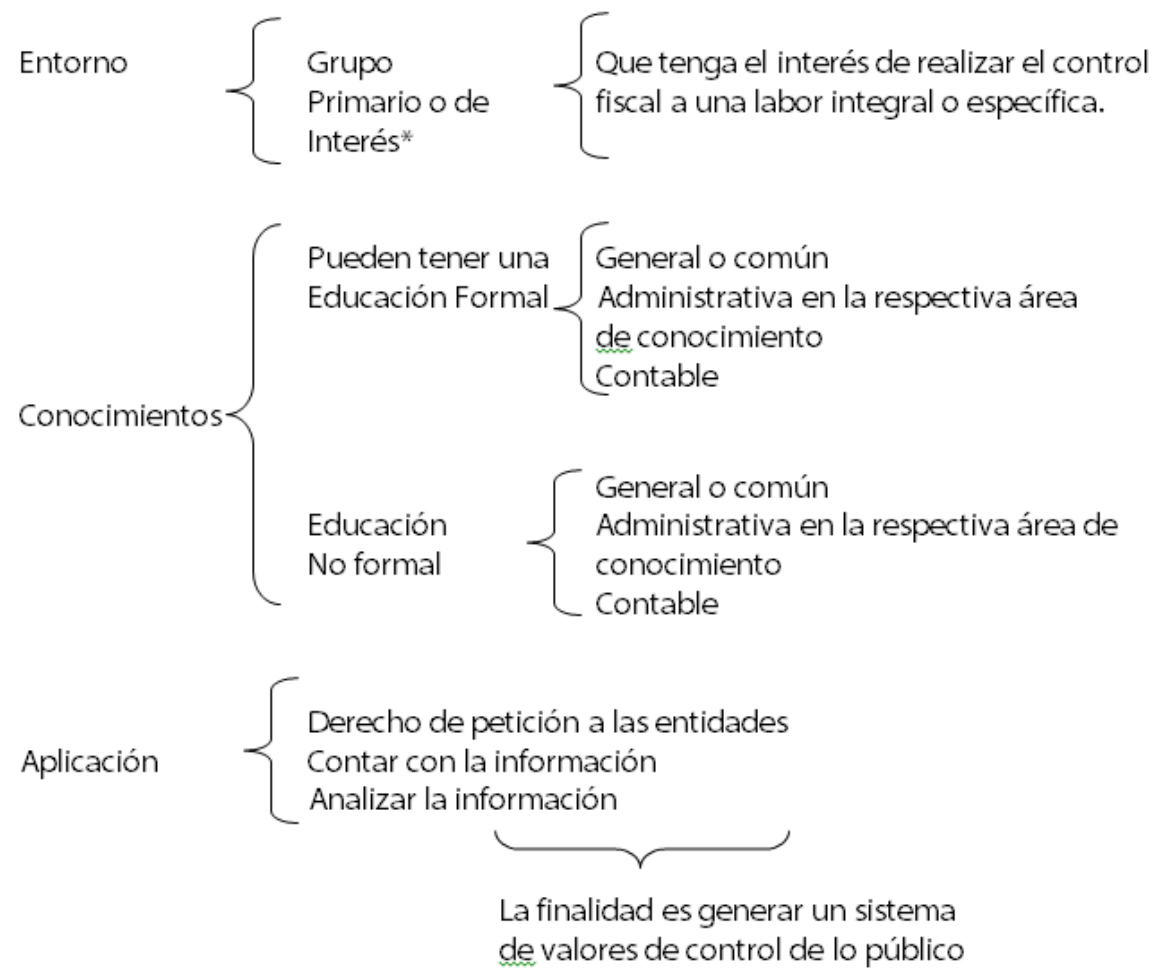

Contar con el grupo primario basado en el interés común de los ciudadanos, pueden formar parte de los mismos las agremiaciones profesionales nacionales o extranjeras, las organizaciones públicas o privada de veedores así como las instituciones educativas públicas o privadas especializadas en la temática pues se debe contar con el conocimiento especial en el área en que se va a realizar el control fiscal en específico, por ejemplo si se trata de una empresa petrolera que quien solicite la información conozca del sector y que pueda comprender el manejo contable y financiero de la organización.

Por lo tanto es importante contar con un equipo asesor que le permita al ciudadano o al grupo de ciudadanos retroalimentar la labor de auditoría que está realizando el grupo primario en la auditoria determinada.

- El grupo primario debe realizar un control, revisión y evaluación de los trabajos realizados para auditar.

El grupo de interés debe tener relaciones cercanas de comunicación (Cashin, 1989). 
En este sentido desde la Asamblea Nacional Constituyente se promovió la participación en el control Fiscal en dos aspectos, primero desde la veeduría a la gestión fiscal, abriendo espacios a la gestión de los ciudadanos plasmada en el artículo 270 constitucional en la que se determinó que “La ley organizará las formas y los sistemas de participación ciudadana que permitan vigilar la gestión pública que se cumpla en los diversos niveles administrativos y sus resultados." y mediante la contratación de servicios especializados de auditoría en empresas privadas (Ochoa Díaz, . Propuesta de un modelo de control fiscal para el estado colombiano: El sistema de control fiscal nacional. , 2003) sin dejar de lado el acompañamiento de entidades sin ánimo de lucro o las instituciones educativas mediante los consultorios contables $\mathrm{o}$ económicos.

Por lo tanto lo más aconsejable es que la ciudadanía se organice en cada localidad, municipio, departamento y a nivel nacional para hacer una verdadera gestión al presupuesto e inversión de los recursos públicos identificando los puntos críticos de inversión de acuerdo a los intereses locales de desarrollo (Contraloria General, 2018), con esto se aumenta la confianza de los ciudadanos en el control fiscal, que tiende a debilitarse cuando se ubica en solo algunas instituciones ${ }^{26}$.

26 Para ORDONEEZ es "ampliamente conocido que existe una falta de confianza en el Control Fiscal, que se apoya por un lado en sus propias deficiencias, y por otro, en una apreciación

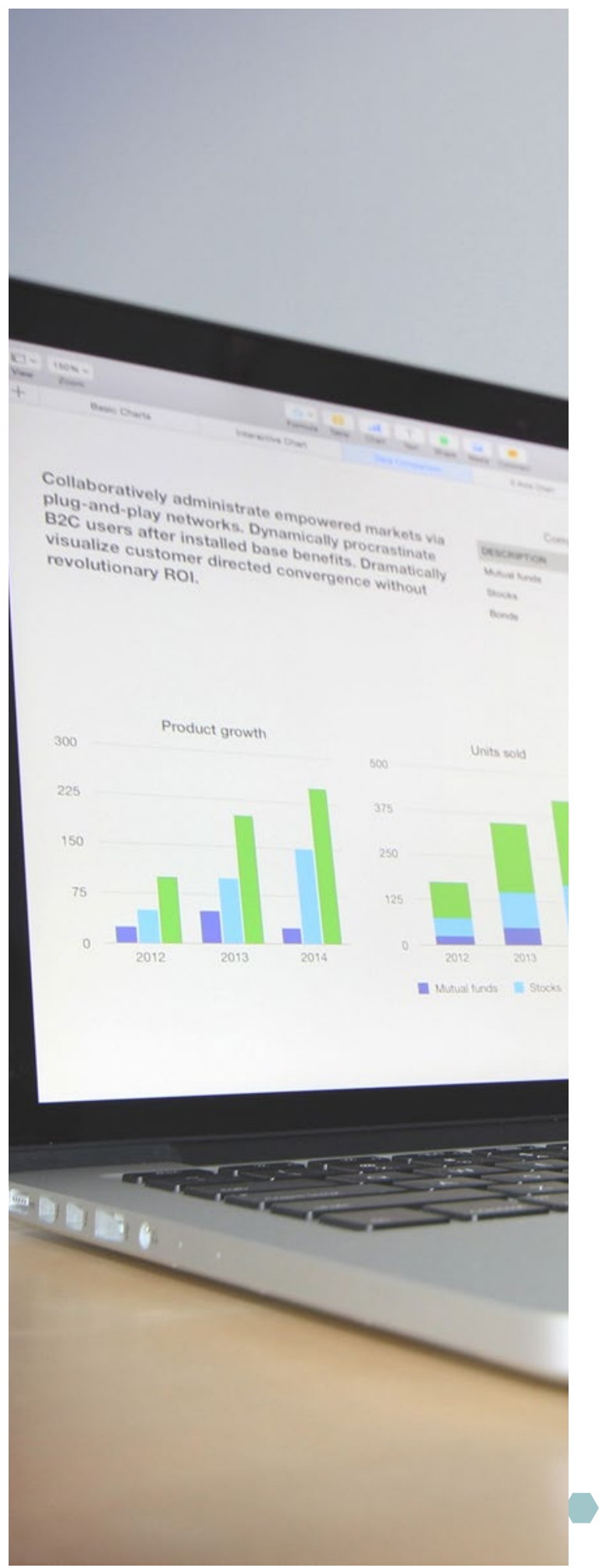




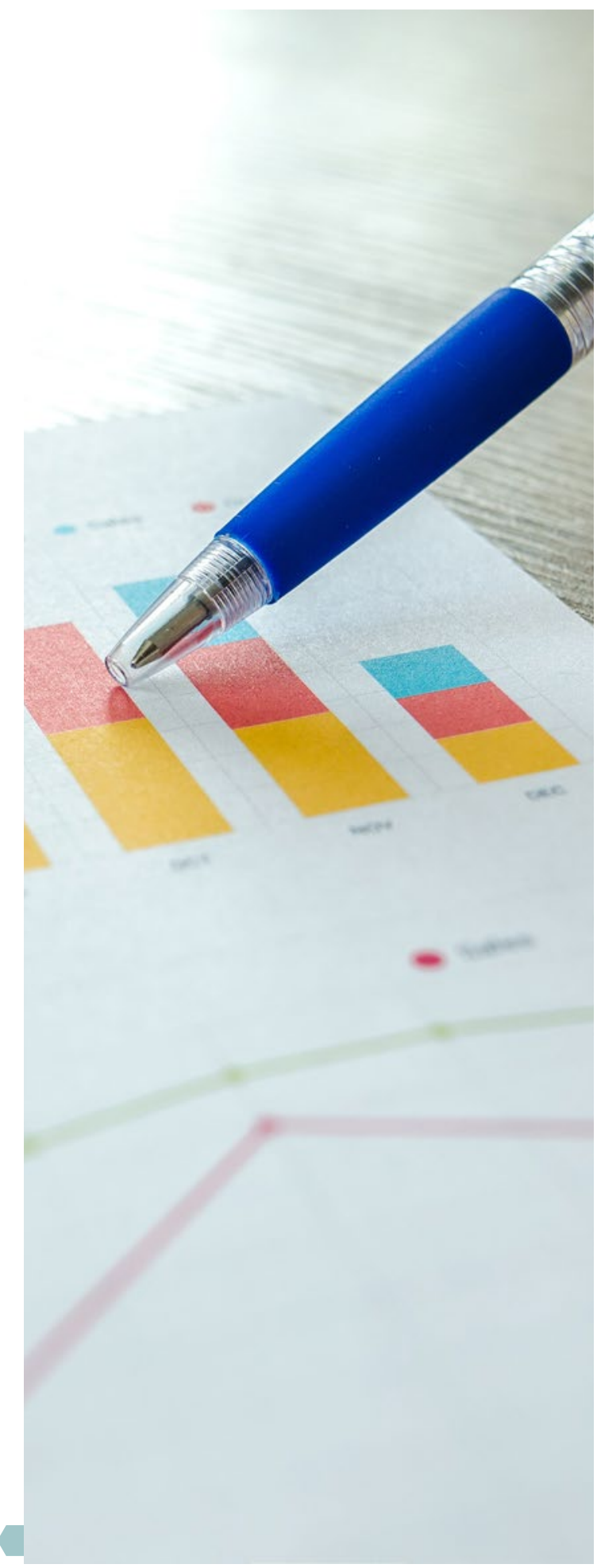

\section{III. ¿Qué no es fiscalizar?}

Fiscalizar no es solo sancionar o cuidar, es igualmente proponer acciones de mejora para que los procesos de asignación, aplicación e inversión de lo público sea eficaz, y esto no solo aplicado a los recursos en efectivo o a los contratos, también a la operación misma del estado, con los servidores públicos y los bienes públicos.

Fiscalizar no es co administrar, pues cuando esto se ha hecho se confunde quien ejecuta y quién vigila, complicando la inversión y aumentando el riesgo de retardar la misma.

La fiscalización no busca identificar actos corruptos, pues lo ideal es que lo público se invierta de forma adecuada y efectiva, la expectativa es verificar los órdenes de inversión y cuando se realicen hallazgos, verificar a que se debe la tergiversación de las cuentas, pues no toda eventualidad es un acto corrupto penal o disciplinario, puede ser un reporte equivocado o la necesidad de invertir los recursos del estado en algo que realmente sea clave para el desarrollo social, educativo, económico o cultural (Ortiz Ospino, Cultura y Desarrollo. Cuenta Satelite de la Cultura, 2014).

Por lo tanto se fiscaliza para lograr alcanzar la igualdad en la distribución de los recursos del estado, pues el estado es fuente de riqueza mediante la asignación de recursos, licencias, concesiones, cargos, empleos, a

de la comunidad sobre el papel que han cumplido los órganos del sistema de control fiscal a lo largo del desarrollo histórico del país". (Ordoñez Vasquez, 2005) 
ciertas personas o empresas, pues el estado no podría dar para todo, justificándose esta selección - desigual -, siempre que la misma produzca beneficios compensadores para todos y, en particular, para los miembros menos aventajados de la sociedad (Rawls, 2006, pág. 27).

De esta manera es necesario enfocar el Control Fiscal más en la efectividad en la inversión de los recursos ${ }^{27}$, que solo en lo que se pierde por efecto de la corrupción, que siendo grave representa solo una parte de los recursos.

\section{Conclusiones.}

El control ciudadano es uno de los más relevantes en el actual desarrollo de la democracia, tanto por el alto nivel de respuesta del estado a las peticiones (derecho de petición, acciones de cumplimiento) como por la aplicación de los medios de comunicación masivos como el internet (twitter, facebook, WhatSap, Correo Electrónico, entre otros), televisión y radio mediante los cuales el ciudadano puede denunciar todo aquello que considera errado o le afecta.

Y aunque la denuncia aplica como un medio idóneo de control, la ciudadanía puede llegar a realizar un control real a la gestión pública mediante la fiscalización del manejo de los recursos del estado, que no se limitan al dinero efectivo, sino al uso de los medios (edificios, maquinaría, empresas, fincas, campos etc ...) y de los servidores públicos, de tal forma que a más de identificar desfalcos al estado, optimicen la inversión pública y la satisfacción del interés de todos los ciudadanos ${ }^{28}$.

La organización de la ciudadanía para fiscalizar las entidades públicas y los privados que manejan recursos públicos apoya de manera idónea el control ejercido desde la Contraloría General de la Nación y las Contralorías Departamentales y Municipales a la gestión directa, y a estas mediante la vigilancia de la Auditoría General de la República.

\section{Referencias Bibliográficas}

Cashin, J. A. (1989). Manual de Auditoria. Filadelfia: Biblioteca Master Centrum.

\footnotetext{
27 Por ejemplo se deben evitar las obras inconclusas "manada de elefantes blancos" en varias regiones del país. (Maya Villazon, 2018)

$28 \quad$ No solo se ejercita un control social mediante las manifestaciones en el espacio público, que como bien lo afirma GONZALEZ ZAPATA, "no es solo un ámbito de circulación sino también un espacio de participación. El acceso al espacio público significa concretamente que las y los organizadores y las y los manifestantes deberían poder utilizar las plazas, carreteras y calles públicas para celebrar reuniones pacíficas, ya sea estáticas o en movimiento. " (Fundación Comité de Solidaridad con los Presos Políticos FCSPP, 2008).
} 
Contraloria General, d. I. (09 de 08 de 2018). Contraloría Delegada para la Participación Ciudadana. Obtenido de https://www.contraloria.gov.co/web/participacion-ciudadana/ contraloria-delegada

Corte Constitucional T-637/2001 .

Corte Constitucional SU-1122/2001.

Corte Constitucional. C-150-15.

Corte Constitucional. C-643/2000 .

Corte Constitucional. Sentencia C-150/15.

Fundación Comité de Solidaridad con los Presos Políticos - FCSPP. (2008). El derecho a la protesta social. Bogotá: Fundación Comité de Solidaridad con los Presos Políticos - FCSPP.

Maya Villazon, E. (9 de Agosto de 2018). Contraloría advierte corrupción en recursos del Gasto Público Social. (R. S.-R. Económica, Entrevistador)

Ochoa Díaz, H. \&. (2003).. Propuesta de un modelo de control fiscal para el estado colombiano: El sistema de control fiscal nacional. . Estudios gerenciales, 13-42.

Ordoñez Vasquez, T. (2005). Colombia: Impunidad en matería Fiscal. La historía de Fortunato Corrupto. Sínderesis No. 8, 73 - 84.

Ortiz Ospino, L. P. (2008). Eficiencia y eficacia en la asignación y ejecución del presupuesto cultural. Bogotá: Auditoria General de la República.

Ortiz Ospino, L. P. (2014). Cultura y Desarrollo. Cuenta Satelite de la Cultura. Bogotá: Convenio Andrés Bello.

Rawls, J. (2006). Teoría de la justicia. México: Fondo de Cultura Económica. 


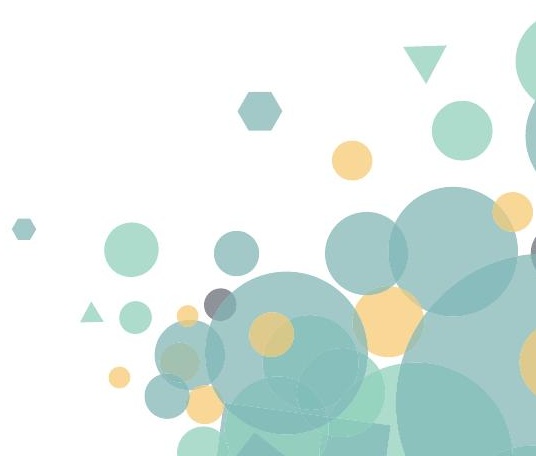




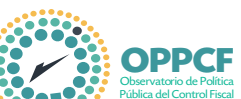

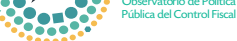

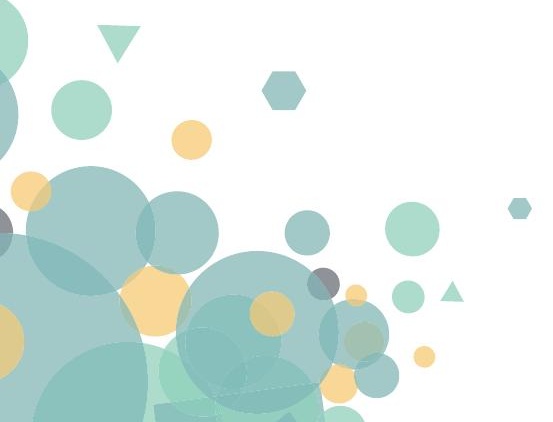

